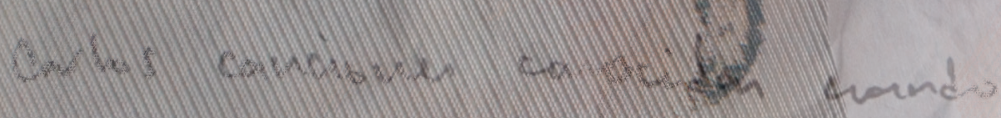

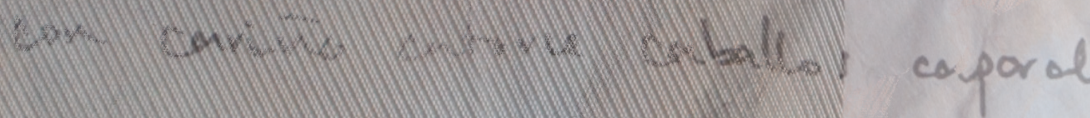

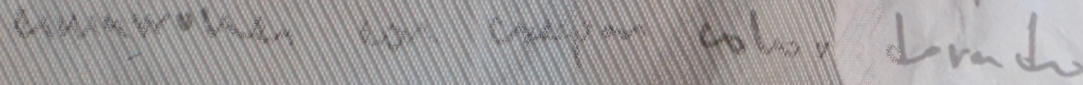

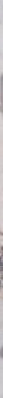
Strategies of Farmers' Organizations as Change Agents

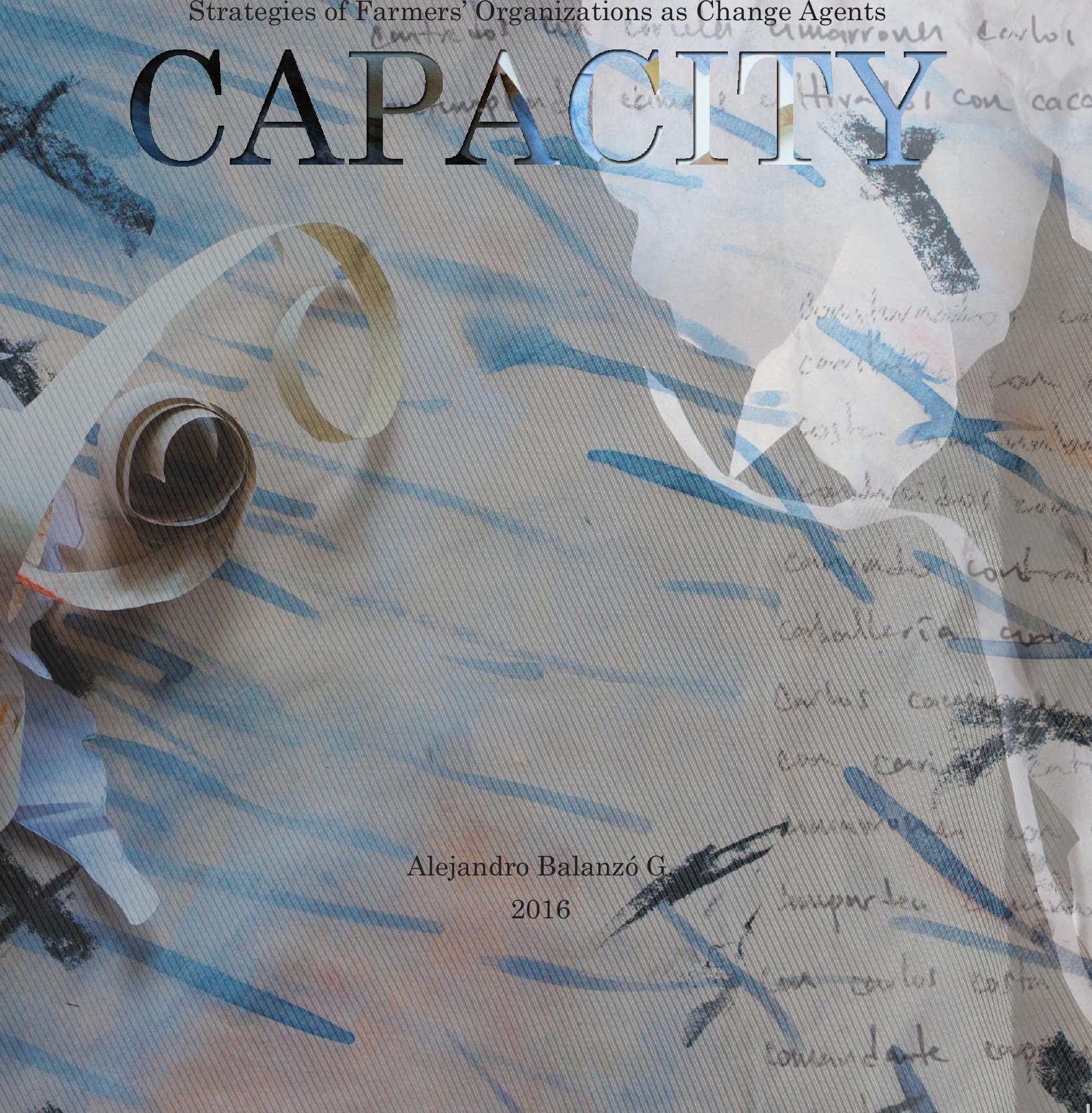






\section{UNFOLDING CAPACITY}

STRATEGIES OF FARMERS' ORGANIZATIONS AS

Change Agents

Alejandro Balanzó G.

2016 
Chairman/Secretary: Prof. dr. Th.A.J. Toonen

Supervisor:

Prof. dr. S. Kuhlman, University of Twente

Co-supervisor:

Prof. dr. H.G. Ordoñez, University of Twente

Members:

Prof. dr. P.Y. Georgiadou, University of Twente

Prof. dr. L.L. Roberts, University of Twente

Prof. dr. A.K. Hornidge, ZMT Bremen

Prof. dr. J.P. Voß, Technical University Berlin

Prof. dr. M. Bucheli, Instituto de Estudios Rurales, Pontificia Universidad Javeriana.

The funding for this research was provided by COLCIENCIAS and

Universidad Externado de Colombia

This thesis was printed with financial support from Colciencias, the Graduate School Science, Technology and Modern Culture (WTMC) and the Department of Science, Technology and Policy Studies (STePS) of the University of Twente

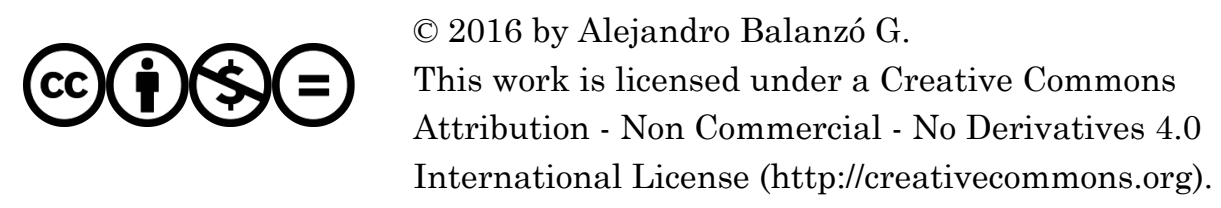

Cover Image by Nicki Carter

Printed by: Gildeprint, Enschede.

ISBN: $978-90-365-4186-2$

DOI: $\quad 10.3990 / 1.9789036541862$

URL: http://dx.doi.org/10.3990/1.9789036541862 


\title{
UNFOLDING CAPACITY
}

\section{STRATEGIES OF FARMERS' ORGANIZATIONS AS CHANGE AGENTS}

\author{
DISSERTATION \\ to obtain \\ the degree of Doctor at the University of Twente, \\ on the authority of the rector magnificus \\ Prof.dr. H. Brinksma \\ on account of the decision of the graduation committee, \\ to be publicly defended \\ on Thursday, 24 of November at 14:45.
}

By

Alejandro Balanzó Guzmán

Born on 24 of March,1976

at Bogotá, Colombia 
This dissertation has been approved by:

Promotor:

Prof. Dr. S. Kuhlmann

Co-promotor: Dr..G. Ordoñez 


\section{Table of Contents}

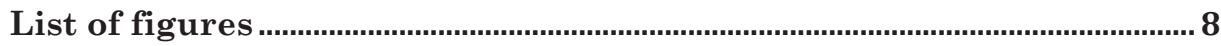

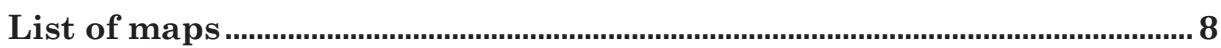

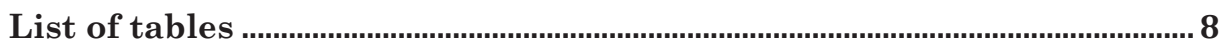

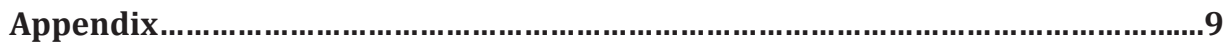

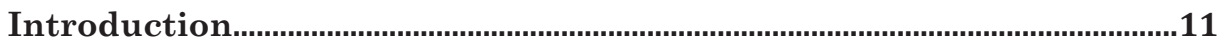

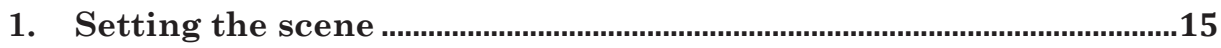

1.1. About farmers' organizations ......................................................................16

1.2. Farmers' organizations roles at the grassroots level..........................18

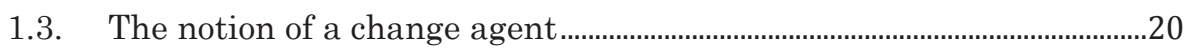

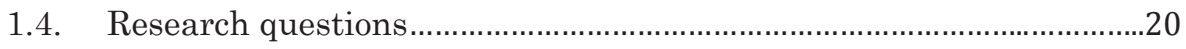

1.4.1. Research rationale: Finding a cadence to dance...................................21

1.4.2. The theoretical realm ..................................................................................22

1.4.3. The empirical realm ........................................................................................23

2. A practice-based conceptual approach ................................................25

2.1. Capacity development as a form of change agency........................................27

2.1.1. Epistemic status of capacity development.........................................29

2.1.2. "Theorizing" social learning as a means of social change .............31

2.1.3. Identifying and linking capacity levels ...............................................32

2.1.4. Analytical scope ........................................................................................33

2.1.5. Change agents as the means of governance........................................34

2.1.6. Grounded theory from capacity development.....................................35

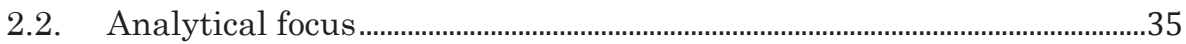

2.2.1. Knowledge stances...................................................................................

2.2.2. Towards the knowledge-repertoires perspective.......................43

2.3. The knowledge-repertoires perspective..........................................................4

2.3.1. Knowledge repertoires ......................................................................4

2.3.3. Final note on knowledge-repertoires theoretical perspective ...55 


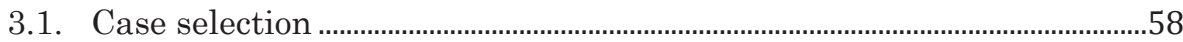

3.2. The Context.............................................................................................................6

3.2.1. Localization .......................................................................................60

3.2.2. Cocoa market in Colombia …..............................................................62

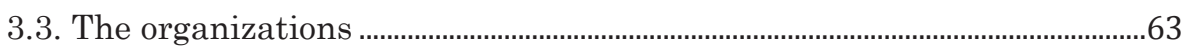

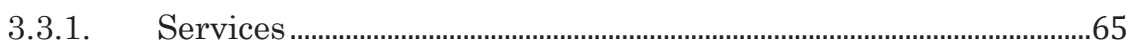

4. Empirical results: What is it like dealing with the world out there?

4.1. What are farmers' organizations' drivers? ............................................................ 79

4.1.1. Values: Farmers' organizations' core drivers.........................................80

4.1.1.1. Create a stable and peaceful environment.....................................81

4.1.1.2. Create Legality ...........................................................................................82

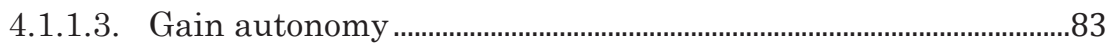

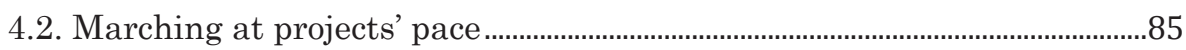

4.2.1. Projects at the roots of organizations................................................86

4.2.2. Projects as schooling ...........................................................................87

4.2.3. Projects as opportunities to increasingly build a local order....89

4.2.4. Projects as a vehicle of external threats ..........................................91

4.3. Affairs at the local level: Games and gamesters on making fate..............96

4.3.1. Dealing with local and regional authorities .....................................97

4.3.2. Organizations' responses: On the brink of politics .........................98

4.3.3 Other music, other dances: The making of support.....................100

4.3.4. Community councils: Identities at stake .........................................102

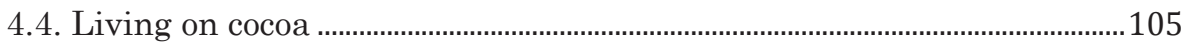

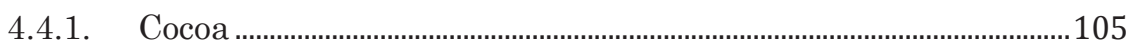

4.4.2. Purchasing conditions .............................................................................106

4.4.3. The quest for specialized niches........................................................107

4.5. Summing up: The short-term drivers...............................................................110

4.5.1. Create income opportunities, finding a market position .............110

4.5.2. Playing a role in local development .....................................................112

4.5.3. Building local capabilities......................................................................... 113 
5.1. Guiding concepts 118

5.2. A single actor, multiple fields.................................................................... 120

5.2.1. The making of cocoa's marketplace .............................................................. 122

5.2.2. Grassroots' Organizations Rule!............................................................... 127

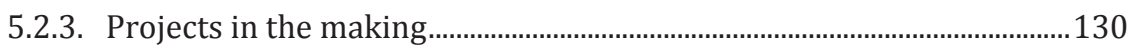

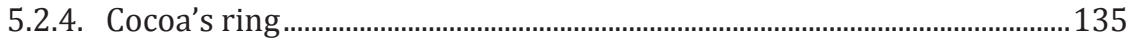

5.2.5. Keep it local.....................................................................................................138

5.2.6. Summing up, a canvas of farmers' organizations' strategies .................140

5.3. Strategies: Knowledge stances as agency patterns.......................................144

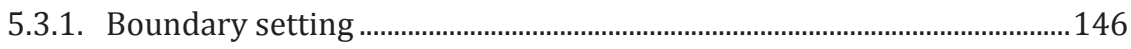

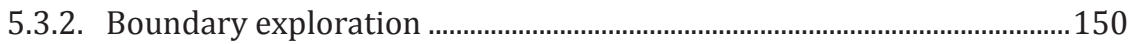

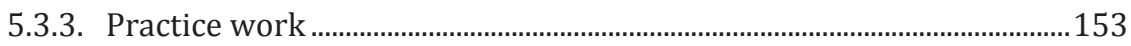

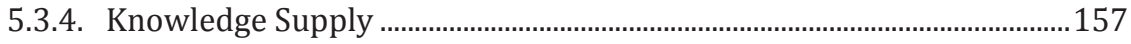

5.3.5. Knowledge intermediation ................................................................... 161

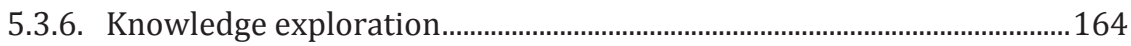

5.4. Knowledge stances: Theoretical insight........................................................167

5.4.1 Knowledge stances: A fully fledged overview......................................168

5.4.2. Revisiting practice, boundaries, and institutions: domains ........170

5.4.3. Summing up: A turn back to the research questions ......................173

6. A typology of farmers' organizations as change agents ................179

6.1. Perform Innerwise.............................................................................................. 181

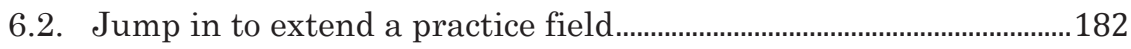

6.3. Bypass bottlenecks and re-scale...................................................................184

6.4. Broker a knowledge cycle to make it happen.........................................186

6.5. Take part in the building of the public sphere.....................................187

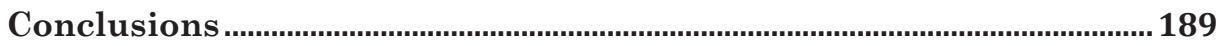

References .................................................................................................................. 199

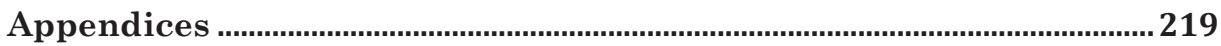

Dutch Summary ..................................................................................................... 225 


\section{List of figures}

Figure 1. Meso-level agency featuring knowledge stances. Basic scheme 43

Figure 2. National Cocoa Network organizations. Distribution by size and

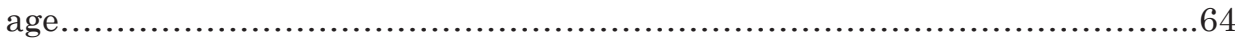

Figure 3. Maturity degree of organizations by node ...................................... 65

Figure 4. Meso-level agency featuring knowledge stances. Basic scheme...... 145

Figure 5. Meso-level agency featuring knowledge stances. Fully fledged scheme 169

\section{List of maps}

Map 1. Location and context. Organizations National Cocoa Network 61

\section{List of tables}

Table 1. Context Overview. National Cocoa Network nodes 74

Table 2. Data coding references. .................................................................. 78

Table 3. Farmers' organizations' core drivers ................................................ 84

Table 4. Farmers' organizations' short-term drivers ................................. 116

Table 5. Summary of farmers' organizations' strategies: ............................ 126

Table 6. Summary of farmers' organizations' strategies: ............................ 129

Table 7. Summary of farmers' organizations' strategies: ............................. 134

Table 8. Summary of farmers' organizations' strategies: .............................. 138

Table 9. Summary of farmers' organizations' strategies: ............................. 140

Table 10. Canvas. Strategies of farmers' organizations as change agents ..... 141

Table 11. Boundary setting strategies ....................................................... 147

Table 12. Relation of boundary setting to other knowledge stances............... 149

Table 13. Boundary exploration strategies ............................................... 150

Table 14. Relation of boundary setting to other knowledge stances............... 152

Table 15. Practice work strategies ............................................................. 155

Table 16. Relation of practice work to other knowledge stances................... 156

Table 17. Knowledge supply strategies .................................................... 159

Table 18. Relation of knowledge supply to other knowledge stances ............. 160

Table 19. Knowledge intermediation strategies........................................... 162

Table 20. Relation of knowledge intermediation to other knowledge stances 163

Table 21. Knowledge exploration strategies.............................................. 165

Table 22. Relation of knowledge exploration to other knowledge stances...... 166 
Appendix

Annex 1. Organizations of the National Cocoa Network ….............................. 220

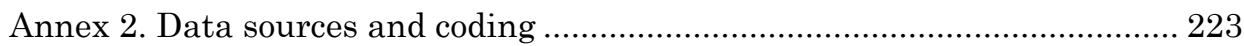




\section{Introduction}


This book describes how farmers' organizations cope with shifting sands around them. In places where weak, ill or inexistent rules of the game, struggling amidst war, depredation, illegal traffic and corruption are everyday occurrences, farmers' organizations are often a means for order and stability.

This picture certainly makes it look like there is more than one game farmers' organizations have to play. Even further, the picture arises where the suspicion that dealing with multiple complexities might not be just a matter of playing a game, but a matter of shifting the rules in which games themselves are set.

This book takes a deeper look at this phenomenon, with a very particular focus. It draws attention not to the game board, as is most often the case, but to the player itself. It brings light to the understanding of how farmers' organizations take their chances as change agents. Rather than giving an account of the roles of farmers' organizations - or their circumstances at a given time-this book aims to shed light on how farmers' organizations strategize when at play.

The rationale of this approach departs from the assumption that a better understanding of farmers' organizations' strategies will provide suitable governance schemes for rural areas, especially those qualifying as poverty pockets (Wienberg, 1987).

It is the case, for example, in Colombia, where peace is being negotiated after more than 50 years of war. A war held in the outskirts of the country, territories whose future is now, finally, bound to have a chance. Following the peace talks, the Colombian government has established an advisory commission to consolidate a perspective on the topic (DNP, 2015). Unsurprisingly, most of its suggestions point to the many rural institutions that should take place. The question suddenly arises, how should these institutions fit in and count on existing local potential so as to boost their impact?

This gives me an excuse to start the book by explaining the reason I chose its title: "Unfolding Capacity." Capacity, the everyday word, refers to the "ability or power to do or achieve something," as one can read in the Oxford Dictionary. At first sight this book is about farmers' organizations' capacity, that is, how farmers' organizations deploy their abilities and 
power to cope with complexity and bring about their views in conflicted contexts.

As for a case in point, this book follows an account of smallholder's organizations producing cocoa in seven Colombian regions. Built as a multi-sited study case, the text goes through the narratives of these organizations and describes how it has been to cope with uncertainty and bring about change. Farmers' organizations' willingness to share their history might be appreciated here as a token of pride.

But there is more about capacity. The word is charged with developmental attitude. It is popular in Latin America and is widely used as a common reference to refer to public affairs, pointing at those missing bits of "something" impeding the success of the public project: actors, resources, abilities (e.g. Cante, 2012; Gangotena \& Herrmann, 2007; Ospina, 2002).

The term capacity is also popular in global development headquarters, where it relates to the multiple quests of global change. It has been nurtured through time with suffixes, as in capacity building or capacity strengthening. In the nest of development practice, capacity has grown as a policy-related concept that has raised very little academic interest outside of developmental-driven scholar activity.

Fascinated with these contours of capacity, I wondered about its explanatory extent as a concept. I found little on the surface, but I saw something in the interstices: There are a number of scholar streams that have nurtured contents about capacity. Comprehensibly, this has not been made explicit in policy documents, where capacity appears as a finished product.

Using a constructive approach to build on these sources appeared to me to be a nice scholastic endeavour. After all, policy tools have been coined as governance technologies (Voß, 2007) and have easily fit into the box of social technologies (Beinhocker, 2006). The question struck me: What could we learn about social change by bringing together, and completing, capacity's epistemic foundations to the surface? Is not it a way to learn out of our own experience? 
These two quests - a fair account of farmers' organizations strategies and a closer look to capacity as a conceptual means-stand as the drivers of my research, the core of an exploration whose first steps are here given.

Naturally, this twofold inquiry will appear throughout the book, as a dance. The research approach was set in such a way that both empirical and theoretical findings would unfold in parallel, mutually reinforcing. Each realm shows choreography of its own and prompts, at the same time, results on the other. This book describes farmers' organizations' endeavours to deal with surrounding actors and bring change about. And to make this description possible, the book develops concepts pointing at actors' gestures and the forms in which knowledge flows on such processes.

The results show an extended repertoire. Drawn as a creative methodological endeavour, the book builds on the value of practice as a guiding reference of scholar concepts. It shows a different way to look at meso-level agency, focused on knowledge repertoires and, once on that track, points at a sound understanding of change-oriented agency, as it is built on farmers' organizations' shoulders: the many games in which practice, institutions and boundaries intertwine.

The book is structured in four main blocks. The first block sets the scene of the research. I discuss literature on farmers' organizations, introduce the research questions and present the research rationale. The second block develops the theoretical realm. I discuss capacity development as an interpretive reference and present the knowledge-repertoires theoretical perspective. It finishes with a detailed account of knowledge stances as analytical units. The third block presents the empirical realm. I discuss the methodological approach and give detail about the multi-sited case. Afterwards I discuss fieldwork results. The fourth block discusses results. The analysis follows a typological rationale, discussing farmers' organizations' strategies. Detail is given about the fields in which farmers' organizations take part as well as the impact of their strategies vis-à-vis practice, institutions and boundaries. The analysis comes to an end with a filtering of those strategies specifically linking to a notion of change agency.

Please, come in. Enjoy the dance. 


\section{Setting the scene}


I will start discussing the research questions and rationale, situating them within the wider scope of research that has been done on farmers' organizations' features and roles. I will start describing the more general scholar approaches to farmers' organizations and later focus on those that are closer to this particular research (i.e. those closer to the specific topic of farmers' organizations' strategies as change agents).

\subsection{About farmers' organizations}

This book refers to farmers' organizations as any form of rural grassroots agency aiming at collective action. As Meinzen-Dick, Digregorio, \& Mccarthy (2004) posit, collective action is any "voluntary action taken by a group to achieve common interests." This broad distinction attempts to account for the many forms collective action takes in rural areas. Aiming at capturing the weakest actors of so-called poverty pockets, this research tracks down those organizations whose members are smallholders (owners of a maximum of 5 hectares of land), having a local or regional reach as organizations and located in rural areas with ill-functioning institutions.

The relevance of farmers' organizations at the rural grassroots level is known. ${ }^{1}$ Farmers' organizations are the closest institution to small farmers and often the only one (SARD, 2007). Farmers' organizations have various legal statuses combining agricultural and non-agricultural purposes (Emprender-Paz, 2011; PROCASUR, 2011), varying in legal presence from market-oriented enterprises to non-governmental organizations. Farmers' organizations grow in various forms: sometimes through community leadership; sometimes by isolated philanthropic efforts or specific advocacy of firms, international organizations or non-governmental organizations. Most of the literature addresses, with an evaluative tone, those being a result of rural development policies.

Various streams describe scholar attention to farmers' organizations' existence and roles. The works of Bratton (1986), Uphoff (1988; 1993) and Bebbington $(1996 ; 1999)$ bring seminal approaches to the topic. Bratton's work brings about the notion of collective action from an institutional

\footnotetext{
${ }^{1}$ Bijman, Muradian, \& Schuurman (2016) reckon these organizations have been labelled differently for a long time. They are known as cooperatives, associations, community-based organizations and, lately, producer's organizations. There is no scholar consensus on the matter, arguably due to complexity of the matter.
} 
perspective as a guiding concept. Aiming to achieve a scope of local institutional and organizational feature, Uphoff describes the grassroots levels. Bebbington discusses social capital as a guiding reference to understanding, addressing and promoting collective arrangements. The "rise and routinization" of the social capital concept in development practice could explain why many efforts to assess farmers' organizations followed these streams (Woolcock, 2010).

Economics is the prevailing discipline offering a variety of approaches employed to analyze farmers' organizations. These works focus on market access and economic sustainability, and usually assess farmers' organizations' performance in the frame of a policy, a region or a crop. Bratton (1986), Berdegué (2001) and Yang (2013) discuss the performance of pro-cooperative policies in Zimbabwe, Chile and China, respectively. Moustier and others (2010) discuss farmers' organizations' access to supermarkets in Vietnam. Deng and others (2010) and Jia and others (2012) discuss the effectiveness of the professional cooperatives program in China. González and others (2005) take a look to farmers' organizations' access to organic markets in Mexico. Fischer and others (2012) and Shiferaw and others (2006) discuss features of farmers' organizations' market access in Kenya; while Hellin and others (2009) do it for Central America. In 2009, Food Policy journal devoted a special issue to collective action. It discusses farmers' organizations' involvement in value chains, looking at various cases from a variety of methods (Barham \& Chitemi, 2009; Devaux, Horton, Velasco, Thiele, López, Bernet, Reinoso, \& Ordinola, 2009; Gruère, Nagarajan, \& King, 2009; Kaganzi, Ferris, Barham, Abenakyo, Sanginga, \& Njuki, 2009; Kruijssen, Keizer, \& Giuliani, 2009; Narrod, Roy, Okello, Avendaño, Rich, \& Thorat, 2009).

Other works consider farmers' organizations as service providers. PROCASUR (2011) presents several cases about how farmers' organizations deliver financial services, namely insurance or microcredit. Trærup (2012) discusses farmers' organizations' potential for insurance provision through rural networks. Yadoo and Cruickshank (2010) present farmers' organizations' role as rural electrification intermediaries. Hagmann and Chuma (2002) describe farmers' organizations' ability to manage natural resources. Tole (2010) makes the case for farmers' organizations in forest management. 
Not surprisingly, some works discuss farmers' organizations' roles in science and technology endeavours. Ortiz and others (2013) analyse potato innovation systems in Bolivia, Ethiopia, Peru and Uganda, assessing farmers' organizations' contributions. De Souza and others (1999) analyze causes for the successful adoption of sustainable technologies, of which farmers' organizations' membership is one. Abdulai and others (2011) come to the same conclusion for adopting irrigation techniques. Other analysis includes Gilbert and others (1990), who research farming systems. Bingen and others (2003) discuss categories of pro-poor farmer innovation policies.

\subsection{Farmers' organizations: Their many roles at the grassroots level}

Despite scholar interest, shown in the great variety of approaches to the topic, there is little work addressing how farmers' organizations strategize to coproduce $^{2}$ public value in the rural sphere. Or, in other words, how farmers' organizations strive to improve local or rural life conditions connected to their immediate contexts.

This topic has been indirectly analyzed, addressing what could be seen as other drivers-non-market related drivers—of collective action. Berdegué (2001) addresses farmers' organizations' networking action, to a limited extent, reckoning its relations to public authorities. Indirectly, Schejtman and Ranaboldo (2009) discuss culture valorization as a driving force for 11 community-based collective action initiatives in Latin America. Also indirectly, Tironi, Salazar, \& Valenzuela (2013) present farmers' organizations' advocacy role against genetically modified organisms (GMOs) policies in Chile.

Non-scholar sources bring other views. Emprender-Paz (2011) presents some community-based farmers' organizations preventing polarized military conflict. PROCASUR (2011) discusses cases featuring farmers' organizations' advocacy and participation in environmental protection, gender inclusion and land access.

Closer to the references used in this research, Gouet, Leeuwis, \& Van Paassen (2009) discuss a theoretical paper reflecting on the roles of

${ }^{2}$ Following (Ostrom, 1996, p. 1079), coproduction is understood here as the process of participation in which "that synergy between what a government does and what citizens do can occur." 
producers' organizations and their implications for capacity development. The paper discusses producers' organizations' roles integrating smallholders in value chains, in democracy and human development, bringing about innovation and overcoming social dilemmas. Innovation relates here to social "reorganizing," network building, social learning and negotiation, following systemic notions of agricultural knowledge and information systems and innovation systems (Röling \& Engel, 1991; Smits \& Kuhlmann, 2004). Effects on capacity development point to recognizing possible roles of organizations in these realms.

Recently, Bijman (2016) proposed a literature-based typology as an introduction for a book on cooperatives, economic democratization and rural development. Bijman's types describe possible distinctions amongst farmers' organizations according to:

i) The informal and formal character of organizations (Bernard \& Spielman, 2009);

ii) Organizations' functions in the productive process (such as providing services when markets fail, providing goods when states fail, and providing a voice in political affairs) (Rondot \& Collion, 2001). This is similar to a possible distinction between "claiming organizations" and "efficiency organizations" (Thorp, Stewart, \& Heyer, 2005), and community-oriented and market-oriented organizations (Bernard, Collion, De Janvry, Rondot, \& Sadoulet, 2008);

iii) Organizations' specialties in the realm of primary productive functions, their role as focused on supply (Wanyama, Develtere, \& Pollet, 2009), marketing, or bargaining (Bogetoft \& Olesen, 2004); and

iv) Organizations' scale, being local, regional or national.

Thomas-Slayter's (1994) analysis of institutions and structural change discusses institutional constraints, dissonance and gaps in the dialectics between African local organizations and national states. Thomas-Slayter draws attention to "local organisations [as] an important part of the local landscape ... not to be dismissed but rather nurtured for the roles they can play in sustainable development" (1994, p. 1486). As it will be shown, international development agencies' current rationales appear to be following Thomas-Slayter's advice. However, there is little evidence of it having been taken by national and subnational governments, who are 
today responsible for most of the underdeveloped rural regions of the world (IFAD, 2011).

\subsection{The notion of a change agent}

This extended view of farmers' organizations' roles bring about scholar evidence about their relevance in rural areas, but also an implicit scholar challenge about how to capture comprehensively the extent of this role. In tune with the use I have given to capacity as a source of inspiration, I will introduce for the time being a provisional guiding label of change agent.

Following the World Bank's definition, change agents are "leaders, groups, coalitions and others that can initiate and drive positive changes towards the achievement of a development goal" (World Bank, 2011). Along the text I will be also referring to change agency, referring the specific form of agency deployed by a change agent. As will be seen, these references will gain various textures along the text and will allow me to delve into various layers of agency.

\subsection{Farmers' organizations as change agents: Research questions}

The central question of this inquiry is the following: What are the strategies of farmers' organizations as change agents? I aim to develop a typology of farmers' organizations' strategies as change agents. This quest is supported by three specific questions:

1. What purposes drive farmers' organizations as change agents?

This question aims to shed light on farmers' organizations' motives, beyond the more evident concern of productive purposes. Arguably, these drivers might give an account about the rationales behind organizations' strategies as change agents.

2. What are farmers' organizations' strategies to coproduce institutions impacting local dynamics? 
This question refers to farmers' organizations' strategies dealing with and about institutions. The question aims at uncovering farmers' organizations' endeavors pursuing the creation, disruption and/or preservation of institutions affecting local realms.

3. What are farmers' organizations' strategies to create, allocate and scale local skills, capabilities and capacities?

This question aims to develop a better understanding of farmers' organizations' strategies to build local capabilities and capacity.

\subsubsection{Research rationale: Finding a cadence to dance}

This research follows an abductive rationale. The specific research questions guide both the theoretical and the empirical inquiries, holding together the pieces of a theory/evidence puzzle in which clarifying theoretical resources and approaching empirical evidence allow delivering plausible insights. Which means, in other words, that tentative conceptual approaches are completed by means of grounded theory (Schwartz-Shea, 2012).

In this case the theoretical realm has a twofold empirical source. On one hand, it brings about capacity as a source of inspiration, as an interpretive reference (Keller, 2011), specifically, capacity as modelled in working documents of development practice. Capacity development, here understood as a development-based conception of agency, is rendered analytically operational in the pursuit of a theoretical framework. On the other hand, naturally, empirical results are a second source of theoretical results. A more detailed view of the theoretical framework is completed by means of a grounded approach (Charmaz, 2014a; Charmaz, 2014b).

The analysis brings a second methodological nuance. I have earlier mentioned this research aims at creating a typology of farmers' organizations' strategies as change agents. To this extent the analysis recurs to a typological way of thinking, taking farmers' organizations' strategies as ideal types (Weber, 1949). Therefore those gestures, plausibly seen as strategies, are "isolated" in such a way that crosscutting analysis can take place, in the search of configurations describing explanatory patterns. This specific aspect is further developed in Chapter 5, using 
found agency patterns to discuss both practice fields as well as meso-level knowledge stances.

Next is a brief introduction to both the theoretical and the empirical pillars of the research.

\subsubsection{The theoretical realm}

The aim of this theoretical quest is identifying concepts and perspectives that allow addressing change agency as such. As previously mentioned, the capacity development framework works here as an interpretive reference (Keller, 2011). Capacity development is a policy tool (Voß, 2007) of international development organizations and, as such, might be also a performative form of knowledge (Van Egmond \& Zeiss, 2010).

As a development tool, capacity development refers to autonomy deployment in the pursuit of developmental value. Its sources are scattered and uneven in purpose and approach. As Alaerts and Kaspersma (2009, p.10) point out, capacity development is not based "on solid and disciplinary research but rather on prima facie observation and intuitive analysis." Mosse (2005, p.171) allows interpreting capacity development as a practicebased model emerging "through critical reflections on practice" providing “"second-order' rationalisations ... helping the way in which ... development practice is represented and communicated." However, it is possible to find here and there pieces and bits of scholar work sourcing capacity development. Institutional and systemic thought are salient amongst them.

So the theoretical quest aims at developing tools rendering capacity development analytically operational. I use various disciplinary streams to nurture and intertwine this very basic design. I introduce institutional work, which building on organizational studies and institutional theory develops notions relating to agency on institutional change. ${ }^{3} \mathrm{I}$ also bring forward works from innovation intermediation, which develop notions relating to agency in innovation processes. ${ }^{4} \mathrm{I}$ examine other sources, such

\footnotetext{
${ }^{3}$ Following, amongst others, Battilana (2009); Lawrence, Leca, \& Zilber (2013); Lawrence \& Suddaby (2006); Pacheco, York, Dean, \& Sarasvathy (2010); Zietsma \& Lawrence (2010)

${ }^{4}$ Following, amongst others, Doganova (2013); Howells (2006); Kilelu, Klerkx, Leeuwis, \& Hall (2011); Klerkx, Schut, Leeuwis, \& Kilelu (2012); Van Lente (2003); Yang, Klerkx, \& Leeuwis (2014)
} 
as the practice turn in sociology ${ }^{5}$ and cognitive studies ${ }^{6}$ so as to complete a more detailed picture.

These scholar streams address multiple dimensions intervening in change efforts. Rather than linearly corresponding to each other, the various facets of these dimensions work complementarily, allowing a broader and more detailed picture of possible features of change agency. I find a way to group them together, taking advantage as much as possible of their various possibilities, finding a common thread.

The result-and as such the overarching analytical tool of this research-is a portfolio of knowledge stances, making it possible to describe meso-level agency. This portfolio details knowledge-related gestures deployed by actors, pursuing means and effects on practice, institutions and boundaries. Knowledge stances are then concepts allowing identifying meso-level knowledge-related patterns, making it possible to afterwards actually point at change agency strategies (See Chapter 2).

Before continuing, it is worth rementioning that I selected the expression change agent as a tentative reference to develop throughout the text. It should be understood that change agent will refer to the various ways the notion could be described by the various scholar streams. In this sense, from institutional thinking a change agent is an actor "functioning as a corporate ... attaching a subjective and instrumental meaning" to its action (Ostrom, 2007, p.278). From innovation studies, a change agent is a systemic intermediary who "focus on support at a strategic level" (Van Lente, 2003) acting "as an agent or broker in any aspect of the innovation process between two or more parties" (Howells, 2006).

\subsubsection{The empirical realm}

In the empirical realm, the research recurs to a multi-sited study case. The inquiry requires emphasis on historical and present accounts of farmers' organizations' relations at the meso level. Observation, interviews and focus groups focus on unveiling how organizations experience relations with other parties, how they cope with the situations they face in those relations. Rather than developing a comparative scheme between

\footnotetext{
${ }^{5}$ Following, amongst others, Barnes (2001); Schatzki, Knorr-Cetina, \& Von Savigny (2001); Whittington (2006)

${ }^{6}$ Following, amongst others, Maturana \& Varela (1990); Varela (2000)
} 
organizations, the inquiry develops thematic accounts unfolding reiterative threads (See Chapter 4).

The selection of the cases aims to expand the possibility of addressing farmers' organizations' strategies, while keeping an adequate balance in the heterogeneity of the cases. 
2. A practice-based conceptual approach 
This section discusses a theoretical approach that allows identifying and better capturing specific features of change agency. This endeavour recurs to capacity development as a source of inspiration. Or, to use a more accurate expression, as an object for dissection. By dissecting capacity development, I mean I will try to bring out its embedded rationalesunderlying assumptions, analytical scopes, reiterative concepts-that allow sourcing theoretical means for a more detailed conceptual approach to change agency.

Before proceeding, it is worth clarifying the rationale I am following in order to carry on this exercise. On one hand, it should be said this exercise rests on the assumption that it is actually possible to dissect capacity development. In a broader perspective, this approach points to the fact that I am reading capacity development as a discursive dispositive, trying to specifically address its knowledge-related contents (Foucault, 1972; Keller, 2011).

In terms of scholar tradition this approach posits this endeavour in the realm of social studies of science and technology, in general, and in the realm of policy analysis, in particular. Which translates here, in practical terms, to assuming capacity development to be a technology of governance (Voß, 2007).

In effect, following Rip and Kemp (1998), Voß discusses the technological features of policy instruments as the "rule-set or grammar embedded in a complex of engineering practices, production process technologies, product characteristics, skills and procedures, ways of handling relevant artefacts and persons, [and] ways of defining problems". For the case in point, this implies investigating capacity development's underlying rationales as a policy instrument.

Further, this exercise points at a higher aim. Namely, this discussion brings to the surface streams of concepts possibly laying under capacity development rationales, and one step further, working and waving them so as to create an overarching conceptual approach for this research, bringing about useful notions to capture the slippery phenomenon of change agency.

The chapter is divided in two main sections, reflecting these aims. The first block discusses capacity development, bringing out its constitutive elements as a policy tool and assessing those elements allowing grounding 
theory (Charmaz, 2014a). The second section discusses a conceptual design, result of an analytical exercise rooting and distilling conceptual overlaps from various scholar streams.

\subsection{Capacity development as a form of change agency}

In this section I will discuss capacity development from a very specific perspective. I aim at clarifying the understanding that capacity development has of change agency. So rather than presenting a review of capacity development foundational concepts, I will discuss its background and rationales as a policy tool. To this extent, the discussion elaborates on its main features, background settings and its epistemic status as means to bring to the fore its assumptions and rationales.

I noted before that capacity development texts are scattered in purpose and approach. Which is natural, as a tool of global development, because capacity development carries the voices, requirements, specific functions and purposes of many multiple participating actors with many multiple roles. To the extent of this specific realm of practice, however, capacity development establishes a reference framework whose broad rationales I will detail in the section, as if drawing on a single entity.

It is worth bringing about the definitions of capacity development, so as to have a first glimpse of its underlying aims and its effect on global development itself. Naturally, the various definitions of capacity development originate from the international development sector.

The most influential definitions include the United Nations' (Capacity Development, 2008, p.4), which defines capacity development as "the process through which individuals, organizations and societies obtain, strengthen and maintain the capabilities to set and achieve their own development objectives over time." Otoo, S., Agapitova, N., \& Behrens, J. (2009, P.3) define the term for the World Bank as the "locally driven process of learning by leaders, coalitions and other agents of change that brings about changes in socio-political, policy-related, and organizational factors to enhance local ownership for and the effectiveness and efficiency of efforts to achieve a development goal." The OECD (2006, p.14) defines the concept as "the ability of people, organisations and society as a whole to 
manage their affairs successfully." Following a systemic approach 7 , Ubels, J., Acquaye-Baddoo, N. \& Fowler, A. (2010, p. 4), define capacity development as "change processes [in] the ability of a human system to perform, sustain itself and self-renew." Overall, capacity development refers to increasing people-based autonomy deployment.

The tenets behind these definitions can be traced to Sen's and Nussbaum's works on human capabilities. Sen (from economics) and Nussbaum (from ethics and law) proposed seminal insights for the human development framework (Gasper, 2003). According to their approach, human beings and sustainability are to be regarded as the priorities for development efforts, where capacities constitute both the means and ends of development. Acknowledging, creating and maintaining capacity is, in this sense, acknowledging, creating and maintaining development (UNDP, 2010a). "When we talk about capacity"—says Sen_-what we are ultimately looking for is for the capacity of human beings, what they are capable of doing, what they have the freedom to do" (UNDP, 2010b). These principles are at the core of the concept's axiological references. ${ }^{8}$

Beyond the realm of discourse, these concepts have brought about institutional change for international development practice. The capacity development approach was used to drive the transformation of technical assistance practices, which with time became also a battleship to bring about changes in international aid architecture, as seen in the various aid summits (Dabelstein, 2012). The concept brought to the table alternative approaches, creating a path (e.g. Browne, 2002) and scoping and embedding new practices on development agencies (e.g. Dac-OECD, 2006; UNDP, 2008; Otoo, et. al., 2009). Many actors built the term, adding formal networks (e.g. Dac-OECD, 2006), informal networks (e.g. LenCD.Org, 2013) as well as independent consultants (e.g. Morgan, 1997).

\footnotetext{
7 The systemic approach was developed by Morgan (2005), and later promoted by the European Center for Development Policy Management ECDPM (2008).

${ }^{8}$ The term development is expressed in the human development framework as "a process of enlarging people's choices. The most critical of these wide-ranging choices are to live a long and healthy life, to be educated and to have access to resources needed for a decent standard of living. Additional choices include political freedom, guaranteed human rights and personal self-respect and the sustainability framework." (Dac-OECD, 2006).
} 


\subsubsection{Epistemic status of capacity development}

What is the reach-and therefore the limits-of capacity development as a reference framework created in the realm of policy? A brief answer to this question allows understanding the particular approach of capacity development to its object, and therefore its theoretical limits. Which, in the context of this research, accounts for why it is needed to go deeper in capacity development tenets in order to better interpret its understanding of change agency.

I argue that capacity development is fundamentally a practice-based reference. Various threads come in line with this statement.

Capacity development knowledgeable sources are practice-based sources. Along the core capacity development reference documents from international organizations it is possible to see semi-formal and informal networks play a role as knowledge reservoirs. These reservoirs include sector organizational and contact information, as well as reference sources. Websites linking to informal networks, such as LenCD.org and Capacity.org, display experiences (cases, editorials, and critical reflections), practice-oriented resources (handbooks, concept notes, toolboxes) or focused peer-to-peer assistance (topic communities). Sometimes they also edit bulletins or journals. These networks are specially focused on capacity development as a topic. Other networks, such as $\mathrm{km} 4 \mathrm{dev}-\mathrm{knowledge}$ management for development-link to them following their interest in addressing knowledge in development, focusing on knowledge-related functions, problems or tools, addressed by and to any setting within the world of development.

The work of Mosse (2005, p.171) about how development is cultivated allows interpreting capacity development as a practice-based reference framework. Following Mosse, it is likely that capacity development emerged "through critical reflections on practice" providing "'second-order' rationalisations ... helping the way in which ... practice is represented and communicated."

Following this thread, the epistemic value of the capacity development framework is shaped by international development cultures to the scope of a model-based, project-sized prescriptive approach. Nurtured from the various development fields, scales and functions within development 
practice, capacity development plays a role as an umbrella concept (Swierstra \& Rip, 2007). More a tentative than a mandatory or stable concept, it works as a transversal reference for the sector, set to affect its everyday routines and operative protocols: core documents of capacity development are meant to bring new rationales into project design (e.g. World Bank, 2012; UNDP, 2008).

However, this does not mean the capacity development framework lacks conceptual anchoring. A knowledgeable reader will see that institutional thought is embedded in the approaches of the World Bank, OECD and United Nations. The systemic complex adaptive thinking shapes, more explicitly, the ECDPM approach. This would allow seeing the capacity development framework as a performative form of knowledge or, as Van Egmond \& Zeiss (2010) have suggested in a similar case, a boundary object informing policy. In any case, scholarly capacity development texts do not delve into these disciplinary fields. They do not give step-by-step accounts of its rationales and assumptions, nor do they discuss any disciplinary research (Alaerts \& Kaspersma, 2009). These texts mostly draw on sources-and their experience-to sketch models that development actors should follow so as to develop the capacity of others.

Scholar references nurturing these networks are scattered in types of content, purpose and approach. The references somehow resemble practice itself, in the sense of bringing in analytical frames to describe, justify or explain everyday uses. In order to do this, disciplinary sources are adapted or re-contextualized. The texts embed disciplinary explanations as model rationales, in the form of normative references (e.g. Otoo, S. et. al., 2009). Innovation studies or knowledge management languages appear often, although their "natural" settings do not necessarily fit development rationales (e.g. Klerkx, Pant, Leeuwis, Cummings, Le Borgne, Kulis, Lamoureux, \& Senmartin, 2011; Ngwenya \& Hagmann, 2011). Interestingly, the development sector is rapidly acquiring innovation languages.

In the following paragraphs I will discuss various overarching aspects lying in the background thinking of capacity development. I will discuss three reiterative rationales. The first relates to the understanding of social learning as a means of social change. The second relates to its analytical scope, situated at the meso level. The third relates to the levels in which capacity is to be found and nurtured. 


\subsection{2. "Theorizing" social learning as a means of social change}

Often capacity development texts aim at making sense of social learning as a vehicle for "development" or "social change," unveiling the necessary means to strive for it (e.g. Brinkerhoff \& Morgan, 2010; Taylor \& Clarke, 2007). These texts try to assemble the various pieces of the puzzle, addressing this subject as comprehensively as possible.

Capacity development texts' understanding of social learning includes the distributed capabilities that would imply the change of individuals, organizations and societies (e.g. Alaerts \& Kaspersma, 2009; Kaspersma, 2013; Morgan, 2005), ${ }^{9}$ but also the role that more complex social processes involving power, local history and change drivers play. Dac-OECD (2006) stresses how "capacity is not only about skills and procedures; it is also about incentives and governance." Interestingly, this link between these dimensions-the account of distributed capabilities and governancesuggests some practical understanding of the cognitive dimension of institutional work (see Lawrence et al., 2013).

Expectedly, capacity development often stresses the importance of the nonmaterial dimension of change. Or at least implies more importance should be given to this aspect as a determinant of change. To specify these realms, Ferreira (2012) introduces the concept of social technologies. Social technologies are "methods and designs for organizing people in pursuit of a goal or goals" (Beinhocker, 2006, p.262). According to Beinhocker, social technologies include institutions_-in North's sense (1990)—but also include "other ingredients such as structures, roles and cultural norms (Beinhocker, 2006, p.262)."

Examples of social technologies are facilitation methodologies, management practices, electoral systems and rural small market cultures. Changes in social technologies, says Ferreira, suppose dialogues between various "local" and "general" knowledges. The use of the plural form for knowledge is deliberate: It implies convergence of multiple sources, rationales and values behind knowledge. These sources would refer to social technologies' components, dimensions or processes. Dialogue between

\footnotetext{
${ }^{9}$ I will come back to this later to give more detail about these various levels.
} 
knowledges, it would be expected, creates new ways of understanding and constructing local realities.

Therefore, in capacity development is assumed that social change is a function of social learning, with change coming about as a result of transformations in individuals, organizations and societies, especially in the realm of social technologies. This is seen through transformations in the ways people organize themselves to go about their circumstances. Expectedly, models adding to the capacity development as a reference framework delve into mechanisms of social learning-one could say absorption, learning, and innovation on social technologies-attempting to tackle these complex layers. These models are here means of theory, in the sense they provide an abstract understanding of the social phenomenon at hand (Abend, 2008).

\subsubsection{Identifying and linking capacity levels}

Where is capacity to be found according to development practice? I have already mentioned capacity is seen as a feature of individuals and organizations. But capacity is also to be found on less concrete levels, such as in society, the system and/or the enabling environments. Capacity development texts often assume a close interrelation between these levels. Now follows some details of this approach.

The notion of an enabling environment describes "the broader system within which individuals and organizations function and one that facilitates or hampers their existence and performance" (Land, Hauck, \& Baser, 2009). In a sense, it describes an aggregation of social technologies, to use Beinhocker's concept. The enabling environment is the changingtrending and/or conflicting-space of encounter between organizations and the cultures it is drawn upon. But it also appears in the multiple forms of institutions: the less tangible "rules of the game" and the formal ones in the form of norms or policies (UNDP, 2008). All these elements constrain or foster change. In spite of the difficulties of effectively addressing this level, it is regarded as a core objective of capacity development efforts.

The organizational level is perceived as functional to the enabling environment level. Therefore, the capacity development framework stresses the organization's effectiveness at delivering on mandates as a core performance criterion (ECDPM, 2008; Mentz, 1997). From this starting 
point, various aspects referring to organizational capabilities extend the capacity development literature. The individual level, again, is subordinated to the organizational level. The capacity development approach supposes an evolution from a generic provision of disperse technical assistance and training initiatives to a more systematic understanding of social learning and decision-making, thus to a more strategic role of an individual's potential in organizational contexts (Browne, 2003).

\subsubsection{Analytical scope}

Expectedly, capacity development texts do not give an explicit account of their analytical scope. It is possible to infer it, however, by means of its role and settings as a concept. In other words, it answers the questions what kind of practice does the concept inform and for whom.

As said, capacity development performs as an embedded tool of developing practice. It informs policy-making, project management and boundary relations of the many international aid stakeholders and operators. Its regular setting is that of the meso level. The meso level is defined as the concrete sphere where encounters between diverse organizations take place. The sphere in which, in the interaction of actors in "fields, arenas or games ... social orders ... are constructed and reproduced" (Fligstein, 2001, p. 5). The meso level comprises the interactions of diverse organizations, whatever their purpose and nature, and the forms of practice and institutional spheres they build in that process. These arrangements play roles at the local, regional, national and international levels.

Capacity development texts attempt to identify and address lasting features of the meso level. Although its rationale is limited to the project level-in tune with development practice-its concern for building enabling environments (e.g. Dac-OECD, 2006; Otoo, S. et. al., 2009; UNDP, 2008) expresses understanding and intentional agency towards sustained governance and institutional depth (e.g. World Bank, 2012), expressed in the design of practical ways to tackle its "multiple levels, multiple actors and multiple dimensions" (Ubels, Acquaye-Baddoo, \& Fowler, 2010).

This form of agency, that is, pro-development through interaction at the meso level, is built and suggested by the collection of models informing the framework. These models are often presented as a result of learning 
processes (e.g. Browne, 2003; Dac-OECD, 2006; ECDPM, 2008). They further inform, guide or frame practice by means of setting guidelines (e.g. UNDP, 2008), assessment of previous experiences (e.g. ECDPM, 2008), evaluation criteria (e.g. Otoo, S. et. al., 2009), or facilitation references (e.g. JICA Research Institute, 2008).

\subsubsection{Change agents as the means of governance}

Who brings about change? One can infer from capacity development texts that social change can be triggered and led by any actor within society. I have introduced the World Bank (2012, p.11) definition, coining change agents as "leaders, groups, coalitions and others that can initiate and drive positive changes towards the achievement of a development goal." In this sense, neither the type of agent nor his or her impact scale is relevant, for developmental value is not exclusively a state matter (Dac-OECD, 2011).

The assumption that "any actor can initiate and drive change" suggests a specific understanding of policy and governance. Here I am reminded of Ostrom's definition of an actor being "a single individual or a group functioning as a corporate actor", and action being those "human behaviors to which the acting individual attaches a subjective and instrumental meaning" (Ostrom, 2007). This understanding implies power distribution at multiple levels, including that of the international and non-governmental agencies authoring the framework.

In effect, pursuing "developmental" value (as any other value) supposes defying (with more or less degrees of antagonism) a certain state of affairs. It is not difficult assuming that such an endeavour enacts a purpose, responds to (more or less legitimate and shared) motives, is expressed in a (more or less elaborated) discourse and is (more or less) contested by other actors. Policy, following this thread, is seen (and enacted) by the capacity development framework as the result of a multiple governance grid (Hupe $\&$ Hill, 2006).

Capacity development texts, as discussed earlier, do not overlook the existence of political struggle in these processes. However, following the rationale of social learning as social change, they emphasize its contents. Or as Li (1999) understands it, render social change as a technical matter. Change agents, from this perspective, are vehicles of knowledge and 
institutional entrepreneurs (Dimaggio, 1988): They are means for the building of competence, organizational accountability and institutions.

Summing up, capacity development texts reflect the means by which actors play a governing role at the meso level. A collection of models, guides, recommendations and reports intended to inform practice, shaped on the base of theoretical sources, including accounts of experience referring to practice itself add to this reference framework. As such, capacity development illustrates the inner workings of a governance technology.

\subsubsection{Constructive means for theory grounded in capacity development}

What does this account of the capacity development framework unveil? In short, the capacity development framework illustrates a detailed example of practical means for governance. It shows detail about the means and rationales of a governance technology. More specifically, the inner workings of a change-oriented governance technology.

As previously said, the framework embeds a theoretically and practically informed understanding of i) governance settings, set at the meso level; ii) governance manifold layered accounts, specified by capacity levels and interaction fields; iii) governance means, focused on the realm of social learning; and iv) explicit embedding of various disciplinary streams. These features are able to set a reference landmark for a theoretical inquiry on agency.

What follows represents a constructive theoretical effort based on these assumptions and an interpretative reading of multiple disciplinary references. It aims at setting theoretical anchors for this research so as to assess farmers' organizations' strategies as change agents. In doing so, it also helps unveil capacity development's (change-oriented) agency black box and inform scholarship from a practice-informed boundary-object model. In other words, this means unpacking a dispositif (Foucault, 1972).

\subsection{Analytical focus}

It is worth a pause to clarify where we are at this point of the argument. This chapter discusses a theoretical approach that allows identifying and 
better capturing features of change agency, and more specifically, those related to its underlying strategies. A couple of threads link to this exercise and are worth bringing back before proceeding with the discussion.

The first thread deals with the overall rationale of this research, following an abductive approach. As explained in the first chapter, this abductive approach aims at bringing about-and intertwining-both empirical and theoretical insights in order to better capture a difficult research object.

Therefore, the conceptual approach was meant as a tentative, yet-to-becompleted frame of reference. Although in this section I discuss the conceptual underpinnings of the exercise to its maximum extent, its completion depended on the inclusion of empirical results. Developed concepts behaved as working propositions, and their depth will be discussed in different sections of this book. In due time I will note how the key notions gained detail and contents from empirical results.

The second thread follows the previous section, following a capacity development reference framework as a source of inspiration-and possible scholar references.

As discussed, capacity development texts describe references to agency at the meso level in pursuit of public value-driven change. As a reference framework, capacity development describes change as a function of social learning that can be triggered by any agent. According to its tenets, change agents should impact one or various levels-individuals, organizations, societies-in order to promote change and enable further opportunities for change. Social change actually emerges as a result of a process of social learning, expressed in skills and capabilities, organizational roles and exchange, rules of the game and institutions.

Following this line, this section builds on linking the capacity development reference framework to plausible scholar streams, aiming to conceptually tackle strategies of change agency, For this, I use literature on institutional work, innovation and learning intermediation and cognitive studies. Here capacity development is shown as a performative form of knowledge, whose roots are worth unveiling and deepening theoretically. This connects to the third thread, the guiding conceptual approach to be discussed in this section. 
I have labelled this conceptual approach as the knowledge-repertoires perspective. This name came to mind when assessing overlaps and complementarities amongst these various scholar sources I was able to see possible transversal linkages worth bringing to the surface as means of a single corpus. In order to spare the reader the trouble of going through the step-by-step building process, I will present it as a finished product, discussing first its more detailed analytical features and later discuss its underlying scholar foundations.

The section is divided in three subsections. The first discusses knowledge stances. A result of the literature synthesis, knowledge stances actually constitute the analytical units under observation and the objects around which the abductive synthesis takes place. The second section discusses knowledge repertoires, describing knowledge-related streams of activity adding to a broader understanding of components making up part of mesolevel agency. As such, this reading of knowledge repertoires supposes a way of intertwining and understanding existing literature. In the third section I go through the streams of literature, giving foundations to this approach.

\subsubsection{Knowledge stances}

This section discusses knowledge stances. Before proceeding I will comment that you will find various concepts I have not discussed yet. These concepts will be broadly defined here, but they will not be discussed at length theoretically. Rather they will be introduced, along with some depth gained through empirical insight.

After various writing experiments I have come to the conclusion this is a clearer way to convey the message. The assumption being that having this overview in mind, the reader will have the chance to better follow the theoretical discussion where I developed knowledge stances as tentative analytical corpus. It is worth remembering here that the rationale of this conceptual exercise was to find overlaps and complementarities amongst various scholar sources in search of features that allow tackling change agency. In this sense, knowledge stances constitute a finished product meant to point at the concrete observable objects under this research's scope of interest.

Knowledge stances are intended to be an analytical synthesis, distilling critical roles of knowledge work in social change. Following capacity 
development, this idea is based on the assumption that change agency mobilizes cognitive means and effects that aim to achieve lasting institutional effects at various levels of society. In other words, change agency describes a variety of repertoires in the pursuit of creating, stabilizing and expanding specific fields of practice. Knowledge stances specify the agency situations in which these repertoires materialize.

Knowledge stances work as hermeneutic references allowing approaching the research object. Each stance specifies a critical moment a change agent face, and points to the way this critical moment involves knowledge. It is worth noting that these critical moments point here more to the features of agency at the given time and circumstances, more than to a possible situation amongst actors. In this sense, knowledge stances group together a set of gestures that agents express.

Having said this, I will discuss now a detailed glossary of knowledge stances. For ease of reading, these definitions already include nuances gained by this research by means of grounded theoretical work. Along the discussion I will discuss empirical reinforcement of the tentative definitions or more nuanced comprehension of the stance itself. To add clarity I will refer to scattered pieces of the history of the capacity development policy tool as means of examples.

\subsubsection{Boundary exploration ${ }^{10}$}

Strategies under this category refer to coping strategies linking organizations to their peers or to other partners. Simply, boundary exploration summarizes moments of "collaborating," "joining forces," "working together to achieve" or "finding solutions together."

Boundary exploration refers to meso-level collaborative quests, suggesting forms of shared agency where boundaries might blur. Implications of collaborative searches vary for involved agents. Boundary exploration is a form of institutional work aiming to create collaborative opportunities to generate or expand existing practice fields.

\footnotetext{
${ }^{10}$ Empirical results did not add conceptually to the understanding of boundary exploration as a knowledge stance. Insights added to a more layered understanding of possible degrees and extent of collaboration and its effects on boundary blurring. I come back to this point in Chapter 5 .
} 
Boundary exploration supposes a form of rescaling the size or reach of the organizations by means of collaborating. The scope and depth of rescaling depends on the means and ends of collaboration, as will be seen later empirically. Boundary blurring appears only in forms of shared performance. These grouped forms of agency overlap local, subregional, national or international scales and can have effects on the practice field as a whole. This stance is at the base of inter-organizational collaboration, at any level, in the search of new institutional arrangements.

Boundary exploration can be seen, for example, in the formal and informal creative spaces that gave shape to capacity development as a policy trend in the realm of international development. In effect, the rise of capacity development as a framework involved an UNDP initiative taken up by OECD. The interplay also included collaboration of formal networks such as GovNET (OECD, 2006) and informal networks, such as LenCD.Org (2013). Knowledge production and facilitation created space to push change at the policy level while attempting to impact a wide practice field. Intense networking involvement also suggests practitioners played a central role in positioning capacity development within development policy.

\subsubsection{Boundary setting ${ }^{11}$}

Boundary setting describes the actor-related and normative contexts bounding an actor's agency, as well as the ongoing actions of an actor towards these contexts. Simply, boundary setting focuses on agency regarding given circumstances in which actors perform.

Boundary setting can refer to boundary situations, focused on the position of an actor in relation to other actors, or can refer to boundary conditions, focused on the effects on the actor of norms, rules or regulations. Boundary conditions and situations bound the extent and means to which organizations can actually interact.

For example, the term capacity development was introduced in the specific setting of international development. Its original base, prior to Monterrey's conference on financing development, is a UNDP research program on technical assistance. As a term, capacity development allowed

\footnotetext{
${ }^{11}$ Boundary setting was broadly defined as "institutional arrangements." Empirical results better detail
} this notion. 
summarizing and making sense of reflections of evaluation results in the attempt to improve the reach of aid programs (See Fukuda-Parr, Lopes, \& Malik, 2002). After many efforts capacity development lays the ground for a new boundary setting. Capacity development will position the language, contents and values of the Paris Declaration (and what afterwards will become a different architecture of international aid). Boundary setting refers, in this example, to the last stage of a process of boundary exploration.

\subsubsection{Practice work ${ }^{12}$}

Practice work describes those arrays of activity enacting, making possible, sustaining on time and shaping the rationale and values of a practice field. Put more simply, practice work refers those activities describing how actors "go about" creating and sustaining a practice field for a long time. An integrating category, practice work adds texture to the understanding of knowledge exploration, intermediation and supply as means to create, consolidate or disrupt a practice field.

For example, to demarcate this notion, soccer clubs "go about" their field by means of being voluntary associations, its field expanding by internal and external selection of players and technical directors. Organizations for the promotion of Zen meditation "go about" their field by means of master-todisciple teaching and past learners' donations, and its field expands by means of voluntary shared practice and specialization of the apprentices.

Coming back to the example, capacity development mise-en-scène includes a broad deployment of practice work. As said, the showcase of a book in Monterrey's conference was the starting point of various mechanisms of knowledge aggregation promoting understanding and wide appropriation of capacity development. Despite the rather stable character of a development sector, "going about" this specific content within the field implied creating specific survival repertoires of inter-institutional support, knowledge exploration, intermediation and supply as means of embedding the new contents within existing business-as-usual protocols.

\footnotetext{
${ }^{12}$ Practice work was tentatively defined as "an integrating category including repertoires of knowledge exploration, intermediation and supply aiming at creating, disrupting or expanding a practice field." Empirical results improve the understanding of the specificities of this notion.
} 
Knowledge supply refers to knowledge delivery complementing other stances. Contents of knowledge supply include local, contextual, technical, expert and/or scientific forms of knowledge. Along with these various forms of knowledge, there are also different knowledge containers. Including upto-date information (e.g. program calls), reports of various kinds (e.g. technical or legal), technologies (e.g. protocols, eventually linking to new objects) and persons. Knowledge supply is a crosscutting stance, performing in boundary exploration, boundary setting and practice work stances.

Possible roles could include informing policy-making (from an expert advisory role) or deepening the practice. Some capacity development documents (e.g. OECD, 2006) perform the former while others (World Bank Institute, 2012) perform the latter.

\subsubsection{Knowledge exploration ${ }^{14}$}

Knowledge exploration refers to knowledge unveiling and production. Knowledge exploration includes research, as broadly understood. But also includes facilitating access to unknown contexts and scaling out of tacit knowledges.

Various moments of capacity development history went through this stance. Besides research results at the origin, other pieces of capacity development, such as Capacity for a Change (Taylor \& Clarke, 2007) and the Capacity Development Results Framework (Otoo, S. et al., 2009) pose examples of tacit knowledge gathering and organizational sense-making, respectively. Schoen, Könnölä, Warnke, Barré, \& Kuhlmann (2011) refer to organizational sense-making as strategic intelligence in the realm of science and technology policy.

\footnotetext{
${ }^{13}$ Empirical results did not add conceptually to the understanding of knowledge supply as a knowledge stance. Insights added to a more layered understanding of its knowledge sources.

${ }^{14}$ Empirical results did not add conceptually to the understanding of knowledge exploration as a knowledge stance.
} 
Knowledge intermediation refers to forms of knowledge work (that is, knowledge storage, manipulation and delivery) aiming to protect a practice field. Knowledge intermediation describes here creative forms of receiving, filtering and delivering knowledge in the attempt to adequately fit boundary crossroads.

Formal and informal networks (e.g. LenCD.org, capacity.org, GovNET) are good examples of knowledge intermediation in capacity development history. These networks-as well as the products they created and circulated-have played a role bridging knowledge divides between diverse stakeholders.

Summing up, knowledge stances work as heuristics addressing moments, scopes, situations or performance of knowledge repertoires. Stances allow for making distinctions amongst various possible gestures of change agency, as well as pointing to the ways these gestures condition one another. Further, knowledge stances point at the ways practice, boundaries and institutions link to one another.

Figure 1 illustrates knowledge stances. Rather than matching to one another linearly, stances complement their various features. The figure sketches the rough, uneven, adaptive landscape in which agency takes place. Stances of boundary exploration, boundary setting and practice work are shown as forms of enacting, positioning and expanding a practice field, tackling the institutional features of the field. Stances of knowledge exploration, intermediation and supply are shown as strategies to enlarge its cognitive base.

\footnotetext{
${ }^{15}$ Knowledge intermediation was tentatively defined as "forms of boundary work aiming to satisfy knowledge demands." Empirical results provide a more localized understanding of the notion as a mean of knowledge work.
} 


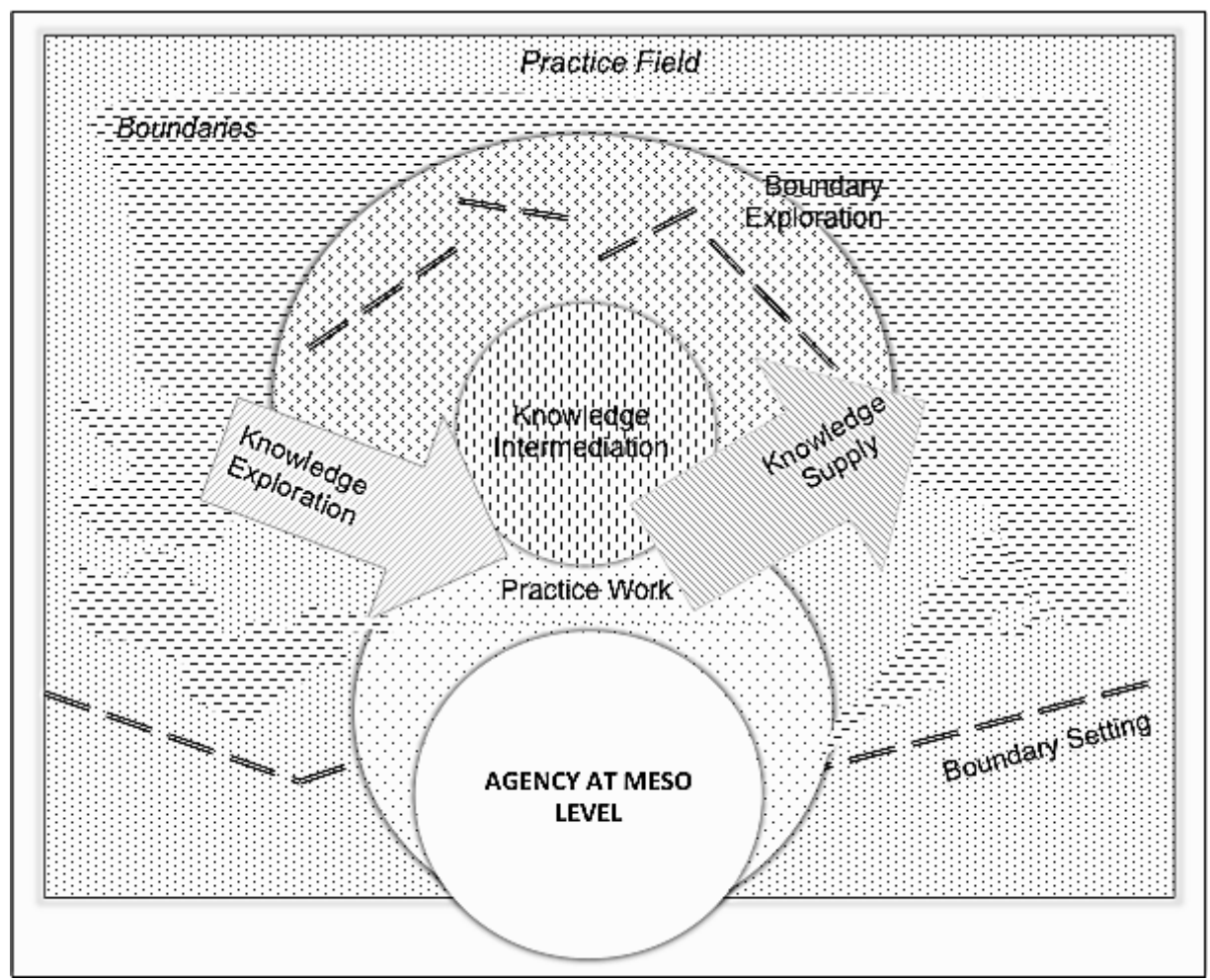

Figure 1. Meso-level agency featuring knowledge stances. Basic scheme

In the next section I will turn back to discuss the conceptual foundations at the base of knowledge stances.

\subsubsection{Building blocks: Towards the knowledge-repertoires perspective}

Before turning to discuss at length the conceptual approach, I will make a brief pause to clarify the purpose of this section. In this chapter I discussed capacity development as a source of inspiration to afterwards present in detail knowledge stances as the analytical focus of this research, discussing a set of guiding concepts. In this section I will discuss the scholar streams on which this conceptual approach was built. I will follow two steps. First I will discuss an overview of the bodies of literature informing this base of reference, afterwards I will discuss its more operative layers, detailing and nurturing its overlapping and complementary features.

As previously said, the capacity development reference framework is understood here as a performative form of knowledge, describing references 
to agency at the meso level in pursuit of public value-driven change. Capacity development depicts change as possibly triggered in various ways and led by diverse types of actors. According to its tenets, a change agent should impact one or various layers of social life in order to promote change. Social change is expected as a result and a mean of knowledge work, expressed in skills and capabilities, as well as in individual and organizational roles, norms and institutions.

Following this thread, change agency strategies are assumed here as the performance of institutional work as well as innovation and learning intermediation strategies. Institutional work is "purposive action aimed at creating, maintaining and disrupting institutions" (Lawrence \& Suddaby, 2006, p. 215), where institutions are understood as "the rules of the game in a society or, more formally, are the humanly devised constraints that shape human interaction" (North, 1990, p. 3). Learning and innovation intermediation, on the other hand, is understood here as the "support of innovation processes between various parties" (Howells, 2006, p. 720) that aims to obtain and sustain knowledge-related assets such as skills, competences and/or new knowledges.

Each of these streams focuses on specific dimensions of change. A brief summary allows finding complementary threads, plausibly allowing a broader picture of agency and is followed by a broad discussion of these scholar streams.

\subsubsection{Institutional work}

The notion of institutional work is used to describe "the broad category of purposive action aimed at creating, maintaining and disrupting institutions" (Lawrence \& Suddaby, 2006, p. 216). As a field of study, institutional work interconnects various roots. The first root brings agency to the fore of institutional change. It describes agency as "dependent on cognitive (rather than affective) processes and structures [and] focuses on understanding how actors accomplish the social construction of rules, scripts, schemas and cultural accounts" (2006, p. 218). This foundation is based on contributions by Dimaggio (1988) and Oliver (1991) on institutional entrepreneurship and institutional processes, respectively. Therefore institutions-and change processes in institutions-are, in this sense, the result of deliberate agency. 
A second root of institutional work comes from the so-called practice turn in sociology. Practice draws attention to how institutions are expressed in embodied, incarnated forms. It refers to "embodied, materially mediated arrays of human activity centrally organized around shared practical understanding" ((Schatzki; Knorr-Cetina et al., 2001, p. 2), quoted by Lawrence \& Suddaby, 2006). Practice is an object of concern of change agency. Practice work, as a form of institutional work, studies "how actors affect the practices that are legitimate within a domain ... [focusing] on how practices are created, maintained or disrupted" (Zietsma \& Lawrence, 2010, pp. 194-195). Practice as institutional work relies on knowledge processes: training, educating, theorizing, building or strengthening skills and capabilities.

A third root of institutional work comes from boundary work. Boundaries draw borders between practices, organizations, constituencies or stakeholders. Boundary work refers to various forms of agency oriented to "establishing, expanding, reinforcing, or undermining" these borders (Zietsma \& Lawrence 2010, p. 194, about Gieryn, 1983, 1999). From a "positioning" perspective of agency, these forms and contexts of boundary work create room for various agency repertoires, depending on the position and contexts of agency.

In a "within" position, an agent creates ways to "protect autonomy, prestige and control of resources" (Zietsma \& Lawrence (2010) quoting Abbott, 1988). In a "between" or "outside" position, agency focuses on strategies to create connections. Creating connections is performing as a boundary spanning actor (Bartel, 2001; Hargadon \& Sutton, 1997) and, going some steps further, aiming at various possible effects at the boundaries. This role might account for managing cross-boundary connections, as Hoppe (2010a) discusses, for science/government interactions in the Netherlands. Or perform, in less collaborative contexts, strategies of boundary breaching, that is, framing and mobilizing resources as strategies to influence opportunity structures (Benford \& Snow, 2000; Zald \& Mccarthy, 1987).

A fourth root of institutional work brings to the fore the role of boundary objects. Boundary objects are any kinds of processes or artefacts establishing a shared context between boundaries (Bechky, 2003; Carlile, 2002; Kellogg, Orlikowski, \& Yates, 2006; Star \& Griesemer, 1989). Boundary objects are relevant in the context of change agency, I argue, because shared contexts create room for repertoires of institutional work 
and practice work. In global development, for example, projects, programmes and policies have special interest. Hoppe (2010b), for example, discusses the extent to which such devices perform as the effective means of collaboration in Intergovernmental Panel on Climate Change (IPCC) efforts.

It is evident that change agency describes forms of institutional work. As such, it is "intelligent, situated institutional action ... [which is based on] the creative and knowledgeable work of actors which may or may not achieve its desired ends and which interacts with existing social and technological structures in unintended and unexpected ways" (Lawrence \& Suddaby, 2006, p. 219). Change agency, therefore, is an attempt to push forward the cycle of creation, maintenance and disruption of institutional change (Zietsma \& Lawrence, 2010).

This section described the role of agency as a force pushing change on and by institutions. It presented various theoretical aspects situating agency, practice, boundaries and boundary objects as means of institutional work. The next section discusses agency features of innovation intermediation to complete an outline of the literature supporting this research.

\subsubsection{Learning and innovation intermediation}

Learning and innovation intermediation is a complementary dimension of change agency. Arguably, in the realm of development practice, the notion of innovation is rather generic. It stands for the incorporation of alternative ways of thinking, doing and organizing. Its relevance resides on its changeoriented purpose and not on the extent of its originality. As might have been noticed by the reader, I have given here this more ample sense by introducing a learning dimension, as developed by Marcus (1995), for a broader understanding of national innovation systems. Along this section I will briefly describe this stream of literature.

An innovation intermediary is defined as an organization or body that acts as an agent or broker in any aspect of the innovation process between two or more parties. Such intermediary activities include helping to provide information about potential collaborators; brokering a transaction between two or more parties; acting as a mediator, or go-between, for bodies or organizations that are already collaborating; and helping find advice, 
funding and support for the innovation outcomes of such collaborations (Howells, 2006).

As in the case of change agents, any actor can play the role of an innovator intermediary. It has been noted how public, private or civil actors perform this role. It has also been noted that this role can be performed as a specialized function (usually coined as "innovation brokering") or as one amongst other activities (Yang, Klerkx, \& Leeuwis, 2014).

Innovation intermediation encompasses a wide range of functions. The World Bank (2007) points out how various support activities are as important as knowledge access in innovation processes. Some of these activities relate forms of institutional work, in various aspects. A first aspect, related to norms and standards, includes farmers' organizations fostering change in norms, regulations or other regulating practices. A second aspect, related to boundary work, includes activities to find and create connections between various actors and prompting policy changes. A third aspect relates to gatekeeping in networking activities, such as filtering and matchmaking (Kilelu et al., 2011).

Interestingly, some of these boundary activities exceed the realm of searching for innovation opportunity settings. Depending on the context, boundary work relates to strategic positioning of the intermediary. Farmer cooperatives, for example, have been described as non-neutral intermediaries aiming to gain a better position for farmers in the agricultural value chain and the agricultural innovation system (Hussein, 2001). Therefore boundary work at this level implies also leverage strategies in markets and political arenas. This aspect shows manoeuvres of institutional work that literature has not discussed yet at length.

Some other innovation intermediation functions relate to knowledge itself. Farmer cooperatives, for example, engage in "generating contextual and integrated knowledge, filling the gap between segmented and fragmented expert knowledge (as present in the agricultural science system) and complex farm-level realities and everyday farming practice" (Yang, 2013, p. 77). Intermediation goes beyond knowledge brokering. Other functions such as organizational development and capacity building have been found to enlarge the picture, presenting other types of knowledge-oriented processes as a complementary support function (Kilelu et al., 2011). 
Literature on innovation intermediaries has labelled some agents as systemic intermediaries. A systemic intermediary is an actor that "functions primarily in networks and systems ..., primarily operate in the public, public-private, but not exclusively in the private domain and focus on support at a strategic level" (Van Lente, 2003, p. 255). Farmers' organizations, to enlighten the case in point, could be addressed also as systemic intermediaries in developing countries (cf. Klerkx \& Leeuwis, 2009). This research will certainly enlarge this line of work.

To some extent, literature seems to indicate that innovation intermediaries are change agents, in the sense that they have been referred to in this paper. It is arguable that the distinction resides on the agency context and the agent nature. Whereas in some contexts (territories, fields or sectors) the quality and extent of an innovation does not have a comprehensive impact, it might have it in others. Following this thread, it can be said that public, private, civil or hybrid agents deploy specific change concerns. Those vehicle of comprehensive changes-systemic innovators-possibly driven by development-oriented values are likely to play the role of change agents as understood in capacity development texts.

I introduced innovation intermediaries, discussing some of its functions. It described how innovation intermediaries also perform various forms of institutional work. It briefly introduced the knowledge-related nature of innovation intermediaries and discussed its relation with the notions of change agency and systemic innovation.

As a whole, the section deepens on the building blocks of the conceptual approach: institutional work and innovation intermediation. The section broadly discussed the roles that agency, practice, boundaries and objects play as aspects of institutional work. It also presented a brief overview of innovation intermediaries' definition and functions. The section also highlights possible overlapping and similarities between these scholar streams, having as a reference backdrop a reflexive search of concepts that allow tackling change agency.

This discussion is meant as an overview of these scholar streams, bringing about core aspects in their scope of interest, showing how they interconnect, at least on a surface level. The next section will discuss deeper analytical layers of these streams, attempting to analytically attune and synthetize them as complementary components of a comprehensive 
approach. I have called this approach the knowledge-repertoires perspective.

\subsection{The knowledge-repertoires perspective}

The section above discussed institutional work and innovation intermediation streams of literature as means of a conceptual overview. These streams, regarded as valuable conceptual references to create a comprehensive view about what an actor does to bring about change, are briefly discussed.

This section discusses deeper layers of these streams attuning them by means of the knowledge-repertoires perspective. This exercise is meant to discuss the more operative layers from institutional work and innovation intermediation as components of a single body of reference. The theoretical exercise points at more specific features in which the actual means of agency towards change are shown, while intertwining and nurturing them.

As a whole, the section shows a strong focus on the cognitive dimension and the knowledge flows embedded in agency about change, while keeping track of its relations to practice, boundaries and institutions. Naturally, these concepts are meant to substantiate knowledge stances as operative means of the analysis. As it has been said before, the approach was carried out only to the level of working propositions. Further empirical feedback was discussed earlier in this chapter-by means of more sharpened definitions-as well as in Chapter 5, where further empirical examples help give more detail about its multiple interconnections.

\subsubsection{Knowledge repertoires}

The notion of knowledge-repertoires shows a collection of gestures deployed by actors. Here agency is seen as an act of positioning (Downey, 1992), describing strategies as adaptive forms of practical coping (Chia \& Holt, 2006). Change agency strategies are, in this sense, a function of agents' relative positions in their contexts. Therefore knowledge contents feeding these repertoires are context specific and relate to a specific appreciation of institutional and cognitive settings, both political (Mosse, 2005) and calculative (Callon, 1998). 
Knowledge repertoires refer to agency gestures, expressing and embedding knowledge-related functions, to be found in change-related quests. These repertoires appear here as plausible heuristics allowing a more precise grasp of knowledge flows at the meso level. Next follows a discussion of four specific knowledge repertoires: enactment, supply, intermediation and exploration. Still developed to an explorative phase, these concepts might appear still unstable to the reader: Definitions do not yet mark sharp distinctions, and relations of repertoires to one another appear somehow unclear or speculative. Yet these references give base to the tentative conceptual exploration that this research has grounded empirically by means of knowledge stances.

\subsubsection{Knowledge enactment}

Knowledge enactment refers to the given base of incarnated knowledge (Berger, 1991; Varela, 2000). Knowledge enactment draws from the assumption that all human action, speech and object embody knowledge. This assertion finds possible scholarly roots in cognitive science (Varela, 2000), sociology of knowledge (Hornidge, 2013; Hornidge, Oberkircher, \& Kudryavtseva, 2013; Keller, 2011), the "practice turn" of sociology (Schatzki T. et. al., 2001) and knowledge management (cf Goldkuhl \& Röstlinger, 2002).

Here knowledge is enacted (related to the world-at-hand in which knowledge has a domain), incarnated (received and shaped in a human body basis), and intersubjective (a product of human collective nature) (Maturana \& Varela, 1990). Knowledge enactment lies at the foundations of the knowledge-repertoires perspective, setting a domain of experience as a first—given, spontaneous-feature of agency.

The domain of experience provides a setting to acknowledge the features of specific agents in their specific contexts. This accounts for the multiple relations of non-tangible human features (e.g. culture, organizational culture, cognition, capabilities, social capital, etc.) as well as their location and multiple possible relations with a materially bounded space and time (Boisier, 2006). Rough shapes of Figure 1 illustrate this idea, depicting the bounded nature of human experience as well as the diverse and multifaceted nature of its agencies. 
Along with this basic, contextual analytical frame, knowledge enactment embeds yet another analytical frame. It relates to practice as a form of enacted knowledge. Practice "consists of humans and their shared practical understandings, and codifications of such understandings in a common language, and also of material objects (artefacts) used in the practice" (Goldkuhl \& Röstlinger, 2002). Practice is a realm of knowledge storage, which is the "intentional or unintentional process leading to accumulated knowledge" in which "the act of adding to the existing knowledge stocks in active use by an individual, group or organization" takes place (Carlile \& Rebentisch, 2003, p. 1187).

This understanding brings about the opportunity to attune the more abstract objects of institutional work with those more concrete objects of learning and innovation intermediation. To the effect of this research, this adds to the aim of capturing the features of agency as an array of deployed repertoires involving knowledge.

Following this thread, practice work refers to a means of change agency, focused on creating, shaping or sustaining practice itself. In the same way, expanding or stabilizing a practice field could be seen as its end. Various aspects might add texture to these propositions.

First, practice is a form of placing boundaries. Practice "determines what actions count as enactments of the practice" (Goldkuhl \& Röstlinger, 2002, p. 2). Practice is performed within a practice (meaning a context, a share code, a set of routines) and to some extent is determined for the practice itself. Practice is set on practice fields. This normative backdrop of practice embodies a cognitive_-enacted_-dimension of institutional work.

Further, this feature is also the source of boundaries. Practice expresses the social technologies of any local culture at a given time, and therefore the features of inter-organizational exchange, encounter, clash, agreement or compromise at the meso level. This token applies to state agencies and international and grassroots organizations alike. Often local cultures depict "invisible" or "contradictory" knowledges hitting intended change (cf. Mosse, 2005). Boundary settings, originated in the realm of local situations, bound practice itself. Boundary settings illustrate the links between knowledge and governance and the interplay of institutional settings as means and arenas of power positioning. 
As for the case of innovation intermediation, knowledge enactment brings about the boundaries of enacted knowledge itself. In effect, enacted knowledge has a specific domain of experience, and a specific set of explanations of that domain (Maturana \& Varela, 1990). Local processes start from enacted knowledge in a given context at a given moment. Exchange - at the spatial, organizational, functional or field level-implies shifting, scaling, expanding, recreating or resignifying the enacted knowledge base and/or the institutional settings. This might take place by means of boundary exploration.

Although these processes could or not imply boundary work in terms of institutional work, they might imply boundary effects in the practice base. In the scope of capacity development strategies, this might imply the creation of practice spaces in which agency is shared. There is no need to stress the challenges (and the real extent of change) this implies both at the policy and the practice levels (Mosse, 2005).

\subsubsection{Knowledge supply}

Knowledge supply refers an offer-demand relation in which knowledge solutions are provided to a knowledge user either directly (on the assumption the agent has the solution his or herself) or indirectly (appointing suitable sources with a solution) (Turnhout, Stuiver, Klostermann, Harms, \& Leeuwis, 2013, p. 361).

Knowledge supply often performs a support function in innovation intermediation. It can be easily associated with capacity building or organizational strengthening efforts. But we should not forget knowledge supply is also performed in other moments, as is the case of legal or technical advice. In such cases, effects of knowledge supply might have a different impact. Therefore, although this repertoire can be spontaneously assimilated as a repertoire close to practice (Zietsma \& Lawrence, 2010), it might have effects also in the realm of boundaries.

However, knowledge supply should not be associated solely with technical or expert forms of knowledge. The literature also addresses context-related knowledges, such as foresights, forecasting, strategic intelligence and market research (Howells, 2006; Kuhlmann, 2002). Further, it is argued this knowledge base includes incarnated forms of knowledge. Experiencing 
contact with specific contexts, such as markets, organizations, procedures or fora, is a form of expanding a practice base and prompting forms of boundary work. Which means, in other words, that knowledge supply-this offer-demand relation-might refer to knowledge enactment as a possible source.

\subsubsection{Knowledge intermediation}

Knowledge intermediation describes various forms of engagement within or between knowledge stakeholders. Here the institutional base is kept and knowledge stakeholders can be recognized as part of separate practice/interest fields or domains. Some literature refers to knowledge intermediation and some to knowledge brokering to describe similar phenomena. Knowledge intermediation brings to the fore the theoretical discussion about mediation (cf. Latour, 1994) and intermediation (Doganova, 2013; Meyer \& Kearnes, 2013; Schlierf \& Meyer, 2013). Knowledge brokering has enlarged a base of repertoires with a more experimental approach (Schut, Van Paassen, Leeuwis, \& Klerkx, 2013; Turnhout et al., 2013). In spite of their backgrounds, I will refer to both terms as synonyms, using them interchangeably.

A first form of the knowledge intermediation repertoire is close to knowledge supply. It involves a clarifying role about the knowledge demand of the user (Turnhout et al., 2013). As shown earlier, for the case of rural organizations this role has been described as "articulating and voicing demand of farmer's needs" (Yang et al., 2014, p. 116). This role resembles the retrieval phase of knowledge management cycles, focused on "identifying knowledge that is likely to result in the satisfaction of a need or solution to a problem" (Carlile \& Rebentisch, 2003, p. 1189), or as Howells (2006) describes it, filtering.

Another form of knowledge intermediation is knowledge processing, generation and combination. Howells (2006) recognizes two forms of this repertoire: first, a combinatorial form, in which the intermediary helps to combine knowledge; second, a generation and recombination form, in which the in-house result is combined with partner knowledge. This repertoire has been studied at the rural grassroots level: There are practices of "engaging and supporting actors (farmers, researchers) in participatory knowledge generation through facilitating demand led research or 
articulating experimental/local knowledge" (Yang et al., 2014, p. 116). In its more specialized forms, intermediation supposes forms of translation between domains and facilitation in pursuit of "doable problems" (Fujimura, 1987; Latour, 1994) within feasible inter-organizational frameworks.

In sum, the knowledge intermediation repertoire stands for a variety of forms of knowledge circulation, scaling out and scaling up. As a function it can be attributed to a variety of agents, and supposes deployment of various possible repertoires. Effects on agents' positions, specific roles and repertoires are dependent on their innovation contexts (Kilelu et al., 2011).

\subsubsection{Knowledge exploration}

The last repertoire is knowledge exploration. Knowledge exploration refers generically to practices of knowledge production. It accounts for various knowledge contents and sources nurturing knowledge supply and intermediation.

However, there is also knowledge exploration in the pursuit of joint quests, as it was pointed out in the knowledge enactment repertoire. Knowledge exploration tends to appear in settings in which uncertainty prevails. A salient feature of this repertoire relates to its effect on boundaries: they tend to blur, or redefine. This repertoire captures "how knowledge intermediators account for the unpredictability and uncertainty of their practices and activities and the fact that new knowledge and identities arise out of this" (Schlierf \& Meyer, 2013, p. 435).

Therefore, the knowledge exploration repertoire has possible effects both at the innovation and the boundary levels. Doganova (2013, p. 450) describes a distinctive characteristic of exploration as the fact that "the sociotechnical collective involved cannot be known ex ante: it is a result of the exploratory process, rather than its point of departure." Hoppe (2010a) discusses a similar image in a different setting. He raises a case about scientific advice and policy-making in the Netherlands, describing how both advisors and policy-makers to some extent share knowledge production at a given time. 
In this sense, a knowledge exploration repertoire could be described as a form of coproduction (Ostrom, 1996; 2005), and as such, a form of boundary work with a twofold possible outcome. The first possible outcome relates to practice innovation in a specific niche (cf. Geels, 2002), affecting practice to some extent (local, sectorial or regime level) by collaborative means. The second outcome relates to describing mechanisms of boundary work as a form of change by engagement in collaborative/explorative settings (cf. Cajaiba-Santana, 2014). This specific feature of knowledge exploration has been addressed as a separate knowledge stance in the theoretical framework, defined as boundary exploration.

To synthesize, this section discussed knowledge repertoires, highlighting the knowledge-related dimension of change agency. It presented various knowledge repertoires: enacting, supply, intermediation and exploration. These repertoires describe forms of agency distilled from the realms of institutional work and innovation intermediation, nurturing the knowledge-repertoires perspective as a comprehensive framework. The section discussed both their specificities and their overlaps. It elaborated on the distinction of the various components and dimensions at play in change agency processes.

\subsubsection{Final notes on the knowledge-repertoires theoretical perspective}

Knowledge stances are discussed as the analytical synthesis of knowledgerepertoires. These are meant as heuristics to identify and address knowledge patterns in the capacity development framework. Knowledge stances give an account of the settings in which knowledge plays a role in the performance of change agency.

Overall, this chapter discusses a constructive theoretical approach to take the capacity development framework steps further. The chapter presents change agents as institutional entrepreneurs and innovation intermediaries, and following this rationale, capacity development aims to promote social change by impacting abilities and skills at various levels and by affecting the rules of the game. Institutional work and innovation intermediation literature bring insights to understand this purpose. By intertwining them analytically, the chapter illustrates a knowledge- 
repertoires perspective on change agency as an overarching approach, with a set of knowledge stances as its analytical tools. This conceptual development is meant to capture change agency gestures.

The theoretical value of a knowledge-repertoires perspective accounts for a twofold purpose. First it addresses the realms of knowledge at stake in change processes, as a means to prompt further research and inform emerging policy settings, development practice and the myriad of local discourses and initiatives currently farmers' organization fostering change. Second it promotes a scope of practice and research that allows framing (capacity) development beyond the project level and the donor-focused scope, which gives, as I noted earlier, a natural reach to the concept of it working as a policy tool. This feature grants me an opportunity to stress a recursive statement: The epistemic status of the capacity development framework (and therefore its conceptual scope) is but a result of the boundary setting in which it was created.

Before finishing, let me present a final note. It is worth remembering that this theoretical approach is meant as a heuristic tool. Clearly it accounts for phenomena with political and ethical implications. Li's (1999) and Mosse's (2005) accounts of development projects describe knowledgeintensive forms of disguising contradictory practice, as well as questionable forms of boundary work with project partners and beneficiaries. It is likely that capacity development in volatile or sensitive contexts prompt "grey" arrangements as forms of strategic coping with exceptional circumstances. The focus on knowledge stances and a cognitive approach will help tackle explicit as well as implicit forms of institutional work, thus maximizing the impact of diverse agencies on social change.

This chapter discussed the conceptual approach of this research. The conceptual approach is anchored in a twofold foundation: On one hand, it uses capacity development as a source of inspiration to identify possible features of change agency. On the other hand, it intertwines operative means of institutional work and innovation intermediation scholar streams as means to substantiate knowledge stances: the operational concepts around which this research pivots.

The next chapter will turn to the empirical component of this research. I will discuss the rationale and methods of the empirical approach and later give an account of fieldwork results. 
3.

The multi-sited case:

Colombian cocoa

organizations 


\subsection{Case selection}

The previous chapter discussed the theoretical approach, detailing the guiding concepts and giving an account of its practice-based and disciplinary anchors. In this chapter I will turn to the empirical realm, giving detail about the case. Before proceeding, I will discuss the rationale shaping the selection of the case, adding detail to those aspects I touched on in Chapter 1.

Naturally, the rationale of this approach relates to the various methodological aspects connecting to the challenge of tackling this research object. It is worth briefly discussing these aspects. The first being that the guiding inquiry, namely the strategies of farmers' organizations as change agents, is, as it is often the case, an arriving point.

The point of departure for this research started with a driving curiosity, as a researcher and practitioner, about how to tackle the problem of institutional instability-and especially its cognitive features-in those isolated rural areas where so-called poverty pockets bud (Wienberg, 1987). I was looking for ways to capture comprehensively the various knowledge paths, divides, conflicts and obstacles in the building of the local realm in such sites. ${ }^{16}$

This object, too ambitious both conceptually and operationally, was narrowed here to the reading of a single actor: farmers' organizations. Expectedly, this focus on farmers' organizations still embedded the purpose of analyzing the multiple layers in which this actor plays a role to the maximum extent possible, which brings about its specific challenges as a research object. Determining farmers' organizations' full extent of its role is still an ambitious target. So it was decided to try and capture a glimpse by focusing on its strategies as change agent, with a twofold aim: to allow capturing an image of the actor with a very broad lens, while conceptually developing on strategies as a vehicle to better grasp their gestures.

Given this specific focus, the empirical quest started with the purpose of building a multi-sited study case, aiming to explore a fuzzy phenomenon by

\footnotetext{
${ }^{16}$ It is worth mentioning this topic is of the utmost relevance in Latin America, for its understanding entails better governance for a vast wealth of territories where the participation of diverse (indigenous, colons and afro-descendant) communities entails multiple challenges. I have added to a Latin American scholar stream building on to the concept of territorialization (In Spanish: territorialización) (Balanzó, 2016).
} 
capturing its expressions on multiple fields or contexts. This is, as Nadai and Maeder (2009) argue quoting Marcus (1995), building on "the juxtaposition of those phenomena that conventionally have appeared to be (or conceptually have been kept) apart". It was meant as an adequate design for a rather explorative inquiry.

Following the aim of accessing volatile environments, criteria such as access, management feasibility and safety also played a key role. Before selecting the final case, conversations were held with various organizations, networks and third parties, exploring possibilities in Colombia, Thailand and Kenya. Selection criteria assessed the potential of comprehensively addressing farmers' organizations' strategies, while taking care of being able to manage heterogeneity of the cases.

An exploratory exercise was carried out in Thailand, with the support of PROCASUR, a knowledge intermediary organization. However, the caseorganizations of smallholder organic vegetable farmers-was dismissed for detailed translation was too expensive. In the case of Kenya, explorations were carried out through Dutch organizations. Suggested cases did not match criteria.

Finally it was decided to focus on Colombian cocoa-producer farmers' organizations because of the scope of access-39 organizations distributed in isolated areas of Colombia. Access was granted with an agreement with the National Cocoa Network. The agreement allowed me to join network and node activities, observe meetings, and freely contact organizations if follow-up inquiries were decided.

This chapter presents an overview of the organizations and its context, aiming at informing the reader broadly about its features and surrounding conditions. As might be expected, information appeared scarce, inaccurate, out-dated or poorly made. In such cases I processed it so as to illustrate a clearer picture, and added or confirmed with field observations. No significant discrepancies were found. Field evidence appears referenced along the text (See detail in Annex 2). 


\subsection{The Context}

\subsubsection{Localization}

National Cocoa Network unites 39 farmers' organizations from Colombia, namely Nariño Bio-Geographic Pacific, Catatumbo Mountain Range, South of Huila, Western Boyacá, Santa Marta Mountain Range, Magdalena River Valley and North-Western Antioquia. Map 1 illustrates the location of these organizations. ${ }^{17}$ More than showing a condition of geographical inaccessibility, which is often the case, isolation refers to a condition of institutional deprivation. In order to illustrate a state of affairs at the local level, the map describes the degree of human rights violations per municipality in 2010 (CINEP, 2014).

These organizations are located in places dealing with a number of features describing weak, volatile or ill institutional contexts. Some of these refer to conflictive income sources in their surroundings. In effect, most of these organizations are located where illegal coca crops used to be (or still remain). In some cases there are other illegal crops (e.g. marihuana in Magdalena valley), other illegal activities (e.g. smuggling in La Guajira or illegal mining in South of Bolívar) or conflictive legal products (e.g. emerald mining in Western Boyacá). Which is to say, in other words, that depredatory regimes are the rule in their surroundings (Wood \& Gough, 2006).

Another feature of these organizations' context refers to the bigger picture of Colombian civil war and the location of each of these territories in the battlefield. On one hand, the role of the territory can be part of military strategic endeavours, that is, as a strategic corridor (e.g. near oil pipes in Catatumbo), a hiding place (e.g. South Pacific) or a historical fort (e.g. Catatumbo, South Pacific). And, on the other hand, these organizations' context relates to the type and presence of armed actors (e.g. one or various guerrilla or paramilitary groups, fighting or coexisting for territorial control).

\footnotetext{
17 Author. Data sources: Agustin Codazzi Geographic Institute. National Cocoa Network. Centre for Education and Popular Research (CINEP, 2014).
} 


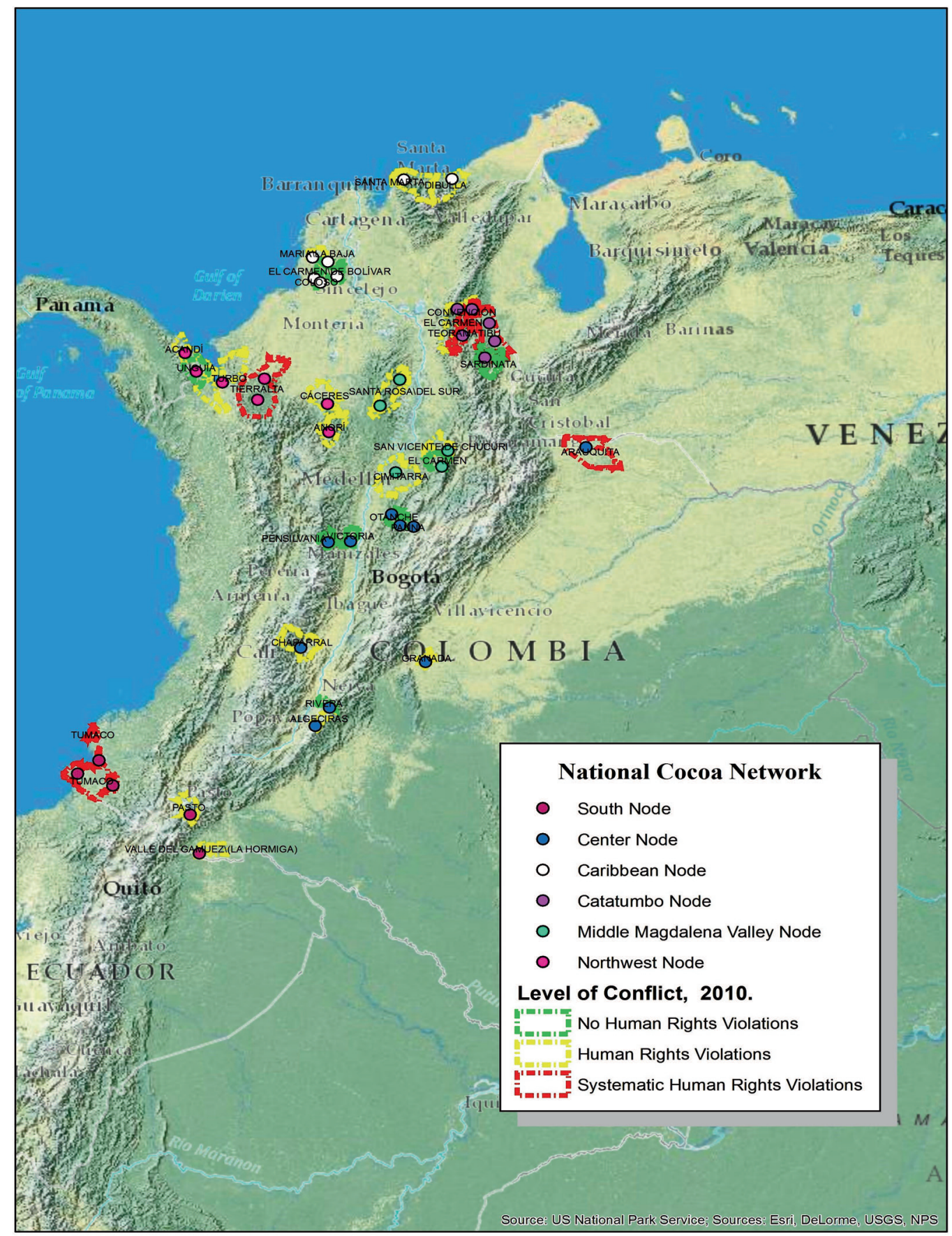

Map 1. Location and context. Organizations of the National Cocoa Network 
Another aspect of the context, adding to institutional deprivation, relates to the broader picture of local political dynamics, rooted in historical and cultural accounts that shape for each case the means and effects of regional authorities. The picture illustrates an uncertain, geographically and institutionally isolated and normatively weak environment.

\subsubsection{Cocoa market in Colombia}

It is worth now turning to the market of cocoa, as it also sets the context of these organizations. As with coffee, Colombia has the potential to produce special cocoa. However, the national market provides little incentive to follow that direction. Three processing factories demand a high quantity of low quality grain. Demand is higher than local offerings and so Colombia has relied historically on imports. Therefore Colombian cocoa shows a quality paradox, in which certainty of low quality local market access frustrates the potential of international high-quality market access (Castellanos, Torres, Fonseca, Montanez, \& Sánchez, 2007).

Naturally, this market landscape creates various context layers for cocoa smallholder organizations. The first layer refers to sector structures, reflecting the market setting. As said, Colombian's cocoa value chain looks like an oligopoly towards the end of the chain with very few buyers. Expectedly, sectorial institutions reflect this: Colombian quality standards, for example, focus on the size of the grain and not on qualities such as flavour or humidity, which are those of the more specialized niches (Obs Mc, 14/01/14).

Cocoa's market also explains why cocoa is usually taken as the choice for rural development programs. Due to the fact that there is a permanent demand, development programs assume cocoa could grant smallholders a steady income source. Naturally, processing factories perform often as allies of these programs, on the condition of long-term contract farming arrangements (e.g. MADR, 2013).

This opens up space for other players to feel power imbalances. Smaller factories argue that contract farming programs exclude them-and by doing so exclude the possibility of pursuing specialized niches-by setting conditions forcing them out of the programs for example, by setting exaggerated working capital minimum standards as a requisite (Interview Cmr 001, 16/06/14). 
Another feature of cocoa market relates to cocoa intermediation at the local level, anchored on the historical presence of middlemen. Expectedly, middlemen have a great power of negotiation vis-à-vis smallholders. Power of negotiation is exerted in many ways, including price, payment readiness and transport (Fg Ct, 20/01/14; Fg No, 16/01/14).

It is worth mentioning here another actor, the Cocoa Federation. A member organization in place for over 50 years, the federation gathers individual producers. The federation plays an important role in managing cocoa's national fund. This fund is financed with a tax on cocoa sales that aims to finance investment in the sector (Fedecacao, 2013).

Despite its aims and role, smallholders do not perceive the federation as a legitimate spokesman nor a worthy partner for various reasons: First, its democratic practices are deemed as questionable. Second, the federation is not open to accept grassroots organizations as members of the federation. Third, smallholders see little return on the mandatory tax they pay with every sold grain (Interview Ldr 001, 13/01/14).

Of course, smallholders are interested in changing this state of affairs. Attempts take place at the market level, naturally, where the National Cocoa Network and other parties (such as small-scale exporters, international organizations, non governmental organizations (NGOs)) share the aim of developing high-quality niche markets. Smallholders also strive to take part at the National Cocoa Council, in which sector actors discuss the sector's guidelines. These spaces are seen as smallholders' means to counterweight "big players" (Interview Ldr 001, 13/01/14). Support activities focus on strengthening new actors (such as the network itself), showing possible markets (mostly origin cocoa and certificated qualities) and creating access opportunities (Interview Ofc 004, 17/10/14). In spite of a noticeable tendency in this direction, national production reaching quality standards is still very limited (Interview $\mathrm{Cmr}$ 001, 16/06/14).

\subsection{The organizations}

Unsurprisingly, the history of these organizations easily links to illicit crop substitution programs. Some of these organizations played (or still play) a 
role as rural development project operators. Allies in these programs include international organizations (e.g. UNDP, European Union, and USAID), non-governmental organizations (such as intermediaries or fund providers) and state actors, mostly from the national level (e.g. the Social Prosperity Department (DPS), a presidential office program). National projects are often supported by international organizations.

Member organizations of the National Cocoa Network assemble small landholders. As usual with grassroots rural organizations, cultural and geographical diversity requires here a flexible understanding of the terms "farmers" and "organizations." Two of these organizations are community councils. Community councils are a collective form of land property. Community councils are the result of afro descendants' struggle for visibility since the 1980s (CEPAC, 2003). There is also an indigenous reserve.

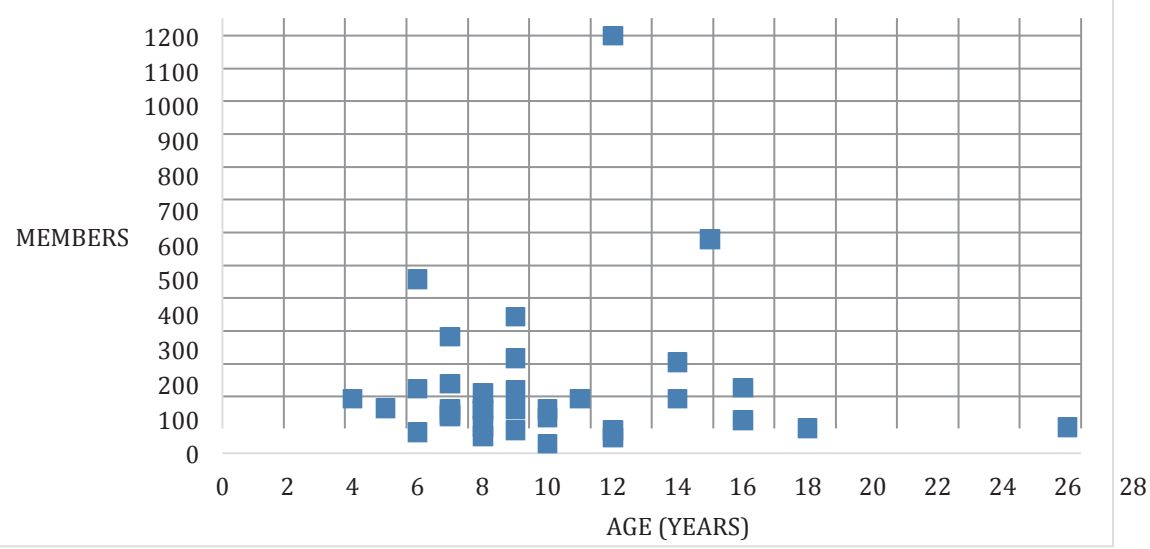

Figure 2. National Cocoa Network organizations. Distribution by size and age ${ }^{18}$

Together, the organizations group about 6,500 members and 30,000 hectares used for cocoa production (DPS, 2012). Figure 2 distributes organizations in terms of how many members they have and how long they have been around. Despite some notorious exceptions, the graphic shows a somewhat even distribution both for organizations' age and number of members. The average age of organizations is 10 years old, while its average size is 196 members.

18 Data from DPS (2012). 
Expectedly, organizations have different degrees of organizational development. To evaluate the maturity degree of the organizations, DPS (2012) reviewed an account of their performance in the realms of associativity, entrepreneurship and social impact. The results assess degrees of formality and standardization, existence of communication channels, teambuilding strategies, the degree of specialization and planning. Figure 3 details the results, illustrating the degree of maturation of organizations belonging to each node.

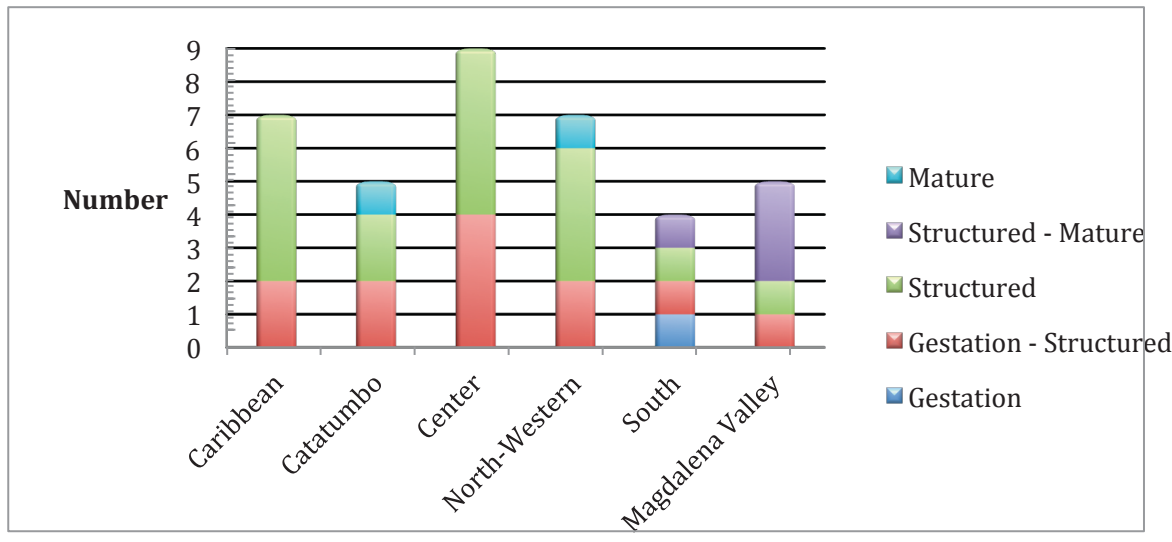

Figure 3. Maturity degree of organizations by node ${ }^{19}$

Following the DPS report, organizational development is shown as a position in various possible organizational stages. The report defines three main stages: gestation, structured and mature, as well as the intermediate stages in between. The graphic shows that more than half of the organizations are at the structured stage or are going to the mature stage. The distribution by nodes allows a glimpse of existing diversity both within and between the nodes of the national cocoa network.

\subsubsection{Services}

Organizations manoeuvre to achieve a diversified income basket. Complementary sources of income include, amongst others, cacao seedlings (Fg Cn, 23/01/14), rubber (Fg No, 16/01/14), cattle and palm (Fg Sr, 27/01/14); forest and mangrove conservation (Interview Ldr 004, 16/06/14);

19 Data from DPS (2012). 
chocolate (Interview Ldr 004, 16/06/14); avocado, cassava, honey (Fg Mc, 14/01/14) and wood (Fg Mc, 14/01/14). It is worth noting these complementary sources also include active engagement of the organizations in other sectors (Interview Ldr 004, 16/06/14; Fg Sr, 27/01/14).

All the organizations provide technical assistance for cocoa. Of the organizations, $5 \%$ transform raw material cocoa into other products (such as covers or drinking chocolate), $17 \%$ provide financial services to members (such as microcredit or insurance) and 31\% combine cocoa breeding with other products, as earlier detailed (DPS, 2012).

Complementarily, organizations play a role in the delivery of social services, linked to human development (Amb, 14/02/14). Organizations do care about being reckoned for this role (Asc, 07/07/14). Social impact strategies tackle topics such as gender, violence within families, local culture (Fg Mc, 14/01/14), housing, agricultural and non-agricultural credit (Interview Tm 001, 16/01/14; Amb, 14/02/14; Fg Mc, 14/01/14), training and education (Amb, 14/02/14), fair access to consumer goods (Fg Ct, 20/01/14) and land access (Fg Mc, 14/01/14). Projects also allow creating third-party partnerships to deploy integral approaches for improving service delivery (Interview Tm 001, 16/01/14).

I will sum up this overview with regional descriptions. Table 1 shows detail about each node. It broadly describes its geographical and institutional conditions, organizational features and the regional or subregional cluster. Further, it describes the place of cocoa in the wider picture of local history and interests. ${ }^{20}$

${ }^{20}$ Data sources: Fg cn 23/01/14; Obs cn, 23/01/14; Fg Ct, 20/01/14; Obs Ct, 20/01/14; Fg Mc, 14/01/14; Obs Mc 14/01/14; Fg No, 16/01/14; Obs No, 16/01/14; Fg Sr, 27/01/14; Obs Sr, 27/01/14. 


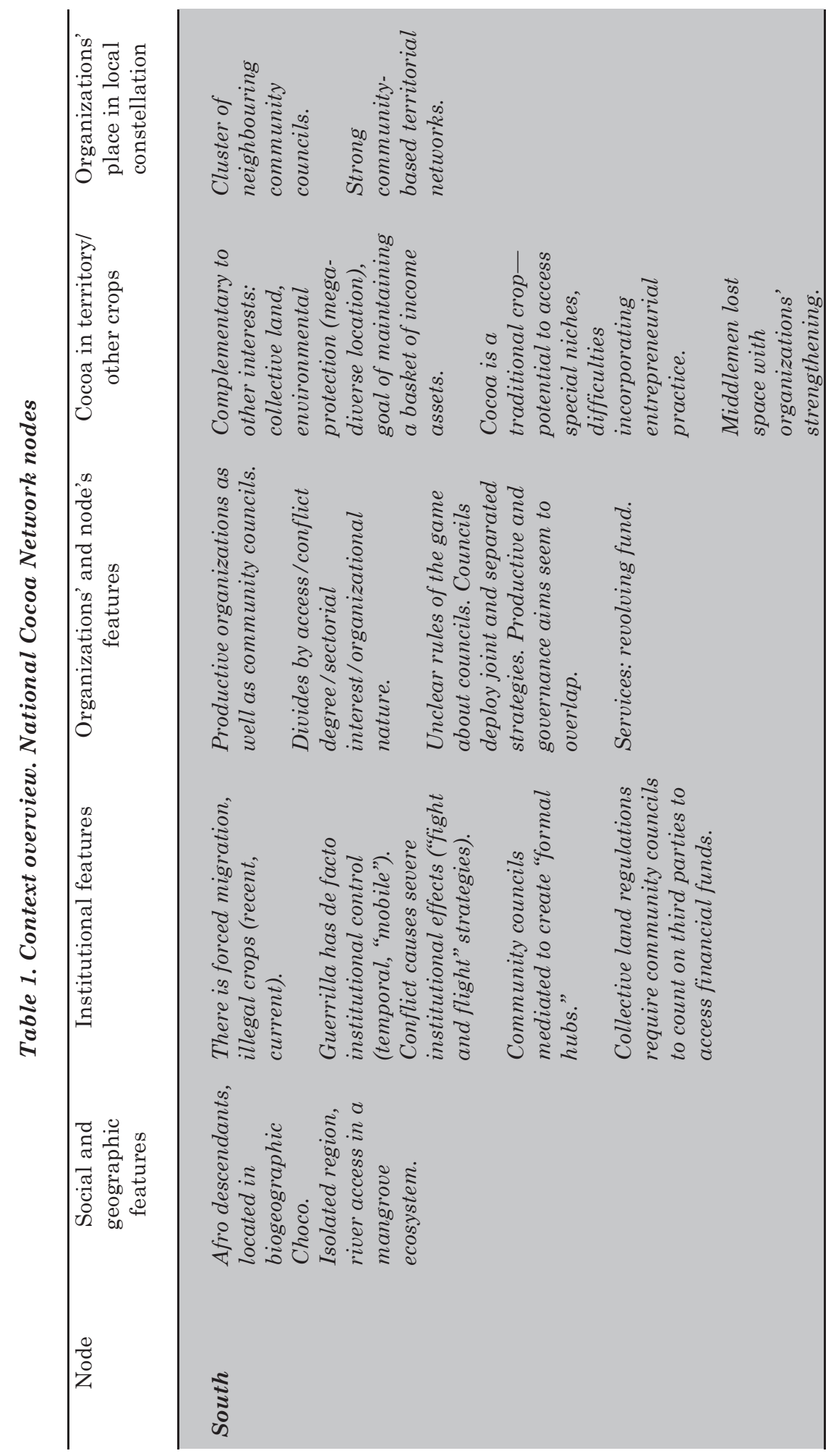

6 


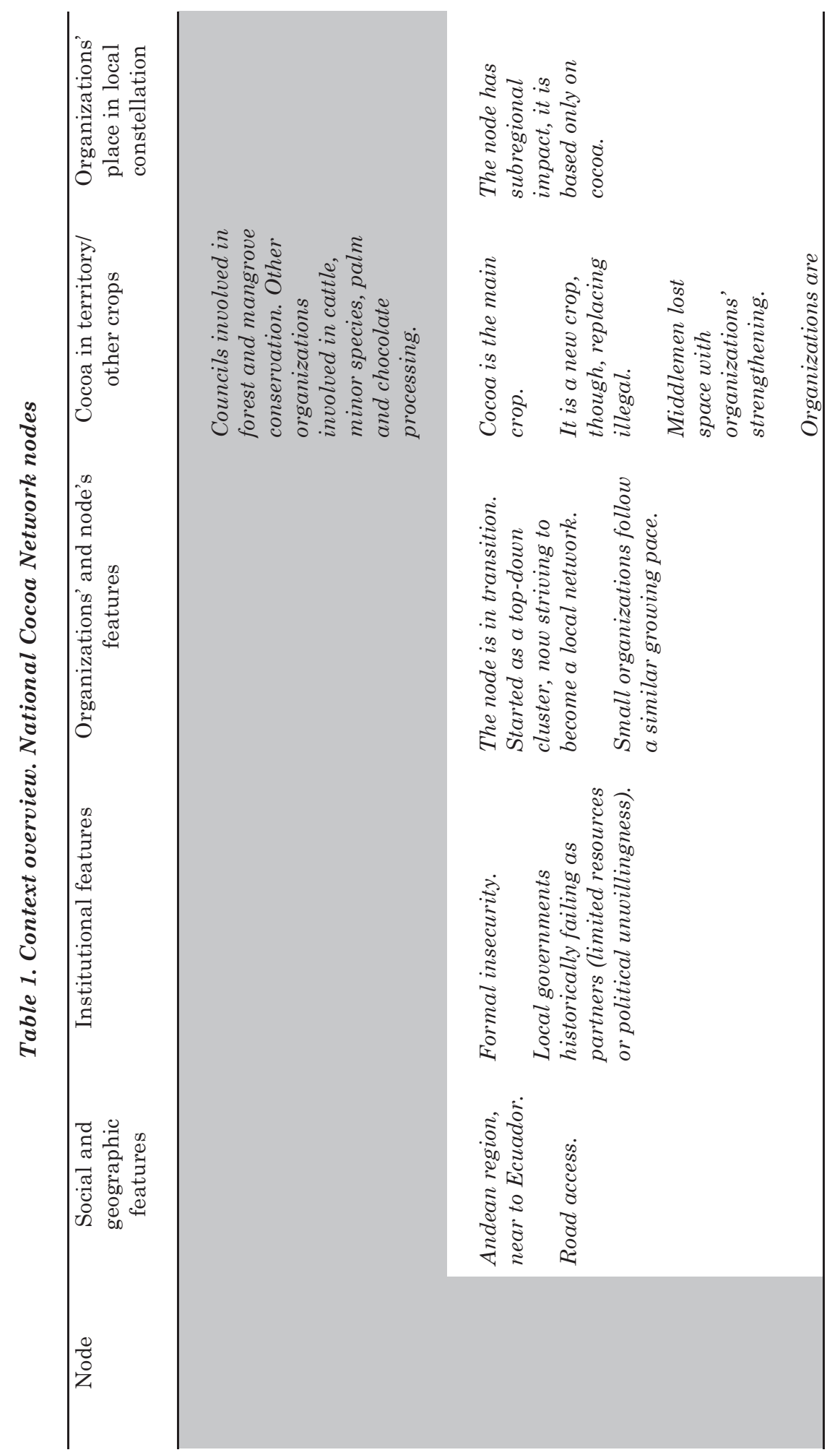




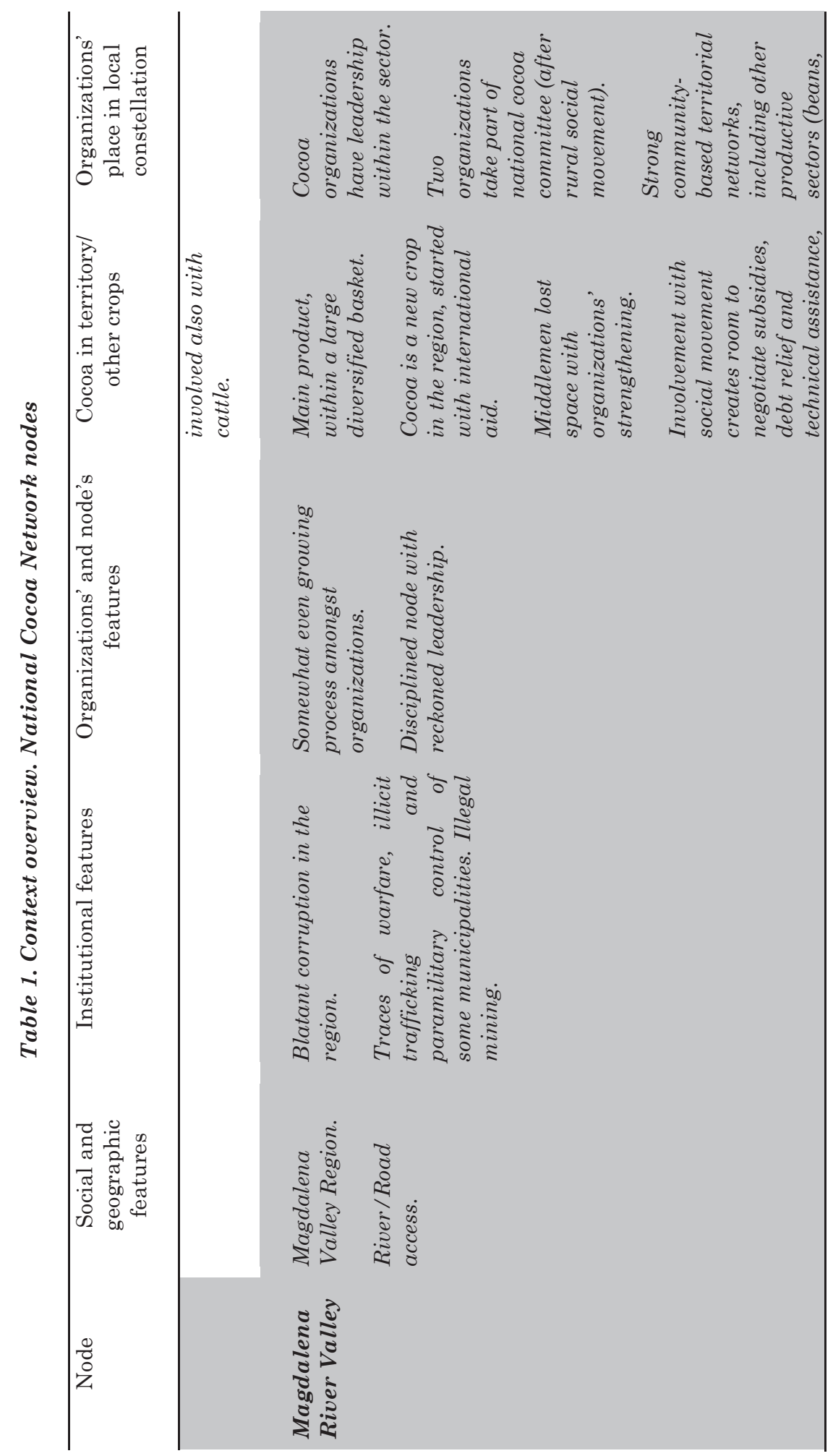

ติ 


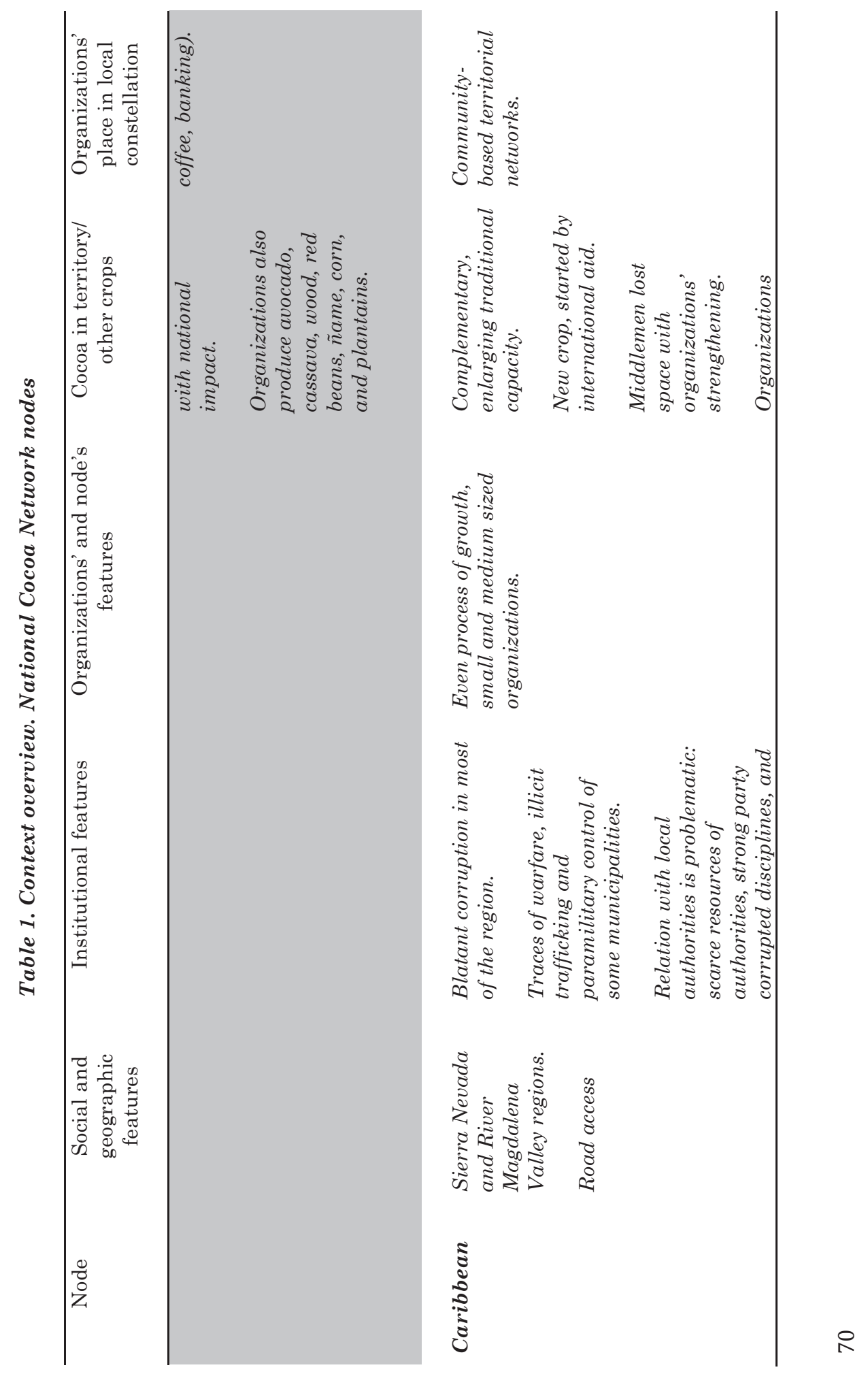




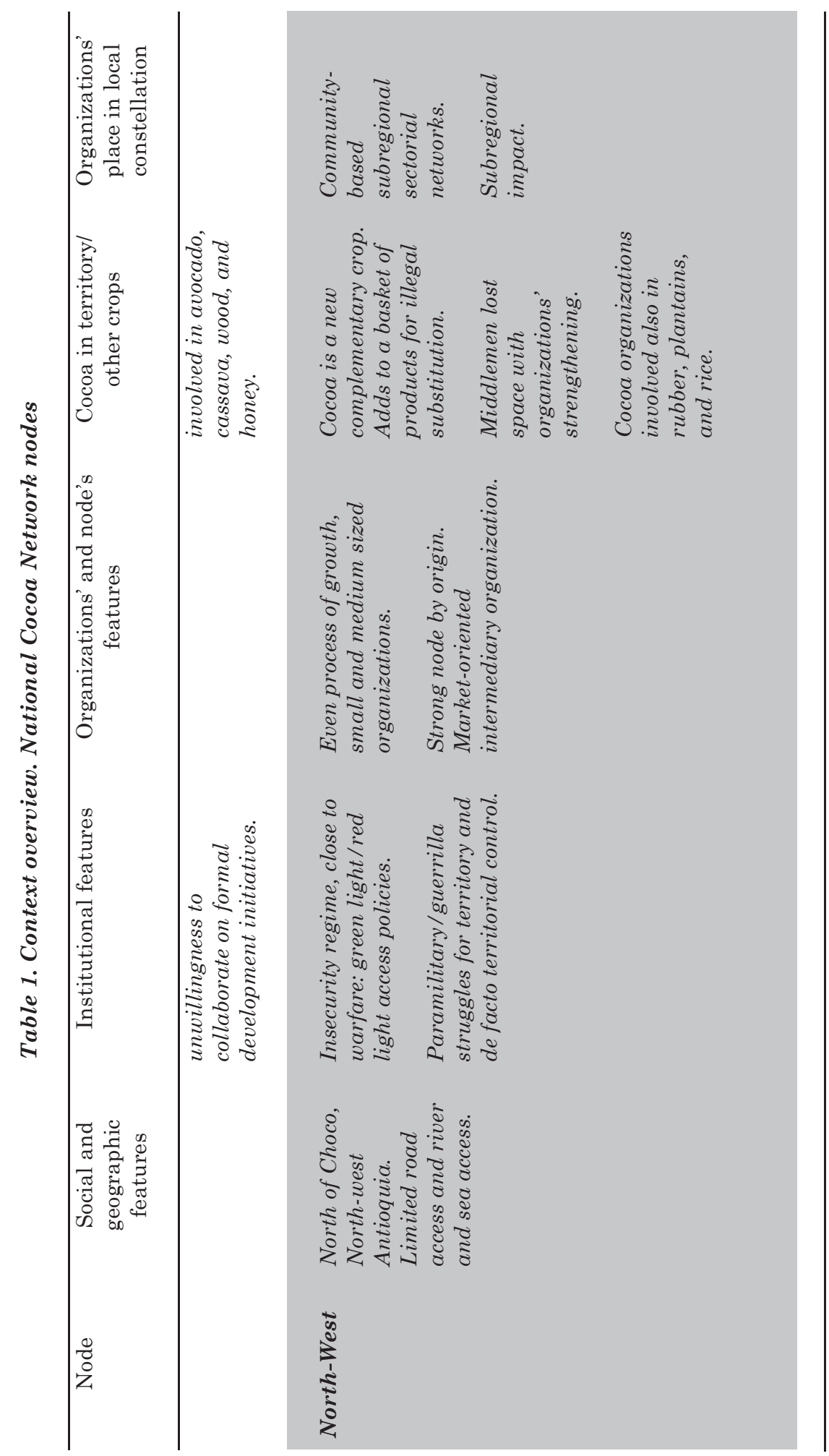

N 


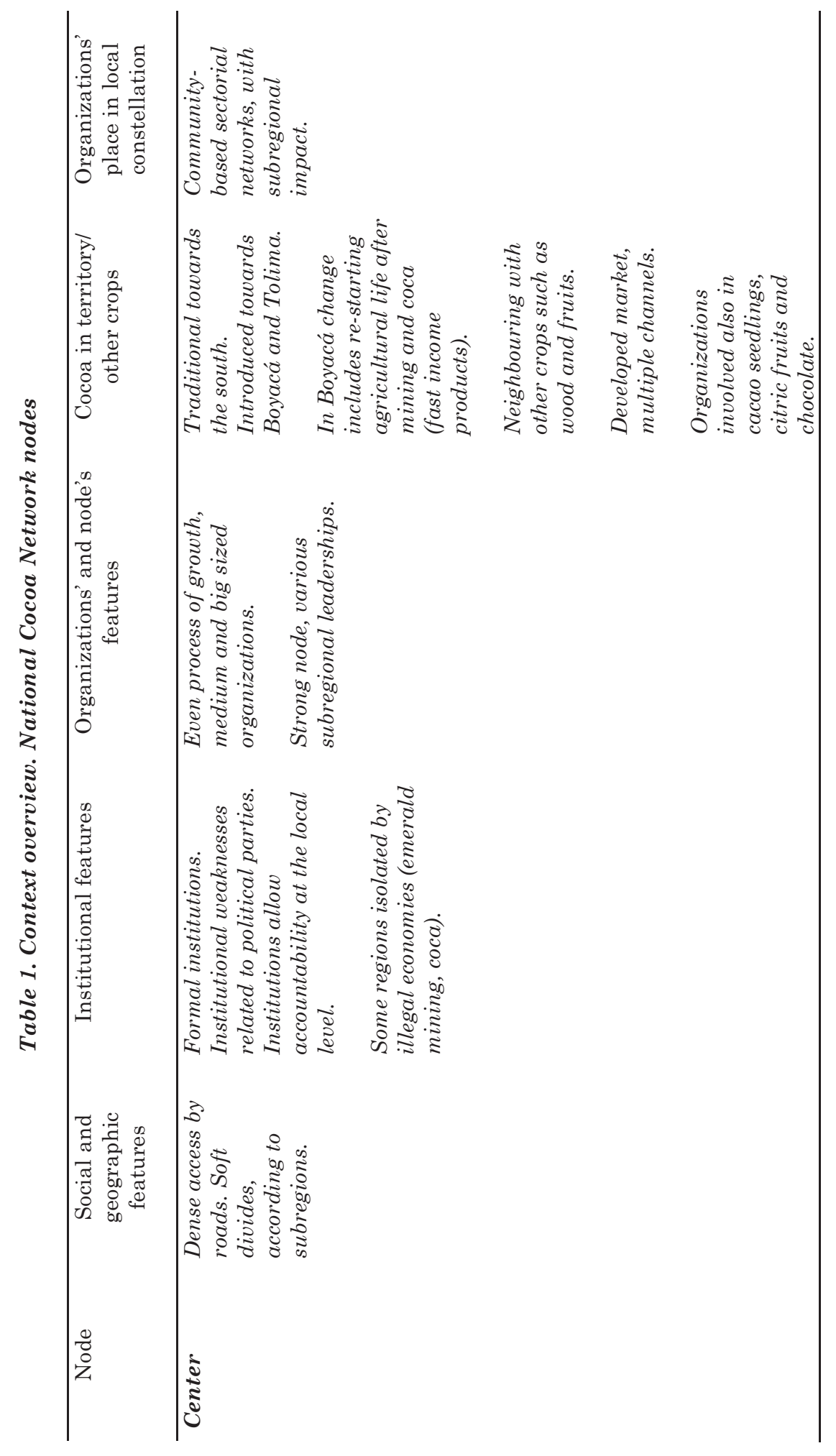

$N$ 


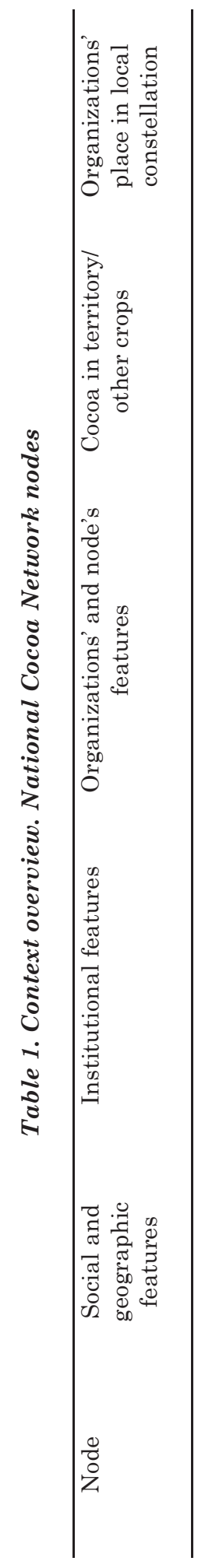

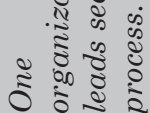

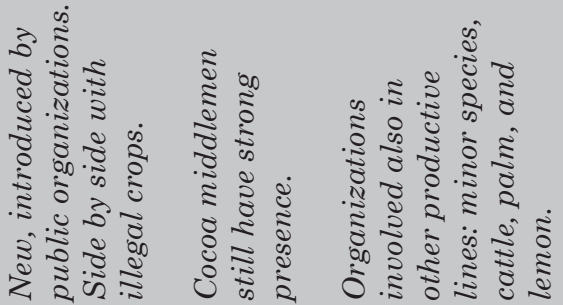

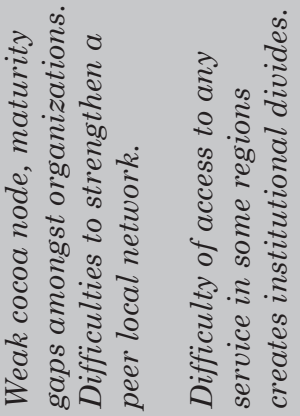

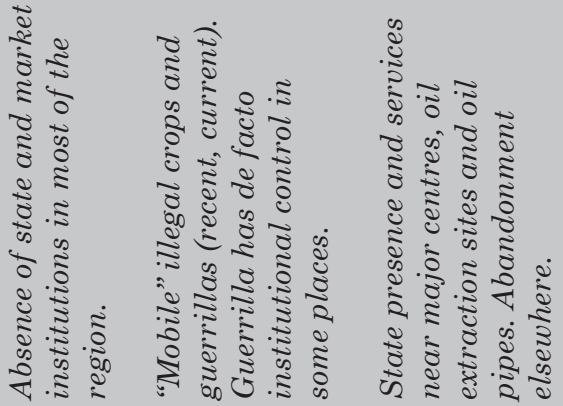

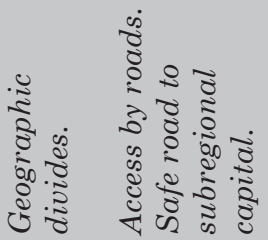

$\frac{0}{0}$ 


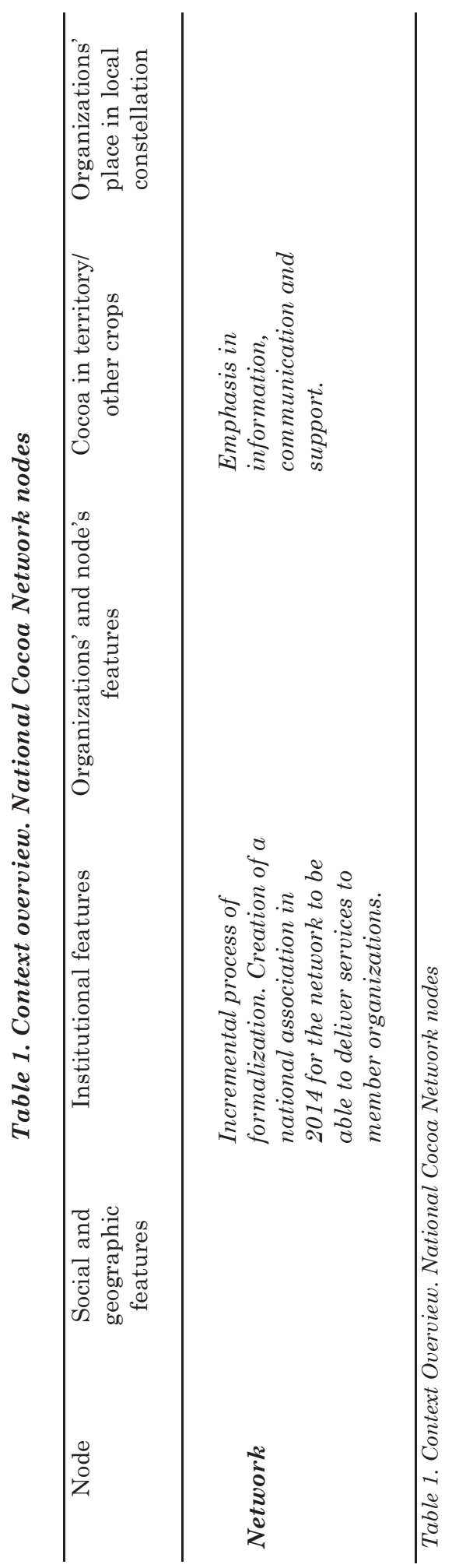




\section{4. \\ Empirical results: What is it like dealing with the world out there?}


In the previous chapter I introduced the multi-sited case. I gave detail about the rationale for its selection and discussed an overview of the organizations and their contexts. In this chapter I will present fieldwork results. Before proceeding, it is worth bringing up some methodological and analytical aspects of the exercise.

In coherence with the tenets of this research, the empirical inquiry followed the lines of an interpretive approach (Schwartz-Shea, 2012; Yanow \& Schwartz-Shea, 2015), focusing on historical and present accounts of farmers' organizations' relations with other parties. Observation, interviews and focus groups unveiled how organizations experience relations with other parties and how they cope with the situations they face in those relations.

Trying to get as close as possible to the object, I joined National Cocoa Network activities. Activities included training workshops taking place in the five regional nodes, taking part of national assemblies in 2014 and 2015, joining visits to potential business partners of organizations in Colombia and the Netherlands, and meeting with organizations' partners and advisors. Subjects include mostly farmers' organizations' leaders, including managers, council members and staff. Other interviewees are international or non-governmental project officers and business partners. Some of the interviews followed up on topics observed to be of interest for the purpose of this research.

Focus groups and semi-structured interviews were carried out. Besides open questions I utilized metaphors in some cases to enliven memories and have also a more nuanced grasp of the contents. Triggers for conversation included questions relating to the drivers of organizations: the history of organizations, focusing specifically on partnership relations-"good" versus "bad" partners, coping strategies in both cases and conflictive moments-and their outcomes, ongoing processes, reiterative situations or conditions vis-à-vis their purposes, recurrent obstacles, recurrent facilitators, and how these all related to managing skills, abilities, capacities of the organizations and its members.

Data include transcription of audio and video, and a facsimile version of fieldwork notes. Annex 2 shows detail of data sources coding and references. I also included a safety measure in data handling concerned with risks rural grassroots leaders face in Colombia (Semana, 2015), 
therefore details that could be used to identify specific actors are omitted. Although these materials are not added as annexes to the dissertation to save space, they are available on request.

Data was coded using Atlas TI. Coding followed a tentative combined strategy, with some codes linking conceptually to the theoretical approach while some others emerged from data.

Following the rationale of this research, discussion of fieldwork results develops a thematic account, rather than a systematic comparative scheme. Themes include i) farmers' organizations' drivers-both the longterm and the short-term, ii) the role of projects, iii) affairs at the local level, and iv) the challenges of the cocoa market. This crosscutting reading aims to reveal overarching interests, situations or patterns triggering response strategies. I will briefly refer to each of them to provide an overview.

In the first section I discuss farmers' organizations' long-term, valuerelated drivers. The section deepens on the understanding of organizations' normative stances, those aspects likely explaining-or justifying-organizations' choices vis-à-vis other actors. This aspect already answers one of the specific research questions: what are farmers' organizations drivers? I will turn back to this later in the analysis as part of the broader reflection on change agency.

The second section discusses organizations' relations and experiences to projects. A reiterative topic along the inquiry, projects appear to be the most frequent social technology through which farmers' organizations relate to other actors. The section is written in such a way so as to unpack the many possible aspects that projects bring to organizations as boundary objects—and the ways organizations respond.

The third section turns to the local realm. Here I turn to farmers' organizations' immediate contexts. The section highlights the institutional circumstances organizations must cope with, and hints to the responses they elicit. The fourth section discusses how to take part of cocoa market. I describe the cocoa's market features as a social construction; deepening in the ways the market is experienced and dealt with by organizations. The last section sums up the chapter, bringing back the attention to immediate 
aims of organizations. These aspects, regarded as farmers' organizations' short-term drivers, bring clarity to their stances.

Before proceeding I will comment on a couple of formal aspects. The reader might have already noticed that I refer to sources using coding references. I will briefly explain with some more detail these labels so as to allow a richer reading experience. Data refer to observations (Obs, focus groups (Fg) and interviews (Interview). Other information in the references refers to the source and date. Detail of data is given in Annex 2. Sources are coded as follows:

\begin{tabular}{|l|c|}
\hline \multicolumn{1}{|c|}{ Source } & Code \\
\hline Magdalena Medio and Caribe & $\mathrm{Mm}$ \\
\hline Noroccidente & $\mathrm{No}$ \\
\hline Centro & $\mathrm{Cn}$ \\
\hline Sur & $\mathrm{Sr}$ \\
\hline Catatumbo & $\mathrm{Ct}$ \\
\hline Amsterdam & $\mathrm{Am}$ \\
\hline Pauna & $\mathrm{Pn}$ \\
\hline Assembly I & $\mathrm{Amb}$ \\
\hline Assembly II & $\mathrm{Asc}$ \\
\hline Leaders & $\mathrm{Ldr}$ \\
\hline Business partners & $\mathrm{Cmr}$ \\
\hline Experts & $\mathrm{Exp}$ \\
\hline Project officers & $\mathrm{Ofc}$ \\
\hline Staff & $\mathrm{Tm}$ \\
\hline
\end{tabular}

Table 2. Data coding references.

Another formal aspect refers to the use of literal quotes. The reader will find in some of the sections literal quotes in Spanish. Naturally, I do not assume the reader to be proficient in Spanish, so the text can be completely understood without the need to refer to the footnotes. I decided to keep the quotes, however, for they beautifully illustrate farmers' voices. Naturally, most of these expressions are not easily translatable without compromising its cultural richness. 


\subsection{What are farmers' organizations' drivers?}

Constructing Cocoa Culture ${ }^{21}$ is a tale about exploring alternatives: A farmer considers whether to grow non-profitable crops or illegal and highly profitable crops. Both are bad choices, but the farmer opts for his peace of mind and takes his chances with cocoa as a possible way out of the struggle (Fg Mc, 14/01/14). ${ }^{22}$ A Guajiro leader wrote this tale. He keeps it always on his mochila (traditional bag) and share it to promote cocoa growing amongst smallholder farmers in La Guajira, northern Colombia (Obs Mc, 14/01/14).

The tale includes idiosyncratic elements of local and rural cultures and illustrates with some detail-and beautiful art-the landscape and the scope of transformations taking place in his town. Similar stories appeared often in groups' conversations. They illustrated accounts of the local history in which the present is described as a result of a change journey. These journeys also describe the state of affairs in the organizations, the role of ongoing projects and the reach and scope of future plans.

\footnotetext{
21 "Consternados con constantes conflictos, campesinos colombianos caribeños, con casta costeña, comúnmente conocido como Carlos Costa, caminaba cansado con 150 caballos castrados conducidos con cuerda de caña. Como Carlos Costa continúa cansado contrata con unos carneros, comprometidos con cuidar cuantiosa caballería. (...)

Cuando caminan, cuatro colonos carneros cantan con Carlos canciones conocidas, cuando cantan Candelaria, cumbia compuesta con cariño, 14 caballeros caporales controlan 50 corceles cimarrones con crepas color dorado, considerado contrabando....

Como comparten camino conjuntamente cuatro caballeros caporales conversan con Carlos Costa, convienen comercializar caballos, Cipriano Cerdeño, comandante caporal, con conciencia caprichosa, considera canjear caballos castrados con corceles cimarrones, (...)

Carlos Costa calla calmadamente contemplando campos cultivados con cacao. (...) . Convencido cada cual canjean corceles cimarrones con caballos castrados, culminada cuantiosa comercialización celebran comiendo cabra condimentada con cebolla cabezona, consumen cerveza, comparten cigarros cubanos. (...)

Cuenta cada centavo conseguido, comienza comprando campos cultivados con cacao, contrata campesinos cacaoteros capacitados, construye casas campestres, compra clones certificados, comercializa cada cosecha con casas chocolateras colombianas, contrae convenios con centros comerciales capitalinos, compra computadores completos, crea correo comercial, compra celulares con cámaras, contrae cuenta corriente, consigna cada centavo, conoce chicas cariñosas, contrae contrato civil casándose con Cristina Cadena,(...)

Cristina con Carlos comen chocolates con crema, contemplan cada cosa conseguida comercializando cacao, Carlos Costa comenta concienzudamente, ¡Caramba Cristina, ¿cuánto cuesta construir cultura cacaotera con cuatro centavos conseguidos comercializando caballos? Carlos Costa culmina cantando contento como cuando caminaba cansado con 150 caballos." (Obs Mc, 14/01/14)

22 "Los caballos castrados son lo improductivo...vea le voy a decir es que si ustedes se dan cuenta el tipo anda cargando con cosas improductivas, ¡mire el chicharrón que cambia! ¡castrados por contrabando que es peor!"
} 
Some aspects appear to be more valuable against this backdrop. These are understood here as farmers' organizations' drivers. In this drivers category I include justifications, interests and decision criteria shaping the path of the organizations. I highlight those that especially relate a standpoint vis-à-vis their mediate environments, those expressing what farmers do care about. These are the reasons these organizations strive to exist and play a role. ${ }^{23}$

\subsubsection{Values: Farmers'organizations' core drivers}

In focus groups, people mentioned various aspects that somehow relate to specific views of the rural long-term values as a relevant driver.

The first of these aspects refers to youngsters' having a chance in rural areas, ${ }^{24}$ which naturally links to a specific understanding of the family. According to organizations' view, family should avoid migration of the youngsters in search of opportunities. ${ }^{25}$ Sense of responsibility is shown in the intention of performing as an example (Fg Mc, 14/01/14), showing that it is possible to project a future, with a long-term perspective, even when there is little money involved (Fg Sr, 27/01/14).

Afro-descendant community councils take this point of view to the community level. It is expressed by means of a constitutive document. This document, called a Life Plan, describes a five- to ten-year vision of community aims (Interview Ldr 004, 16/06/14).

A second thread linking to long-term rural drivers refers to rural identity. References to rural tradition are expressed as values and show an identity that organizations strive to position (Downey, 1992). Naturally some of

\footnotetext{
${ }^{23}$ In order to convey as accurately as possible the farmers' voice, this section includes original quotes in footnotes. Main ideas translated into English will move the discussion in the paragraphs.

24 "Hoy en Colombia hay una gran dificultad que debemos atacar y el problema es que el campo se va envejeciendo, mire yo recuerdo productores que hace diez años vivían en el campo con dos y tres hijos en su finca y hoy diez años después, está él solo y los pelados no quieren volver porque no ven negocio, cuando yo como hijo veo que mi papá se queja, que no da para la comida, que se quiere ir para otra actividad, pues yo como hijo yo volver a sufrir a donde mi papá pues no, pero ya que el campo sea un tema rentable y productivo los muchachos van a volver, pero hoy el campo se está envejeciendo. Yo creo que tenemos que trabajarle al tema del arraigo, hacer que la gente se enamore del pedacito de tierra que tiene, sea muy productiva o no tan productiva pero que se enamore y que ese cultivo sea productivo también y ahí entra la responsabilidad de nosotros como organizaciones, como gerentes o como representantes hay que trabajarle eso" (Fg Mc, 14/01/14).

${ }^{25} \mathrm{Se}$ trata de "la familia porque es que nosotros los campesinos somos campesinos y debemos cultivar la tierra, y la educación entra por casa, no motivar al hijo a que se vaya para la ciudad a hacer no sé qué cosas, la empresa la tiene en el campo" (Fg No, 16/01/14).
} 
these descriptions refer to personal and familiar aspects underlying rural roots (Fg Mc, 14/01/14), but some others refer to wider features of rural life. There is here an extended, perhaps territorial, understanding26: Rural life is mostly about working and protecting the land and the environment (Fg Mc, 14/01/14).

A last driver referring to long-term rural values refers to local history of violence, and the wish to overcome it. This thread focus on a very intimate and sensitive subject, rooted in the fear of rupture within families and communities $^{27}$ (Fg Mc, 14/01/14). As will be seen, this subject connects with the search of peace or legality, discussed next. Here, however, overcoming violence points to its concrete scope of realization in community settings. Peace (legality, development) is not just a matter of income. It is also a matter of wellbeing, values, trust, and respect ${ }^{28}$ (Fg Mc, 14/01/14).

\subsubsection{Create a stable and peaceful environment}

Interestingly, the narrative often comes back to the unforeseen effects of breeding coca. Farmers could not see the consequences coca would bring when they started producing it. The worst effect refers to violence, experienced in a twofold way. One form of violence refers to social friction by means of individualism, laziness and avarice ${ }^{29}$ (Interview Ldr 002,

\footnotetext{
26 "Primero la familia, dos, el arraigo a la tierra, tres, la raza que me identifica con la naturaleza en todos los aspectos, mirando de las cosas que nos da la tierra y en las cosas que debo incluir para protegerlas."

27 "Y el tema de motivación familiar mío fue que la mayoría de mis hermanos eran coqueros, cuando arrancó el programa yo dije ¡A mí lo que me gusta es esto, a mí no me gusta la coca!, yo por accidente me metí a ahí y el reto y la motivación que yo tuve fue, ¿Cómo yo lograba que parte de mi familia y parte de mis hermanos erradicaran y se metieran en el cultivo de cacao? La primera vez que yo le dije a mis hermanos, porque era hermano si hubiera sido un desconocido me pegan, me dijeron de todo y yo les dije si ustedes no le hacen yo si le arranco. Y yo ya había hecho donde me regalaron mi pedacito una sociedad, eran como 10 hectáreas con unos primos y ahí yo arranco, por fortuna a los dos años a la mayoría les habían arrancado o fumigado y yo dije ¡Oiga si esta región ya empezó a cambiar de lo ilegal a lo legal! para mí se convirtió como en un reto familiar el ver como mis hermanos y familiares erradicaban y sembraban cacao."

28 "Pero adicionalmente que la familia se sienta bien, las familias que hoy tienen mucha plata pero no viven bien, ahí no hay autoestima, no hay valores, no hay respeto, ahí prevalece (la plata) por encima de lo que son las personas"

29 "Entonces todo el mundo empezó a sembrar coca, a sembrar coca. Pero nadie dijo ni vimos las consecuencias de lo que genera la comercialización y la transformación de los cultivos de coca como tal. Porque como dice es una mata como sembrar cacao: hay que fertilizarla, desyerbarla y cuidarla igual. Pero el tema es las consecuencias que eso trae de aceptar los procesos con los ilícitos".

-Dígame una de esas consecuencias.

"La violencia, claro. Al haber abundancia de dinero, hay descomposición social. Bueno, eso ahí se permiten muchas cosas. Lo único que interesa es la plata. A los jóvenes no les interesa estudiar. Como
} 
$10 / 06 / 14)$, that is, violence as a form of rupture within the family and the community. The other form refers to involvement of armed groups in the business and its effects in territories. Here violence refers to loss of autonomy and increased vulnerability to third parties (Interview Ldr 002, 10/06/14; Fg Ct, 20/01/14; Fg Mc, 14/01/14; Obs No, 16/01/14) .

Therefore, peace as a driver aims to transform this unsatisfactory state of affairs, in various levels. The first level refers to personal awareness, in which peace is described as a personal experience, as a result of personal choice. People say breeding illegal crops implies anxiety, even if it is a source of great income. Therefore, wellbeing is framed as a state of mind resulting also from productive decisions ${ }^{30}(\mathrm{Fg} \mathrm{Sr}, 27 / 01 / 14)$. The second level relates to collective affairs. It is understood that trust and stability are favourable conditions to social cohesion and collectively addressing common interests. ${ }^{31}$ Peace is assumed here to be a condition of freedom and participation (Obs No, 16/01/14).

\subsubsection{Create Legality}

Peace as a driver is closely linked to the promotion of legality. Facts as the assassination of two leaders and the kidnapping of another can give an idea about the intensity of the conflict and the various interests and

\footnotetext{
hay recurso fácil entonces todo el mundo se la gasta más fácil y bueno, eso da para que el tema social se empiece a descomponer y a salirse de las manos realmente de lo que tiene que ser.

Entonces ahí pues tras de eso vienen hechos de violencia porque entonces Que yo quiero ser más que el otro. Que yo tengo ya plata. Que yo no me dejo. Que yo le quito, que yo le robo, que yo le tumbo. Empiezan los grupos al margen de la ley a poner los ojos en regiones donde el negocio se pone de un gran tamaño, donde el lucro puede ser bastante para ellos. Entonces empiezan a meterse y a tener injerencia en el negocio y empezaron a tener presencia ya acá. Ya trataron de meterse la guerrilla por un lado, y posteriormente los paramilitares. Entonces eso hizo que la gente dijera No!”

30 "La tranquilidad y la paz no tienen precio. Porque muchas veces por mucho dinero que se tenga pero si no tiene paz, no se es una persona realmente... ¿Cómo se dice...? Sanos. No es una persona saludable, porque, por mucho dinero que tenga uno, muchas veces llegan las enfermedades por la intranquilidad. Enfermedades, que por mucho dinero que tengan, no van a poder ser sanadas, y los van a llevar a la tumba."

31 "La asociatividad y la unidad. Sabemos que una hormiguita no hace hormiguero, si nosotros estamos asociados podemos lograr grandes metas, cambios y transformar mentalidades de nuestros campesinos, y obviamente producir con calidad y competir con calidad. Generar oportunidades de desarrollo en la misma comunidad, mejoramiento por supuesto de la calidad de vida de las familias del campo que es el objetivo de todas las organizaciones, porque al generar una economía en el seno familiar obviamente mejora la calidad de vida, y en consecuencia contribuir con el desarrollo y paz del país, que es la que nos tiene bastante aporreados."
} 
overlapping sets of rules of the game at stake in these territories ${ }^{32}$ (Interview Ldr 002, 10/06/14).

Stressing this point, leaders emphasize the legitimacy of local leadership as the persuasion tool making it possible to transcend illegality (Interview Ldr 003, 16/06/14). Leaders express that change processes take place mainly because they are themselves examples of the possibility of change. Leadership (both theirs and others') is therefore a vehicle of improvement $^{33}$ (Interview Ldr 002, 10/06/14).

\subsubsection{Gain autonomy}

Autonomy as a driver refers to ownership of local priorities decisions. It appears in various forms. First, it appears as a demand of ownership of available means for "social change." This demand has an expression in practical terms as ownership of projects implemented at the local level. Of course this touches various aspects, to be later discussed. As a value, however, ownership is understood as a mean of stability, ${ }^{34}$ expressing the intention of directing local energy towards local aims (Interview Ldr 002, 10/06/14).

Autonomy also appears in leaders' narratives as self-determination. Autonomy expresses the base of organizations' political stances as channels of grassroots interests: "We can speak, we can do things; also

\footnotetext{
32 "Hubo (...) un líder de cacao que fue asesinado por eso. Y creo que en Colombia en muchas regiones ha pasado. Empiezan a generar cambios para transformación para generar que muchas personas, que conscientemente saben que lo que se está haciendo está bien, pero no les conviene (...)

Entonces hubo el asesinato del líder de los cacaoteros (...) fue de las situaciones más difíciles. No era fácil llegarle a la fuerza pública y decirle que el líder fue el que me la echó o fue Fulano el que me la trajo. Pero fueron generando conciencia (...) porque por ejemplo [Líder], era uno de los que más tenían coca ¿Sí? Entonces digamos que nosotros nos basamos en nuestra propia realidad. Nosotros contamos lo que hemos visto y lo que hemos vivido (...) entonces de una u otra manera vivimos en carne propia toda la transformación.

Y la gente lo conoce y sabe que estuvimos dentro del cuento entonces por eso yo creo que el proyecto ha tenido impacto. Diferente a cuando viene una persona que no conoce, que no ha vivido y que venga a hablar del tema entonces ¿Usted para qué viene a hablarme de eso? Pues ya el proyecto empieza a tener credibilidad en el proceso".

33 "Yo creo que lo interesante del tema es que este proceso se está dando porque los que estuvimos ahí metidos en ese conflicto, que somos nosotros los campesinos, los que tenemos una finquita allá, nos dimos en la tarea de hacer el cambio. Y algunas personas que tenían más vocería, a tomar las riendas de estos proyectos, con liderazgo, con vocería; ellos nos han permitido mejorar en el tiempo".

34 "De pronto si llega alguien de afuera, alguien externo, mientras que hubiera estado acá, pues bien, pero ¿si se va? Se pierde de nuevo... Entonces desde adentro como lo estamos viendo nosotros, eso nos ha permitido mantenernos, que el vínculo se sostenga todavía. Es seguir abriendo puertas a la gente de la región que se vincula a este proyecto".
} 
politics, we are independent, we can do our own politics, a healthy politics, a culture politics in which we can see our sons, in which we can see our leaders. We've managed this with our own criteria"35 (Fg Sr, 27/01/14).

This also expresses a view and a purpose towards political actors and institutions: "They call us poor. We are not poor; we don't need mountains of money to be well. Our aim is managing what we have, to get trained in every aspect to be free and own the knowledge"36 (Interview Ldr 003, 16/06/14)

In sum, data highlights the making of a peaceful rural lifestyle as the most important driver of these organizations. This is, in other terms, making sure the "human scale" lifestyle remains (Cruz, Stahel, \& MaxNeef, 2009). Table 3 sums up this section.

\begin{tabular}{|c|c|c|}
\hline \multicolumn{3}{|c|}{ Table 3. Farmers' organizations' core drivers } \\
\hline Drivers & Aspects & Features \\
\hline \multirow{2}{*}{$\begin{array}{l}\text { Create a stable and } \\
\text { peaceful environment }\end{array}$} & Individual peace & $\begin{array}{l}\text { Overcoming social } \\
\text { unrest }\end{array}$ \\
\hline & Collective peace & $\begin{array}{l}\text { Overcoming } \\
\text { vulnerability }\end{array}$ \\
\hline \multirow[t]{2}{*}{ Create legality } & Stabilize local order & $\begin{array}{l}\text { Bring about local } \\
\text { institutions }\end{array}$ \\
\hline & Grant legitimacy & $\begin{array}{l}\text { Make sure local } \\
\text { institutions respond } \\
\text { to local priorities }\end{array}$ \\
\hline \multirow[t]{2}{*}{ Gain autonomy } & $\begin{array}{l}\text { Achieve ownership of the means } \\
\text { for change }\end{array}$ & Profit local potential \\
\hline & Ownership as self-determination & Set local priorities \\
\hline
\end{tabular}

Rural traditions, family, nature and culture, hand in hand with peace, autonomy and legality, seem to be at the forefront of farmers'

\footnotetext{
35 "Nosotros podemos hablar, nosotros podemos hacer las cosas; los temas políticos también nosotros, somos independientes, podemos hacer nuestra propia política, una política sana, una política de cultura, en la que miremos reflejados a nuestros hijos, miremos reflejados nuestros líderes. Todo esto lo hemos estado manejando desde nuestro propio criterio."

36 "A nosotros ... nos dicen pobres. Nosotros no somos pobres, ni tampoco necesitamos montañas de dinero para vivir y satisfechos. Nosotros a lo que estamos apuntando es a organizar lo que tenemos, capacitar a nuestra gente en todos los aspectos para ser libres y tener el conocimiento."
} 
organizations' drivers. At the end of this chapter I will come back to more tangible expressions of these priorities. I will now discuss projects roles in farmers' organizations' experience.

\subsection{Marching at projects' pace}

Earlier in this chapter I stated that projects appear to be the most common device through which farmers' organizations relate to other actors. Which is to say, in other words, that projects appear as a recurring boundary object in the experience of organizations. In effect, the term "project," referring to various kinds of development projects formulated by various kinds of actors, appeared often in focus groups and interviews. It appeared in conversations as a site in which relations take place, or for example, as an analytic unit of activity. Projects are a source of resources for organizations, perhaps the most important.

Given the relevance of the topic, this section discusses an overarching view of the organizations in light of projects. It is worth remembering the discussion is set transversally and does not aim at describing single cases or give a comparative account amongst organizations. The discussion rather describes those features that appear to be relevant to the purpose of understanding what projects entail as a social technology for communities and organizations.

The discussion will take place following various threads. The first thread discusses projects in relation to the origin and growth of organizations within the practice of cocoa. The second thread discusses projects as a schooling device, describing ways projects provide knowledges. The third thread discusses projects as opportunities to build a local order. There is a shift of tone here, showing how organizations look to intentionally build stability given the fact projects function like steps of their ladder. The fourth thread discusses projects as vehicles of external threats, linking to the actors and the overarching practices in which projects are embedded. Naturally, each of these threads follows organizations' descriptions, also allowing a glimpse into their strategies. 


\subsubsection{Projects at the roots of organizations}

Projects appear as the most common vehicle for sociotechnical change in the context under study. Promoters - a varied number of actors - and local allies embarking on projects are seen as risk takers, attempting something different or new. Initial projects take place in unstable situations, in periods of social rupture arising every kind of suspicion. Local partners are described as explorers or adventurers taking their chances (Fg Mc, 14/01/14). Size of projects vary, but some of them have had subregional reach with investments of up to 1.4 million euro (Fg Cn, 23/01/14; Fg Sr, 27/01/14)

Social change through projects is expected in various layers. The first layer is material change, relating to crops, as in the case of replacing illegal coca plantation with legal cocoa plantation, or incorporating complementary income alternatives (Interview Ldr 004, 16/06/14). Crop change implies also incorporating a range of practices attached to the new crop. These practices are considered a condition of economic success and take place both in and out of the farm. Embedding these practices is not an easy process. It is seen as achieving a new identity (Fg Sr, 27/01/14).

For most of organizations cocoa is the core of this new productive basket, and organizations care about being considered good managers of the sector's resources (Amb, 14/02/14). This implies involvement in various aspects. The first refers to biological materials (that is, cocoa varieties). Organizations get involved in projects characterizing local assets (Fg Mc, 14/01/14), trying new materials (Fg Cn, 23/01/14) and managing seedlings (Fg Cn, 23/01/14). Other infrastructure includes tools, distribution (such as weighing balances), drying (greenhouses) and storage (storehouses). According to organizations, infrastructure is a means for market access and its availability is a way to build trust with other parties ( $\mathrm{Fg} \mathrm{Cn}$, 23/01/14).

In the case of cocoa, the more spread dictum-the preferred amongst organizations-says spending time on the farm taking care of the crop by hand increases productivity, and therefore, resilience of smallholders. But there are other views: Controversy has arisen with third parties recommending the use of pesticides ( $\mathrm{Fg} \mathrm{Sr}, 27 / 01 / 14)$. In any case, organizations know that handling of the new crop might not be easily acquired. Regions with traditional plantation or less entrepreneurial 
cultures have difficulties incorporating these practices (Interview Ofc 004, 17/10/14).

A second layer of change links to the creation of grassroots organizations. New organizations can be a product of projects (Interview Ldr 002, $10 / 06 / 14$ ) or a requirement to access projects as beneficiaries. In this case projects are incentives or windows of opportunity to consolidate local aims (Fg No, 16/01/14). Projects are seen both as a reward for changing and as means to deepen change (Fg Mc, 14/01/14).

Projects also play a role at the network level. Peer networking seems to be a natural feature of these organizations. Organizations are born integrated (Fg Cn, 23/01/14; Fg No, 16/01/14) or integrate into facilitate resource allocation at the subregional level (Fg Cn, 23/01/14). They act collaboratively: Team work achieves shared goals or creates intermediary organizations (Fg Mc, 14/01/14; Fg No, 16/01/14).

Projects are also a means to strengthen regional nodes and the national network. This aim covers a wide range of aspects. It includes access and participation, by taking charge of traveling expenses (Amb, 14/02/14), peer-to-peer exchange (Amb, 14/02/14), international peer exchange (with Peruvian producers, for example) (Asc, 07/07/14), financing acquisition of communication and information technologies (Amb, 14/02/14), legal expert advice (Asc, 07/07/14), collaboration for strategic planning (Interview Ofc 004, 17/10/14; Asc, 07/07/14) and training (Amb, 14/02/14).

Projects also play a role linking actors of the cocoa value chain (Amb, 14/02/14; Fg Cn, 23/01/14; Fg Ct, 20/01/14; Fg Mc, 14/01/14; Fg No, 16/01/14; Fg Sr, 27/01/14), sometimes making it possible for organizations to play a role on the more sophisticated end of the chain, transforming raw cocoa (Fg Sr, 27/01/14). Development actors interested in this realm aim at stabilizing an export platform, linking state actors at the national level and industry stakeholders (Interview Ofc 004, 17/10/14).

\subsubsection{Projects as schooling}

Projects are the main vehicle for acquiring knowledge. Various overlapping layers of knowledge appear on projects. First, projects embed knowledge: a particular form of organizing, managing and reporting. Performing projects is a form of learning by doing. In the organizations' 
view, partners should understand this facet of projects. Ignorance about some rules and procedures, organizations claim, is not unwillingness to do the right thing ( $\mathrm{Fg} \mathrm{Cn}, 23 / 01 / 14)$. Organizations often feel ill-treated while dealing with non-technical aspects of projects, especially when facing unexpected consequences of their mistakes (Obs Exp 001, 16/07/14; Fg Cn, 23/01/14). Project-related practices such as accounting or taxes appear in an organization's experience as unexpected forms of knowledge.

The second layer refers to project aims. Projects are a vehicle to allocate capabilities on various levels of the organization. Knowledge appears here in the form of direct training (Fg Sr, 27/01/14), expert technical advice on various possible fields and levels (Interview Ldr 004, 16/06/14) or technologies (Amb, 14/02/14). Naturally, there are diverse kinds of capabilities amongst farmers, technical assistants, administrative assistants or managers (Fg Cn, 23/01/14). Projects are therefore a vehicle to increase organizational capacity as a whole. New functions (this might be, new project initiatives) imply newly acquired capabilities and organizational capacity (Fg Sr, 27/01/14). External assistance, regarded as good facilitation, often creates collaborative schemes to go about project activities, valorizing existing local knowledge. This is regarded as a form of trust and team building (Interview Ofc 002, 05/02/14).

Organizations ask for support (Interview Ldr 004, 16/06/14). Projects are a mean for organizations to grow and strengthen (Fg Mc, 14/01/14). Projects are a vehicle to keep track and report on what has been done (Amb, 14/02/14). They are also a vehicle to expand. Expansion aims to increase a basket of income alternatives (Fg Mc, 14/01/14; Fg No, 16/01/14), size (enlarging its reach to more beneficiaries; Interview Tm 001, 16/01/14; Fg Sr, 27/01/14), infrastructure (Interview Ldr 002, 10/06/14) and services to beneficiaries. This last aspect counts both for individual members as well as for organizations (as is the case of intermediary organizations and networks) (Interview Ofc 004, 17/10/14).

Organizations' learning processes are not exempt of flaws. Organizations overestimate their capacity to deliver on project partnerships. This includes, for example, errors in geographical reach, exceeding organizational capacities (Interview Ldr 004, 16/06/14) or agreeing on how to manage exports but noticing too late they still lack thorough understanding of some practical on-site details (Fg No, 16/01/14). 
Organizations are aware of their governing role at the local level. Some leaders say the organizations are the state at the local level. In their view, organizations bridge relations between individual farmers and other actors beyond the local sphere, especially public actors (Interview Ldr 004, 16/06/14).

Further, organizations have an understanding and a stance towards what happens in their closest environments and strive to bring alternatives to counteract them. This might not relate to illegal crops, as could be easily assumed, but to unsustainable environmental practices, for example. Organizations are concerned about mining and wood extraction, regardless if carried out as legal or illegal activities. By striving to solve situations deemed as unsatisfactory, organizations link outer contexts and opportunities to local resources, bringing along new players, services and rules of the game (Interview Ldr 004, 16/06/14; Fg Sr, 27/01/14).

Naturally, organizations aim at obtaining structural solutions for the territory. There is a clear focus on governing the long term. Valorizing and strengthening local capabilities and capacities on its many possible levels is regarded as a form of sustainability, of continuity in time of the local effort (Fg Cn, 23/01/14). This purpose of sustainability can be seen in many layers, the more salient being perhaps the attempt of long-term leadership training. Organizations do pay attention to generational change-over and to technical and leadership training of youngsters (Interview Tm 004, 20/01/14; Amb, 14/02/14; Fg Sr, 27/01/14).

Another layer of this idea of long-term sustainability touches upon the handling of projects - and of those actors bringing about projects-as the main contact channel with the outer world. There is a sort of buffering role through which organizations clarify the pace and scope of relations between project partners and smallholder farmers.

This buffering role stands on the fact that, against all odds, so-called beneficiaries are not always willing to participate in projects. Their disposition depends on previous experiences as much as it does on the promise of possible benefits of a new project (Fg Ct, 20/01/14). Arguably, willingness to take part is dependent on a certain harmony, a flow of the process. Organizations' main role is therefore attuning external interventions to local long-term interests (Interview Ldr 004, 16/06/14). 
Unsurprisingly, it is clear to organizations that success in this role is a source of legitimacy for the organizations at the local level, reaching even beyond the organizations' members (Fg No, 16/01/14).

Several buffering strategies were identified, varying in degree, intentionality and contents.

Some better illustrate a protective intention, a shielding role, through gatekeeping (Fg Sr, 27/01/14), avoiding risk of local disruption-as is the case, for example, with externally enforced schemes of selection of beneficiaries-(Fg Cn, 23/01/14) and blocking (Interview Ldr 004, 16/06/14). The latter, naturally, is a form of blunt opposition to third-party initiatives. Interestingly, there is kind of an external mirror effect, by means of which organizations take a shielding role vis-à-vis external parties: stabilizing territories allowing them to enter ( $\mathrm{Fg} \mathrm{Sr}, 27 / 01 / 14$ ) or, in case of severe warfare, playing the role of other actors, mimicking their functions at the local level by means of deals under the table ( $\mathrm{Fg} \mathrm{Sr}$, 27/01/14).

Some others illustrate a facilitating role, carrying out activities to ease the processes. Some of them refer to what can be seen as ways of tackling the local organizational climate, such as informing, including and team building (Interview Ldr 004, 16/06/14; Fg No, 16/01/14) and creating new opportunities to maintain local morale (Fg No, 16/01/14). Some others refer to the challenge of divides between existing and desired sets of capabilities, such as anticipating, preparing and translating contents $(\mathrm{Fg}$ Sr, 27/01/14), adjusting training tools (Fg Sr, 27/01/14) and adapting local methods to external requirements (Fg Ct, 20/01/14).

Expectedly, some others aim at making it possible to allocate resources incrementally. Organizations keep track and mobilize call opportunities (Amb, 14/02/14), manoeuvre to reformulate interventions (Interview Ldr 004, 16/06/14; Fg Ct, 20/01/14), negotiate requirements and infrastructure (Fg Cn, 23/01/14), or lobby to position a local vision and bring about missing pieces on their capability puzzle (Interview Ldr 004, 16/06/14).

Finally, there are some strategies referring to the presence itself of the organization and its impact. These strategies refer to an organization's reputation and incorporated practices, such as behaving transparently and performing (Interview Ofc 002, 05/02/14; Fg Mc, 14/01/14; Fg No, 16/01/14; Fg Sr, 27/01/14), and if it has a certain local effect, such as 
manoeuvring to set minimum local cocoa prices (Fg Cn, 23/01/14; Fg Ct, 20/01/14; Fg Mc, 14/01/14; Fg No, 16/01/14; Fg Sr, 27/01/14). As the following paragraphs will show with some more substance, these strategies take place in extremely uncertain and volatile contexts.

\subsubsection{Projects as a vehicle of external threats}

Projects are not exempt of flaws. Not just by their risk of failure, but because projects are a vehicle of the ill structures of organizations implementing them. Project settings are affected by the nature of their partners, and farmers' organizations face dealing with this bitter reality as part of their governing role. Organizations see themselves as located in "abandoned" places (Fg Ct, 20/01/14). Abandonment speaks about lack of state (that is, public services, public institutions), if not about blatant corruption (Fg Mc, 14/01/14). These contexts illustrate to some extent the immediate sense of (a lack of) order and stability, and the extent to which broader societal patterns-market, policy, politics, state-are played. Organizations fear-and often face-impediments, delays or troubling conditions undermining local potential (Interview Ofc 004, 17/10/14). The next section details the sources of these threats.

\subsubsection{Threats induced by the politic-administrative apparatus}

Institutional weaknesses of the political-administrative apparatus pose a first vehicle of external threats. A common feature of project delivery is a requirement of third-party approvals or co-financial schemes, bringing local or regional agendas, party disciplines and tied supply to the local scene. The tied supply is often poor, inadequate or incapable supply (Fg Ct, 20/01/14; Obs Mc, 14/01/14; Fg No, 16/01/14; Fg Sr, 27/01/14).

As a result, organizations engage in political activities at the local and regional level to counteract the heft of undermining forces (Interview Tm 004, 20/01/14; Obs Cn, 23/01/14; Obs Mc, 14/01/14; Obs Sr, 27/01/14).

Organizations' involvement include supporting political allies at the local level (Fg Cn, 23/01/14; Fg Mc, 14/01/14; Fg Sr, 27/01/14), attempting direct political involvement (Amb, 14/02/14; Obs Mc, 14/01/14), supporting-with various degrees of individual or organizational involvement-the rural social movement (Interview LdrSM 001, 07/03/15; Interview Ldr 003, 
16/06/14; Amb, 14/02/14) or creating spaces for municipal accountability with candidates or elected authorities (Fg Cn, 23/01/14; Fg Mc, 14/01/14). Exhaustion from these efforts is telling: "By means of disappointment or anger, we must keep relations" (Fg Sr, 27/01/14).

\subsubsection{Threats induced by power imbalances on the productive} sector

The second field refers to the way an actor is distributed and exerted within the cocoa sector. As the reader might remember, the sector looks like an oligopoly towards the end of the chain, meaning that a few enterprises have control over most of national cocoa demand.

This situation touches farmers' organizations right on the core: The most common project approach within the cocoa value chain consists in connecting grassroots organizations to the national chocolate industry. In this approach, the latter provides working capital to the organizations that is subject to long-term buying contracts (Fg Ct, 20/01/14). The chocolate industry has interest in securing the local cocoa supply because of its local demand and sensitivity to flavour changes (Interview Ofc 004, 17/10/14), and allegedly, this setup should benefit the producers for it secures a stable demand. However there is a downside for organizations: They face the risk of getting stuck in a market situation undermining their full potential.

In fact, this setup is regarded by organizations as a form of industry-laden policy-making, sometimes supported naively by international aid (Interview Ofc 004, 17/10/14). Organizations see international organizations and non-governmental organizations as possible allies to overcome this situation (Fg Ct, 20/01/14; Fg Mc, 14/01/14). However, often these allies have a strong social accent and overlook the structural market conditions of the sector. Few public investments actually "take care of business as it is needed" (Interview Ofc 004, 17/10/14).

This limited focus on "business"-that is, the material, technological, market dimension of cocoa-is labelled by organizations as patch project making. Organizations deal with not knowing how to sell what they cultivated (Fg No, 16/01/14), not knowing what kind of cocoa do they have (Obs No, 16/01/14) or not knowing where the best one is (Obs Cn, 23/01/14; Fg Sr, 27/01/14). Or they could also have mixed cocoa varieties (including 
non-certified varieties) and therefore struggle with contradictory normative incentives: specialized markets asking for varieties they should not breed (Obs Cn, 23/01/14). Naturally-and paradoxically-support under these circumstances limit organizations' access to opportunities (Obs Ct, 20/01/14; Obs No, 16/01/14; Obs Sr, 27/01/14).

Arguably, these situations could be solved by means of scientific research. Unfortunately the picture in the case of scientific collaborative support does not look very different. With a few limited successful exceptions (Interview Ldr 002, 10/06/14; Interview $\operatorname{Tm}$ 004, 20/01/14), the relationship of organizations to research activities tends to be indirect. Collaboration for scientific purposes appears but organizations regard it as a difficult and not a straightforward endeavour. The anecdotes indicate this is due to farmers and researchers expecting different research outcomes.

While research institutes seem to be happy with results whatever they are, organizations expect solutions to immediate needs. Or at least a focus on applied research linking practical day-to-day problems to research problems (Interview Tm 004, 20/01/14). Researchers are seen, in this sense, as bureaucracy, certainly marking a pejorative accent on the word. One leader said, jokingly, about non-applied research on water, "What do they expect us to do with those results? Irrigate crops with papers?" (Interview Ldr 002, 10/06/14).

To make things worse, organizations have a hard time accessing funds to secure stable cocoa purchasing. In some cases there is prohibition (in the case of publically funded projects). In other cases, there are access barriers to financial products. Banking practices overlook cocoa's market features, often inducing organizations to sudden debt increases (Fg Cn, 23/01/14). From the organizations' point of view, scarce working capital of their own hinders potential access to more profitable niches and reaching a better position to regulate local prices (Fg Sr, 27/01/14).

\subsubsection{Severely unstable rural development offer}

Following this line it is comprehensible that support for rural development is seen as severely unstable by organizations. It is worth introducing some nuances connecting to this picture. 
The first relates to features of the available offer for rural development. Support is regarded as scattered-dealing with many uncoordinated and diverse actors (Fg Cn, 23/01/14; Fg Sr, 27/01/14); incomplete-dealing with small projects and being subject to normative contradictions, fragmented formulation (Interview Ldr 004, 16/06/14; Fg Cn, 23/01/14) and based on incomplete information (Interview Ldr 004, 16/06/14); or, simply put, inappropriate - which is often the case with unsolicited initiatives ( $\mathrm{Fg} \mathrm{Cn}$, 23/01/14). Bluntly put, project-based rural development is considered the more salient feature describing the poor public offer for rural development in the country (Fg Cn, 23/01/14).

Scales on institutional contradictions vary. Reported contradictions at the project level include state actors not sharing decision criteria. Examples refer to organizations being eligible or not for calls as intermediary organizations (Interview Ldr 002, 10/06/14) or having requirements for beneficiaries (e.g. projects that cannot benefit smallholders without a bank account or tax register) (Fg Ct, 20/01/14). In the organizations' eyes these affect both efficiency and equitability of resource allocation at the local level.

In its more severe level, institutional contradiction deals with material effects of the war on drugs. Military deployment with "red light/green light" categories for territories forbids some smallholders from accessing national programs. Organizations deal with this disruption at the local level, managing severe inclusion/exclusion divides (Fg Cn, 23/01/14; Fg Ct, 20/01/14; Fg No, 16/01/14). In the worst cases, farmers have suffered glyphosate air fumigation after the establishment of the legal crops. In these cases people felt forced to migrate (Fg Sr, 27/01/14).

Incomplete support is a common concern. For example, a few years ago an international organization funded an online information system for the National Cocoa Network. The rationale of the project was that having information about land, farmers and crops would strengthen the network. The project funded the website as well as the engineering. But it overlooked the non-technological component of the process. After two years the platform barely has data. At the 2014 national assembly the project officer from the international organization drew attention to the fact. In his speech, the network secretary answered with a few words, reckoning how useful the tool will be. 
I asked about the platform in the interviews and focus groups. Organizations understand the value of the platform and feel uncomfortable about the situation. Most of the organizations lack the information therefore there is nothing to be uploaded. Some, at most, have partial bits. Organizations do not think it is feasible to obtain the information with their current operational capacity. Further, some of them feel cautious about software interoperability with accounting systems and fear a loss of investment if actualizing uploaded information might bring limited management options afterwards. Their common answer, after a meaningful silence, is "we are seeking the means to hire a team to gather this information, it is important to have it" (Amb, 14/02/14).

Loss of investment is not an unlikely threat. Changing partners, conditions or partners overlooking existing assets can result in financial risk, loss of face with partners or beneficiaries (Fg Mc, 14/01/14) or difficulties accessing markets (Interview Ldr 002, 10/06/14; Fg Cn, 23/01/14).

\subsubsection{Shortcomings in arrangements for project delivery}

Projects also embed rationales that organizations regard as detrimental. Some relate to prejudices or assumptions amongst participating actors. Often they refer to the pace of interaction, to time or space considerations: Interestingly, rural and urban cultures show the mark of their existing cognitive divides. If I may say, its embodied divides. Organizations refer to project schedules (Interview Ldr 004, 16/06/14), requirements, mobility, communications or language assuming local rhythm (and possibilities) just as those "of the capital city" (Fg Sr, 27/01/14).

Other project rationales regarded as detrimental refer to the existence and roles of external project intermediaries, which organizations disapprove of for various reasons. To begin with, organizations argue intermediaries harm investment efficiency. People resent the fact that resource allocation spends "more on bureaucracies than on farmers" (Interview Ldr 004, 16/06/14; Fg Cn, 23/01/14). To their eyes, external operators are expensive, not just because of their salaries, which expectedly might be higher, but because they "usually spend more than needed." A leader expressed it good-humouredly: "They even bring psychologists for the trees" (Fg Cn, 23/01/14). 
More important in their eyes, organizations are sceptic of a project operator's commitment to grassroots aims. The starting point for organizations is that external actors take longer to build a constructive dialogue with local lifestyles. And even if they succeeded on that account, the organizations fear external actors will not remain accountable at the local level (Fg Sr, 27/01/14). In their experience, external "project operators focus more on checklists so they can charge, than understanding and addressing local priorities" (Interview Ofc 004, 17/10/14; Fg Cn, 23/01/14). This line of thinking naturally connects with the idea, previously mentioned, of "local sustainability." It refers to the fact that external operation does not impact strengthening and involvement of local talent. On the contrary, it might "take away people's responsibility for their own opportunities" (Interview Ofc 004, 17/10/14).

Another project rationale, which is regarded as detrimental, prevents organizations to receiving and/or managing project resources (especially financial) through their own means. This can be seen as a form of embedded asymmetry, based on third-party assumptions of organizations' lack of capabilities. Naturally, this changes along the organizations' path to maturity. Donors or operators try step-by-step strategies to hand over resources (Interview Ofc 002, 05/02/14) or devise collaborative strategies, where the organization has control over a part of the cake (Interview Ofc 004, 17/10/14). More often than expected, it is management of emerging situations dealing with local contexts that pave the way towards increasing autonomy. These cases demonstrate to outsiders that the extent of local capabilities is naturally adapted to local environments (Interview Ofc 002, 05/02/14).

\subsection{Affairs at the local level: Games and gamesters on making fate}

Before proceeding I pause to remind the reader where we stand at this point. This chapter discusses fieldwork results. I have already discussed the long-term drivers of farmers' organizations and a crosscutting view of projects as relevant devices through which organizations link to other actors. Now I will turn to the local realm, describing organizations' 
experiences with local and regional authorities as well as the responses they elicit.

\subsubsection{Dealing with local and regional authorities}

Institutional weaknesses and political flaws of municipalities and departments are reported as frequent challenges for cocoa-producing organizations. Local authorities are deemed as having poor leveraging capacity or not being accountable. Local authorities lack interest, sometimes being blatantly indifferent to farmers' concerns (Fg Sr, 27/01/14), or commit on the surface but fail to contribute to multi-party projects (Fg Cn, 23/01/14; Fg No, 16/01/14; Fg Sr, 27/01/14). In short, local and regional authorities are not worthy partners (Interview Ldr 003, 16/06/14).

Party practices bound local municipalities' decision-making. The organizations cope with changes every political period and are subject to political debate (Fg No, 16/01/14). Parties winning the election often favour decision-making towards party supporters, neglecting the broader community (Fg Sr, 27/01/14), which is not entirely a downside: The balance is sometimes on the side of organizations, when the elected candidate is a friend. Naturally, organizations tend to have stronger links with cadres who grew in grassroots movements and have a history of helping each other (Obs Mc, 14/01/14; Fg Sr, 27/01/14).

Despite this possibility, organizations prefer to not take risks and to remain at a prudent distance. Sooner or later they realize "there is nothing for us in municipalities" (Fg Cn, 23/01/14). Managing relations proves to be a challenging task. Elected politicians often pay ill service to organizations' efforts. Politicians are interested in getting political profit out of grassroots achievements, providing little help and claiming recognition afterwards. Of course, this is a very unsettling situation for organizations, often appearing at the start-up stage (Fg Cn, 23/01/14; Obs Mc, 14/01/14). Politicians have been known to ask organizations to include their own constituency, out of the blue, as beneficiaries of organizations' projects (Fg Mc, 14/01/14).

Or even worst they ask for bribes, contriving fraudulent intermediation arrangements against smallholders (Fg Cn, 23/01/14) or profit from an organization's achievements, as was the case when an organization 
received an invitation for an international official exchange and regional authorities appointed someone else, someone who lacked credentials (Fg $\mathrm{Cn}, 23 / 01 / 14)$. If not cynical enough, some politicians have disregarded bonding agreements that organizations devised as ways to counteract uncertainty (Obs Mc, 14/01/14).

Program delivery at the regional and local levels is not exempt of this aura. Selection procedures on regional calls are felt as non-transparent (Fg Cn, 23/01/14; Obs Mc, 14/01/14) and involvement of municipalities and departments in multi-stakeholder initiatives is felt like a form of window dressing (Fg Cn, 23/01/14). Warfare adds complexity to this scenery. The presence of guerrilla or paramilitary groups in specific sites is argued to be a reason to deny support to organizations, creating divides amongst organizations' members (Fg Sr, 27/01/14).

\subsubsection{Organizations' responses: On the brink of politics}

"If you live in hell you have to talk to Devil"-said a community council representative. Organizations see their role as making things happen in the territory, opening windows of opportunity in an uncertain, conflictive and threatening environment (Fg Sr, 27/01/14). This includes performing as a local vehicle of extra-territorial opportunities and bringing actors, capabilities and resources to create or maintain social functions. As said, amongst others functions, organizations deliver also those functions of the state.

Organizations invest in developing successful partnerships (Obs Mc, 14/01/14), avoiding as much as possible any kind of mediation by local authorities (Interview Ldr 001, 13/01/14). As noted, this might include also facilitating access for other actors (e.g. the national training department, the bank) and, in the worst of the situations, mimicking their roles (Fg Sr, 27/01/14)

Organizations here act like representatives of smallholder farmers, yet attempt to tentatively manage the political contours of this function on what is a very thin blade. They do so by trying to maintain coherence around a business-like independent position focused on values such as the rural life, the family and the human being (Interview Ofc 001, 05/02/14). 
However, coping with local and sector circumstances and strategizing to achieve better negotiation positions bring organizations to the arena.

In effect, organizations take roles vis-à-vis other actors. Organizations lobby at the local and regional levels looking for investment on the sector and collaborate in the formulation of public investment projects (Obs $\mathrm{Cn}$, 23/01/14). In a different facet of this role, organizations cluster with other grassroots organizations to demand accountability from authorities or position specific demands (Interview Ldr 003, 16/06/14; Obs Mc, 14/01/14).

Organizations' peer partnerships also take place at the sector level. According to organizations' logic, their positioning as organizations entails visibility and access to smallholder producers (Obs Cn, 23/01/14). Organizations' efforts elicit responses from other actors, giving some reason to this logic. Their place at the National Cocoa Council, for example, is seen but as a natural and spontaneous recognition of this role (Interview Ldr 001, 13/01/14). Needless to say this logic is engrained in organizations' relations with one another, always supportive through the networks of those newly-born organizations or weak organizations. Weak organizations are often described as "paper" or "crippled" organizations, that are still in the way to better understand their purpose (Obs $\mathrm{Cn}$, 23/01/14)

Organizations also strive to position their long-term territorial visions as institutional references, in local or regional policies and development plans. The scales and scope of policy impacts vary according to local contexts and interests: Organizations report initiatives related to sustainable resource management and subregional sectorial policies. Community councils promote those visions guiding their life plans (Fg No, 16/01/14; Fg Sr, 27/01/14).

Expectedly, these schemes take organizations in the path of electoral politics and, indeed, the case has been given. Out of experience, organizations learnt that intrinsic party forces might easily overrun their own organizational coherence or, yet having won, isolate the elected cadre (Obs Mc, 14/01/14). Therefore organizations avoid getting involved in party disciplinary politics.

Of course, pressure to get involved is persistent. Organizations strive to perform, taking part in local rural councils (Obs No, 16/01/14), being 
accountable as representatives (Interview Ldr 002, 10/06/14) and playing a role as local links of extra-territorial partners (Fg Cn, 23/01/14). The visibility of these many roles often prompts local demands for their leaders to engage in electoral politics (Interview Ldr 001, 13/01/14).

Again, the case has taken place. At least one cocoa leader has engaged in politics, running to the senate for a national circumscription (Obs $\mathrm{Cn}$, 23/01/14). Yet, organizations draw boundaries by acknowledging the process (and any kind of support) as a matter of individual choice within the rights and duties of citizenship. Interestingly, the same token applies when organizations' members join rural strikes.

Of course, these boundaries are subject to subtle controversies. At this level, says the former candidate, boundaries are but self-imposed limits failing to realize a natural process of voicing farmers' demands (Interview LdrSM 001, 07/03/15). On the counterpart, organizations' sense of independence and commitment to its business-like identity make them feel that politics is too much of a risk to take.

\subsubsection{Other music, other dances: The making of support}

Organizations therefore look actively for sources of support as means of strengthening their capabilities and capacities. This is done, of course, responding to local circumstances, where collaborative means appear to be scattered and dispersed. Available support offered at the local level depends on context-specific conditions and circumstances triggering possible partners' interests. Various possible partners appear on organizations' radars.

Cocoa players are naturally a first option for organizations, by means of contract farming arrangements. National rural development programs enable these kinds of arrangements and are subject to conditions of "legality" (Fg Mc, 14/01/14). As it has been said, these programs favour the big players' market: Organizations receive working capital but have little room to manoeuvre and improve their crops to attend international markets (Fg Sr, 27/01/14).

Therefore, organizations look to create a diversified basket of support, setting up arrangements with smaller players: those having a regional reach or access to specialized cocoa niches (Obs Cn, 23/01/14). These 100 
arrangements allow organizations to access alternative purchasing funds and learn other productive technologies. Other state actors, International Organizations (IOs) or NGOs at the national level sometimes facilitate access to such arrangements through multi-party project platforms (Fg Sr, 27/01/14).

Naturally, organizations attempt to engage on long-term collaborative schemes with such actors, intermediating to bring other possible players to the table (e.g. the rural bank) and aiming at other possible development targets (e.g. funding, investment in complementary crops, scaling operations) (Interview Ldr 001, 13/01/14). Long-term engagement has an effect on human relations. Friendship with cadres often results in partnership opportunities as project officers change jobs: "They know local processes and trust organizations" (Fg Cn, 23/01/14).

Long-term arrangements create room for iterative processes. Organizations renegotiate conditions with partners, aiming to cast aside intermediary organizations and adjust monitoring systems to work with local-laden performance indicators ( $\mathrm{Fg} \mathrm{Cn}, 23 / 01 / 14)$. More interesting from a knowledge sustainability point of view, organizations manoeuvre to scale out and up the solutions they devise on each project (e.g. innovations for smallholders' access to credit, best practice toolkits). Capitalizing on acquired knowledge, however, is not possible with every partner. "There is some kind of knowledge waste, because every partner has their own recipe and they want to apply it" (Obs Mc, 14/01/14).

Besides actors in productive value chains, organizations mention other actors having an impact at the local level, such as oil enterprises or energy companies neighbouring agricultural practices. Organizations expect these actors to engage in constructive schemes at the local level, but it does not seem to be often the case. Organizations complain about these companies giving little information, allowing little room for deliberation or showing no interest in understanding the whole of the local basket ( $\mathrm{Fg} \mathrm{No \text {, }}$ 16/01/14).

Technical assistance via the national learning service varies. Organizations are very active in shaping their means, both in scope and content. Valorizing local talent often appears as a priority goal through prompting local talent to learn and perform afterwards within the organization (Fg Sr, 27/01/14), or, in an extended way, to staff local capabilities with human resources (Obs Cn, 23/01/14). These also link with 
the aim of creating tailor-made, long-term formation schemes for youngsters (Obs Mc, 14/01/14). In pursuit of these aims, organizations manoeuvre to maintain support and funding schemes (Obs Cn, 23/01/14).

Organizations also take care to harmonize technical assistance contents with their views on productive technologies and their actual priorities. For instance, organizations will manage to apply a focus on "soft" contents (Fg Mc, 14/01/14), devise pre-project preparation modules (Obs Cn, 23/01/14) or check the contents of the "hard" technological aspects. Organizations take good care to identify knowledge gaps and ask for support on these topics. Often they partner with authorities to create demonstrative farms, seedlings or cloned trials (Fg No, 16/01/14). Controversies might arise between organizations and training providers with different approaches (Fg Sr, 27/01/14).

\subsubsection{Community councils: Identities at stake}

It is worth highlighting here community councils' particular features. Let us remember community councils were created as a means to locally regulate afro-descendant collective land property, under Law 70. As such, Law 70 is understood as an afro-descendant quest since the late 1970s for visibility and autonomy. Councils make continuous reference to Law 70, using it as a mean of legitimacy. The role of the councils is, the leaders say, about "learning and knowing that policy by heart" (Interview Ldr 004, 16/06/14).

So it is not surprising that community councils' expectations about their roles actually stretch the law's intended reach: Councils strive to position themselves as public actors in charge of local public affairs. And to some extent, they actually are after having paved this long road. In effect, for a long period councils struggled to mark differences between official authorities and other sublocal structures, such as the communal boards (Interview Ldr 003, 16/06/14).

And yet, apparently there is not agreement on a common vision about their actual reach. Or perhaps, to do more justice to the actual situation, the actual role of the community councils bring about discussions about what, how and to what extent councils should manage public affairs. Naturally these discussions are flavoured with the kind of problems that 
might be easily attributable to the realm of public matters: public versus private interest, legitimacy and legal order.

The leaders often bring to the table (and give an opinion about) the challenges of balancing councils' various roles (e.g. managing collective land property versus performing as a local development agent) (Interview Ldr 004, 16/06/14; Fg Sr, 27/01/14); and the related question about the need of different legal personas for different purposes (e.g. creating cooperatives to deal with productive aspects). Some also mention the need of transparency mechanisms for the management of public resources, especially in terms of accountability to a community's assembly.

The fact that councils belong to the National Cocoa Network is itself telling about how these discussions get settled in the end. "Learning by doing" and "regulating the way to make it possible" styles tend to prevail (Interview Ldr 003, 16/06/14; Interview Ldr 004, 16/06/14).

As it might be expected, community councils also face pitfall risks on locallevel relations.

Those participating in the cocoa network endeavour to overrule forms of coercion exerted by armed groups, creatively engage in program design and territorial negotiations (Interview Ldr 004, 16/06/14). Needless to say this has had a cost in human lives. On the less conflicted side of operations, councils naturally bridge relations with other actors at the local and regional levels (Interview Ldr 003, 16/06/14).

In their case, however, tensions with municipalities are stronger. On one side, the institutional architecture of ethnic affairs requires community councils to be recognized by municipalities as a step of formal endorsement at the national level. On the other, given the fact that collective land is not subject to patrimonial laws (that is, not able to be seized by legal authorities), councils require municipal checks in order to get access to projects (Fg Sr, 27/01/14).

\subsubsection{Councils responses: Creating sustainable development businesses}

Again, councils' responses are similar to that of farmers' organizations. Councils set long-term life plans where they set route maps for local and 
regional authorities. To individual life plans, councils add policy documents with regional recommendations, issued by the council network and positioned at the department level (Interview Ldr 003, 16/06/14).

Councils' discourses covers broader ideas related to sustainable development. In this light, life plans are not only devices to keep their culture alive (Interview Ldr 004, 16/06/14), but also include views on how to manage the extended surrounding territory. Actual projects responding to these imperatives include environmental conservation (with a project of reduced emissions of mangrove and forest deforestation and degradationREDD), creating economic opportunities (based on local valorization, such as exotic fruits from their cultural basket) and securing private income and foreseeing management of "public" income coming from the carbon fund (Interview Ldr 003, 16/06/14). It is within this last specific context that cocoa enters a council's landscape, under very specific breeding conditions.

Expectedly, it is not surprising that councils strive to have a place and an opinion on decisions affecting communities and manoeuvres to be a permanent interlocutor of local and regional authorities. There is concern about verifying that every project has "the right format"- that is, complies with communities' views on the means and ends of development-and, in case of failure, block their execution and explain to the community their reasons and possible outcomes of the decision (Interview Ldr 003, 16/06/14).

On the more proactive side, councils also take a role. Councils ask for support and endeavour to align extra-territorial sources with local resources, appointing expert knowledge according to their goals (Interview Ldr 003, 16/06/14). This is the case, for example, of the special cocoa export platform. It is a multi-actor initiative, with the participation of an international NGO and a specialized niche business partner. It links locally to a purchasing network breeding origin cocoa while tackling subregional logistical challenges related to the geographic location of the producers (Interview Ldr 003, 16/06/14). As in the case of other organizations, councils also strive to manage resources autonomously and succeed: Through recent agreements, one community council will be able to operate municipal resources (Interview Ldr 003, 16/06/14). 


\subsection{Living on cocoa}

Before proceeding I remind the reader where we stand at this point. This chapter discusses fieldwork results. I have already discussed the longterm drivers of farmers' organizations. I have also discussed how organizations experience projects and the local realm. Now I will turn to the cocoa market, focusing on its features as a social construction, detailing how farmers' organizations express experiencing it.

\subsubsection{Cocoa}

Cocoa is not a single crop. There are multiple varieties known as "clones" because of the technologies used to breed them. Some of them are native and have grown spontaneously. It is likely there are still some cocoa treasures hidden, offering amazing origin cocoa flavours. Some other clones have been introduced that have usually been developed to respond to productivity or offer resistance to certain conditions.

The sector has accumulated some knowledge about the behaviour of native and foreign adapted clones. Clones are reproduced with seedlings. Control of cocoa breeding takes place by means of seedling certificates. Features of each clone have an impact in post-harvest management as well as in market access. Each clone has a specific set of qualities, making it more or less special, which means a chance to get better or worst paid.

Despite this accumulated knowledge, there is not a clear national approach. There are mixed clones in every region. Most of them have not been characterized (that is, there is no thorough analysis of the crop fields assessing installed varieties). Naturally, demands of the sectors' actors differ. Some stress the use of certified seedlings, while some focus on the use of special seedlings, even if they are not certified. There is not a common criteria or even a base for discussion about it (Obs Cn, 23/01/14). Lack of structure benefits the few big players who set a mainstream market based on low quality. Acquiescence of other links of the chain to this setup creates path dependence (Interview Ofc 004, 17/10/14).

From the view of organizations the sector is unstructured: The core aspect is that there is not a clear competitiveness policy for cocoa in Colombia. The landscape looks worst when compared particularly to Ecuador and 
Peru. Cocoa fields with mixed clones affect organizations, since it hinders the chances to obtain high-quality grains. Different clones require different fermentation lapses and produce different flavours. Consequences are telling: "We sent some samples to a customer"- told a leader-"we got 14 good quality chocolates, with 14 different flavours. How the hell are we going to be able to sell that?" (Fg Cn, 23/01/14).

Prices in the national market follow international trends. At the local level prices are also affected by middlemen's presence, varying from one region to another. Production is very sensitive to price because of the low yield smallholders actually earn.

In recent price drops some families abandoned cocoa fields. Abandonment is a plausible option: Leaving the field abandoned is actually cheaper than harvesting (Fg Ct, 20/01/14; Fg No, 16/01/14). These farmers looked for means in mining ( $\mathrm{Fg} \mathrm{No}, 16 / 01 / 14)$. It is also commonly known that construction jobs in cities bring comparable income options (Interview Ofc 004, 17/10/14).

Producers strategize with their crops, managing subsistence and income. Depending on markets and available crops on the farm, farmers opt to leave or intensify one product or the other (Interview Ofc 002, 05/02/14). Productive culture, or the "entrepreneurial identity" is yet another obstacle. "A more productive farm makes a more resilient farmer-says a project officer. Traditional farmers have difficulties getting used to being productive, even being aware of how the math works" (Interview Ofc 004, $17 / 10 / 14)$.

\subsubsection{Purchasing conditions}

Organizations strive for buying as much cocoa as possible at the best price possible. Organizations aim at maintaining increased yields for producers ( $\mathrm{Fg} \mathrm{Sr}, 27 / 01 / 14)$, even if part of the product goes to middlemen ( $\mathrm{Fg} \mathrm{Sr}$, 27/01/14). Funding purchasing is a constant concern of the organizations, so as to be able to back producers' trust, overrule middlemen prices and harmonize local price with outside trends (Interview Ldr 002, 10/06/14; Fg Ct, 20/01/14; Fg No, 16/01/14; Fg Sr, 27/01/14). Private partners and international organizations are often funding partners (Fg Cn, 23/01/14; $\mathrm{Fg} \mathrm{Sr}, 27 / 01 / 14)$. Yet, available funding is always limited (Fg Sr, 27/01/14). 
Space for manoeuvring is reduced. Some subregions are crowded by middlemen (Fg Ct, 20/01/14; Fg No, 16/01/14; Fg Sr, 27/01/14). Organizations recognize that, if educated, middlemen could play a valuable role (Fg Sr, 27/01/14). However, current middlemen practices block direct distribution and promote unclear-when not bluntly unfairrules of the game (Fg Ct, 20/01/14; Fg No, 16/01/14; Fg Sr, 27/01/14).

When a component of contract farming arrangements, purchase funding, limits organizations' flexibility to regulate local prices (Fg Ct, 20/01/14) organizations sometimes intermediate without profit, earning a small margin via savings in logistic costs of purchase and processing (Fg Sr, 27/01/14). From organizations' points of view, farmer yield is a priority: "that way you allow the farmer to earn what he deserves" (Fg $\mathrm{Sr}$, 27/01/14)

Infrequent situations might better illustrate the extent and limits of organizations' price regulation role in a depredatory regime: In 2014, after the rural strike, the government agreed to subsidize cocoa production. The subsidy would be transferred directly to producers' accounts on an invoice declared by the buyer. Middlemen or bigger producers saw an opportunity to capture the subsidy, bribing smallholders with a better purchasing price at the moment of the sale (Fg Ct, 20/01/14; Fg Sr, 27/01/14). Organizations' lack of purchase funds was an obstacle for them to take care of smallholders' interests (Fg Ct, 20/01/14).

It is worth mentioning the intermediary function is performed only for cocoa, in spite of the involvement of organizations promoting other products in the local basket. Other crops have a direct market, mainly because of their trade in the fresh market. Smallholders behave as harvesters in those other chains, taking their product to the open market when the season comes (Fg Mc, 14/01/14).

\subsubsection{The quest for specialized niches}

National mainstream market demands low quality cocoa, to be paid at low prices. Financing crop installation and purchase is part of the offerdemand arrangement of cocoa supply. "It used to be the setting with drug dealers, it is also the setting with middlemen and public programs" (Interview Ldr 003, 16/06/14). For organizations, any value added to the 
grain makes sense if it helps accessing specialized niches (Fg Sr, 27/01/14). In their view, higher quality equals higher yield for producers: "[We] must participate in value at every link of the chain to increase income. That's the only way" (Fg Sr, 27/01/14).

The national mainstream market creates a vicious loop for organizations, described bluntly in these terms: "You produce trash, you sell trash, and you get paid for trash" (Interview Ofc 004, 17/10/14; Fg Ct, 20/01/14; Fg Sr, 27/01/14). Organizations aim at moving away from the cycle, attempting to compromise as little as possible. "What we are doing is not for the national market. Big houses do not pay quality" (Fg Sr, 27/01/14).

Mainstream market indifference to quality is seen as an opportunity: "They do not expect us to sell good grain to them, so we can do our own businesses" (Fg Sr, 27/01/14). A low quality mainstream market gives organizations a chance to rely on a stable demand while striving to create a quality offer. "For the time being we stick to the agreement; it is what we have" (Fg Sr, 27/01/14).

The national network takes on building and showing quality culture hand in hand with other partners. Quality promotion includes first-hand understandings of world-class quality standards and practices (Am, 14/11/14), promoting quality, through participating in international contests, creating a national contest (held every year since 2013), setting and rewarding best practices (niche-quality production, commitment to networking, strategic use of social media, social impact, women leadership, generational change) (Interview $\mathrm{Cmr}$ 001, 16/06/14; Amb, 14/02/14), promoting willingness to accept external investment, brokering export opportunities and devising support schemes (Interview Ofc 004, 17/10/14; Asc, 07/07/14).

Organizations strive to access other markets and manoeuvre to attain a better position in the value chain: "There's still plenty of leaves to cut from cocoa trees," (Interview Ldr 003, 16/06/14). Organizations take on niche certifications, such as Fairtrade (Fg Sr, 27/01/14), Organic (Interview Tm 002, 16/01/14; Fg No, 16/01/14) and Rain Forest Alliance (Fg Mc, 14/01/14). Others devise ways to develop "institutional markets" (selling to schools, hospitals, wellbeing family centres) (Fg Sr, 27/01/14) or create a diversified client basket to cut off dependence (Fg Cn, 23/01/14). Four of them currently transform cocoa into various forms of chocolate (Amb, 
14/02/14). This path, however, has its flaws. Bigger companies have attempted to apply exclusive conditions on farmers' organizations, taking advantage of their reputation (Fg Mc, 14/01/14).

Organizations build high-quality cocoa offer on its expectations. There is actually a national capacity gap in which critical processes that allow developing a stable offer are still underdeveloped (e.g. standardized postharvest processes). Human resources with such capabilities are needed to break through the bottle-neck (Interview Ofc 004, 17/10/14). Some organizations create incentives, such as linking purchase prices to quality, increasing yield for better quality and teaching producers how to earn it (Fg Mc, 14/01/14; Fg Sr, 27/01/14). Others negotiate support for improving technical capabilities as part of supply negotiations with niche-focused companies (Interview Ldr 004, 16/06/14; Fg Cn, 23/01/14; Obs Pn, 19/03/15).

Organizations deploy halfway solutions in order to cope with standards while dealing with the capability gap. Strategies include scaling-down, that is, delegating processes to smaller units (such as smaller organizations or champion farmers) (Fg Ct, 20/01/14); networking to gather volume, purchase cocoa, store grain or negotiate price and delivery points (Amb, 14/02/14; Fg Mc, 14/01/14; Fg Sr, 27/01/14); peer training (Fg $\mathrm{Ct}, 20 / 01 / 14)$; gathering and circulating market information (Fg Ct, 20/01/14); and assessing funding opportunities from possible investors or partners (Interview Ldr 002, 10/06/14; Fg Mc, 14/01/14).

There are also strategies at the network level (Interview Ofc 002, 05/02/14). In late 2014 the network created a legal structure. The legal criteria to decide on related to inclusiveness, legal capacity to engage in partnerships, capacity to receive support, feasibility of capitalizing on existing network structures and the capacity to buy and sell cocoa (Asc, 07/07/14). Quality development support at the network level foresees creating intermediate steps towards standards (Interview Ofc 004, 17/10/14). 


\subsection{Summing up: The short-term drivers}

So far, this chapter has shown various features of the roles and the contexts in which organizations exist. Overall, the section sheds light on the contexts and priorities - and the nature of the commitment-these organizations show towards handling their business in institutionally deprived regions. Various threads have been discussed in length to increasingly add texture and achieve a deeper understanding of the phenomenon at hand. It is clear these organizations strive to be a vehicle of change, and increasingly demand autonomy on that quest.

To close the chapter, this section will discuss immediate drivers of farmers' organizations: those aspects that appear to be directly under their scope of interest. As such, the section wraps up some aspects already mentioned, pointing to the more practical immediate goals organizations are tackling. Overall, one can see a consistent effort of building social orders connected to the more abstract values with which this discussion began. Here again I bring forward farmers' voices, as a way to flavour the picture for Spanish proficient readers.

\subsubsection{Create income opportunities, finding (a favourable) market position}

A reiterative remark on the conversations states that adoption of cocoa as an alternative crop entails the adoption of a market-oriented culture. Not solely on attention to productive and market specificities of the crop, but because its breeding supposes assuming (and enacting) market rationales. The role of "rural entrepreneurs" replaces the label of "harvesters." This aim is understood as a profound change, affecting peasant identity ${ }^{37}$ (Interview Ldr 002, 10/06/14).

Connected with this aim comes that of finding favourable market positions in response to conditions of local markets. As previously mentioned, intermediation often pays ill service to smallholders. Overcoming disadvantageous intermediation mechanisms appears therefore as a reiterative driver. Manoeuvres in this realm illustrate a double effect.

\footnotetext{
37 "Si esto lo vemos como una empresa, si dejamos de ser cosecheros, como decimos, y nos volvemos productores, la cosa cambia. Si esto es producción de cacao y yo sé que en cinco Has. me permite vivir holgadamente, entonces ahí está el cambio. El cambio debe ser total y fundamental. Digamos que aquí sí sembraban. Los que estaban en el campo sembraban maíz, cacao, café, algunas vacas, pero de ahí no pasaba. El tema ahora es pro-duc-ti-vo."
} 
On one hand, this search triggers a role of farmers' organizations as local market regulators. The aim of setting a minimum local price implies the priority of market regulation over that of profitability ${ }^{38}$ (Obs Ct, 20/01/14). Observations have shown that the reach of this role varies from one case to the other, depending on variables such as the maturity and size of the organization or the heft of cocoa in the local basket. As an operative rationale, however, regulating cocoa's local price is a common priority.

On the other hand, this search entails devising coping mechanisms to counteract market disadvantage ${ }^{39}$ (Fg Ct, 20/01/14). Peer networking works as a reiterative strategy. It is due, in some cases, to actual settings in which the organizations were created (Interview Ldr 002, 10/06/14; Fg Cn, 23/01/14; Fg Mc, 14/01/14), from working as a tool to overcome logistic challenges (Interview Ldr 004, 16/06/14; Fg No, 16/01/14; Obs Sr, 27/01/14) or from obtaining access to development resources (Interview Ldr 001, 13/01/14; Interview Ofc 001, 05/02/14; Interview Ldr 002, $10 / 06 / 14)$. This means that features of the networking strategy adapt to its specific contexts.

It is worth remembering here that the same rationale applies in the case of the National Cocoa Network, perceived as a natural result for organizations to play a role in the sectorial realm ${ }^{40}$ (Fg Ct, 20/01/14). In the eyes of organizations it is clear that in order to counteract policy and market effects of Colombia's cocoa oligopoly, smallholders need a shared platform.

\footnotetext{
38 “...y sin embargo sirve porque usted controla los precios. Así sean cien pesos mas usted controla los precios.

- $\mathrm{Si}$, siempre ha servido.

Ahí sirve usted como de regulador."

39 “A mi lo que me motivó de este cuento de la asociación es que yo veía que allá me iba a vender un kilo de cacao y me pagaban y me lo pagaban como querían. Llegaban lo colocaban en la báscula y lleva 50 kilos, casi el bulto a 55 kilos, y era lo que decían ellos, entonces un día me tocaron el tema que sería bueno que la asociación, que existía hace 5 años ya, 6 años; pero no había habido la motivación un fondo de comercialización y ahí yo fui e investigue y si que estaba la plata, entonces yo dije qué hay que hacer para sacar esa plata, para comenzar a comprar el cacao y pagarle bien a la gente?... Y si, se hizo, se buscó, se hicieron las cosas y se desembolsó esa plata, y la tenemos trabajando ahorita."

40 "Hoy las asociaciones cacaoteras han entendido que solas no pueden. Si los agricultores en un momento entendieron que no se podía solos, que debían asociarse, hoy en día las asociaciones han entendido que al sector cacaotero es mejor manejarlo desde el punto de vista global, ó sea hay que entender que hay situaciones que no puede manejar cada uno."
} 
Clearly farmers' organizations play a role de facto in stabilizing conflictive territories. They not just mediate to make possible implementing a new practice and delivering services ${ }^{41}(\mathrm{Amb}, 14 / 02 / 14)$, but also create a path for other institutions to be able to deliver services (e.g. the bank, technical assistance, the state) ${ }^{42}$ (Fg Sr, 27/01/14).

"Playing a role" as a driver refers to obtaining effective recognition of this role by third parties. This is, in other words, positioning their identity as a channel between farmers and any other actor beyond the local universe $^{43}$ (Interview Ldr 004, 16/06/14; Fg Ct, 20/01/14). ${ }^{44}$. Building on this reputation, organizations expect to strengthen their likelihood to be partners of public and private institutions for processes affecting the local realm (Obs No, 16/01/14). This, of course, has effects on autonomy. Farmers' organizations aim at collaborative arrangements in which this condition is expressed in (increased) independence for resource prioritizing and management.

An underlining layer of this concern naturally responds to volatility of local (political) institutions. Farmers' organizations explain that there is a permanent tension on collaborative agreements with authorities at various levels. Party interests or corrupted practices conflict with a de facto condition of "previous approvals" or "collaborative" work ${ }^{45}$ (Fg Sr, 27/01/14).

\footnotetext{
41 "Hoy las cuarenta organizaciones al menos están ejecutando un convenio o un contrato, ninguna organización de la red ha cerrado el chuzo o el letrero, han cambiado gerentes, aciertos y desaciertos pero hoy esas cuarenta estamos vigentes y eso demuestra la capacidad de gestión ... y de hecho si uno sumase hoy todos los contratos ... estamos operando un gran porcentaje para el sector cacaotero."

42 "Yo creo que todo parte de raíz por la apertura de espacio. Esa es la visión que yo tengo. Cuando llegué, digamos, allá donde nosotros, en el 2006, ni el banco prestaba un peso, ni había ningún [Servicio capacitación técnica], ni había nadie. Era una zona totalmente desprotegida pues, del Estado." 43 "Entonces el Sr. Gobernador, que es el del municipio, él no va a llegar allá al territorio en donde estamos nosotros. Entonces él debería trabajar de la mano con nosotros, y trabajaría mucho mejor. Lo haría él como gobernador y el alcalde de Tumaco. Entonces nosotros seríamos como una segunda alcaldía. Lo que él no puede hacer, lo que él no se da cuenta, nosotros sí, y seríamos nosotros los voceros de él. Entonces trabajaríamos mucho mejor, haríamos con poca plata, muchas cosas. Pero esas cosas no se manejan...."

44 "Y hay agricultores que tienen mucho más conocimiento que uno pero lo que pasa es que no les damos el espacio para que se sienten aquí y trabajen, entonces esa gente siente que el Estado y las regiones los valoran y la diferencia está ahí, en empezar a hacer trabajo social, hablar con la gente, la gente es consciente. Yo sí creo que el Estado debe considerar esa condición de que la asociación no solamente es un representante de los agricultores sino que también es la representante del Estado ante esos productores."

45 "Yo lo que quiero decir es que las organizaciones no pueden ser políticas y es decir hoy APROCASUR le está haciendo campaña a Luis Pérez del partido equis, porque si el partido equis no
} 
As mentioned, organizations have deployed various strategies to cope with these kinds of situations. Some include direct political engagement (with negative results for isolation of elected cadres or capture by patron-client party practices) (Obs Mc, 14/01/14), supporting organizations' allies as a form of "indirect" political engagement (Interview Ldr 004, 16/06/14; Obs Mc, 14/01/14), implementing pre-electoral sectorial fora with candidates (Obs Cn, 23/01/14), and last, obstructing projects implemented without previous consultations or limited local participation (Interview Ldr 004, 16/06/14).

\subsubsection{Building local capabilities}

A last driver of farmers' organizations refers to their interest in strengthening capabilities and securing the use of the local workforce ${ }^{46}$ (Fg Cn, 23/01/14). To this extent, organizations manoeuvre to provide training services directly, or intermediate with various actors (state, international organizations, non-governmental, sectorial). Various rationales connect to this driver, which are described next.

\subsubsection{Staffing the local level with local talent}

The first rationale refers to the aim of capitalizing local human resources to the maximum extent possible ${ }^{47}$ (Fg Cn, 23/01/14; Fg Sr, 27/01/14).

\footnotetext{
pasa y ganaron los zeta esos zeta las van a acabar. Entonces las organizaciones como organizaciones tienen que estar al margen, pero el otro punto es que las organizaciones tienen que trabajar con la institucionalidad, con las alcaldías, gobernaciones, ministerios.

¿Y eso cómo lo hacen?

Nuestra organización ha ejecutado varios proyectos de los cuales ha solicitado cofinanciación del departamento y la alcaldía, nunca así tenga una reunión se les invita, nunca dan el aporte que tienen que dar, tenemos que suplirlo nosotros de alguna u otra forma y ellos se hacen los de la vista gorda.

Casi siempre no aportan económicamente sino a través de la UMATA que mandan algunos técnicos que orienten, que al final no son técnicos.

- ¿Cómo hacen ustedes para suplir eso?

A veces nuestros hijos han estudiado una carrera técnica y uno los orienta por ahí y si necesitamos al técnico ahí lo tenemos, de pronto al agrónomo y ahí nos apoyamos en él. Nosotros nos auto apoyamos en la organización para sacar adelante nuestro cultivo, no apoyamos nosotros mismos o apoyamos a un profesional con nuestros propios recursos."

46 "Nosotros como campesinos y representantes no podemos quedarnos atrás del mundo, debemos ir a la par con ellos y estos espacios nos permiten eso, pero tenemos que mirar, si no podemos proveernos nosotros mismos de las herramientas, nos podemos proveer de los conocimientos pero no de las herramientas como tal, pues a ver quién nos las puede suministrar y hay las formas así que debemos empezar a articular quién nos puede ayudar."

47 "Se contrataron unos técnicos, no todos, algunos sí sabían de cacao, otros se formaban en cacao, otros se basaron del internet, pero algo se hizo. Entonces dijimos, "Bueno carajo, ¿y entonces qué?
} 
There is an interest in creating a human resource base for incipient institutions. Local talent has here an extended meaning and also includes outsiders willing to contribute ${ }^{48}$ (Interview Ldr 003, 16/06/14).

This aim appears frequently with the intention of staffing the local level through national technical assistance programs (Interview Ldr 003, 16/06/14; Fg Sr, 27/01/14). At least in one case the head of an organization was also appointed as a trainer (Obs $\mathrm{Cn}, 23 / 01 / 14)$. In various cases the organizations absorbed technical experts coming from external projects. These cadres play a role formulating and implementing more complex projects under the name and guidance of the organizations (Interview Ldr 002, 10/06/14; Obs Mc, 14/01/14).

\subsubsection{Implement educative formulas}

Various initiatives refer to educating youngsters (Amb, 14/02/14; Obs Cn, 23/01/14; Fg No, 16/01/14). Some of them are implemented in collaborative settings with schools. Others are a result of specific training demands on national public services. Consistent with other drivers, outstands an initiative of long-term education aiming to educate rural leaders (Obs $\mathrm{Mc}$, 14/01/14).

There are also initiatives for adult education. Peer-to-peer exchange via organizations is practiced as a way to access experience-based knowledge (Amb, 14/02/14). Practice is also strengthened by incentivizing productive pilots exploring income opportunities (Fg Mc, 14/01/14).

\subsubsection{Coproduce relevant knowledge}

Unsurprisingly, farmers' organizations also take part in rural innovation initiatives. These organizations manoeuvre to create research-intensive solutions. Some of them are explorative, such as cocoa trials (Fg Cn, 23/01/14), or valorization of traditional products (Interview Ldr 004,

¿Nosotros qué somos entonces?” Cuando que todos los recursos, todos, todos, deberían quedarse en la zona. Que hay uno que suministre insumos, que hay uno que suministre información y bueno, de todo." 48 "De igual manera en el material humano, hoy lo que nosotros necesitamos como decir, vertical. Aquí en el Pacífico necesitamos 60 ingenieros agroforestales y aspiramos, para el 2020, tener esos 60 ingenieros agroforestales bien capacitados para poder pensar en lo que es ya los proyectos propios...

-De la comunidad.

La misma región de la gente. No importa que sea indio, que sea blanco, quien venga al territorio, pero a lo que le apuntamos es a fortalecer el territorio. A eso nosotros le colocamos el valor agregado. Porque ya tenemos claro que si capacitamos el material humano, vamos a ser mejor." 
16/06/14). Some of them imply various realms of collaboration with universities, research centres or private enterprises. These focus on biological material accounts aiming for competitive clones (Obs Mc, 14/01/14), experimentation with new biological materials (Interview Ldr $002,10 / 06 / 14)$ or post-harvest experimentation aiming to access niche markets (Fg Cn, 23/01/14), respectively. The impact of these innovations has often exceeded the local realm. These mentioned collaborative settings have achieved subregional (Interview Ldr 002, 10/06/14) and regional impact (Fonseca Rodríguez, Arraut Camargo, Contreras Pedraza, Correa Cantillo, Castellanos Domínguez, Universidad Nacional De Colombia, \& Universidad Tecnológica De Bolívar, 2011).

\subsubsection{Use projects as schools}

Another aspect worth mentioning refers to the function of rural development projects providing educative experiences. Here I am not referring to the aims of projects themselves, discussed earlier in various threads. I am referring to learning processes taking place along its implementation. Projects embed forms of knowledge appreciated as valuable by these organizations, such as accountancy and legal aspects of boundary relations. In this sense, projects "enact" institutions of the outer world. Dealing with projects is seen as a form of training ${ }^{49}$ (Fg Sr, 27/01/14).

Farmers' organizations' short-term drivers somehow resemble the longterm drivers, as tangible means expressing values and deeply rooted concerns. Further, short-term drivers express a stance in the face of organizations' immediate surroundings and circumstances. Table 4 sums up the short-term drivers:

\footnotetext{
49 “ - - ¿ ¿eso cómo lo hacen? Como por medio de escuelas, reuniones, capacitaciones...

- Como lo que estamos haciendo hoy aquí. Uno llega, a la organización de uno. Tiene su reunión trimestral o semestral, o cada mes, y uno les replica, "vea se habló de esto, y esto, y esto" y se les explica, y ellos empiezan a acatar las cosas que se está haciendo. $\mathrm{Y}$ eso ha sido muy bueno porque el agricultor se ha formado, y uno como líder también se ha formado mucho. En cuanto a recursos, para nosotros ha sido fundamental [proyecto], porque eso nos va a dejar a nosotros formados. Con [proyecto], si usted no sabe trabajar, es muy bueno pero si usted no sabe trabajar también es bien malo, porque eso le cierra las puertas también. Un [proyecto] mal ejecutado, cierra las puertas, un [proyecto] bien ejecutado, te abre caminos.

-Entonces ahí es como si el programa fuera una escuela. Entrar implica aprender...

- Sí, porque ahí se forma un gerente, se lo forma en la parte socio-empresarial; se forma al campesino, se lo forma en la parte técnica. Esto es una escuela si se le sabe aprovechar obviamente, y los recursos sí se van dando."
} 
Table 4. Farmers' organizations' short-term drivers

\begin{tabular}{|c|c|c|}
\hline Drivers & Aspects & Features \\
\hline \multirow{2}{*}{$\begin{array}{l}\text { Create income } \\
\text { opportunities finding } \\
\text { a favourable market } \\
\text { position. }\end{array}$} & Regulate local market & $\begin{array}{l}\text { Prioritizing smallholder } \\
\text { benefits via price }\end{array}$ \\
\hline & $\begin{array}{l}\text { Counteract market } \\
\text { disadvantage }\end{array}$ & $\begin{array}{l}\text { Finding a more profitable } \\
\text { niche }\end{array}$ \\
\hline $\begin{array}{l}\text { Play a role in local } \\
\text { development }\end{array}$ & $\begin{array}{l}\text { Be recognized for playing a } \\
\text { role }\end{array}$ & $\begin{array}{l}\text { Achieving capacity and } \\
\text { legitimacy vis-à-vis } \\
\text { external actors. }\end{array}$ \\
\hline \multirow{4}{*}{$\begin{array}{l}\text { Build local } \\
\text { capabilities }\end{array}$} & Staff the local realm & Securing local potential \\
\hline & $\begin{array}{l}\text { Implement educative } \\
\text { formulas }\end{array}$ & $\begin{array}{l}\text { Securing long-term local } \\
\text { ownership and } \\
\text { opportunities }\end{array}$ \\
\hline & $\begin{array}{l}\text { Coproduce relevant } \\
\text { knowledge }\end{array}$ & $\begin{array}{l}\text { Understanding local } \\
\text { assets and fitting } \\
\text { technologies }\end{array}$ \\
\hline & Use projects as schools & Training local resources \\
\hline
\end{tabular}

With this section I finish the discussion of fieldwork results. I discussed the core and long-term, and short-term drivers of farmers' organizations. I also discussed how organizations experience projects, the local realm and cocoa market. In the next chapter I will turn to discussing results, focusing on finding the strategies of farmers' organizations as change agents. 


\section{Discussion: Growing fields, Harvesting strategies}


The previous chapter discussed fieldwork results. I introduced voices from the field, describing reiterative topics around dealing with other actors while attempting to cope with challenging surroundings and bringing change about. Overall, the section gives detail about the interests, dreams and aims driving organizations' efforts, as well as the various games they play in order to achieve them. The result shows organizations dealing with a rather complex, volatile setup in which they strive to survive by deploying responses of every kind.

In this chapter I will discuss these results. The first aim of the chapter is to present a comprehensive canvas of farmers' organizations' strategies as change agents. It is worth remembering strategies are here understood as the ways in which organizations cope with everyday situations. Strategies are here gestures rather than plans. As seen in the previous chapter, these situations take place on many possible fields. The first section of the chapter aims at clarifying and summarizing the strategies observed in these fields.

I will also read strategies in a transversal form, aiming at unveiling relevant patterns recurring on meso-level relations of farmers' organizations. This approach aims at pointing at the deeper layers of meso-level existence and interaction that are the root of social change. The second section of the chapter analyses strategies from the point of view of knowledge stances.

Before proceeding, I will discuss in more detail the guiding concepts of the analysis.

\subsection{Towards a typology of farmers' organizations' strategies: Guiding concepts}

Following the rationale of this research, the analysis supposes a twofold analytical exercise. On one side, it entails an abductive synthesis: Tentative conceptual notions, presented in Chapter 2, are refined by means of empirical results. On the other, empirical results are read in the light of these concepts. But there is still another aspect worth deepening. In order to carry out the analysis I worked on a typological way of thinking. This approach followed the purpose of "isolating" strategies in 
order to analyse them. Before proceeding, I will discuss this aspect in more detail.

According to Weber (1949, p.90) an ideal type is formed "by the one-sided accentuation of one or more points of view and by the synthesis of a great many diffuse, discrete, more or less present and occasionally absent concrete individual phenomena which are arranged according to those one-sidedly emphasized viewpoints to a unified analytical construct." This section typifies farmers' organizations' strategies, as a way to isolate them and put them under a lens. Let us remember that strategies are here adaptive forms of practical coping (Chia \& Holt, 2006).

According to George and Bennett (2005, p.235), a typological theory "provides hypotheses on how (variables) operate individually, but also contingent generalizations on how and under what conditions they behave in specified conjunctions or configurations to produce other effects." This analysis clusters individual types according to resembling features and contingent generalizations. As mentioned, fields and conceptual references act as guiding references for each building block. This iterative/creative exercise creates the means of the analysis, making it possible to deepen, contrast and filter results.

The results are threefold. The first component is theoretical, adding detail to the tentative conceptual approach. In order to make it easier for the reader, core aspects of these results were discussed in Chapter 2, specifically adding to definitions of knowledge stances. Towards the end of the chapter I will turn back to the theoretical realm, showing further theoretical insights achieved along the inquiry.

The second component allows discussing a more nuanced reading of organizations' strategies, anchored in the fields in which farmers' organizations play their games. These typological configurations illustrate organizations' forms of adaptation linking to broader meso-level patterns, conditions and situations.

The third component discusses a transversal reading of organizations' strategies, in light of the conceptual approach. Strategy types are categorized according to knowledge stances. The discussion informs a broader understanding of farmers' organizations' strategies as actors, while deepening the understanding of knowledge stances. This canvas 
allows a grounded reflection on practice, institutions and boundaries and sets the base for the last chapter of the book, a filtering exercise.

Aiming at giving the reader some clarity, I have concealed various steps of the analytical process, while increasingly added detail at every step of the discussion. The section will unfold various parallel threads, adding to core analytical layers. I hope I have succeeded in providing a balance, making it possible for the reader to go along the discussion while having timely guiding references.

\subsection{A single actor, multiple fields}

This research departed with the assumption-and little scholar evidence-that farmers' organizations' strategies take place in various fields. That assumption was verified empirically. Fields were found as distinguishable spaces in which meso-level agency takes place, demarcated from others by means of their inherent rationales and involved actors, that is, their driving interests, specific relational protocols, practical knowledge and powering strategies. The multi-sited case explored five fields, soon to be discussed in tandem with organizations' strategies.

Before proceeding, it is worth highlighting some tenets shaping this section of the analysis. The first is theoretical and brings me back to the notion of strategy as the core pivoting concept of this research. As previously introduced, a strategy is defined here as an adaptive form of practical coping (Chia \& Holt, 2006). This definition lays various foundations. The first describes farmers' organizations' rationality. In effect, understood as adaptive forms of practical coping, strategies also involve the contexts to which strategies react and act upon.

This idea links theoretically to various streams, already discussed in Chapter 2. I will very quickly go through them again to clarify the point. Chia \& Holt's (2006) definition of strategies as "adaptive forms of practical coping" builds on various sources. They build on the practice turn, as earlier discussed. Moreover, they brought about the notion of immanence (Heidegger, 1967) to stress those features linking to a world that presents itself as "'ready-at-hand." 
These ideas connect also to some basic assumptions within systemic thought, building on the metaphor of organizations as open systems. First developed theoretically by von Bertalanffy (1969) from a biological standpoint, later circulated in various disciplines, including organizational theory (Morgan, 2006) and cognitive studies (Maturana \& Varela, 1990; Varela, 2000), systemic thought not only embraces the view of the world as ready-at-hand, but describes its construction as an intersubjective, enacted and incarnated process.

This translates to the case as an epistemic assumption. Given the fact that farmers' organizations' strategies engage creatively into given contexts, those contexts' rationales, protocols, languages, institutional configurations, etc., shape to some extent organizations' agency. Therefore this tenet sets a first reference frame for this exercise: Plausible typological configurations pivot around fields as reference backdrops.

The second tenet is methodological. It is worth remembering that the empirical approach of this research was based on a multi-sited case. Rationale of this choice aimed at identifying organizations' strategies within a rather extensive set of subjects, 39 organizations. Thus analysis filtered crosscutting features, rather than deepened on single cases.

This typological configuration will draw on this set with a specific approach, finding patterns making it possible to describe the fields setting organizations' contexts. These fields will be discussed distinctively. For each of them I will aggregate organizations' strategies responding to it. In effect, each field captures a possible dimension of organizations. Demarcation of each field allows a better glimpse of organizations' multiple identities as social devices for rural governance.

Five fields where found to be part of famers' organizations' strategies. I brought about comical names for them so as to stress their qualities and make it easier for the reader to follow the exposition: The Making of Cocoa's Marketplace, Grassroots' Organizations Rule!, Projects in the Making, Cocoa's Ring and Keep it Local.

As might be expected in a typological approach, there is not any existing organization describing a complete adaptation to respond to any of these fields. Organizations rather evidence tones or combinations of their various aspects, arguably as a result of endogenous factors (e.g. cultural aspects, local history, features of local institutions). Notwithstanding, the 
discussion will return to existing features of the various organizations and refer to empirical evidence feeding each profile.

The exposition follows a specific order, set for the convenience of the reader. I will discuss the ways in which each field shapes agency, highlighting its overarching rationales and features. I will then discuss its contents and the strategies deployed by organizations. I will discuss phenomena making use of the conceptual approach, by reflecting on strategies in terms of knowledge stances. I expect this will help the reader to familiarize with this set of notions. This section presents, overall, a comprehensive summary of results.

\subsubsection{The making of cocoa's marketplace}

This section discusses cocoa's market as a field, while detailing the strategies farmers' organizations deploy both to cope with it and develop it. Table 5 summarizes the section, including the set of strategies attributable to this field.

The most salient feature of this field is calculative agency on markets (Callon, 1998). Rationales about this field involve understanding the markets, defining suitable positions and striving to access them. Finding a better position refers to a twofold aim. The first relates to building linkages within the chain itself, striving to play a role.

Going through the lines of the multi-sited case one can see this field is also about building suitable markets for smallholder farmers, or actually, allowing a market to actually set in motion cocoa productive practice itself. It is worth noting that in the context of volatile conditions, setting in motion cocoa productive practice might account for mimicking other actors' functions, as shown in the case of under-the-table arrangements for the organization to perform in place of a cocoa buyer (Fg Sr, 27/01/14).

There is more to it. Organizations' self-assigned role as market regulators (Fg Ct, 20/01/14; Fg Sr, 27/01/14) also shows a distinctive way of going about the market at the local level. Farmers' organizations do behave as firms in the field, but not as any firms would do.

Here we can see a distinctive form of practice work, in which organizations use price as a means to change an unsatisfactory local state of affairs, usually vis-à-vis cocoa middlemen. Organizations try and break 
the market situation via price incentives: Price stabilizes context conditions by altering exchange situations with other agents, thus granting a better outcome for smallholders. Setting a price is here a means to affect boundary conditions.

Organizations' fight goes beyond the local level. A lot has been said in this book about farmers' organizations' interest in bypassing the structural conditions of the Colombian cocoa market (Interview Tm 001, 16/01/14; Asc, 07/07/14; Fg Ct, 20/01/14; Fg Sr, 27/01/14). Getting to know the market implies increasing sensitiveness and understanding of its driving incentives-products, agents, niches, price-and making sense of the positions in which organizations are placed in this universe.

Organizations strive to identify a specialized niche and step into and play a role within a value chain. Use of the plural "markets" highlights the fact that games on the field take place at various levels through various channels. Rather than an intellectual process, market understanding appears to organizations as a matter of experience of criteria, protocols and drivers of the many intervening parties and as a learning-by-doing process of calculative iteration.

Organizations set productive standards and best practices in the pursuit of a specific vision of market access, aiming at developing practice in a specific direction (Fg Mc, 14/01/14; Obs Pn, 19/03/15; Fg Sr, 27/01/14). A form of practice work, normalizing aims to steer the practice field in a specific direction making use of regulations. In this case, recurring to process and outcome standards affecting the productive cycle.

Expectedly, practice regulations are usually based on specific forms of knowledge. Organizations carry out research and development (both as an independent endeavour, or collaboratively) in order to identify biologic materials and establish post-harvest procedures (Obs Cn, 23/01/14; Obs Mc, 14/01/14; Obs No, 16/01/14). By all means this is their most important asset. Here organizations are deploying knowledge exploration in the attempt of deepening their field of practice.

Another way of strategizing turns to collaboration. It is clear farmers' organizations exhibit many forms of collaboration, or to use my own terms, forms of boundary exploration. To deal with market situations, organizations partner up to share assets. Physical assets include logistical solutions, distribution channels and storage infrastructure (Am, 14/11/14; Fg Ct, 20/01/14; Fg No, 16/01/14; Obs Pn, 19/03/15). 
Organizations also share intangible assets, such as information about market conditions and support opportunities, peer-to-peer technical and non-technical training and advising (Asc, 07/07/14; Fg Cn, 23/01/14; Obs Pn, 19/03/15). These can also be seen as forms of knowledge supply, and will be detailed later.

There are other modes of collaboration showing shared operations. These illustrate forms of boundary expansion. It is the case with the various subregional clusters of organizations (Obs No, 16/01/14; Obs Pn, 19/03/15; Obs Sr, 27/01/14). Unlike the former, where boundaries are kept except to take better advantage of specific assets, shared operations blur boundaries between organizations.

There is here an effect on the expansion of the practice field, in terms of the reallocation of functions (that is, the creation of scaled autonomies) as well as the shaping of the practice field itself (that is, having possible effects on actors' situations, the development of the knowledge base and the scaling of standards within the practice field).

This changes knowledge supply. In effect, under these conditions knowledge, human resources and productive processes might be reallocated, by means of in-house sourcing (Obs Mc, 14/01/14; Fg Sr, 27/01/14), delegation (Interview Ofc 003, 05/02/14; Obs Mc, 14/01/14) or shuffling of functions (Fg Sr, 27/01/14).

But there is something more to it. Boundary exploration also appears as a means to operate shared positions. Whether within or outside collaborative stages-for example, collecting cocoa grain-organizations also strive to coordinate positions allowing them to negotiate prices with big buyers (Fg Ct, 20/01/14; Fg Sr, 27/01/14).

Another form of collaboration refers to partnering with third parties within the value chain. Partnering might lead to forms of practice work such as devising support schemes (for example, for post-harvest training) (Fg Cn, 23/01/14; Obs Pn, 19/03/15), creating funding opportunities (Interview Cmr 001, 16/06/14) and allocating resources incrementally (Asc, 07/07/14).

Increasing revenues is also a significant goal for organizations. Revenues are the means to create social benefits by allocating fair prices to producers as much as possible. 
Aiming at expanding its productive base, organizations also create investment schemes (Asc, 07/07/14; Obs Pn, 19/03/15). Investment schemes create opportunities for collaboration with other actors in the market, as a form of deepening practice. Of course, intermediation entails various others strategies. On one hand organizations deploy some boundary provisions, assessing risk of partnerships and keeping gates, usually attempting avoiding local disruption (Obs Mc, 14/01/14; Obs Pn, 19/03/15). On the other hand, intermediation might be also place for knowledge translation and mediation with organizations' knowledge base. This is the case, for example, when organizations adjust local capacities prior to projects (Obs Sr, 27/01/14) or agree to adjust post-harvest protocols (Fg Cn, 23/01/14; Obs Pn, 19/03/15).

Positioning in the value chain also entails organizations' investment in other links of the chain. Some organizations process cocoa for third parties (Fg Sr, 27/01/14), some invest in champion farmers to process and strengthen local markets (Fg Mc, 14/01/14), while some others attempt to develop their own brand to access the direct consumer market (Obs Pn, 19/03/15). All of these are forms of exploration outside of their basic environment and attempt to secure a role on the more sophisticated ends of the value chain.

This links to another aim, related to securing farmers' assets outside of the cocoa value chain. This purpose develops a diversification strategy, by means of which organizations attempt to include other products in the productive basket so as not to depend on a single alternative. These products might aim at securing food consumption or stand as complementary income sources. In this case, organizations explore aiming at expanding their field.

Table 5 summarizes strategies deployed by organizations in this field. Strategies appear clustered in categories. I am aware that to this point I have not yet given detail to the reader about these categories. I have preferred to follow this order to allow the reader to get used to the terms and make sense of them. In the next chapter I will turn back to these topics at length. 


\section{Table 5. Summary of farmers' organizations' strategies: Cocoa's marketplace field}

\begin{tabular}{|c|c|c|}
\hline Strategies & Category & $\begin{array}{c}\text { Knowledge } \\
\text { stance }\end{array}$ \\
\hline Negotiate to exist and play a role & \multirow{3}{*}{$\begin{array}{l}\text { Boundary } \\
\text { situating }\end{array}$} & \multirow{6}{*}{$\begin{array}{l}\text { Boundary } \\
\text { setting }\end{array}$} \\
\hline Assess risk of partnerships and keep gates & & \\
\hline Avoid risk of local disruption & & \\
\hline Create investment schemes & \multirow{3}{*}{$\begin{array}{l}\text { Boundary } \\
\text { conditioning }\end{array}$} & \\
\hline Regulate local price & & \\
\hline Create quality incentives & & \\
\hline Partnering (to allow and deepen practice) & \multirow{4}{*}{ Re-scaling } & \multirow{4}{*}{$\begin{array}{l}\text { Boundary } \\
\text { exploring }\end{array}$} \\
\hline Strengthen network & & \\
\hline Logistics, distribution, storage & & \\
\hline Price negotiation via volume & & \\
\hline Mimic other actors' functions & Enactment & \multirow{7}{*}{ Practice work } \\
\hline Device support schemes & \multirow{3}{*}{$\begin{array}{l}\text { Intermediating } \\
\text { means }\end{array}$} & \\
\hline Create funding opportunities & & \\
\hline $\begin{array}{l}\text { Allocate resources incrementally, inform, } \\
\text { include }\end{array}$ & & \\
\hline Position a vision to influence policy & \multirow{3}{*}{ Normalizing } & \\
\hline Set visions about market access & & \\
\hline Set and reward standards and best practice & & \\
\hline Clarify knowledge demands, appoint providers & Filtering & \multirow{4}{*}{$\begin{array}{l}\text { Knowledge } \\
\text { supply }\end{array}$} \\
\hline $\begin{array}{l}\text { Scale down and up knowledge, human } \\
\text { resources and value chain processes }\end{array}$ & \multirow[t]{2}{*}{ Allocate } & \\
\hline Staff the local realm & & \\
\hline $\begin{array}{l}\text { Training, gather and circulate market } \\
\text { information }\end{array}$ & Delivery & \\
\hline Anticipate, adapt, adjust, prepare and translate & Translation & \multirow{2}{*}{$\begin{array}{c}\text { Knowledge } \\
\text { intermediatio } \\
\mathrm{n}\end{array}$} \\
\hline Store a knowledge base & Mediation & \\
\hline Perform in other links of the value chain & \multirow{2}{*}{ Expand field } & \multirow{3}{*}{$\begin{array}{l}\text { Knowledge } \\
\text { exploration }\end{array}$} \\
\hline Pilot complementary income sources & & \\
\hline Collaborate on research and development & Deepen field & \\
\hline
\end{tabular}




\subsubsection{Grassroots' Organizations Rule!}

This section discusses the specific field of grassroots-focused institutional endeavours, while giving detail about the strategies farmers' organizations deploy both to cope with the field and develop it. Table 3 summarizes the section and includes the set of strategies attributable to the grassroots field.

The rationale of the field focuses on creating spaces and conditions for farmers' identities to exist and evolve through time within a set of values. Its predominant feature relates to identity creating and positioning.

Here the organization is a means through which communities pursue autonomy. The organization is seen as one of the many possible devices through which the community strives to build its own order while coping-but also tuning, compromising with or rejecting-broader institutions and societal patterns.

Organizations are set in motion as an instrumental device making it possible to link to other actors, but, more important to the eyes of organizations, to be reckon as able actors playing a role (Interview Ldr 003, 16/06/14; Asc, 07/07/14; Fg Ct, 20/01/14; Fg Mc, 14/01/14).

As a device the organization has but an instrumental role, along with other forms of legal existence (e.g. the cooperative, the council, the association), and its role channels specific aspects of a more substantive positioning strategy. The organization allows practice work to go about the higher ambition of autonomy.

Identity positioning is political in the sense that it marks distinctions between "us" and "them." Identity is based upon various possible pivots. It is self-evident when identity refers to ethnicity or the role of peasants in rural life (Obs Mc, 14/01/14; Obs Sr, 27/01/14), but it also relates to territorial aspects, such as productive vocation and land ownership (Fg Mc, 14/01/14; Fg Sr, 27/01/14).

Overall, this identity is projected as a means to envision, nurture and protect historically rooted community aims. Naturally, identity is built on a knowledge base of its own, treated actively within communities as a mode of acknowledging and understanding culture and projected to inspire the youngsters (Interview Ldr 004, 16/06/14). 
Organizations as community means play here as schooling devices, as sites of mentorship for intergenerational change (Obs Mc, 14/01/14; Fg Sr, 27/01/14; Obs Sr, 27/01/14). Naturally, this also entails that staffing organizations themselves are part of the deal (Interview Ldr 004, 16/06/14; Obs Mc, 14/01/14). Knowledge exploration and supply show a wider scope of intentionality.

The use of organizations as instrumental expressions describes the intent of governance deployed by these communities. It embeds forms of autoorganization, as defined by Jessop (2003). As told, organizations strive and demand to have a place alongside other actors, be it guerrilla groups, government offices or international organizations. Standing up as an actor is a form of creating foundational boundaries, demarcating an autonomous stance towards other actors. At the origins of this governance intent lays the willingness to open a door for third parties to enter the territory (Interview Ofc 002, 05/02/14; Interview Ofc 003, 05/02/14).

In some cases, boundary setting through other actors is a form of protecting the local realm. Communities address-and manoeuvre to shift on their advantage — various levels of order affecting them. This can be seen with national or municipal programs risking disruption of the local social balance. Here organizations manoeuvre to block, negotiate or reformulate conditions, as it was often the case when alternative development programs started (Interview Ldr 003, 16/06/14; Fg Ct, 20/01/14).

Organizations also collaborate to have a voice in these spheres. Collaboration at this level aims at congregating peers and agreeing on shared ends regarding the territory (Obs Pn, 19/03/15; Obs Sr, 27/01/14), but also on positioning their visions as guiding institutions in the highly unstable realm of Colombian public institutions (Interview Ldr 003, 16/06/14; Obs Sr, 27/01/14). These visions also entail an economic view about territories: plans transformed into programs and projects used as means to translate community values into a community-laden view of its closest environment (Interview Ldr 003, 16/06/14; Obs Sr, 27/01/14).

These matters bring politics under the spotlight, but not in an open, straightforward way as could be expected. When it comes to politics, organizations play with a different, overlapping boundary setting: Organizations deploy these strategies as treats of individuals, not of organizations. This shift, itself, describes a shielding strategy. As told, organizations fear capture by party disciplines or political involvement to 
an extent that could risk the integrity of organizations themselves (Amb, 14/02/14; Obs Mc, 14/01/14; Obs Pn, 19/03/15). Political involvement is seen as a complementary activity, whose means and ends run in parallel but not within the organizations. Clearly a slippery boundary, it points to the ways organizations cope with functional differences amongst fields, while fiercely striving to be visible.

Not only legal personas, but also levels of discourse are instrumental to these aims. Here organizations condition boundaries by means of discourses vis-à-vis other actors. Human rights and human development, or specific laws, for example, appear as existing normative references useful for organizations to demarcate and protect an autonomous stance (Interview Ldr 003, 16/06/14). These discourses are more than argumentative devices. In effect, organizations also award best practice regarding these aspects, as it is the case with women empowerment, for example, or sustainability (Asc, 07/07/14).

Table 6 summarizes strategies deployed by organizations in this field. Strategies appear clustered in categories. I am aware that to this point I have not yet given detail to the reader about these categories. I have preferred to follow this order to allow the reader to get used to the terms and make sense of them. In the next chapter I will turn back to these topics at length.

\begin{tabular}{|c|c|c|}
\hline $\begin{array}{r}\text { Table 6. Summary of farmer } \\
\text { Grassroots' orga }\end{array}$ & $\begin{array}{l}\text { nizations' stı } \\
\text { ons rule! }\end{array}$ & Sies: \\
\hline Strategies & Category & $\begin{array}{c}\text { Knowledge } \\
\text { stance }\end{array}$ \\
\hline Negotiate to exist, to play a role & \multirow{3}{*}{$\begin{array}{l}\text { Boundary } \\
\text { situating }\end{array}$} & \multirow{5}{*}{$\begin{array}{l}\text { Boundary } \\
\text { setting }\end{array}$} \\
\hline Assess risk of partnership, keep gates & & \\
\hline $\begin{array}{l}\text { Avoid risk of local disruption, boundary } \\
\text { shifting }\end{array}$ & & \\
\hline $\begin{array}{l}\text { Adjust terms and conditions of support } \\
\text { schemes (block, negotiate, reformulate) }\end{array}$ & \multirow{2}{*}{$\begin{array}{l}\text { Boundary } \\
\text { Conditioning }\end{array}$} & \\
\hline Exist as a legal persona & & \\
\hline Partnering (to allow and deepen practice) & \multirow{3}{*}{ Re-scaling } & \multirow{3}{*}{$\begin{array}{l}\text { Boundary } \\
\text { exploration }\end{array}$} \\
\hline Strengthen network & & \\
\hline Scale up public investment & & \\
\hline
\end{tabular}


Table 6. Summary of farmers' organizations' strategies: Grassroots' organizations rule!

\begin{tabular}{|c|c|c|}
\hline Strategies & Category & $\begin{array}{l}\text { Knowledge } \\
\text { stance }\end{array}$ \\
\hline Perform & \multirow[b]{2}{*}{ Enactment } & \multirow{6}{*}{ Practice work } \\
\hline $\begin{array}{l}\text { Create a space for other institutions to } \\
\text { deliver services }\end{array}$ & & \\
\hline Device support schemes & \multirow[b]{2}{*}{$\begin{array}{l}\text { Intermediating } \\
\text { means }\end{array}$} & \\
\hline $\begin{array}{l}\text { Allocate resources incrementally, inform, } \\
\text { include }\end{array}$ & & \\
\hline Position a vision & \multirow{2}{*}{ Normalizing } & \\
\hline Set and reward standards and best practice & & \\
\hline $\begin{array}{l}\text { Clarify knowledge demands, appoint } \\
\text { providers }\end{array}$ & Filtering & \multirow{4}{*}{$\begin{array}{l}\text { Knowledge } \\
\text { supply }\end{array}$} \\
\hline $\begin{array}{l}\text { Scale down and up knowledge, human } \\
\text { resources and processes }\end{array}$ & \multirow{3}{*}{ Allocate } & \\
\hline Staff the local realm & & \\
\hline Peer training and advise & & \\
\hline $\begin{array}{l}\text { Anticipate, adapt, adjust, prepare and } \\
\text { translate }\end{array}$ & Translation & \multirow{2}{*}{$\begin{array}{c}\text { Knowledge } \\
\text { intermediation }\end{array}$} \\
\hline $\begin{array}{l}\text { Devise long-term training schemes for } \\
\text { youngsters }\end{array}$ & Mediation & \\
\hline Collaborate on research and development & Deepen field & $\begin{array}{l}\text { Knowledge } \\
\text { exploration }\end{array}$ \\
\hline
\end{tabular}

\subsubsection{Projects in the making}

This section discusses the specific field of rural development support, while giving detail about the strategies farmers' organizations deploy both to cope with the field and to develop it. Table 4 summarizes the section and includes the set of strategies attributable to the projects in the making field.

The rationale of the field focuses on obtaining resources to create or expand preferred rural practices, which are those of cocoa. Support access is granted by engaging in relations with other actors for and through rural development projects. More often than reckoned, collaboration blurs boundaries between involved parties. This goes so far that long-term 
processes are seen as teamwork (Asc, 07/07/14), or that at some point it is not possible to say who is leading the process in one way or another (Am, 14/11/14; Asc, 07/07/14).

Although roles and relations to projects vary depending on specific roles (e.g. beneficiary, provider or ally) project protocols, underlying discourses and implementing procedures shape the usual protocols of the field. Projects are the most common social technology in the near context of farmers' organizations. As a vehicle of relations with other actors at the meso level, projects can be seen as boundary objects. A good deal of organizations' strategies take place within and about projects.

The field of rural development focuses on creating or expanding practice through development projects. The organization plays a bridging role, searching for and allocating resources to increase members' assets or income, as well as to strengthen specific capabilities of its members or organizational capacities. This can be seen as a form of practice work, where the organization intermediates to obtain the resources allowing it to secure the practice field.

The size, length and depth of projects vary. The organization strives to achieve a continuous process, its success depending on an organization's ability to complete a puzzle usually having missing pieces. Therefore intermediating is actually less subject to the availability of grants than to the ability to create call opportunities.

Organizations carry on this task by engaging in ongoing discussions with authorities or international organizations ( $\mathrm{Fg} \mathrm{Mc}$, 14/01/14; Obs Pn, 19/03/15). Organizations strive to secure a role: having a place in public fora, making sure their voices are heard and their experiences are visible for every possibly involved actor. Organizations care for being known to those taking part in public discussions, whether they focus on the technical or the political aspects (Asc, 07/07/14).

The organization strives to position itself as a worthy ally, partner or program operator of national or international public organizations. Organizations perform in order to gain this recognition (Fg No, 16/01/14) and also strive to be visible. Visibility and recognition are conditions to grant further support and attain autonomy, but also to gain reputation through third parties, especially state actors (Interview Ofc 001, 05/02/14; Interview Ldr 003, 16/06/14; Obs Pn, 19/03/15). Performing is, to the 
extent of its specific features for each organization, a core form of practice work.

The organization knows development discursive trends and frequently uses them by drawing on rural families, communities or smallholders alike. These discourses also link to broader trends, such as human development, sustainability, local development and competitiveness, mostly addressing productive practices, for example, how incorporating productive standards has a positive impact on a more ordered farm and lifestyle, or how empowered women lead to more resilient households. Discourses are, of course, boundary conditions. But they are also forms of knowledge within this practice field, acquired by taking part of the field. Development projects are themselves a form of schooling, particularly having effects at the level of managers ( $\mathrm{Fg} \mathrm{Sr}, 27 / 01 / 14)$. Knowledge supply appears here enacted, as a form of experience, often referred to as "learning by doing."

Organizations make use of development projects' jargon. Projects' practice is explained in terms of objectives, rationales and impact, detailing numbers about funding sources, size of investment and beneficiaries. It also refers to funding agencies or partners themselves and expresses positioning strategies in two possible ways. Organizations position themselves by showing evidence of their knowledge about specific development approaches and project protocols (those of multilateral agencies or country aid donors, for example), representing both organizational capacity as well as situational reputation.

Organizations also position by rendering themselves as local institutions with detailed understanding of local priorities. This is not a minor treat. Drawing boundaries around existing abilities, capabilities and capacities at the local level, organizations seek to protect and expand their practice field in the local realm, convincing their partners about the need to further develop that potential (Interview Ldr 004, 16/06/14; Obs Pn, 19/03/15; Fg Sr, 27/01/14). Whenever possible, organizations will attempt to translate these boundaries into conditions for project delivery ( $\mathrm{Fg} \mathrm{Sr}$, 27/01/14).

Organizations' aims, structures, protocols and financial sustainability are set on their ability to formulate and implement development projects. The extent of collaboration with other parties for their execution depends on various possible boundary conditions of which projects are, naturally, not exempt. 
Some projects operate within restricted templates with little room to manoeuvre, or, as has been told earlier in this book, with actual obstacles for organizations at the local level, requiring third-party checks or involvement (Fg Cn, 23/01/14; Fg Mc, 14/01/14; Fg No, 16/01/14); some others operate in a more collaborative atmosphere, open to adjustment (Am, 14/11/14; Fg Mc, 14/01/14). These are boundary settings organizations necessarily have to cope with and learn to manage. This way organizations avoid possible disruptions within project beneficiaries or the neighbouring communities (Asc, 07/07/14; Fg Cn, 23/01/14; Fg Mc, 14/01/14).

This implies pertinence and the opportunity of projects also depends on a partner's readiness to adjust, which, of course, depends on a partner's internal settings and project protocols. Situation shifts depend heavily on the quality of relations: Substantive changes in project rationales take place between projects rather than during projects.

This aspect brings to the fore an interesting aspect worth detailed attention: Boundary exploration appears here also as a means of learning about the shortcomings of shared experiences, or, to be more exact, about shortcomings of shared experiences through boundary objects, such as projects. Expanding a practice field in conditions of boundary exploration - that is, in a set of multi-party collaboration-is actually an endeavour in which all involved parties go through learning processes. Policy tools tend to easily overlook this fact, emphasizing only one side of the string.

But it is not always the case. Projects related to strengthening the National Cocoa Network, for example, build a case illustrating this rationale. Here it is possible to see various parties sharing a strong focus on observing and developing networking as a valuable form of practice work within the practice field (Asc, 07/07/14; Fg Ct, 20/01/14; Fg Mc, 14/01/14).

On a different note, it is worth noting organizations' coping strategies exceed the local level. In the presence of weak local institutions-or in the total absence of local institutions, as is often the case-organizations manoeuvre to complete the missing pieces. After realizing the local level is not an able source of support, organizations search other levels, both within the value chain or in the wider public administrative scale ( $\mathrm{Fg} \mathrm{Cn}$, 23/01/14; Fg Ct, 20/01/14; Fg Mc, 14/01/14; Fg No, 16/01/14; Fg Sr, $27 / 01 / 14)$. 
Roles and presence of the development organization grow increasingly in scope, scale and complexity. Organizations' reach and influence spread to neighbouring regions, enlarging their membership (Fg Ct, 20/01/14; Fg Mc, 14/01/14). Reach and influence also extends to build a resilient productive basket, including complementary crops and finance sources. These forms of knowledge exploration aim at expanding or deepening organizations' practice fields.

Naturally, organizations not only take part in multi-party collaborative arrangements, but also in peer-to-peer arrangements. In this case boundary exploration leads to an expansion at the base of the practice field. Growth is addressed by downscaling functions, delegating operations to members or staffing subregional offices with local allies. Knowledge supply is therefore re-scaled within the available expanded sources (Fg No, 16/01/14; Obs Pn, 19/03/15; Fg Sr, 27/01/14).

Table 7 summarizes strategies deployed by organizations in this field. Strategies appear clustered in categories. I am aware that to this point I have not yet given detail to the reader about these categories. I have preferred to follow this order so as to allow the reader to get used to the terms and make sense of them. In the next chapter I will turn back to these topics at length.

\begin{tabular}{|c|c|c|}
\hline \multicolumn{3}{|c|}{$\begin{array}{c}\text { Table 7. Summary of farmers' organizations' strategies: } \\
\text { Projects in the making }\end{array}$} \\
\hline Strategies & Category & $\begin{array}{l}\text { Knowledge } \\
\text { stance }\end{array}$ \\
\hline Negotiate to exist, to play a role & \multirow{3}{*}{$\begin{array}{l}\text { Boundary } \\
\text { situating }\end{array}$} & \multirow{4}{*}{$\begin{array}{l}\text { Boundary } \\
\text { setting }\end{array}$} \\
\hline Assess risk of partnerships and keep gates & & \\
\hline Avoid risk of local disruption & & \\
\hline $\begin{array}{l}\text { Adjust terms and conditions of support } \\
\text { schemes (block, negotiate, reformulate) }\end{array}$ & $\begin{array}{l}\text { Boundary } \\
\text { conditioning }\end{array}$ & \\
\hline Partnering & \multirow{4}{*}{ Re-scaling } & \multirow{4}{*}{$\begin{array}{l}\text { Boundary } \\
\text { exploration }\end{array}$} \\
\hline Strengthen network & & \\
\hline Access public investment & & \\
\hline Scale up public investment & & \\
\hline Perform & Enactment & \multirow{3}{*}{ Practice work } \\
\hline $\begin{array}{l}\text { Create support opportunities, bypass level } \\
\text { restrictions }\end{array}$ & $\begin{array}{l}\text { Intermediating } \\
\text { means }\end{array}$ & \\
\hline Position a vision to influence policy & Normalizing & \\
\hline
\end{tabular}


Table 7. Summary of farmers' organizations' strategies:

Projects in the making

\begin{tabular}{|c|c|c|}
\hline Strategies & Category & $\begin{array}{c}\text { Knowledge } \\
\text { stance }\end{array}$ \\
\hline Set visions about market access & & \\
\hline Set and reward standards and best practice & & \\
\hline Clarify knowledge demands, appoint providers & Filtering & \multirow{4}{*}{$\begin{array}{l}\text { Knowledge } \\
\text { supply }\end{array}$} \\
\hline $\begin{array}{l}\text { Scale down and up knowledge, human } \\
\text { resources }\end{array}$ & \multirow[t]{2}{*}{ Allocate } & \\
\hline Staff the local realm & & \\
\hline $\begin{array}{l}\text { Training, gather and circulate support } \\
\text { information }\end{array}$ & Delivery & \\
\hline $\begin{array}{l}\text { Anticipate, adapt, adjust, prepare, and } \\
\text { translate }\end{array}$ & Translation & \multirow{2}{*}{$\begin{array}{l}\text { Knowledge } \\
\text { intermediation }\end{array}$} \\
\hline Devise long-term training schemes & Mediation & \\
\hline Collaborate on research and development & Deepen field & $\begin{array}{l}\text { Knowledge } \\
\text { exploration }\end{array}$ \\
\hline
\end{tabular}

\subsubsection{Cocoa's ring}

This section discusses the specific field of the cocoa sector, while giving detail about the strategies farmers' organizations deploy both to cope with the field and develop it. Table 5 summarizes the section, including the set of strategies attributable to cocoa's ring field.

This field is related to smallholder representation roles and lobbying manoeuvres for policy-making within the cocoa sector. Rationales of the field focus on stressing visibility of smallholder producers, presence in sector spaces at the local, regional and national levels, and organizations' attempts to obtain bigger influence on the sector structure, regulations and agenda.

This field prompts a scaled view of the organizations. The organizations are displayed here in their various possible clustered views, representing smallholders' organizations at subregional, regional and national scales, as a federation. In the words of a leader, organizations have understood that they must join efforts to affect the status quo, the same way smallholders join organizations (Fg Ct, 20/01/14). For what is left of this 
discussion, I will refer then to the federation for a short while, to name this clustered view of organizations.

The federation aims at having an impact on the sector's practices according to smallholders' points of view. Conceptually, this picture illustrates forms of boundary exploration amongst organizations-and boundary setting vis-à-vis other actors-aiming at positioning an expanded presence.

The federation aims at gaining recognition so as to be present in sector spaces at the local, regional and national levels. These spaces can be public (e.g. cocoa table, linking to agriculture ministry) or private (e.g. national and international cocoa contests) (Interview Cmr 001, 16/06/14; Interview Ldr 001, 13/01/14; Asc, 07/07/14). Presence is a means of influencing sector structure, public investment channels, technological inputs to practice, extension means and public agenda.

Practice work is here a means to link strategically to the overarching trends of the sector. Moreover, is a means to drive some specific trends within the sector: specifically those related to strengthening a high-quality cocoa market.

Naturally, some of these spaces are shared with other actors. Some of these actors are part of the value chain, (e.g. big-holder producer associations, processing factories), while others are state actors neighbouring the field (e.g. social department, commerce and agriculture ministries, public research institutes, extension services). There might be political tensions amongst these actors, due to the scale or legitimacy of producers' representation or to path-inherited power imbalances. It is the case, for example, with Fedecacao (Interview Ldr 001, 13/01/14).

However, these tensions are concealed, or suspended, giving heft to the sector as a higher common purpose. This does not mean there are effects on boundaries. On the contrary, boundaries are kept except when the opportunity emerges to agree on punctual projects. Disagreements on the table do not block the possibility of partnering (Asc, 07/07/14; Obs Pn, 19/03/15). We see here, again, a boundary shift, where this case shields hands-on possibilities of developing the practice field.

Expectedly, the federation aims at standing as a legitimate interlocutor of authorities and might have, depending on the level and specific presence emphasis, influence on public investment and regulations. 
Sustained presence of the organization grants having an opinion on designs at the policy, program and project levels, if the opportunity were to arise (Asc, 07/07/14; Fg Ct, 20/01/14; Obs Pn, 19/03/15). This relates not only on public incentives for the specific sector, but to support functions. As is the case, for example, of programs delivered to strengthen productive organizations (Fg Sr, 27/01/14).

The federation has also an internal facet, regarding functions vis-à-vis organizations. These are focused on developing services for producer organizations, as means of building an overarching support scheme. It is intended as a means to counteract operative or logistical weaknesses of organizations (Interview Ofc 004, 17/10/14).

One line of services aims at facilitating and developing market access. Draws attention to the realization of quality fairs, through which quality standards are set and enforced (Amb, 14/02/14; Asc, 07/07/14). We see here a broader reach of practice work, scaled at the national level, as way to set goals—while setting standards—-for the practice field.

Complementarily, the federation also shares information and offers support with export logistics. Sharing information is actually an extension of other forms of peer-based knowledge supply, usually taking place within and between nodes. Export logistics, on the other side, is rather a means of survival for the federation. Yet, naturally, export logistics is also a mechanism to support the weakest amongst the network (Interview Tm 001, 16/01/14; Interview Ofc 004, 17/10/14).

Table 8 summarizes strategies deployed by organizations in this field. Strategies appear clustered in categories. I am aware that to this point I have not yet given detail to the reader about these categories. I have preferred to follow this order to allow the reader to get used to the terms and make sense of them. In the next chapter I will turn back to these topics at length. 
Table 8. Summary of farmers' organizations' strategies:

Cocoa's ring field

\begin{tabular}{|c|c|c|}
\hline Strategies & Category & $\begin{array}{c}\text { Knowledge } \\
\text { stance }\end{array}$ \\
\hline Demand attention & $\begin{array}{l}\text { Boundary } \\
\text { situating }\end{array}$ & \multirow{2}{*}{$\begin{array}{l}\text { Boundary } \\
\text { setting }\end{array}$} \\
\hline $\begin{array}{l}\text { Adjust terms and conditions of support } \\
\text { schemes (block, negotiate, reformulate) }\end{array}$ & $\begin{array}{l}\text { Boundary } \\
\text { conditioning }\end{array}$ & \\
\hline Partnering & \multirow{4}{*}{ Re-scaling } & \multirow{4}{*}{$\begin{array}{l}\text { Boundary } \\
\text { exploration }\end{array}$} \\
\hline Strengthen network & & \\
\hline $\begin{array}{l}\text { Lobby and presence with a national } \\
\text { network }\end{array}$ & & \\
\hline Scale up public investment & & \\
\hline Perform & Enactment & \multirow{6}{*}{ Practice work } \\
\hline Devise support schemes & \multirow[b]{2}{*}{$\begin{array}{c}\text { Intermediating } \\
\text { means }\end{array}$} & \\
\hline $\begin{array}{l}\text { Create support opportunities, bypass level } \\
\text { restrictions }\end{array}$ & & \\
\hline Position a vision to influence policy & \multirow{3}{*}{ Normalizing } & \\
\hline Set visions about market access & & \\
\hline $\begin{array}{l}\text { Set and reward standards and best } \\
\text { practice }\end{array}$ & & \\
\hline $\begin{array}{l}\text { Clarify knowledge demands, appoint } \\
\text { providers }\end{array}$ & Filtering & \multirow{3}{*}{$\begin{array}{l}\text { Knowledge } \\
\text { supply }\end{array}$} \\
\hline $\begin{array}{l}\text { Scale down and up knowledge, human } \\
\text { resources }\end{array}$ & \multirow[t]{2}{*}{ Allocate } & \\
\hline Staff the local realm & & \\
\hline $\begin{array}{l}\text { Anticipate, adapt, adjust, prepare, and } \\
\text { translate. }\end{array}$ & Translation & $\begin{array}{c}\text { Knowledge } \\
\text { intermediation }\end{array}$ \\
\hline Collaborate on research and development & Deepen field & $\begin{array}{l}\text { Knowledge } \\
\text { exploration }\end{array}$ \\
\hline
\end{tabular}

\subsubsection{Keep it local}

This section discusses the local realm as a field, while giving detail about the strategies farmers' organizations deploy both to cope with it and develop it. Table 9 summarizes the section and includes the set of strategies attributable to this field. 
This field is bounded by territorial boundaries, its overarching rationale aiming at strengthening the local public realm. Here organizations perform as an actor of local civil society.

Some of these priorities relate, naturally, to obtaining local support to further develop organizations' plans (Fg Cn, 23/01/14; Obs Mc, 14/01/14; Fg No, 16/01/14). However, this field stresses a different side, demanding accountability of local authorities and granting investment in a wider sense, attempting to address the topics of a local agenda. This field draws attention to environmental aspects (especially when there are neighbouring mining activities) (Interview Tm 002, 16/01/14; Obs Mc, 14/01/14; Obs Sr, 27/01/14), education (especially views on better managing challenges for the rural youth) (Fg $\mathrm{Cn}, 23 / 01 / 14$; Obs $\mathrm{Mc}$, 14/01/14; Obs Sr, 27/01/14) and, overall, wellbeing and services for smallholder families (Fg Cn, 23/01/14; Fg Ct, 20/01/14; Fg Mc, 14/01/14; Fg No, 16/01/14; Fg Sr, 27/01/14).

Organizations' concerns for stability translate into granting a permanent and productive relation with local powers, despite their political colors (Fg $\mathrm{Cn}, 23 / 01 / 14 ; \mathrm{Fg} \mathrm{Mc}, 14 / 01 / 14)$. In isolated areas this might also include illegal actors or weak or corrupted municipalities (Fg Ct, 20/01/14; Obs Mc, 14/01/14; Fg No, 16/01/14). Once cleared to open a practice path, the organization strives to bring topics to the local agenda. Performing as a representative is an original gesture of organizations in the realm of practice work.

Organizations manoeuvre to trigger local authorities' responses. They stand as local actors, as representatives, whether by positioning smallholder visions and priorities on the local agenda (Fg Cn, 23/01/14; Obs Mc, 14/01/14; Fg No, 16/01/14; Obs Pn, 19/03/15; Fg Sr, 27/01/14) or by demanding transparency and visibility (Fg Cn, 23/01/14; Fg Mc, 14/01/14). Both strategies attempt to tackle the backdrop of local instability by securing responses from authorities. The first is a normalizing strategy around a vision - a card also played in other fields and the second, a manoeuvre of boundary situation.

Producers from other sectors might come to the organization to learn about farmers' associations, valuing their existence as positive enterprises. It is regarded as a means of interlocution with other actors, but also an example about what can be done for other local productive sectors (Obs Pn, 19/03/15). Peer productive organizations respect each other's fields and maintain continuous exchange about local 
circumstances. The underlying idea is political in the sense of creating means for smallholders to have actual access to opportunities. Local peer networks might turn also into regional networks (Obs Mc, 14/01/14; Obs Sr, 27/01/14).

Table 6 summarizes strategies deployed by organizations in this field. Strategies appear clustered in categories. I am aware that to this point I have not yet given detail to the reader about these categories. I have preferred to follow this order to allow the reader to get used to the terms and make sense of them. In the next chapter I will turn back to these topics at length.

\begin{tabular}{|c|c|c|}
\hline \multicolumn{3}{|c|}{$\begin{array}{c}\text { Table 9. Summary of farmers' organizations' strategies: } \\
\text { Keep it local field }\end{array}$} \\
\hline Strategies & Category & $\begin{array}{l}\text { Knowledge } \\
\text { stance }\end{array}$ \\
\hline Demand attention & $\begin{array}{l}\text { Boundary } \\
\text { situating }\end{array}$ & \multirow{3}{*}{ Boundary setting } \\
\hline $\begin{array}{l}\text { Adjust terms and conditions of support } \\
\text { schemes (block, negotiate, reformulate) }\end{array}$ & \multirow{2}{*}{$\begin{array}{l}\text { Boundary } \\
\text { conditioning }\end{array}$} & \\
\hline Demand local accountability & & \\
\hline Partnering & \multirow{2}{*}{ Re-scaling } & \multirow{2}{*}{$\begin{array}{l}\text { Boundary } \\
\text { exploration }\end{array}$} \\
\hline Strengthen network & & \\
\hline Perform & Enactment & \multirow[t]{2}{*}{ Practice work } \\
\hline Position a vision to influence policy & Normalizing & \\
\hline $\begin{array}{l}\text { Clarify knowledge demands, appoint } \\
\text { providers }\end{array}$ & Filtering & Knowledge supply \\
\hline $\begin{array}{l}\text { Scale down and up knowledge, human } \\
\text { resources }\end{array}$ & Allocate & \multirow{2}{*}{$\begin{array}{c}\text { Knowledge } \\
\text { intermediation }\end{array}$} \\
\hline $\begin{array}{l}\text { Anticipate, adapt, adjust, prepare, and } \\
\text { translate }\end{array}$ & Translation & \\
\hline
\end{tabular}

\subsubsection{Summing up, a canvas of farmers' organizations' strategies}

To conclude this subsection I will summarize strategies deployed by organizations in an overview. This summary will facilitate the reader to 140 
have a broader view of the harvest. Table 10 presents a canvas of strategies. Here strategies are clustered according to similar patterns belonging to specific knowledge stances.

Earlier I promised I would give detail about the categories used to cluster specific strategies. The third column of Table 10 clarifies the criterion that was used to cluster each specific set of strategies. These clusters will help the reader to better understand the many layers this research addresses.

In the next section I will shift the focus of the discussion, turning from a field perspective to a knowledge stances perspective. This overview is useful as a bridge, allowing the reader to grasp a sense of the whole before entering again a more detailed thread of analysis.

\section{Table 10. Canvas. Strategies of farmers' organizations as change agents}

\begin{tabular}{|c|c|c|c|}
\hline $\begin{array}{c}\text { Knowledge } \\
\text { stance }\end{array}$ & Category & Criteria & Strategies \\
\hline \multirow{10}{*}{$\begin{array}{l}\text { Boundary } \\
\text { setting }\end{array}$} & \multirow{5}{*}{$\begin{array}{l}\text { Boundary } \\
\text { situating }\end{array}$} & \multirow{5}{*}{$\begin{array}{l}\text { Actual efforts to shift } \\
\text { positions in the } \\
\text { pursuit of a more } \\
\text { suitable position with } \\
\text { respect to other } \\
\text { actors. }\end{array}$} & $\begin{array}{l}\text { Negotiate to exist } \\
\text { and play a role }\end{array}$ \\
\hline & & & $\begin{array}{l}\text { Assess risk of } \\
\text { partnerships and } \\
\text { keep gates }\end{array}$ \\
\hline & & & $\begin{array}{l}\text { Avoid risk of local } \\
\text { disruption }\end{array}$ \\
\hline & & & Demand attention \\
\hline & & & $\begin{array}{l}\text { Exist as a legal } \\
\text { persona }\end{array}$ \\
\hline & \multirow{5}{*}{$\begin{array}{l}\text { Boundary } \\
\text { conditioning }\end{array}$} & \multirow{5}{*}{$\begin{array}{l}\text { Actual efforts to affect } \\
\text { rules or regulations } \\
\text { impacting the } \\
\text { practice base and } \\
\text { other actors }\end{array}$} & $\begin{array}{l}\text { Create investment } \\
\text { schemes }\end{array}$ \\
\hline & & & Regulate local price \\
\hline & & & $\begin{array}{l}\text { Create quality } \\
\text { incentives }\end{array}$ \\
\hline & & & $\begin{array}{l}\text { Adjust terms and } \\
\text { conditions of } \\
\text { support schemes } \\
\text { (block, negotiate, } \\
\text { reformulate) }\end{array}$ \\
\hline & & & $\begin{array}{l}\text { Demand local } \\
\text { accountability }\end{array}$ \\
\hline
\end{tabular}


Table 10. Canvas. Strategies of farmers' organizations as change agents

\begin{tabular}{|c|c|c|c|}
\hline $\begin{array}{c}\text { Knowledge } \\
\text { stance }\end{array}$ & Category & Criteria & Strategies \\
\hline \multirow{6}{*}{$\begin{array}{l}\text { Boundary } \\
\text { exploring }\end{array}$} & \multirow{6}{*}{ Re-scaling } & \multirow{6}{*}{$\begin{array}{l}\text { Coping strategies } \\
\text { linking organizations } \\
\text { to peers or third } \\
\text { parties, expanding } \\
\text { the reach of its } \\
\text { practice field }\end{array}$} & $\begin{array}{l}\text { Partnering (to allow } \\
\text { and deepen } \\
\text { practice) }\end{array}$ \\
\hline & & & Strengthen network \\
\hline & & & $\begin{array}{l}\text { Logistics, } \\
\text { distribution, } \\
\text { storage }\end{array}$ \\
\hline & & & $\begin{array}{l}\text { Price negotiation } \\
\text { via volume }\end{array}$ \\
\hline & & & $\begin{array}{l}\text { Scale up public } \\
\text { investment }\end{array}$ \\
\hline & & & $\begin{array}{l}\text { Lobby and have } \\
\text { presence with a } \\
\text { national network }\end{array}$ \\
\hline \multirow{10}{*}{ Practice work } & \multirow{3}{*}{ Enactment } & \multirow{3}{*}{$\begin{array}{l}\text { A set of practice (or } \\
\text { its promise) is } \\
\text { incorporated in } \\
\text { organizations' actions }\end{array}$} & Perform \\
\hline & & & $\begin{array}{l}\text { Mimic other actors' } \\
\text { functions }\end{array}$ \\
\hline & & & $\begin{array}{l}\text { Create a space for } \\
\text { other institutions to } \\
\text { deliver services }\end{array}$ \\
\hline & \multirow{4}{*}{$\begin{array}{l}\text { Intermediating } \\
\text { means }\end{array}$} & \multirow{4}{*}{$\begin{array}{c}\text { Ways of sourcing and } \\
\text { financing required } \\
\text { knowledges }\end{array}$} & $\begin{array}{l}\text { Devise support } \\
\text { schemes }\end{array}$ \\
\hline & & & $\begin{array}{l}\text { Create funding } \\
\text { opportunities }\end{array}$ \\
\hline & & & $\begin{array}{l}\text { Allocate resources } \\
\text { incrementally, } \\
\text { inform, include }\end{array}$ \\
\hline & & & $\begin{array}{l}\text { Create support } \\
\text { opportunities, } \\
\text { bypass level/sector } \\
\text { restrictions }\end{array}$ \\
\hline & \multirow{3}{*}{ Normalizing } & \multirow{3}{*}{$\begin{array}{c}\text { Setting rules as } \\
\text { means to guide and } \\
\text { stabilize a field of } \\
\text { practice }\end{array}$} & $\begin{array}{l}\text { Position a vision to } \\
\text { influence policy }\end{array}$ \\
\hline & & & $\begin{array}{l}\text { Set visions about } \\
\text { market access }\end{array}$ \\
\hline & & & $\begin{array}{l}\text { Set and reward } \\
\text { standards and best }\end{array}$ \\
\hline
\end{tabular}


Table 10. Canvas. Strategies of farmers' organizations as change agents

\begin{tabular}{|c|c|c|c|}
\hline $\begin{array}{c}\text { Knowledge } \\
\text { stance }\end{array}$ & Category & Criteria & Strategies \\
\hline & & & practice \\
\hline \multirow{5}{*}{$\begin{array}{l}\text { Knowledge } \\
\text { supply }\end{array}$} & Filtering & $\begin{array}{l}\text { Organizations (or } \\
\text { their scaled forms) } \\
\text { identify knowledge } \\
\text { gaps and look for } \\
\text { means to satisfy them }\end{array}$ & $\begin{array}{l}\text { Clarify knowledge } \\
\text { demands and } \\
\text { appoint providers }\end{array}$ \\
\hline & \multirow{3}{*}{ Allocate } & \multirow{3}{*}{$\begin{array}{c}\text { Distribute knowledge } \\
\text { means }\end{array}$} & $\begin{array}{l}\text { Scale down and up } \\
\text { knowledge, human } \\
\text { resources and } \\
\text { processes }\end{array}$ \\
\hline & & & $\begin{array}{l}\text { Staff the local } \\
\text { realm }\end{array}$ \\
\hline & & & $\begin{array}{l}\text { Peer training and } \\
\text { advise }\end{array}$ \\
\hline & Delivery & $\begin{array}{l}\text { Perform a knowledge } \\
\text { providing function }\end{array}$ & $\begin{array}{l}\text { Training, gather } \\
\text { and circulate } \\
\text { market information }\end{array}$ \\
\hline \multirow{3}{*}{$\begin{array}{c}\text { Knowledge } \\
\text { intermediation }\end{array}$} & Translation & $\begin{array}{l}\text { Endeavour to better } \\
\text { match endogenous } \\
\text { capabilities with } \\
\text { external input }\end{array}$ & $\begin{array}{l}\text { Anticipate, adapt, } \\
\text { adjust, prepare and } \\
\text { translate }\end{array}$ \\
\hline & \multirow[b]{2}{*}{ Mediation } & \multirow{2}{*}{$\begin{array}{l}\text { Design long-term } \\
\text { educative means }\end{array}$} & $\begin{array}{l}\text { Store a knowledge } \\
\text { base }\end{array}$ \\
\hline & & & $\begin{array}{l}\text { Devise long-term } \\
\text { training schemes } \\
\text { for youngsters }\end{array}$ \\
\hline \multirow{3}{*}{$\begin{array}{l}\text { Knowledge } \\
\text { exploration }\end{array}$} & \multirow{2}{*}{ Expand field } & \multirow{2}{*}{$\begin{array}{l}\text { Enlarge the practice } \\
\text { field by participating } \\
\text { in complementary } \\
\text { fields }\end{array}$} & $\begin{array}{l}\text { Perform in other } \\
\text { links of the value } \\
\text { chain }\end{array}$ \\
\hline & & & $\begin{array}{l}\text { Pilot } \\
\text { complementary } \\
\text { income sources }\end{array}$ \\
\hline & Deepen field & $\begin{array}{c}\text { Build a knowledge } \\
\text { base for the field of } \\
\text { practice }\end{array}$ & $\begin{array}{l}\text { Collaborate on } \\
\text { research and } \\
\text { development }\end{array}$ \\
\hline
\end{tabular}




\subsection{Strategies: Knowledge stances as agency patterns}

Once guiding concepts have been discussed and a more detailed view about the fields in which organizations play and the strategies they deploy have been illustrated, it is worth turning to the strategies themselves.

As discussed with the empirical results and seen in the discussion of the various fields, some strategies appear reiterative. These are patterns of coping strategies. Time and again farmers' organizations' strategies refer to similar objects or deploy a similar rationale. This section identifies and analyses these patterns.

The analysis will discuss knowledge stances as a reference framework. A first part describes strategies, categorized according to knowledge stances, that is, strategies about boundary setting, boundary exploration, practice work, knowledge supply, knowledge exploration and knowledge intermediation. To easily enter this analysis, it is worth remembering the rationale of the theoretical approach.

As said, knowledge stances account for knowledge-related settings specifying a "situation." A stance specifies critical moments involving knowledge, which change agents might experience. That is, a stance relates sets of conditions expressing positions of agency at a given moment.

Figure 4 illustrates this idea. Rather than matching to one another linearly, these dimensions complement their various features. The figure sketches the rough, uneven, adaptive, landscape in which agency takes place. Repertoires of boundary exploration, boundary setting and practice work are shown as forms of positioning and expanding a practice field, pointing at the institutional dimension. Repertoires of knowledge exploration, intermediation and supply are shown as strategies enlarging a cognitive base.

Stances work as heuristics addressing moments, scopes, situations or performance of knowledge repertoires. Stances mark distinctions of overlapping features or mutual conditioning by pointing to specific contexts impacting practice and boundaries processes of stabilizing institutions. Knowledge stances are here assumed as hermeneutic references that allow approaching the research object. 


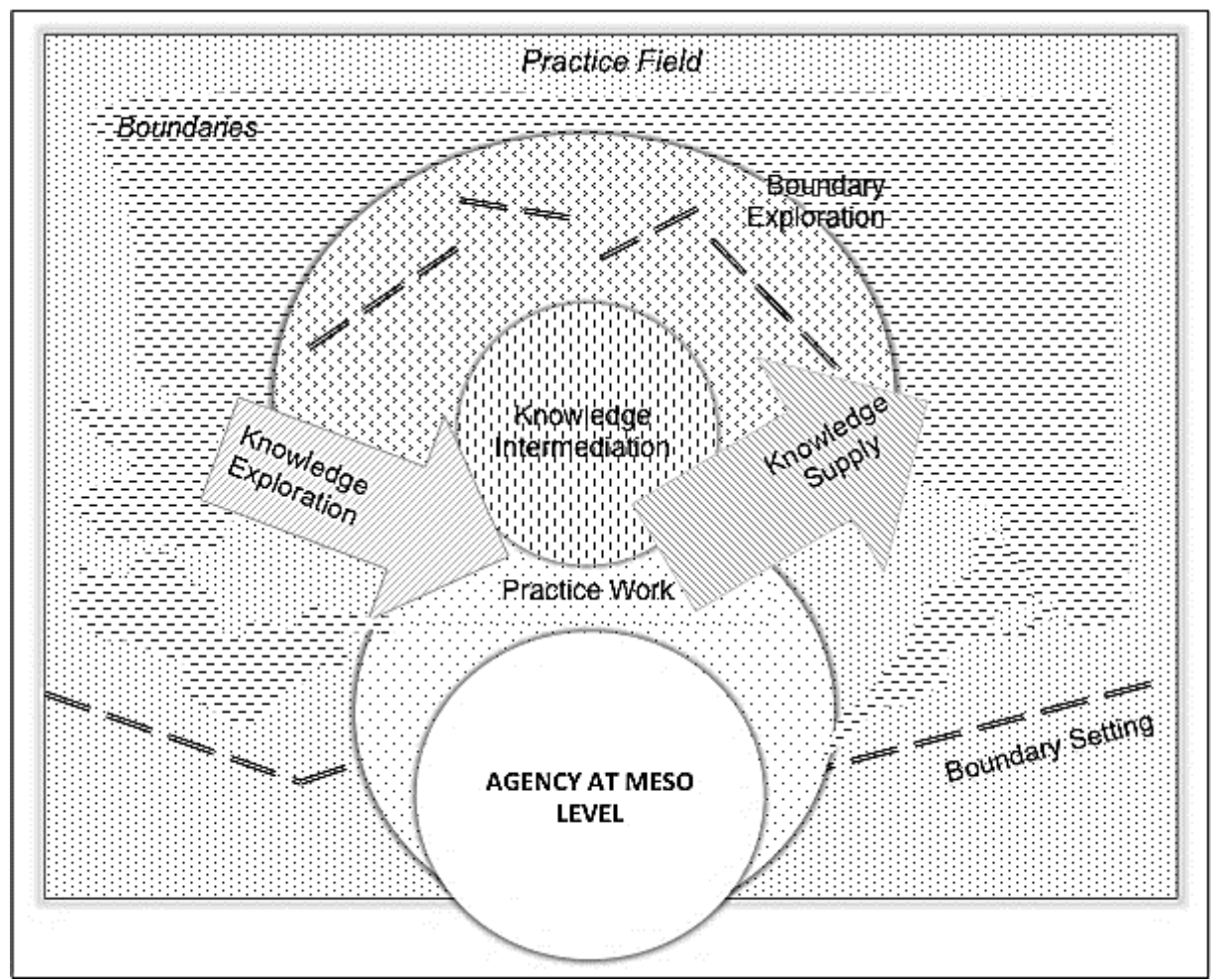

Figure 4. Meso-level agency featuring knowledge stances. Basic scheme

In the following pages I will elaborate on how knowledge stances are shown to work empirically. By referring continually to farmers' organizations' strategies, this exercise also allows further describing features of their agency as actors.

Empirical results help describe with more detail the extent of each knowledge stance, as well as the ways in which they connect to one another. As a matter of fact, these connecting vessels have brought various analytical challenges. Demarcating categories proved a more difficult task when single strategies where found to overlap, complement or fit various possible stances. In such cases I chose those categories better stressing the relevance of the strategy itself. I will highlight these aspects along the exposition. 
The exposition of each knowledge stance follows a specific order. I will discuss each knowledge stance bringing back its definition. Then I will turn to elaborate on sets of features allowing a deeper understanding of its specificities. To clarify this discussion I will turn systematically to empirical examples, taken from the various described fields. I will finish elaborating by describing connecting vessels amongst each knowledge stance and the others.

\subsubsection{Boundary setting}

Broadly speaking, boundary setting refers to those gestures of agency of an actor by means of which the actor reacts to arrangements at the meso level. Boundary settings can respond to either boundary situations or conditions.

A boundary situation describes a position of an actor in relation to other actors. Boundary situating refers to actual efforts to shift positions in the pursuit of a more suitable balance with respect to other actors. For example, the National Cocoa Network is an attempt to re-scale organizations' negotiation positions at the local and sectorial levels (Asc, 07/07/14)

On the other hand, boundary conditions refer to a state of affairs regarding actual rules or regulations. There are cases in which actors respond to, adapt or use existing norms, rules or regulations for their own purposes. It is the case, to give a few examples, when organizations define contractual terms of support schemes (Obs Ct, 20/01/14; Obs Pn, 19/03/15; Obs Sr, 27/01/14), use human rights as a discursive mean to position their views at the local level (Obs Sr, 27/01/14) or analyse the existing normative framework conditioning the features of the national network as an intermediary organization (Asc, 07/07/14). Although situations and conditions can be closely related-and overlap in some cases-this distinction allows tracing less evident phenomena.

Table 11 shows an overview of boundary setting strategies found empirically. The reader will note I have added a new column, intention. I will use it to further discuss boundary setting, specifically regarding the purpose of boundary setting taking place behind every strategy. 
Table 11. Boundary setting strategies

\begin{tabular}{|c|c|c|c|}
\hline $\begin{array}{l}\text { Knowledge } \\
\text { stance }\end{array}$ & Category & Intention & Strategies \\
\hline \multirow{11}{*}{$\begin{array}{l}\text { Boundary } \\
\text { setting }\end{array}$} & \multirow{5}{*}{$\begin{array}{l}\text { Boundary } \\
\text { situating }\end{array}$} & Positioning & $\begin{array}{l}\text { Negotiate to exist and play a } \\
\text { role }\end{array}$ \\
\hline & & Positioning & Demand attention \\
\hline & & Protecting & $\begin{array}{l}\text { Assess risk of partnerships and } \\
\text { keep gates }\end{array}$ \\
\hline & & Protecting & Avoid risk of local disruption \\
\hline & & Protecting & Shift boundaries \\
\hline & \multirow{6}{*}{$\begin{array}{l}\text { Boundary } \\
\text { conditioning }\end{array}$} & Positioning & Exist as a legal persona \\
\hline & & Positioning & Create investment schemes \\
\hline & & Protecting & Regulate local price \\
\hline & & Positioning & Create quality incentives \\
\hline & & Positioning & $\begin{array}{l}\text { Adjust terms and conditions of } \\
\text { support schemes (block, } \\
\text { negotiate, reformulate) }\end{array}$ \\
\hline & & Protecting & Demand local accountability \\
\hline
\end{tabular}

Some strategies relate to positioning patterns while others relate to protecting patterns. When positioning, organizations are striving to be visible, to highlight their existence and determine the way to go about their business. This can take place in the realm of boundary situations (as in the case of demanding attention from authorities at the local level) or conditions (as in the case of creating a legal persona as a means of existence and representation at the national level).

Some other strategies attempt protecting a space. Drawing boundaries shows here a rather defensive move, shielding the organization or its practice base. It is the case with strategies such as assessing risk of partnerships and keeping gates, avoiding local disruption and adjusting terms and conditions of support schemes. The latter also include strategies such as blocking, negotiating and re-formulating.

Organizations deploy protecting strategies to safeguard their boundaries by filtering exogenous input, for example, when public initiatives seem unfit for organizations' priorities or when project terms have been set beforehand. Adjusting terms or blocking initiatives are forms of buffering, 
or shielding. The organizations take care of their boundaries by deploying means to take place before or after engaging in partnerships, both within and between contracts and projects.

Amongst these, shifting boundaries deserve some attention. This strategy appeared empirically in two situations. One, it appeared as a move to shield the organization from politics by rendering politics a matter of individuals. Two, it appeared to shield practice by engaging in projects with contested actors from the sector, despite bitter negotiations taking place at the negotiation table. The strategy speaks for itself on the complexity of social phenomena always at play, and somehow points to further scholar links yet to be made in order to tackle its full extent vis-àvis, for example, literature on social movements.

It is worth mentioning that the deployment of some of these strategies takes place in markets. In these cases, the boundary strategy employs price as a means of calculative agency (as in the case of local price regulation and quality incentives) or expected return (as in the case of investment schemes).

\section{Boundary setting in relation to other knowledge stances:}

Another stream of analysis of knowledge stances relates to the relations between all of the knowledge stances. As it is clear now for the reader, boundary setting describe manoeuvres of actors vis-à-vis other actors, in the attempt to create and expand a practice field. Boundary setting has in this sense a central role, establishing configurations allowing or impeding arrays of activity. Some of these arrays pertain to other stances. This does not mean there is a sort of dead end on boundary settings as unmovable configurations. As was explained conceptually, knowledge stances complement each other in multiple ways.

In order to better illustrate this mutual conditioning, I will discuss some examples. Table 12 describes a series of statements about boundary setting in relation to other knowledge stances. After each statement, I have included an example as a means to bring evidence and facilitate the reader to follow the exposition. 
Table 12. Relation of boundary setting to other knowledge stances

Boundary setting...

\begin{tabular}{|c|c|c|c|c|}
\hline $\begin{array}{l}\text {...Is a possible } \\
\text { result of... }\end{array}$ & $\begin{array}{l}\text {...Creates space } \\
\text { for... }\end{array}$ & ...Employs... & ...Employs... & $\begin{array}{l}\text {...Creates space or } \\
\text { hampers... }\end{array}$ \\
\hline $\begin{array}{c}\text { Boundary } \\
\text { exploration }\end{array}$ & Practice work & $\begin{array}{l}\text { Knowledge } \\
\text { supply }\end{array}$ & $\begin{array}{c}\text { Knowledge } \\
\text { intermediation }\end{array}$ & $\begin{array}{l}\text { Knowledge } \\
\text { exploration }\end{array}$ \\
\hline $\begin{array}{l}\text { e.g. legal } \\
\text { creation of } \\
\text { regional } \\
\text { clusters as } \\
\text { intermediary } \\
\text { organizations } \\
\text { (Obs No, } \\
16 / 01 / 14 ; \text { Obs } \\
\text { Pn, 19/03/15) }\end{array}$ & $\begin{array}{l}\text { e.g. negotiation } \\
\text { with guerrilla } \\
\text { groups and } \\
\text { national } \\
\text { programs to set } \\
\text { initial terms of } \\
\text { cocoa projects } \\
\text { (Obs Ct, } \\
20 / 01 / 14 \text {; Obs } \\
\mathrm{Sr}, 27 / 01 / 14)\end{array}$ & $\begin{array}{l}\text { e.g. expert } \\
\text { legal advice } \\
\text { to establish } \\
\text { intermediary } \\
\text { organizations } \\
\text { (Asc, } \\
07 / 07 / 14 \text { ) }\end{array}$ & $\begin{array}{l}\text { e.g. informing } \\
\text { and } \\
\text { negotiating } \\
\text { with } \\
\text { community } \\
\text { about further } \\
\text { steps of rural } \\
\text { development } \\
\text { projects }(\mathrm{Obs} \\
\mathrm{Sr}, 27 / 01 / 14)\end{array}$ & $\begin{array}{l}\text { e.g. collaborative } \\
\text { research } \\
\text { agreements } \\
\text { universities, } \\
\text { using national } \\
\text { research funds } \\
\text { (Fg Cn, 23/01/14; } \\
\text { Obs Mc, 14/01/14) }\end{array}$ \\
\hline $\begin{array}{l}\text {...Establishes } \\
\text { the extent of... }\end{array}$ & $\begin{array}{l}\text {...Facilitates or } \\
\text { hampers... }\end{array}$ & $\begin{array}{l}\text {...Sets the } \\
\text { scene and } \\
\text { possibilities } \\
\text { for forms of... }\end{array}$ & $\begin{array}{l}\text {...Sets the } \\
\text { scene and } \\
\text { possibilities } \\
\text { for forms of... }\end{array}$ & $\begin{array}{l}\text {...Facilitates or } \\
\text { hampers... }\end{array}$ \\
\hline $\begin{array}{l}\text { Boundary } \\
\text { exploration }\end{array}$ & Practice work & $\begin{array}{l}\text { Knowledge } \\
\text { supply }\end{array}$ & $\begin{array}{l}\text { Knowledge } \\
\text { intermediation }\end{array}$ & $\begin{array}{l}\text { Knowledge } \\
\text { exploration }\end{array}$ \\
\hline $\begin{array}{l}\text { e.g. } \\
\text { organizations' } \\
\text { room for } \\
\text { manoeuvre in } \\
\text { national } \\
\text { projects } \\
\text { requiring local } \\
\text { approval (Obs } \\
\mathrm{Ct}, 20 / 01 / 14 ; \\
\text { Obs } \mathrm{Sr}, \\
27 / 01 / 14)\end{array}$ & $\begin{array}{l}\text { e.g. depredatory } \\
\text { middlemen } \\
\text { taking } \\
\text { smallholders' } \\
\text { subsidies (Obs } \\
\text { Ct, 20/01/14) }\end{array}$ & $\begin{array}{l}\text { e.g. } \\
\text { agreements } \\
\text { with the } \\
\text { national } \\
\text { extension } \\
\text { service for } \\
\text { youngsters' } \\
\text { education } \\
\text { (Amb, } \\
14 / 02 / 14 \text {; Obs } \\
\mathrm{Cn}, 23 / 01 / 14 \text { ) }\end{array}$ & $\begin{array}{l}\text { e.g. } \\
\text { organizations' } \\
\text { design and } \\
\text { delivery of } \\
\text { advisory and } \\
\text { training (Fg } \\
\mathrm{Cn}, 23 / 01 / 14 \text {; } \\
\text { Fg Ct, } \\
\text { 20/01/14; Fg } \\
\mathrm{Mc}, 14 / 01 / 14)\end{array}$ & $\begin{array}{l}\text { e.g. terms and } \\
\text { orientation of } \\
\text { research funding } \\
\text { programs } \\
\text { (Fg Cn, 23/01/14) }\end{array}$ \\
\hline
\end{tabular}




\subsubsection{Boundary exploration}

Boundary exploration summarizes notions such as "collaborating," "joining forces," "working together to achieve" or "finding solutions together." Strategy types under this category refer to coping strategies linking organizations to their peers or to other partners.

Types under this strategy pattern refer to forms of boundary re-scaling by means of collaborating. The scope and depth of re-scaling depend on the means and ends of collaboration, as will be discussed. These grouped forms of agency overlap scales (e.g. local, subregional or national) as well as sectors (e.g. development, value chain, local actors) and can have effects on the practice field as a whole.

Table 13 shows an overview of boundary exploration strategies found empirically. The reader will note I have added a new column, intensity. I will use it to further discuss boundary exploration, specifically regarding the intensity of boundary blurring taking place along collaborations.

Table 13. Boundary exploration strategies

\begin{tabular}{|c|c|c|c|}
\hline $\begin{array}{c}\text { Knowledge } \\
\text { stance }\end{array}$ & Category & Intensity & Strategies \\
\hline \multirow{6}{*}{$\begin{array}{l}\text { Boundary } \\
\text { exploring }\end{array}$} & \multirow{6}{*}{ Re-scaling } & Shared performance & $\begin{array}{l}\text { Partnering (to allow and } \\
\text { deepen practice) }\end{array}$ \\
\hline & & Power positions & Strengthen network \\
\hline & & Shared assets & $\begin{array}{l}\text { Logistics, distribution, } \\
\text { storage }\end{array}$ \\
\hline & & Power positions & $\begin{array}{l}\text { Price negotiation via } \\
\text { volume }\end{array}$ \\
\hline & & Shared performance & $\begin{array}{l}\text { Scale up public } \\
\text { investment }\end{array}$ \\
\hline & & Power positions & $\begin{array}{l}\text { Lobby and presence } \\
\text { with a national network }\end{array}$ \\
\hline
\end{tabular}

The first set of strategies relates to partnering to share assets. Physical assets include logistical solutions, distribution channels and storage infrastructure (Fg No, 16/01/14; Obs Pn, 19/03/15). Some other intangible assets could also be included here, such as information about market 
conditions and support opportunities, linking to organizations' peer-topeer technical and non-technical training, and advising (Amb, 14/02/14; Asc, 07/07/14). Because of its natural link to knowledge practices it will be detailed later. It is worth noting, however, that peer-to-peer knowledge supply is also a feature of boundary exploration.

Another group of strategies refers to forms of shared performance, namely, networking to access public investment, partnering with third parties and scaling public investment. Unlike the first set, where boundaries are kept except to take better advantage of specific assets, these types describe modes of shared operation, showing repertoires of boundary expansion. This is the case of some clusters of organizations at subregional levels (Fg No, 16/01/14; Obs Pn, 19/03/15). Shared operation, interestingly, takes place also in some collaborative projects involving enterprises, farmers' organizations and NGOs (Am, 14/11/14; Asc, 07/07/14).

The last set of types relates to boundary exploring as a means to power shared positions, namely, to coordinate positions to negotiate prices (which might entail also partnering to collect cocoa grain), gain sector influence and demand local accountability. Boundary strategies here attempt to supersede disadvantageous boundary situations by means of showing the extent of re-scaled potential. While this might work at the business level to negotiate price (Fg Ct, 20/01/14; Fg Mc, 14/01/14; Obs Pn, 19/03/15), this allows organizations at the sector level to voice their interests in policy-making fora (Asc, 07/07/14). At the local level this allows organizations to bring topics to the territorial agenda (Obs $\mathrm{Cn}$, 23/01/14; Obs Mc, 14/01/14; Obs Pn, 19/03/15; Obs Sr, 27/01/14).

Strengthening the network is itself another type. Which is telling about the place of this strategy in organizations' priorities. In effect, networking aims to be useful for organizations in terms of facilitating economies of scale, optimizing support access and striving to gain a steering position (Amb, 14/02/14; Asc, 07/07/14; Fg Ct, 20/01/14).

Relation of boundary exploration to other knowledge stances:

As it is clear now for the reader, boundary exploration describe incidence of forms of collaboration-boundary blurring-in the attempt to create and expand a practice field. Boundary exploration has in this sense a central role, as a vehicle of practice beyond boundaries themselves, 
establishing configurations allowing arrays of activity. As was explained conceptually, knowledge stances complement themselves in multiple ways.

In order to better illustrate this mutual conditioning, table 14 describes a series of statements about boundary exploration in relation to other knowledge stances. After each statement I have included an example to bring evidence and help the reader follow the exposition.

Table 14. Relation of boundary setting to other knowledge stances

\begin{tabular}{|c|c|c|c|c|}
\hline $\begin{array}{l}\text { Possibly leads } \\
\text { to the creation } \\
\text { of... }\end{array}$ & $\begin{array}{l}\text { Expands a } \\
\text { field for... }\end{array}$ & $\begin{array}{l}\text { Employs } \\
\text { experiential } \\
\text { forms of... }\end{array}$ & Employs... & $\begin{array}{l}\text { Creates space } \\
\text { for... }\end{array}$ \\
\hline $\begin{array}{l}\text { Boundary } \\
\text { setting }\end{array}$ & Practice work & $\begin{array}{l}\text { Knowledge } \\
\text { supply }\end{array}$ & $\begin{array}{c}\text { Knowledge } \\
\text { intermediation }\end{array}$ & $\begin{array}{l}\text { Knowledge } \\
\text { exploration }\end{array}$ \\
\hline $\begin{array}{l}\text { e.g. founding } \\
\text { of the national } \\
\text { network as an } \\
\text { intermediary } \\
\text { organization } \\
\text { (Asc, } 07 / 07 / 14 \text { ) }\end{array}$ & $\begin{array}{l}\text { e.g. multi- } \\
\text { party } \\
\text { collaborative } \\
\text { platforms with } \\
\text { enterprises } \\
\text { and NGOs } \\
\text { (Obs Pn, } \\
\text { 19/03/15; Obs } \\
\mathrm{Sr}, 27 / 01 / 14)\end{array}$ & $\begin{array}{l}\text { e.g. } \\
\text { international } \\
\text { business } \\
\text { rounds, meeting } \\
\text { logistic } \\
\text { intermediaries } \\
\text { and buyers (Obs } \\
\text { Am, 14/11/14) }\end{array}$ & $\begin{array}{l}\text { e.g. projects } \\
\text { carried out by } \\
\text { subregional } \\
\text { clusters of } \\
\text { organizations } \\
\text { (Obs No, } \\
\text { 16/01/14; Obs } \\
\text { Pn, 19/03/15) }\end{array}$ & $\begin{array}{l}\text { e.g. } \\
\text { collaborative } \\
\text { research } \\
\text { programs with } \\
\text { enterprises, } \\
\text { developing } \\
\text { tailored post- } \\
\text { harvest } \\
\text { practices (Fg } \\
\mathrm{Cn}, 23 / 01 / 14)\end{array}$ \\
\hline $\begin{array}{l}\text { Is bounded by } \\
\text { existent... }\end{array}$ & $\begin{array}{l}\text { Expands a } \\
\text { field for... }\end{array}$ & $\begin{array}{l}\text { Sets the scene } \\
\text { and possibilities } \\
\text { for re-scaled } \\
\text { forms of... }\end{array}$ & $\begin{array}{l}\text { Sets the scene } \\
\text { and possibilities } \\
\text { for re-scaled } \\
\text { forms of... }\end{array}$ & $\begin{array}{l}\text { Sets the scene } \\
\text { and possibilities } \\
\text { for re-scaled } \\
\text { forms of... }\end{array}$ \\
\hline $\begin{array}{l}\text { Boundary } \\
\text { setting }\end{array}$ & Practice work & $\begin{array}{l}\text { Knowledge } \\
\text { supply }\end{array}$ & $\begin{array}{c}\text { Knowledge } \\
\text { intermediation }\end{array}$ & $\begin{array}{l}\text { Knowledge } \\
\text { exploration }\end{array}$ \\
\hline $\begin{array}{l}\text { e.g. rationale } \\
\text { and } \\
\text { requirements } \\
\text { of national } \\
\text { royalty funds } \\
\text { (Fg Cn, } \\
23 / 01 / 14)\end{array}$ & $\begin{array}{l}\text { e.g. partnering } \\
\text { to create } \\
\text { subregional } \\
\text { intermediary } \\
\text { organizations } \\
\text { (Fg No, } \\
\text { 16/01/14; Obs } \\
\text { Pn, 19/03/15) }\end{array}$ & $\begin{array}{l}\text { e.g. agreements } \\
\text { for education for } \\
\text { the youngsters } \\
(\mathrm{Amb}, 14 / 02 / 14)\end{array}$ & $\begin{array}{l}\text { e.g. network- } \\
\text { based training } \\
\text { and technical } \\
\text { assistance } \\
\text { delivery (Fg Sr, } \\
27 / 01 / 14 \text { ) }\end{array}$ & $\begin{array}{l}\text { e.g. cocoa- } \\
\text { characterizing } \\
\text { research with } \\
\text { subregional } \\
\text { reach (Obs Mc, } \\
\text { 14/01/14; Obs } \\
\text { Pn, 19/03/15) }\end{array}$ \\
\hline
\end{tabular}




\subsubsection{Practice work}

Practice work describes those arrays of activity enacting, making possible, shaping and sustaining practice, an array of activity having shared meaning, in time. Put in simpler words, practice work includes those gestures describing how actors "go about" creating and strengthening a specific practice field.

"Going about" a practice field should be understood here as the array of features by which an actor's presence in a field can be distinguished from others. We could say farmers' organizations go about cocoa business in a different way than other players. Not just in the more evident sense of having a specific place and heft in a value chain, but in the sense of striving to perform in such a way that will secure having a societal impact (Amb, 14/02/14; Asc, 07/07/14).

Practice work takes place through different means. The first way is through agency itself, by means of enactment. A set of practices (often starting with a promise) is incorporated in the actions of an organization to engage or develop with a practice field, as is the case when local champions take on breeding cocoa as an alternative and strive to convince others to follow (Fg Cn, 23/01/14; Fg Ct, 20/01/14; Fg Mc, 14/01/14; Fg No, 16/01/14; Fg Sr, 27/01/14).

Organizations are here a vehicle of exogenous practices entering the local realm. Knowledge is enacted by organizations' own means or by bringing third parties to the table in what constitutes a form of bringing about a role and positioning an identity. It is the case when leaders risk everything to start with a cocoa project out of the blue (Fg Ct, 20/01/14; Fg Mc, 14/01/14). Actors' presence comprises here a form of knowledge supply, embedding itself as a culture, a way of doing, an example of practice. These acts embed or mark an initial or original stance. Arguably, this stance goes hand in hand with the boundary strategy of "negotiate to exist" as its inner facet. Later in this chapter I will develop this point.

A second means of practice work refers to intermediation through practice. Here organizations devise ways of sourcing and financing practice itself. In effect, deepening existence of the practice field as an embedded social reality implies accessing, for example, financial resources (Obs Mc, 
14/01/14), technologies (Obs Cn, 23/01/14) and legal advice (Obs Exp 001, 16/07/14).

Strategies include creating funding and support opportunities and bypassing level restrictions. This latter strategy refers to organizations' attempts to solve gaps at the local level due to corruption or municipal weakness. It is worth remembering these strategies are played in different fields and therefore require deployment of different protocols. Some are business based (Fg Sr, 27/01/14), while others are development-project based (Obs Sr, 27/01/14) or politically lobbied (Obs Pn, 19/03/15). Its common pattern relates to meso-level endeavours to secure means allowing developing the field of practice.

Organizations look for partnerships or sponsorships making it possible to fund research, training or specialized staffing. Often the process describes some sort of triangulation: A partnership lacks a piece of a puzzle and then the organization strives to obtain it. For example, an organization can fund specialized internships in agreement with an university, the logistic costs of expert training or a cocoa quality lab (Am, 14/11/14; Obs Mc, 14/01/14; Obs Pn, 19/03/15). Organizations deploy these strategies to strengthen the endogenous realm with a long-term rationale, striving to breed the field of practice. Complementary types, namely, allocating resources incrementally, informing and including are telling about organizations' aims given a scarce or shifting context.

The last means of practice work refers to normalizing practices. Here organizations set rules as means to guide and stabilize a field of practice. For example, they can set rules with quality contests (Interview Ofc 002, 05/02/14; Amb, 14/02/14), best organizational and developmental practices (Amb, 14/02/14), or visions attempting to influence local policies (Obs Mc, 14/01/14; Obs Sr, 27/01/14).

Some of these strategies, such as setting a market access vision, productive standards or best practices, take place within the sphere of action of organizations. Here organizations aim at developing practice in a specific direction by utilizing these normative devices (Amb, 14/02/14; Fg Cn, 23/01/14; Obs Mc, 14/01/14; Obs Pn, 19/03/15).

Some other attempts go beyond the immediate sphere of action of organizations, as with organizations' attempts to position a vision to 
influence policy (Amb, 14/02/14; Fg Cn, 23/01/14; Fg Sr, 27/01/14). Policy is a way organizations stream their visions, values and interests at territorial and sectorial levels. By targeting policy, organizations strive to set a guiding compass in a broader scale, shaping mid-to-long-term planning sceneries of other actors.

Table 15 shows an overview of practice work strategies found empirically. The reader will note I have added a new column, intention. I will use it to further discuss practice work, specifically regarding the various forms by which the actor aims at streamlining specific arrays of activity in the practice field.

\begin{tabular}{|c|c|c|c|}
\hline \multicolumn{4}{|c|}{ Table 15. Practice work strategies } \\
\hline $\begin{array}{l}\text { Knowledge } \\
\text { stance }\end{array}$ & Category & Intention & Strategies \\
\hline \multirow{10}{*}{$\begin{array}{l}\text { Practice } \\
\text { work }\end{array}$} & \multirow{3}{*}{ Enactment } & Set & Perform \\
\hline & & Connect & Mimic other actors' functions \\
\hline & & Connect & $\begin{array}{l}\text { Create a space for other } \\
\text { institutions to deliver services }\end{array}$ \\
\hline & \multirow{4}{*}{$\begin{array}{l}\text { Intermediating } \\
\text { means }\end{array}$} & Set & Devise support schemes \\
\hline & & Connect & Create funding opportunities \\
\hline & & Set & $\begin{array}{l}\text { Allocate resources } \\
\text { incrementally, inform, include }\end{array}$ \\
\hline & & Connect & Bypass level restrictions \\
\hline & \multirow{3}{*}{ Normalizing } & Set & $\begin{array}{l}\text { Position a vision to influence } \\
\text { policy }\end{array}$ \\
\hline & & Set & Set visions about market access \\
\hline & & Set & $\begin{array}{l}\text { Set and reward standards and } \\
\text { best practice }\end{array}$ \\
\hline
\end{tabular}

Two intentions are shown to take place in practice work strategies. First is the intention of connecting. Organizations connect with other parties as a way to enter the practice field, to strengthen its base, or to secure its means. These parties perform different roles vis-à-vis the practice field. While some take part in the practice field itself, as, for example gilds or 
processing factories, some others have a circumstantial presence, as is the case of international organizations or municipalities.

The protocols, justifications and aims of these connections respond to the fields in which these connections take place, but also to their reach in relation to the role of organizations in the practice field: They are shown here as a means of practice itself, support devices or bridges to regulation. Overall, they operate as external sources of organizations on their way to secure practice institutionalization.

A second intention of practice work refers to setting. Stabilization of the practice field refers to identifying and deepening its routines. This aspect accounts for practice itself, as a socially embedded trait, but it also accounts for the means that makes it possible. Organizations' goals to set a practice include that of setting the pool of support and conditions by which their desired way of practice might last over time, that is, a take on practice also as an institutional trait. Evidence appears to indicate that in the volatile contexts of these organizations, this pool of support is as important as practice itself-even if somehow out of its immediate scope.

\section{Relation of practice work to other knowledge stances:}

As it is clear now for the reader, practice work describes ways to go about the practice field itself. Practice work has in this sense a central role, as the vehicle by means of which practice is shaped. As was explained conceptually, knowledge stances complement themselves in multiple ways.

In order to better illustrate this mutual conditioning, I will discuss some examples. Table 16 describes a series of statements about practice work in relation to other knowledge stances. After each statement, I have included an example, as a means to bring evidence and facilitate the reader to follow the exposition.

Table 16. Relation of practice work to other knowledge stances

Practice work...

\begin{tabular}{|l|l|l|l|l} 
Makes use of... & $\begin{array}{l}\text { Takes place in } \\
\text { the context of... }\end{array}$ & $\begin{array}{l}\text { Is } \\
\text { appropriated } \\
\text { through... }\end{array}$ & Makes use of... & $\begin{array}{l}\text { Is clarified and } \\
\text { set via... }\end{array}$
\end{tabular}




\begin{tabular}{|c|c|c|c|c|}
\hline $\begin{array}{l}\text { Boundary } \\
\text { setting }\end{array}$ & $\begin{array}{l}\text { Boundary } \\
\text { exploration }\end{array}$ & $\begin{array}{l}\text { Knowledge } \\
\text { supply }\end{array}$ & $\begin{array}{c}\text { Knowledge } \\
\text { intermediation }\end{array}$ & $\begin{array}{l}\text { Knowledge } \\
\text { exploration }\end{array}$ \\
\hline $\begin{array}{l}\text { e.g. Defining } \\
\text { productive and } \\
\text { developmental } \\
\text { standards } \\
\text { (Amb, 14/02/14; } \\
\text { Asc, O. } \\
07 / 07 / 14 \text { ) }\end{array}$ & $\begin{array}{l}\text { e.g. taking part } \\
\text { of alternative } \\
\text { development } \\
\text { projects (Obs } \\
\text { Cn, 23/01/14; } \\
\text { Fg Ct, } \\
20 / 01 / 14 \text {; Obs } \\
\text { Mc, 14/01/14; } \\
\text { Obs No, } \\
16 / 01 / 14 ; \text { Obs } \\
\text { Sr, 27/01/14) }\end{array}$ & $\begin{array}{l}\text { e.g. post- } \\
\text { harvest } \\
\text { training (Obs } \\
\text { Pn, O. } \\
\text { 19/03/15; } \\
\text { Fg Cn, } \\
(23 / 01 / 14)\end{array}$ & $\begin{array}{l}\text { e.g. community } \\
\text { evaluations } \\
\text { before, during } \\
\text { and after } \\
\text { development } \\
\text { projects (Fg } \mathrm{Sr} \text {, } \\
27 / 01 / 14 \text { ) }\end{array}$ & $\begin{array}{l}\text { e.g. definition } \\
\text { of appropriated } \\
\text { crops and best } \\
\text { possible post- } \\
\text { harvest } \\
\text { practices (Obs } \\
\text { Pn, 19/03/15) }\end{array}$ \\
\hline $\begin{array}{l}\text { Is facilitated or } \\
\text { hampered by... }\end{array}$ & $\begin{array}{l}\text { Leads to } \\
\text { processes of... }\end{array}$ & Makes use of... & Makes use of... & $\begin{array}{l}\text { Is clarified and } \\
\text { set via... }\end{array}$ \\
\hline $\begin{array}{l}\text { Boundary } \\
\text { setting }\end{array}$ & $\begin{array}{l}\text { Boundary } \\
\text { exploration }\end{array}$ & $\begin{array}{l}\text { Knowledge } \\
\text { supply }\end{array}$ & $\begin{array}{c}\text { Knowledge } \\
\text { intermediation }\end{array}$ & $\begin{array}{l}\text { Knowledge } \\
\text { exploration }\end{array}$ \\
\hline $\begin{array}{l}\text { e.g. legal } \\
\text { conditions or } \\
\text { arrangements } \\
\text { allowing } \\
\text { degrees of } \\
\text { manoeuver to } \\
\text { organizations } \\
\text { (Asc, O. } \\
07 / 07 / 14)\end{array}$ & $\begin{array}{l}\text { e.g. specialized } \\
\text { niches farming } \\
\text { contracts }(\mathrm{Obs} \\
\mathrm{Sr}, 27 / 01 / 14 ; \\
\mathrm{Fg} \mathrm{Cn}, \\
23 / 01 / 14)\end{array}$ & $\begin{array}{l}\text { e.g. training on } \\
\text { standards (Fg } \\
\mathrm{Mc}, 14 / 01 / 14 ; \\
\mathrm{Fg} \mathrm{Ct} \\
20 / 01 / 14 ; \\
\mathrm{Fg} \mathrm{Cn} \text {, } \\
23 / 01 / 14)\end{array}$ & $\begin{array}{l}\text { e.g. devising } \\
\text { learning-by-doing } \\
\text { schemes on } \\
\text { projects (Fg Sr. } \\
27 / 01 / 14 \text { ) }\end{array}$ & $\begin{array}{l}\text { e.g. specialized } \\
\text { legal advice } \\
\text { (Interview } \\
\text { Exprt 001, } \\
\text { 16/07/14) }\end{array}$ \\
\hline
\end{tabular}

\subsubsection{Knowledge Supply}

Knowledge supply refers to knowledge delivery taking place within or in relation to other knowledge stances. Contents of knowledge supply include local, contextual, technical, expert and/or scientific forms of knowledge.

Along with these various forms of knowledge, there are also different knowledge containers, which include training (e.g. post-harvest technologies), up-to-date information (e.g. program calls), reports of various kinds (e.g. technical or legal), technologies (e.g. protocols, eventually leading to new objects) and persons. It is worth remembering that this research knowledge links to enacted knowledge and knowledgeable people rather than abstract types. Knowledge supply is a crosscutting stance in boundary exploration, boundary setting and practice work stances. 
Knowledge supply includes strategies related to knowledge filtering, allocating and delivery. First I will refer to knowledge filtering. Here organizations (or their scaled forms) cope with knowledge requirements or gaps and manoeuvre to satisfy them. For example, organizations request legal advice to assess possible intermediary legal structures (Asc, 07/07/14; Obs Pn, 19/03/15) or develop a better understanding of their assets and decide on technological requirements to access specialized marketing niches (Am, 14/11/14; Obs Mc, 14/01/14; Obs Pn, 19/03/15). Knowledge filtering includes strategies such as clarifying knowledge demands and appointing providers.

The second group of strategies describes knowledge allocation. The term allocation stresses a conscious function of targeting or distributing knowledge means, in various ways. One way, knowledge scaling, focus on training strategies, assigning at different scales (that is, at member, organizational, node or network levels). Another way, staffing, refers to appointing or shifting the appointment of people and knowledge provisions to other levels, as is the case, for example, with member-sourced provision schemes (Obs Mc, 14/01/14) or the flexible scaling or re-design of organizations based on sub organizational emerging capabilities (Obs No, 16/01/14; Obs Sr, 27/01/14).

The last group of strategies clusters forms of knowledge delivery. Naturally, delivery stresses the knowledge providing function as such. Here belong strategies such as training, gathering and circulating information, and peer advising. When in different fields, these take on its specific contents and rationales. In-field technical aspects of seedling breeding (Obs $\mathrm{Cn}, 23 / 01 / 14$ ), for example, have different vehicles and containers than project management (Obs Sr, 27/01/14). It is worth taking a minute to reflect on peer-to-peer training and advice, pointing to the fact that organizations regard their peers' knowledge and experience as a valuable learning source (Amb, 14/02/14; Obs Ct, 20/01/14; Obs Mc, 14/01/14)

Table 17 shows an overview of knowledge supply strategies found empirically. The reader will note I have added a new column, labelled target. I will use it to further discuss knowledge supply, specifically regarding the targets organizations are likely pointing at with their supply strategies. 
Table 17. Knowledge supply strategies

\begin{tabular}{|c|c|c|c|}
\hline $\begin{array}{c}\text { Knowledge } \\
\text { stance }\end{array}$ & Category & Target & Strategies \\
\hline \multirow{6}{*}{$\begin{array}{l}\text { Knowledge } \\
\text { supply }\end{array}$} & \multirow{2}{*}{ Filtering } & Capabilities & \multirow{2}{*}{$\begin{array}{l}\text { Clarify knowledge } \\
\text { demands, appoint } \\
\text { providers }\end{array}$} \\
\hline & & Capacities & \\
\hline & \multirow{3}{*}{ Allocate } & Capacities & $\begin{array}{l}\text { Scale down and up } \\
\text { knowledge, human } \\
\text { resources and } \\
\text { processes }\end{array}$ \\
\hline & & Capacities & Staff the local realm \\
\hline & & Capabilities & $\begin{array}{l}\text { Peer advising and } \\
\text { training }\end{array}$ \\
\hline & Delivery & Capabilities & $\begin{array}{l}\text { Training, gather and } \\
\text { circulate market } \\
\text { information }\end{array}$ \\
\hline
\end{tabular}

Some strategies target capabilities while others target capacities. The focus on capabilities relates to the skills or abilities of individuals. This takes place regardless of the field or contents. Targeting capabilities includes farmers' training (Obs $\mathrm{Pn}, 19 / 03 / 15)$ and project management training (Fg Sr, 27/01/14), for example.

The focus on capacities relates to contents adding to organizational performance, or, given the case, extra-organizational performance, which also includes nodes and communities (Obs Pn, 19/03/15; Obs Sr, 27/01/14). Appointing local human resources and abilities evidences a strong focus on increasingly developing autonomy. Knowledge contents targeting capacities relate to expert contextual knowledge, such as legal advice (Obs Exp 001, 16/07/14) or that of specialized niches (Interview Ofc 004, 17/10/14).

Although one could say that in the long term the targets of capacities and capabilities tend to overlap, it is worth considering the differences-and the tensions - these aspects play on organizations' priorities in view of a long-term set of aims. 
As it is clear now for the reader, knowledge supply describe manoeuvres of knowledge delivery serving different stances of organizations. Knowledge supply has in this sense a central role, feeding organizations' capabilities and capacities. Naturally, other stances also impact knowledge supply.

In order to better illustrate this mutual conditioning, I will discuss some examples. Table 18 describes a series of statements about knowledge supply in relation to other knowledge stances. After each statement, I have included an example, as a means to bring evidence and facilitate the reader to follow the exposition.

Table 18. Relation of knowledge supply to other knowledge stances

\begin{tabular}{|c|c|c|c|c|}
\hline \multicolumn{5}{|c|}{ Knowledge supply... } \\
\hline $\begin{array}{l}\text { Is bounded by } \\
\text { and takes place } \\
\text { in various } \\
\text { possible... }\end{array}$ & $\begin{array}{l}\text { Is scaled } \\
\text { through... }\end{array}$ & $\begin{array}{l}\text { Follows } \\
\text { drivers, } \\
\text { rationales, } \\
\text { protocols and } \\
\text { contents of... }\end{array}$ & $\begin{array}{l}\text { Delivers from } \\
\text { processes of... }\end{array}$ & $\begin{array}{l}\text { Finds its } \\
\text { contents (also) } \\
\text { in processes } \\
\text { of... }\end{array}$ \\
\hline $\begin{array}{c}\text { Boundary } \\
\text { setting }\end{array}$ & $\begin{array}{l}\text { Boundary } \\
\text { exploration }\end{array}$ & Practice work & $\begin{array}{c}\text { Knowledge } \\
\text { intermediation }\end{array}$ & $\begin{array}{l}\text { Knowledge } \\
\text { exploration }\end{array}$ \\
\hline $\begin{array}{l}\text { e.g. project } \\
\text { management } \\
\text { training within } \\
\text { learning-by- } \\
\text { doing schemes } \\
\text { (Fg Sr, } \\
27 / 01 / 14 \text { ); } \\
\text { collaborative } \\
\text { training } \\
\text { provision within } \\
\text { an NGO- } \\
\text { Organization } \\
\text { partnership } \\
\text { (Interview Ofc } \\
\text { 001, 05/02/14; } \\
\text { Interview Ofc } \\
002,05 / 02 / 14 \text { ) }\end{array}$ & $\begin{array}{l}\text { e.g. downscaling } \\
\text { project } \\
\text { operations } \\
\text { within a } \\
\text { subregional } \\
\text { cluster of } \\
\text { organizations } \\
\text { (Fg Sr, 27/01/14) }\end{array}$ & $\begin{array}{l}\text { e.g. } \\
\text { maneuvering } \\
\text { to set possible } \\
\text { outcomes of } \\
\text { collaborative } \\
\text { research with } \\
\text { enterprises } \\
\text { (Fg Sr, } \\
27 / 01 / 14)\end{array}$ & $\begin{array}{l}\text { e.g. training } \\
\text { protocols within } \\
\text { organizations } \\
\text { (including } \\
\text { technical aspects } \\
\text { and human } \\
\text { development) } \\
\text { (Obs Ct, 20/01/14; } \\
\text { Obs Mc, 14/01/14) }\end{array}$ & $\begin{array}{l}\text { e.g. Setting } \\
\text { and } \\
\text { promoting } \\
\text { post-harvest } \\
\text { protocols (Fg } \\
\mathrm{Sr}, 27 / 01 / 14)\end{array}$ \\
\hline Shift scales of... & $\begin{array}{l}\text { Gets contents } \\
\text { through } \\
\text { processes of... }\end{array}$ & $\begin{array}{l}\text { Follows } \\
\text { drivers, } \\
\text { rationales, } \\
\text { protocols and }\end{array}$ & $\begin{array}{l}\text { Delivers from } \\
\text { processes of... }\end{array}$ & $\begin{array}{l}\text { Is clarified } \\
\text { and set via... }\end{array}$ \\
\hline
\end{tabular}




\begin{tabular}{|c|c|c|c|c|}
\hline & & contents of... & & \\
\hline $\begin{array}{l}\text { Boundary } \\
\text { setting }\end{array}$ & $\begin{array}{l}\text { Boundary } \\
\text { exploration }\end{array}$ & Practice work & $\begin{array}{c}\text { Knowledge } \\
\text { intermediation }\end{array}$ & $\begin{array}{l}\text { Knowledge } \\
\text { exploration }\end{array}$ \\
\hline $\begin{array}{l}\text { e.g. schemes of } \\
\text { member } \\
\text { provision within } \\
\text { organizations } \\
\text { (Obs Mc, } \\
\text { 14/01/14) }\end{array}$ & $\begin{array}{l}\text { e.g. collaborative } \\
\text { projects on } \\
\text { sustainable } \\
\text { development } \\
\text { with NGOs and } \\
\text { traders (Obs Sr, } \\
27 / 01 / 14 \text {; } \\
\text { Interview Ldr } \\
004,16 / 06 / 14)\end{array}$ & $\begin{array}{l}\text { e.g. training } \\
\text { on standards } \\
\text { (Fg Mc, } \\
\text { 14/01/14; } \\
\text { Fg Ct, } \\
20 / 01 / 14 \text {; } \\
\text { Fg Cn, } \\
23 / 01 / 14 \text { ) }\end{array}$ & $\begin{array}{l}\text { e.g. making use of } \\
\text { forms adjusted to } \\
\text { local contexts (Fg } \\
\text { Sr. } 27 / 01 / 14)\end{array}$ & $\begin{array}{l}\text { e.g. } \\
\text { specialized } \\
\text { legal advice } \\
\text { (Interview } \\
\text { Exprt 001, } \\
\text { 16/07/14) }\end{array}$ \\
\hline
\end{tabular}

\subsubsection{Knowledge intermediation}

Knowledge intermediation refers to forms of knowledge work (that is, knowledge storage, manipulation and delivery) aiming to protect a practice field. Knowledge intermediation describes here creative forms of receiving, filtering and delivering knowledge in the attempt to better fit boundary crossroads.

Knowledge intermediation includes types related to knowledge translation and mediation. The first types, namely, anticipate, adapt, adjust, prepare and translate. These types illustrate attempts to better match endogenous interests or capabilities with external input, manoeuvring to synchronize paces and priorities, adjusting internal and external languages and providing internal bases to match external standards.

Another set of types describes a mediation function, namely, devising long-term training schemes for the youngsters and storing a knowledge base. By using the term mediation, I try to stress organizations' conscious design of educative means. This type, naturally related to knowledge delivery, stresses a specific repertoire in which organizations strategize with knowledge itself.

Further, these types describe organizations' interests in securing mid-tolong-term knowledge provisions, which I referred to before as a keen interest in knowledge sustainability. Evidence also indicates the interest to deliver education in both physical and social technologies, this includes 
technical productive aspects as well as managerial and personal development knowledges. To this end, organizations partner with actors both from the rural development sector as well as actors within the cocoa value chain (Obs Exp 001, 16/07/14; Amb, 14/02/14; Obs Cn, 23/01/14; Obs Mc, 14/01/14).

Table 19 shows an overview of knowledge intermediation strategies found empirically. The reader will note I have added a new column, labelled timing scope. I will use it to further discuss knowledge intermediation, specifically regarding the various scopes of impact the actor aims to target with knowledge work.

\begin{tabular}{|c|c|c|l|}
\hline \multicolumn{4}{|c|}{ Table 19. Knowledge intermediation strategies } \\
\hline \multirow{2}{*}{ Knowledge stance } & Category & $\begin{array}{c}\text { Timing } \\
\text { scope }\end{array}$ & \multicolumn{1}{c|}{ Strategies } \\
\hline \multirow{2}{*}{$\begin{array}{c}\text { Knowledge } \\
\text { intermediation }\end{array}$} & Translation & Pace & $\begin{array}{l}\text { Anticipate, adapt, } \\
\text { adjust, prepare } \\
\text { and translate }\end{array}$ \\
\cline { 2 - 4 } & Mediation & Long term & $\begin{array}{l}\text { Store a knowledge } \\
\text { base }\end{array}$ \\
\cline { 2 - 4 } & Long term & $\begin{array}{l}\text { Devise long-term } \\
\text { training schemes } \\
\text { for youngsters }\end{array}$ \\
\hline
\end{tabular}

Knowledge intermediation strategies show different timing scopes. Some are focused on pace, while others on the long term. Pace-related strategies refer to forms of adjusting internal-that is, those of smallholder members or beneficiaries - and external rhythms - that is, those of partners.

Here we see knowledge work responding to boundaries, facilitating a better match of local conditions regarding external input. Pacing strategies include, for example, mechanisms of adaptation, such as iterative post-harvest trials (Fg $\mathrm{Cn}, 23 / 01 / 14$ ), and translation, such as continuous dialogues with communities and beneficiaries about project contents and management situations (Fg Sr, 27/01/14).

Long-term timing strategies address the more uncertain aspects of the future. Here organizations attempt to build a knowledge base of their own 
making it possible to grant autonomy towards the future (Fg Cn, 23/01/14; Fg Mc, 14/01/14; Obs Mc, 14/01/14). By a similar vein, they also strive to form the next generation, in what constitutes a serious bet on their current choices (Amb, 14/02/14; Obs Mc, 14/01/14; Fg Sr, 27/01/14).

Relation of knowledge intermediation to other knowledge stances:

As it is clear now for the reader, knowledge intermediation describe manoeuvres of knowledge work at the crossroads of boundaries. Knowledge work has in this sense a central role, adjusting internal and external realms. Naturally, other stances also have an impact on knowledge intermediation.

In order to better illustrate this mutual conditioning, I will discuss some examples. Table 20 describes a series of statements about knowledge supply in relation to other knowledge stances. After each statement, I have included an example, as a means to bring evidence and facilitate the reader to follow the exposition.

Table 20. Relation of knowledge intermediation to other knowledge stances

\section{Knowledge intermediation...}

\begin{tabular}{|c|c|c|c|c|}
\hline $\begin{array}{l}\text { Responds to one } \\
\text { or various } \\
\text { coexisting... }\end{array}$ & $\begin{array}{l}\text { Might embed } \\
\text { shifted scales } \\
\text { or include } \\
\text { contents } \\
\text { through } \\
\text { processes of... }\end{array}$ & $\begin{array}{l}\text { Is set through } \\
\text { underlying } \\
\text { drivers, } \\
\text { rationales, } \\
\text { protocols and } \\
\text { contents of... }\end{array}$ & $\begin{array}{l}\text { It's a form of } \\
\text { devising } \\
\text { schemes for... }\end{array}$ & $\begin{array}{l}\text { Finds its } \\
\text { contents (also) } \\
\text { in processes } \\
\text { of... }\end{array}$ \\
\hline Boundary setting & $\begin{array}{c}\text { Boundary } \\
\text { exploration }\end{array}$ & Practice work & $\begin{array}{l}\text { Knowledge } \\
\text { supply }\end{array}$ & $\begin{array}{l}\text { Knowledge } \\
\text { exploration }\end{array}$ \\
\hline $\begin{array}{l}\text { e.g. negotiating } \\
\text { and } \\
\text { manipulating } \\
\text { project design, } \\
\text { methods and } \\
\text { forms for a } \\
\text { better match } \\
\text { with } \\
\text { "beneficiaries" } \\
\text { (Fg Ct, 20/01/14; } \\
\text { Fg No, 16/01/14; } \\
\text { Fg Sr, 27/01/14) }\end{array}$ & $\begin{array}{l}\text { e.g. carry out } \\
\text { clustered } \\
\text { technical } \\
\text { assistance } \\
\text { projects }(\mathrm{Fg} \\
\mathrm{Cn}, 23 / 01 / 14 \text {; } \\
\text { Fg No, } \\
16 / 01 / 14)\end{array}$ & $\begin{array}{l}\text { e.g. securing } \\
\text { collaborative } \\
\text { settings for } \\
\text { training } \\
\text { (including } \\
\text { leadership, } \\
\text { agriculture } \\
\text { general aspects } \\
\text { and technical } \\
\text { priorities) } \\
\text { (Amb, } \\
\text { 14/02/14) }\end{array}$ & $\begin{array}{l}\text { e.g. long-term } \\
\text { educative } \\
\text { designs for the } \\
\text { youngsters } \\
\text { (Amb, } \\
14 / 02 / 14 ; \mathrm{Fg} \\
\mathrm{Cn}, 23 / 01 / 14)\end{array}$ & $\begin{array}{l}\text { e.g. } \\
\text { development of } \\
\text { grain-drying } \\
\text { infrastructures } \\
\text { (Obs Pn, } \\
19 / 03 / 15)\end{array}$ \\
\hline
\end{tabular}


Table 20. Relation of knowledge intermediation to other knowledge stances

Knowledge intermediation...

\begin{tabular}{|c|c|c|c|c|}
\hline $\begin{array}{l}\text { Might be } \\
\text { facilitated or } \\
\text { hampered by... }\end{array}$ & $\begin{array}{l}\text { Might embed } \\
\text { shifted scales } \\
\text { or include } \\
\text { contents } \\
\text { through } \\
\text { processes of... }\end{array}$ & $\begin{array}{l}\text { Is set through } \\
\text { underlying } \\
\text { drivers, } \\
\text { rationales, } \\
\text { protocols and } \\
\text { contents of... }\end{array}$ & $\begin{array}{l}\text { It's a form of } \\
\text { devising } \\
\text { schemes for... }\end{array}$ & $\begin{array}{l}\text { Finds its } \\
\text { contents (also) } \\
\text { in processes } \\
\text { of... }\end{array}$ \\
\hline Boundary setting & $\begin{array}{l}\text { Boundary } \\
\text { exploration }\end{array}$ & Practice work & $\begin{array}{l}\text { Knowledge } \\
\text { supply }\end{array}$ & $\begin{array}{l}\text { Knowledge } \\
\text { exploration }\end{array}$ \\
\hline $\begin{array}{l}\text { e.g. partnering } \\
\text { and project } \\
\text { schemes } \\
\text { overruling } \\
\text { organizations } \\
\text { priorities and } \\
\text { devices (Obs Mc, } \\
\text { 14/01/14; Obs } \\
\mathrm{Pn}, 19 / 03 / 15 ; \mathrm{Fg} \\
\mathrm{Sr}, 27 / 01 / 14)\end{array}$ & $\begin{array}{l}\text { e.g. carry out } \\
\text { long-term } \\
\text { education for } \\
\text { the youngsters } \\
\text { (Amb, } \\
14 / 02 / 14)\end{array}$ & $\begin{array}{l}\text { e.g. adapting } \\
\text { training } \\
\text { standards to } \\
\text { local contexts } \\
\text { (Interview Ofc } \\
004,17 / 10 / 14 \text { ) }\end{array}$ & $\begin{array}{l}\text { e.g. adapting } \\
\text { projects to local } \\
\text { contexts }(\mathrm{Fg} \\
\text { Sr. } 27 / 01 / 14)\end{array}$ & $\begin{array}{l}\text { e.g. } \\
\text { collaborative } \\
\text { development of } \\
\text { post-harvest } \\
\text { management } \\
\text { (Fg Cn, } \\
23 / 01 / 14)\end{array}$ \\
\hline
\end{tabular}

\subsubsection{Knowledge exploration}

Knowledge exploration refers to forms of knowledge unveiling or discovery. It includes research, as is commonly understood. But it also refers to facilitating access or understanding unknown contexts and scaling out of tacit knowledges.

Some strategies describe repertoires of knowledge unveiling outside the immediate practice field of organizations, namely, performing in other links of the value chain and piloting complementary income sources. Not the original core of organizations' activities, these are understood as forms of expansion by means of relating to complementary fields, often linking to territorial or sectorial scaling strategies (Obs Ct, 20/01/14; Obs Mc, 14/01/14; Obs Pn, 19/03/15; Obs Sr, 27/01/14).

Other strategies refer to knowledge exploration within the field of practice, which, in other words, refers to its deepening as a field. For 
example, organizations' attempts to identify and try biologic materials is by all means their most important asset (Obs $\mathrm{Cn}, 23 / 01 / 14$; Obs Mc, 14/01/14; Obs No, 16/01/14). Creating, actualizing and retrieving knowledge as strategies relate to a core aim: building a knowledge base for the field of practice, in other words, setting reference foundations to normalize its practice field.

Table 21 shows an overview of knowledge exploration strategies found empirically. The reader will note I have added a new column, source. I will use it to further discuss knowledge exploration, specifically the sources.

Table 21. Knowledge exploration strategies

\begin{tabular}{|c|c|c|l|}
\hline $\begin{array}{c}\text { Knowledge } \\
\text { stance }\end{array}$ & Category & Source & \multicolumn{1}{|c|}{ Strategies } \\
\hline \multirow{2}{*}{$\begin{array}{l}\text { Knowledge } \\
\text { exploration }\end{array}$} & Expand field & Experience & $\begin{array}{l}\text { Perform in other links } \\
\text { of the value chain }\end{array}$ \\
\cline { 2 - 4 } & Deepen field & Experience & $\begin{array}{l}\text { Pilot complementary } \\
\text { income sources }\end{array}$ \\
\cline { 2 - 4 } & Science & $\begin{array}{l}\text { Collaborate on } \\
\text { research and } \\
\text { development }\end{array}$ \\
\cline { 2 - 4 } & Experience & \multicolumn{2}{|c}{} \\
\hline
\end{tabular}

Strategies of knowledge exploration utilize either experience or science as possible knowledge sources. Experience refers to first-hand, incarnated, embodied exploration of an unknown context, technology, product or process. This experience brings comprehensive understanding. It is the case, for example, when organizations visit specialized niche depots in European ports. Going through import conditions and checklists of intermediaries, producers understand what has to be done back home about post-harvest and logistics (Am, 14/11/14). Similar processes, yet varying in time scale, take place with productive, market or project explorations, either expanding or deepening the field. As might be the case of exploring fruit production (Obs $\mathrm{Pn}, 19 / 03 / 15)$, chocolate fabrication (Fg $\mathrm{Cn}, 23 / 01 / 14$; Fg Sr, 27/01/14) or new financial schemes for beneficiaries (Interview Tm 001, 16/01/14). 
Science exploration refers to scientific sources of knowledge acquired by means of collaboration, for example, through arrangements with universities (Fg Mc, 14/01/14) or research institutes (Obs Pn, 19/03/15).

Relation of knowledge exploration to other knowledge stances:

As it is clear now for the reader, knowledge exploration describes repertoires aiming at accessing new knowledges. Naturally, knowledge exploration refers in many ways to other knowledge stances.

In order to better illustrate this mutual conditioning, I will discuss some examples. Table 22 describes a series of statements about knowledge exploration in relation to other knowledge stances. After each statement, I have included an example, as a means to bring evidence and facilitate the reader to follow the exposition.

Table 22. Relation of knowledge exploration to other knowledge stances

\begin{tabular}{|c|c|c|c|c|}
\hline \multicolumn{5}{|c|}{ Knowledge exploration... } \\
\hline $\begin{array}{l}\text { Takes place in } \\
\text { various } \\
\text { possible... }\end{array}$ & $\begin{array}{l}\text { Is a possible } \\
\text { driver and a } \\
\text { means of... }\end{array}$ & $\begin{array}{l}\text { Is set through } \\
\text { underlying } \\
\text { drivers, } \\
\text { rationales, } \\
\text { protocols and } \\
\text { contents of... }\end{array}$ & $\begin{array}{l}\text { Is a source of } \\
\text { contents } \\
\text { for... }\end{array}$ & $\begin{array}{l}\text { Is a source of } \\
\text { contents for... }\end{array}$ \\
\hline $\begin{array}{l}\text { Boundary } \\
\text { setting }\end{array}$ & $\begin{array}{l}\text { Boundary } \\
\text { exploration }\end{array}$ & Practice work & $\begin{array}{l}\text { Knowledge } \\
\text { supply }\end{array}$ & $\begin{array}{c}\text { Knowledge } \\
\text { intermediation }\end{array}$ \\
\hline $\begin{array}{l}\text { e.g. R\&D } \\
\text { collaboration } \\
\text { with firms, } \\
\text { universities, } \\
\text { research } \\
\text { institutes (Obs } \\
\text { Cn, 23/01/14; } \\
\text { Obs Mc, } \\
\begin{array}{l}\text { 14/01/14; Obs } \\
\text { Pn, 19/03/15) }\end{array}\end{array}$ & $\begin{array}{l}\text { e.g. } \\
\text { collaborative } \\
\text { research with } \\
\text { research } \\
\text { centres about } \\
\text { crops (Obs Cn, } \\
23 / 01 / 14 ; \quad O b s \\
\text { Pn, 19/03/15) }\end{array}$ & $\begin{array}{l}\text { e.g. collaboration } \\
\text { schemes with } \\
\text { firms, } \\
\text { universities, } \\
\text { research } \\
\text { institutes (Obs } \\
\text { Cn, 23/01/14; } \\
\text { Obs Mc, } \\
\text { 14/01/14; Obs Pn, } \\
\text { 19/03/15) }\end{array}$ & $\begin{array}{l}\text { e.g. post- } \\
\text { harvest } \\
\text { protocols (Fg } \\
\text { Cn, 23/01/14; } \\
\text { Obs Pn, } \\
\text { 19/03/15) }\end{array}$ & $\begin{array}{l}\text { e.g. experiential } \\
\text { knowledge about } \\
\text { local needs and } \\
\text { state of affairs } \\
\text { (Fg Ct, 20/01/14; } \\
\text { Fg No, 16/01/14; } \\
\text { Fg Sr, 27/01/14) }\end{array}$ \\
\hline $\begin{array}{l}\text { outcomes } \\
\text { depend on }\end{array}$ & $\begin{array}{l}\text { Is a possible } \\
\text { driver and a }\end{array}$ & $\begin{array}{l}\text { Extends or scales } \\
\text { the practice field }\end{array}$ & & \\
\hline
\end{tabular}


Table 22. Relation of knowledge exploration to other knowledge stances

\begin{tabular}{|c|c|c|c|c|}
\hline \multicolumn{5}{|c|}{ Knowledge exploration... } \\
\hline partners'... & means of... & $\begin{array}{l}\text { to alternative } \\
\text { fields via... }\end{array}$ & & \\
\hline $\begin{array}{l}\text { Boundary } \\
\text { setting }\end{array}$ & $\begin{array}{l}\text { Boundary } \\
\text { exploration }\end{array}$ & Practice work & $\begin{array}{l}\text { Knowledge } \\
\text { supply }\end{array}$ & $\begin{array}{c}\text { Knowledge } \\
\text { intermediation }\end{array}$ \\
\hline $\begin{array}{l}\text { e.g. academic } \\
\text { outcomes vs. } \\
\text { practical } \\
\text { outcomes (Fg } \\
\text { Cn, 23/01/14) }\end{array}$ & $\begin{array}{l}\text { e.g. } \\
\text { collaborative } \\
\text { research with } \\
\text { firms about } \\
\text { post-harvest } \\
\text { protocols (O. } \\
\text { Obs Pn, } \\
\text { 19/03/15; } \\
\text { Fg Cn, } \\
23 / 01 / 14)\end{array}$ & 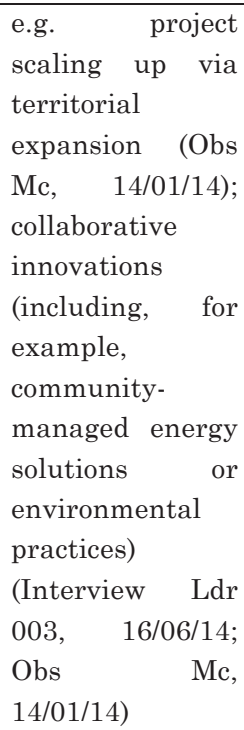 & & \\
\hline
\end{tabular}

\subsection{Knowledge stances: Theoretical insights}

It is worth at this point recapitulating briefly the chapter so far. The chapter started describing the tenets of the analysis and turned first to pinpoint farmers' organizations strategies-which is actually the object of this research. To do this, I described the fields in which organizations participate and focused on the strategies organizations deploy in each of them.

Having built a thorough base, I then turned to discuss a transversal analysis of the strategies. To do this, I brought back knowledge stances as a reference framework. Through the analysis I discussed strategies belonging under each knowledge stance. The exercise brings both detail about strategies and further understanding of the scope and features of each knowledge stance. 
This section aims at capturing insights of the discussion, outlining the various analytical ways that have been discussed, and bring them to a close.

First, I will summarize the more detailed view of knowledge stances. Afterwards I will turn to discuss deeper connecting patterns amongst stances in light of institutions, boundaries and practice. This is, in other words, turning back to the theoretical core, discussing overarching domains found to exceed the demarcating criteria I myself proposed. These domains will add transversal understanding of the categories, making sense of the nature of its resemblances. The section-and the chapterrounds up with a discussion of research questions in light of research results.

\subsubsection{Knowledge stances: A fully fledged overview}

In the previous section I brought about a more nuanced view of knowledge stances, adding details along the discussion. It is worth turning back to these features as part of a whole. As stated before, knowledge stances express a possible position of meso-level agency at a given moment, specified by the way in which knowledge flows are involved. Detailed features of knowledge stances relate to aspects of agency such as intentionality, scope and targeted interests. Figure 5 illustrates these aspects, adding to the original sketch presented in Figure 1.

I will discuss here knowledge stances as belonging to two different, yet complementary, sets. The first set describes what can be seen as the realm of institutional work. Here we see the presence of organizations as actors and their actions showing efforts to create and maintain fields of practice. This realm includes stances of boundary setting, boundary exploration and practice work as its overarching means.

Boundary setting shows intentions of positioning or protecting a field visà-vis various possible boundaries. Organizations do this by means of striving to be visible, to highlight existence as an actor or to play defensive moves, shielding the organization or its practice base. This is shown in Figure 5 as accommodating or rejecting intentions taking place in boundary setting moves. 
Boundary exploration shows the intensity of intentions to engage with other actors. Organizations do this to the extent of performing jointly or join forces to supersede disadvantageous positions, completely blurring boundaries in order to show re-scaled positions. Or otherwise, organizations engage with other parties just to a more operative extent, sharing assets. This is shown in Figure 5 as degrees of opening taking place in boundary exploration.

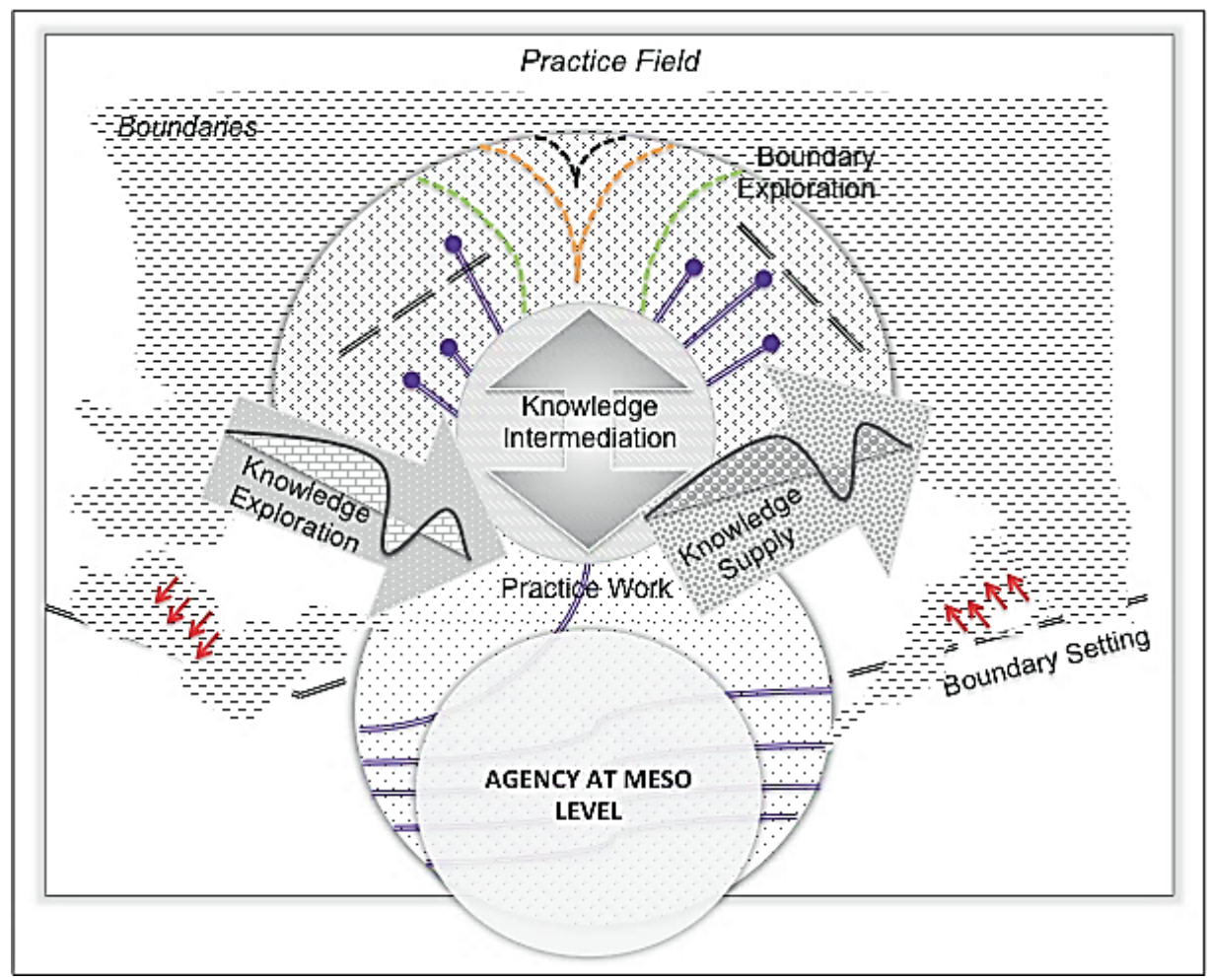

Figure 5. Meso-level agency featuring knowledge stances. Fully fledged scheme

Practice work shows ways of streamlining specific arrays of activity in the practice field. Organizations do this by connecting with other parties as means to enter the practice field, to strengthen its base or to secure its means. This is shown in Figure 5 as connecting vessels linking the organization to other actors in the realm of exploration. Organizations also attempt to stabilize the practice field by deepening its routines. This is shown as a weaving thread growing at the base of practice work. 
The second set of knowledge stances describes what can be seen as the realm of knowledge work. Here we see organizations identifying, feeding and allocating cognitive resources in the practice field. This realm includes stances of knowledge supply, knowledge intermediation and knowledge exploration. Figure 5 shows this realm as a belt at the core of knowledge stances. In this realm, knowledge stances describe both the means and the ends of knowledge work.

Knowledge supply features point here to the aims of knowledge supply, or the specific targets knowledge supply is adding to or solving. Organizations focus on strengthening capabilities-as skills or abilities of individuals_or capacities, as contents adding to organizational or extraorganizational performance. These are shown in Figure 5 as differentiated layers within knowledge supply.

Knowledge intermediation shows the time-scope that organizations are interested in tackling by means of knowledge translation and mediation. Organizations deploy pace-related strategies when adjusting internal rhythms versus external circumstances. Or they deploy long-term timing strategies in the attempt to grant a knowledge base for the future. These are shown in Figure 5 as a double pointing arrow linking the internal and the external realms or agency.

Knowledge exploration focuses on sources feeding repertoires of knowledge unveiling. Organizations gather knowledge by means of experienced-that is, first-hand, incarnated, embodied exploration of an unknown context, technology, product or process-or scientific exploration. These are shown in Figure 5 as differentiated sources feeding the agent's practice base.

\subsubsection{Revisiting practice, boundaries, and institutions: Common domains}

There are evident crosscutting resemblances amongst knowledge stances as well as their more specific strategy clusters. I argue these resemblances relate to domains. These are common to the various stances in which strategies perform. I will give some detail about them, bringing back single strategies, while pointing at how each domain relates to boundaries, practice and institutions. 
The first domain relates an existential domain, marking the core underpinnings of the organization as an actor. This domain demarcates those strategies responding to the actor's foundational gestures, its existence and identity. In the realm of boundaries, these foundations are expressed as stances and intentions of the organization facing others (e.g. negotiate to exist, to play a role, demand attention).

In the realm of practice, existential domain is performative. Organizations' gestures express concrete means of their drivers, their visions. It is worth highlighting that performative practice also includes the milieu of meso-level relations linking to the practice field (e.g. perform, partnering to allow and deepen practice) in the sense that connects an actor to others of its kind as well as its practices to the wider fields they belong to.

In a similar way, the existential domain is also performative in the realm of institutions. Organizations' gestures connect to the wider stream of patterns in which cocoa (and the extended rural practice) takes place. Organizations turn into a vehicle of exogenous extended or complementary existing practices, which means, for example, opening the door to practices such as "saving."

It is worth noting that some of these practices are not always known or intended beforehand and surprise organizations. These appear as parasitic forms of knowledge linked to broader institutional patterns, embedded in other actors. Accounting reports and tax declaring is a good example of this aspect, often pushing organizations to taste the rather bitter flavour of audits in project implementation (Fg Cn, 23/01/14).

The second domain is normative. This domain refers to agency with and about rules, norms or regulations taking place within and outside organizations.

In the boundary realm, the normative domain performs forms of regulating relations with other actors or sets regulations to shape their actions. Strategies such as "positioning visions to influence policy" or "adjusting terms and conditions of support schemes" are illustrative as examples. 
In the practice realm, the normative domain refers to setting a particular practice as a standard practice, as seen in manoeuvres such as "setting standards" and "rewarding best practice." It is likely this particular practice will respond to specific drivers, bringing about an inner normative stance. In the realm of institutions this domain is performative, showing boundaries and practice as expression channels of the basic notion of institutions as "norms or rules of the game."

The third domain refers to meso-level interaction. In a broad sense it refers to those activities linking organizations to other actors or fields looking for, sharing, creating, contesting or protecting means to go about practice.

In the boundary realm meso-level interaction includes establishment of collaborative relations (e.g. create funding opportunities) but also engages in relations in other fields in the attempt to ensure support access (e.g. engage in political activities and support political allies) or situate boundaries protecting their space (e.g. regulate prices, block initiatives).

In the practice realm meso-level interaction refers to drivers, rationales and devices organizations deploy to build practice itself. This is illustrated by strategies such as "allocating resources incrementally," or "devise support schemes." Boundary objects such as development projects or contract farming play a relevant role as vehicles of boundary collaboration, through which practice might take place.

The fourth domain refers to practice extension, including arrays of collaborative activity strengthening the practice field. Naturally, practice extension deepens a specific feature of meso-level interaction. Yet it is worth demarcating it as a different category, for it shows those arrays of activity shifting scales on the field of practice extending, deepening or localizing its reach along many possible clusters of participating actors.

In the realm of boundaries, practice extension domain is performative. It illustrates scale shifting by means of peer and exogenous collaboration as shown in the set of "re-scaling" strategies. Each field prompts different possible boundary games, as seen in "social movement participation" (focused on individuals) versus "lobby and presence with a national network" (focused on organizations). 
By the same token, practice extension domain is performative in the practice realm. It embeds the means to deepen and promote practice as it is escalated through various possible forms of boundary blurring, often also linking different but complementary fields. Again, institutions are here performative, expressed through boundaries and practice themselves.

The last domain is cognitive. It refers to agency about producing and reproducing knowledge for and within the practice field. In the boundary realm, this domain refers to knowledge development and access via mesolevel relations. As shown in strategies such as "peer advising"; "training" and "circulating relevant context information"; and "carrying out collaborative research and development."

In the practice realm the cognitive domain is performative and refers to every knowledge search and design to further develop and promote practice, as seen in strategies such as "storing a (rural development) knowledge base" or "devise long-term educative schemes for the youngsters." In the realm of institutions this domain is also performative, showing detail about its cognitive dimension.

Through the lenses of these domains, we can see here the ways in which knowledge, practice, boundaries and institutions are intertwined as complementary facets of meso-level agency. The existential, normative, cognitive, meso-level interaction and practice expansion domains coexist as underlying grounds in which organizations' agency takes place, as the means by which extended societal patterns' meso-level agency is shaped. These domains have specific expressions in boundaries, practice and institutions, with specific features emerging in each field.

\subsubsection{Summing up: A turn back to the research questions}

It is time to turn to the core of this research. I will take a moment to situate the overall rationale of this section and its place as part of the whole: This research followed an abductive rationale. Therefore development of the conceptual and the empirical grounds of the research were carried out somehow independently, having the research questions as a pivot. This chapter tied those more or less loose results into a comprehensive empirical and theoretical whole. It is worth discussing the research questions in light of the findings. Here I will discuss how the 
various threads of unfolding results add to the understanding of the guiding questions.

\subsubsection{What purposes drive farmers' organizations' strategies as change agents?}

The first research question-what purposes drive farmers' organizations' strategies as change agents?-was addressed empirically. Chapter 4 provides descriptive detail. Interestingly, answers to the question brought light not only to values driving farmers' organizations-securing longterm rural life, peace, legality, autonomy-but also revealed the means organizations set in motion to carry out their purposes. Drivers such as creating income opportunities, creating a favourable market position, playing a role in local development and building local capabilities broadly illustrate the fields in which organizations play their game.

As a backdrop of the overarching research question, drivers also point at the inner normative stances from which organizations stand as actors. This aspect, to be further discussed in the next section empirically, points here to values as a substantive mould of organizations' gestures as agents.

\subsubsection{What are farmers' organizations' strategies to coproduce institutions impacting local dynamics?}

The second research question is the following: What are farmers' organizations' strategies to coproduce institutions impacting local dynamics?

I will discuss this research question by pointing to various layers taking place in the question itself. But beforehand, it is worth stating that fields are the specific contexts of coproduction. Coproduction takes place in the various fields in which farmers' organizations play at the meso level. "Coproduction" is here seen as a process through which organizations assume, extend and deepen the reach of rationales and protocols of various fields impacting the territory. As seen, coproduction includes markets, grassroots' goals and (rural and local) development goals. It is worth noting fields exceeding the local realm also have a local effect, as when it comes to sectorial interests. 
The first layer refers to the multiple ways in which organizations are shown to coproduce institutions, its mechanisms. In this light, coproduction refers to the many forms institutions might take and to the many ways institutions are to be co-produced.

As earlier discussed, the normative domain is expressed in various forms of agency, to be seen in the various knowledge stances. Evidence describes normative agency as a feature of boundary work. Farmers' organizations' strategies aim at conditioning meso-level interaction, both by setting external rules (for example, striving to set policies) or reaching meso-level agreements (for example, arranging the terms of projects).

Normative agency can be seen also in the realm of practice work. Here institutions appear as a means to secure and shape practice. Practice work expresses the ways farmers' organizations go about their practice field: their stance as an actor with very particular operative means, connecting and reinforcing relations about various fields.

It can be said that the role organizations play in protecting practice, and creating means and ends to interact with it, is a requisite of enduring sociotechnical change in these contexts. ${ }^{50}$

Creating means for practice naturally links to normalizing as another normative dimension of practice work. The multi-sited case shows setting standards and best practice as reiterative patterns of stabilizing practice. Interestingly, normalization not only refers to productive means, as with certifications or protocols, but also to the expected behaviour of organizations about their developmental role: generational change, women inclusion and use of social media, for example.

A second layer brings about the fact that institutions are also produced by means of "field expansion," that is, the sites of coproduction. Here we see practice spreading by linking actors and chains of actors. In the multisited case this is seen with farmers' and international organizations' collaboration as well as with peer collaboration. This allows pointing to a broader sight of farmers' organizations, not only performing as actors, but as vehicles of expression of specific practices, and of deeper existing institutional patterns.

\footnotetext{
${ }^{50}$ It is worth noting this aspect reinforces the strong emphasis capacity development gives to social technologies as means of social change, as described in Chapter 2.
} 
This phenomenon takes place through many possible social technologies, with the most important in farmers' organizations' context being projects. In effect, projects create boundary situations where farmers' organizations and other actors collude to deepen specific practice fields.

However, as boundary objects, projects-and the patterns they embedalways risk overlooking, hampering or distracting local priorities, stability and local energy. Taking part in sites of coproduction does not grant a positive outcome for organizations.

The capacity development policy trend, long ago forgotten in international development headquarters, appears to have barely reached national and non-governmental actors. Projects are not vehicles of capacity not just because of a power imbalance - as we have seen often appearing — but also by lousy design, scope and rationales. There is much still to improve in the ways these social technologies are deployed in isolated regions.

A third layer refers to findings in the realm of strategies. Strategies to coproduce institutions impacting local dynamics imply all sorts of coping behaviours. These are the tricks for coproduction, showing different sorts of games.

One game refers to the various facets around creating possibilities for, protecting and nourishing the field of practice, as seen in strategies taking place in boundaries, like "keeping gates" or "allocating resources incrementally." It can also be seen with strategies taking place with knowledge work within the organization, such as "translating" strategies. Here the organization further deploys means for practice.

Another game refers to managing risks of losing organizational autonomy, legitimacy or coherence. These risks emerge when organizations-as natural devices for representation-reach close to the realm of politics or social movements. Here farmers' organizations shift boundaries, leaving politics to the sphere of individuals. The effect is that farmers redefine boundaries to bargain negotiation positions in the less structured-and often institutionally ill—field of politics.

There is a last game yet. It brings about another facet of power: that of meso-level games for acquiring better negotiating positions. Some farmers' organizations' strategies take place in the realm of boundaries-peer 
networking outstanding-but some others take place in the realm of practice (with price regulation, for example).

These entrance points-mechanisms, sites and tricks-add to the understanding of farmers' organizations' manoeuvres with coproducing institutions impacting the local realm. The whole approach details the inner workings of the fields in which organizations play and provides a closer view of meso-level agency and the various layers of the institutional process. It is worth stressing here that this discussion points to one salient fact: Enduring change-even its possibility-depends on social technologies as much as it depends on physical technologies in institutionally deprived contexts.

\subsubsection{What are farmers' organizations' strategies to create, allocate and scale local capacity assets?}

The third research question is the following: What are farmers' organizations' strategies to create, allocate and scale local capacity assets? Here the attention was focused on the cognitive domain in the attempt to highlight the knowledge-related repertoires in organizations' endeavours. Results appear to be straightforward on this account, though somehow overlapping with the previous question. I will discuss a couple of aspects that relate to the question itself.

The first aspect relates to the creation and allocation of capabilities and capacity assets as means of institutional work. The evidence points at the fact that knowledge-related schemes are subject both to practice work (that is, the ways to go about the practice field) as well to boundary settings (that is, conditions attached to knowledge sources). In contexts of dispersed, heavily standardized, ill-captured or incomplete rural development offers, farmers' organizations strive to build knowledge assets that are suitable to their needs.

Knowledge assets can be also institutional assets. Capacities would be those gestures adding to actors' potential and autonomy (e.g. scaling up or down functions, staffing the local realm), while capabilities would add to the level of officers or members (e.g. training, appointing providers). Despite the fact that in the long run this distinction tends to overlap, it is 
useful to spot the reach of knowledge flows. This aspect signals a turn back to capacity, to be developed next chapter.

The second aspect relates to knowledge work. Farmers' organizations do engage actively in knowledge supply, intermediation and exploration. As seen, organizations filter, allocate, deliver, translate and mediate knowledges. These repertoires might take place at the capacity level. For example, knowledge filtering related to legal presence: specialized inquiries of organizations inform the creation of intermediary organizations at regional or national levels.

But most knowledge work is functional to the expansion of the practice base, targeting capabilities. It is interesting to see here organizations address not just the immediate scope of requested capabilities (that is, those of organizations' members at hand) but also those of future generations. Knowledge work illustrates here an example of coherence about means and ends and about coping solutions aiming at satisfying values.

With this note I finish this analysis. Overall, the analysis features a more detailed lens to see the institutional extent of farmers' organizations: the fields in which they take place, the coping schemes fields trigger and the many ways they are built. The last chapter will turn back to this analysis from a different perspective, filtering results to highlight those strategies more specifically referring to change agency. 


\section{A typology of farmers' organizations as change agents}


This section discusses a typology of strategies of farmers' organizations as change agents. It is intended as an analytical synthesis of the inquiry, filtering and clustering strategies around change agency. As such, this typology comes back to capacity development as a source of inspiration and aims at pinning down a way to better address its means. Before proceeding I will clarify the rationale I will follow along the discussion.

Early in this research (see Chapter 1) I introduce the notion of change agent. It was extracted from a World Bank toolkit on capacity development: Change agents are "leaders, groups, coalitions and others that can initiate and drive positive changes towards the achievement of a development goal" (World Bank, 2011).

Along the discussion the notion of change agent appeared as a tentative reference, in view of the search of theoretical substantiation I was looking for. Aiming to operationalize capacity development, I deepened and intertwined various scholar streams, avoiding to some extent leaning too much into any specific disciplinary approach.

Based on sociology's way of thinking, I introduced notions from the practice turn in sociology institutional work, institutional entrepreneurship innovation intermediation and cognitive studies. Each of these sources labels farmers' organizations in a specific way, as institutional entrepreneurs or innovation intermediators, for example. Arguably, the analysis carried out in the previous chapter, bringing a comprehensive view, discusses farmers' organizations' as actors.

This section brings a new turn. The expression change agent stresses a potential of an actor. Specifically, it points to those aspects featuring an actor's chance to be a vehicle of increasing autonomy deployment, to add to the ability of a system to "manage affairs successfully" (OECD, 2006), "achieve a development goal" (World Bank, 2011), or "perform, sustain itself, and self-renew" (Land et al., 2009), that is, its features as a change agent in the realm of capacity development.

To this purpose, I will develop in this section an interpretive twist to the guiding question of this research. In asking what the strategies of farmers' organizations as change agents are, I will address strategies plausibly adding developmental value — that is, change potential — to society, to the 
local and the rural realm, and to the more comprehensive whole in the surrounding context of these organizations.

Autonomy deployment refers here to an aggregated view of the social process in which presence and gestures of farmers' organizations might have effects on a wider scope. The section follows the typological theorizing rationale so far applied to the analysis. It will build on a particular way of understanding configurations of strategies, using both empirical and theoretical references as building blocks. It is worth remembering stances are here ways to demarcate specific gestures of agency.

The section attempts to grasp the elusive object of change agency. Rather than recurring to the more common approach of posing ex ante normative references, here normative aspects arise from evidence. These are to be read in knowledge stances, its possible significance assessed in light of broader meso-level patterns.

\subsection{Perform Innerwise}

"Cocoa is the means, People are the ends." This is the slogan of a farmers' organization. Beyond its catchy tone, the slogan evidences the purpose of the organization as a tool of collective welfare. Change strategies-here strategies to achieve collective welfare-go beyond the discursive realm: Change strategies are a form to go about organizations, a form to go about business, a form to go about cocoa. Performing innerwise means here performing in such a way that the organization' reflects its members' values and drivers.

In effect, social aspects are at the core of farmers' organizations' operational rationales not only because of the provision of services (e.g. promoting a differentiated productive basket, providing human development programs, facilitating access to goods and services), but also because the organization is a way to access and distribute collective means. The priority of regulating local prices is a tangible example.

Moreover, this operational core leans organizations closer to the realm of sustainable development. Plausibly this is an effect of farmers' organizations' drivers, connecting also to their search of niche 
opportunities outside the mainstream cocoa market. Social aims link to environmental concerns with the use of productive certifications (e.g. fair trade, organic, rainforest alliance).

Naturally, these tenets have effects in what and how farmers' organizations connect to fields, as well as the ways and priorities by which farmers' organizations relate to boundaries at the meso level. Evidence suggests farmers' organizations do care about demonstrating consistence. Farmers' organizations' ways about cocoa's business reflect the identity that organizations aim at positioning.

Conceptually this change agency strategy is set in the realm of practice work. Here change agency is evidenced in going about practice in a particular way. Practice work as a means of change implies allowing values to perform as operational references. For the case in point, this implies setting collective aims—supported by rural life values—as guiding references of organizational means and ends.

Practice work as an organizational feature illustrates a form of enactment at the meso level, which can be jokingly described as one of the "be the change you want to be" kind. Organizations secure change by performing in a way fitting their values and expectations.

An element worth mentioning here refers to sustainability of the practice itself. In a context of volatility and isolation, organizations are the means for practice to endure over time. Not only do they perform as vehicles for practice to link to wider patterns (such as markets, development practice, state), but to secure its normalization by means of best practice or certifications. Farmers' organizations provide practice with a safer institutional environment.

\subsection{Jump in to extend a practice field}

Many farmers' organizations actually exist because they were willing to collaborate in breeding cocoa instead of illegal crops. This choice, it was earlier discussed, came as a matter of trust with project officers; was a result of negotiations with the government about what, whom, where and how illegal crops were to be handled; or resulted from a shared reiteration 
of willingness after a failure with cattle. It has been a long history of collaboration.

It is likely this choice resulted from reasons different than those of organizations' allies, yet it shows organizations' compromises on cocoa as a plausible alternative to illegal crops. Farmers' organizations' change agency strategy being, precisely, to collaborate to locally build such a practice field.

Alliances to collaborate were carried out on a project basis, certain of an end date and quite likely following promises of extension. Scale, reach and pace mark differences amongst projects, not to mention the various templates for monitoring and evaluation. Productive cultures transformed, via projects, in managerial activities including checking lists, receiving visits, writing reports and showing off.

Those were not the only differences amongst projects. Other differences were seen in the flexibility of partners to listen and adjust. Moreover, there are differences in partners' willingness to collaborate and team up to succeeding in growing cocoa as a practice field. These differences are an effect of the uses of their allies and are certainly (and comprehensibly) conditioned by the way they reach out as actors: their missions, their visions, their rules, and their rationales. This is shaped by the way they go about cocoa as a practice, as a market and as a sector.

Years have gone by. Those farmers' organizations still operating have grown autonomous. Autonomy was built on their understanding and making of cocoa a market, a niche within a sector and a product in a local basket. Their voice strengthened, they are more aware of the contours and challenges of representation at the local level and in the sector. Their means were scarce and their survival rested on their ability to sell cocoa and formulate projects. Success came from their willingness to collaborate with peers, with other parties and getting allies. The change agency strategy is still the same: collaborate to extend and deepen cocoa's practice field.

Conceptually, this change strategy shifts lenses, focusing on the practice field rather than on the actor. Here change agency is seen as the willingness of an actor to participate in an endeavour. Actors can simply enter the field or, as is often seen in developmental efforts, participate 
along with others by means of boundary objects. These can be calls for proposals, programs or projects.

Through boundary objects actors link together to nurture a field of practice. Joint efforts bring a different understanding of meso-level agency, regardless of levels or the actors' natures. These joint efforts describe what could be addressed as a form of collective action. Unsurprisingly, this is reminiscent of capacity development's prodevelopment-through-interaction-at-the-meso-level form of agency, as described in Chapter 2.

This form of collective action does not imply boundaries are blurred amongst actors. On the contrary, each actor participates with a different purpose and assumes a different function. Each actor has different stakes and power on the ways the practice field is configured. Each actor pursues means and ends of the practice field with a different intensity. This is not relevant from the point of view of the practice field: It configures itself as a self-contained entity in which actors participate.

From this point of view, the extent of change-its scale, depth and endurance-depends on the nature of actors and the existing boundary objects setting their interactions. What forms of practice work bound actors' agency? Do boundary objects serve to deploy actors' autonomies about the practice field? Do boundary objects allow a comprehensive knowledge cycle targeting practice knowledge, capabilities and capacities within the practice field?

These questions are not new: The topic of building "horizontal" relations with farmers' organizations has been long on the table of rural development (Rondot \& Collion, 2001). Let us remember now capacity development itself was created as a policy tool to promote support schemes based on ownership and autonomy.

\subsection{Bypass bottlenecks and re-scale}

It was discussed earlier that actors' intensities and methods of collaboration on extending a practice field differ from one another. This might be a result of the context or of features of the practice field itself. 
But mostly it is an effect from readiness and interest of actors themselves. Some change agency strategies link to these degrees of intensity, bringing to the fore facets in which agency-and its stances-come to play a central role again.

Colombian cocoa, the case in point, shows a rather disperse landscape as a practice field. It reflects the conditions and situations of its actors. Cocoa mainstream production supersedes special niches. Actors interested in niches struggle over a scattered knowledge flow and an unstable practice base. While some actors attempt building this practice field by strengthening autonomies of weaker links, others act in bluntly detrimental ways.

To overcome this situation, farmers' organizations strive to collaborate with those actors better fitting their aims. Matching and actively pursuing collaborative efforts with allies-whether peers, third parties or potential peers-is a way to incrementally overcome adverse situations and conditions related to power structures on the sector. Strengthening the practice field by means of linking to similar actors exceeds conditions of location, scale or actors' purposes. Agency of change is here limited to the extension of the practice field itself.

Conceptually, this change strategy refines the scope of collaborating to create and expand a practice field. It demonstrates a meso-level collaborative rationale, focused on strengthening specific features within the field itself. In this context, bypassing describes attempts to shift both individual and collective positions. Bottlenecks such as local or regional ill-functioning institutions or big-player-leaning program rationales are less pressing to weaker actors if a collaborative practice support base exists and extends.

Re-scaling appears as crystalized forms of bypassing. Collaborative means starting as means of support become more structured forms of alliances. Evidence describes how farmers' organizations collaborate to re-scale at various levels: local, subregional and national. They are following various purposes: demanding attention at the local level, shifting negotiating positions in the market and influencing policies within the sector. Organizations also show various levels of integration, from the shallower level of sharing information to the creation of intermediary organizations. 
Conceptually, these change strategies are set on the realms of boundary exploration and boundary setting. By shifting scales, actors alter their negotiating positions and are able to set deeper institutional pathways aiming to strengthen practice fields. This has effects both for normalizing practice as well as in the setting of favourable boundary situations and conditions. Change is secured by means of extending the means and ends of the practice field in what otherwise is an ill environment for it to thrive.

\subsection{Broker a knowledge cycle to make it happen}

Discussing capacity development I brought about the assumption that social learning is social change. This assumption brings a complementary effect: It poses knowledge, enacted knowledge, as the means of change agency. Further, it describes the many facets of practice as its natural object. Farmers' organizations appear to be a good example to demonstrate this case.

It is useful to sketch here the contents of what a "cocoa knowledge cycle" looks like, as an example. Farmers' organizations learn and promote visions about market access (e.g. understanding fine grain market), set a knowledge reference (e.g. being sure what grain the organization has and understanding how to handle it), shape practice according to that vision (e.g. a step-by-step protocol for post-harvest) and, at the end, obtain a different boundary situation (e.g. niche differentiation by means of quality) (Obs Cn, 23/01/14).

Each of these steps carries some knowledge-related activity. Some imply acquiring knowledge through getting experience and understanding practice within a niche and relating that understanding to specific productive aims. Some other steps bring about scientific and technological quests, unveiling local assets and tweaking post-harvest procedures. Other steps imply translating this knowledge base into educative means and sets of practical knowledge are set in step-by-step protocols.

We see in this very simple example how various knowledge sources-also varying in nature and repertoire-feed the practice field. Each knowledge source answers to specific purposes and requires specific ways to be addressed. We also know this example shows only a partial picture. 
Farmers' organizations' interests and features bring other layers to the scene. A comprehensive example would deal not only with capabilities of organizations' members but also with capacities of organizations themselves and, quite likely, to those of their immediate environments. Overall, a rather complex matrix with overlapping fields results, as was discussed in previous chapters.

As a change agency strategy, brokering a knowledge cycle is a means to adapt local potential to the practice realm, but not in the sense of adopting the practice realm as a given template but rather manoeuvring to locally assess, create and re-create those features fitting a local role vis-à-vis practice. Knowledge repertoires are here means to unfold local potentiallocal talent, territorial features-which is, in other words, a way to substantiate ownership of this potential. It is this completeness, or comprehensiveness, that marks the relevance of the cycle as an aim.

Conceptually, brokering a knowledge cycle links to repertoires of knowledge exploration, intermediation and supply. Brokering the cycle is expanding and deepening the understanding of organizations' practice field and matching local situations with field requirements by translating and mediating knowledges. In doing that, it is also about giving means to this cycle: filtering knowledge providers and contents; allocating capabilities, processes, and staffing; and directly delivering knowledge, with trainings or peer advice. These aspects, appearing here as the software of a process, will in the long run develop its institutional structure.

\subsection{Take part in the building of the public sphere}

State, territory and democracy are always unfinished quests. In those areas with unstable, volatile or ill-functioning institutions, farmers' organizations constitute a platform for more formal political institutions to expand locally. Theoretical views on this matter regarding democracy (Gouet et al., 2009) are here confirmed by evidence. Not a straightforward equation, farmers' organizations' roles in the building of the public sphere are shown in various possible layers.

The first layer brings about farmers' organizations as civil society organizations. Their role of representation focused on demanding 
attention and creating spaces for local deliberation. It was described that organizations work with other organizations to bring topics to the local public agenda. What, in terms of the public sphere, can be understood as a role on the realm of politeia (Maldonado, 2002): the realm in which politics is nurtured with the matters of life.

The second layer brings about farmers' organizations as a platform for individual citizenship. As shown, organizations deal sinuously, to say the least, with the practice of representative democracy by attempting as much as possible not to engage directly in such processes. This very fact is an expression of the nature of surrounding institutions and the depths of political struggle involving political institutions themselves. Here, if not a platform for direct social mobilization and participation of representative elections, farmers' organizations are a space to channel their possibilities. Organizations give smallholders an opportunity for deliberation and access to wider fora.

The last layer brings about farmers' organizations as local institutions themselves, actors playing roles in the public order, what (Maldonado, 2002) has referred to as the realm of politike. Farmers' organizations locally extend institutions from the outer world. They follow the aim of attuning local potential with exogenous drivers and, in this sense, work as a tool of local autonomy.

Conceptually, this change strategy connects with various forms of boundary work. The first layer recalls forms of boundary exploration and re-scaling as means to affect boundary situations and conditions, as seen when grassroots organizations demand attention from local authorities in matters of public interest. The second layer implies a boundary shift. When it comes to strategies in the realm of representative politics and social movements, organizations shield themselves by framing these traits as belonging to the realm of individuals. Indeed an interesting phenomenon, further research is still needed to clarify how these punctuated forms of boundary shielding overlap. The last layer connects with practice work, its deeper contours discussed earlier in this chapter: farmers' organizations are set as vehicles of organizations' inner drivers. 
Conclusions 
I have devoted some time to address the inspiring question of this book: What are farmers' organizations' strategies as change agents? This specific perspective as change agents stresses the normative stance of the organizations and focuses on those aspects of agency allowing a more detailed picture of how this specific dimension is deployed. In sum, farmers' organizations i) perform innerwise, ii) collaborate to extend a practice field, iii) bypass bottlenecks and re-scale, iv) break a knowledge cycle to strengthen local practice fields and v) take part in the building of the public sphere.

But there is more to it. In order to answer the question I use an interpretive abductive approach, tentatively linking conceptual and empirical sources. As I progressed, I went through a process of mediation, searching for ways to address and make sense of the object and build it as a circulating reference (Latour, 1999). The process brought various conceptual, methodological and practical aspects worth revisiting. I will take some time in this section to go back to these aspects and reflect on their significance.

1. A meandering interpretive approach for an elusive object

If I were to reflect on my own research from a distance, I would say it is Foucauldian research, specifically because it assumes technologies of power to be knowable objects (Jessop, 2006). Rather than develop a criticism of power, which is a more common interpretive approach, the research develops ways to address the various means deployed by grassroots actors to have a share in the more practical means of power. Specifically those mechanisms in which knowledge flows play a role.

In order to address the topic I developed a rather meticulous methodological approach. I discussed it as an abductive rationale with a double twist. The first twist relates to an exercise of grounding theory based on capacity development as a source for the theoretical tentative component. The second twist is analytical and relates to an analytical approach based on a typological exercise.

The methodological approach proved useful for a substantive exercise. Still a complex endeavour, it allowed me to note various crosscutting layers of meso-level agency: the fields in which it takes part; meso-level 
relation to practice, institutions and boundaries; and the evidence of more subtle strategies at the meso level to go about change.

It is worth highlighting two relevant outcomes arising from this methodological approach. The first outcome relates to the value of dialogue with practice-based knowledge objects, such as capacity development. On one hand it proved to be useful as a guiding reference, with its substance emerging from a critical, yet understanding, point of view. On the other hand, it allowed feeding back both theoretical and practical endeavours about social change. This approach allowed pointing out - that is, giving a name - to various core aspects worth addressing in times where change is intended as an intentional endeavour.

The second outcome refers to the theoretical reach of the typological approach. Farmers' organizations' strategies were characterized into strategy types to allow finding and recognizing agency patterns playing at various fields. These patterns, shown as reiterative means of meso-level endeavours towards practice and boundaries, brought a more detailed view. Further, they allowed a more comprehensive picture of the knowledge-related aspects of institutional work.

2. Knowledge stances: Analytical units to address meso-level agency

Although the guiding question of this research aims at unveiling a specific dimension of farmers' organizations' strategies-as change agents-most of the analysis delves into a more comprehensive view of meso-level agency. This is a result of the underlying theoretical challenge of the research: how to actually address meso-level agency. This research is, in this sense, an attempt to grasp conceptually the gestures of an actor.

I propose knowledge stances as an analytical unit allowing this purpose. I draw on capacity development as a policy-based knowledge reference and various scholar streams. Knowledge stances specify critical moments change agents face, pointing to the way these moments involve knowledge. Stances are meant as heuristics to identify and address meso-level agency through knowledge-related patterns.

The solution brings about a twofold result. On one side, it demonstrates knowledge stances as a plausible solution to the problem. Knowledge 
stances allow a more detailed grasp of agency. As analytical units, knowledge stances allow pointing at meso-level agency patterns, independently of the nature of each specific actor. The distinctive feature of this approach is that it does not depart from normative frames, as is the case in streams such as capacity development itself, social innovations or transitions to sustainability. Knowledge stances rather focus on mesolevel patterns, mutual conditioning and coproduction of practice fields.

However, knowledge stances' perspective on farmers' organizations brought about conceptual clues and empirical examples about change agency itself. Change agency, every day a more pressing topic, appears here as a collection of possible repertoires. Change repertoires illustrate possible dimensions of change visible in meso-level agency, expressed as possible unique configurations of knowledge stances. They point sensitively to possible ways and degrees of engagement with change.

\section{Capacity development: Explicit ends, implicit means}

This research used capacity development as a knowledge reference, a source for conceptual inspiration (Keller, 2011). Sources linking more or less explicitly to capacity development were operationalized as components of a tentative conceptual approach, such as institutional thought and innovation intermediation. Some of capacity development tenets are regarded as pivoting points of the analytic exercise. Therefore there is a sort of natural link between this research and capacity development.

As a policy tool, capacity development is attached to normative aims from specific actors. It is a tool for development actors to conceive development projects, which, using concepts from this research, illustrates capacity development as a result of knowledge exploration within specific boundary settings and scaled means. In effect, capacity development intended to nurture international development practice field. Its richness comes from the challenges development practice entails, prompting the creation of models as means for action. By attempting to be comprehensive, these models use knowledge sources and rationales otherwise divided. This policy tool appears as a performative form of knowledge (Van Egmond \& Zeiss, 2010), the exercise proposed in this research as an attempt to unpack it. 
How does this exercise add to capacity development? There are various aspects. From a meta-analytic perspective, this research shows a thorough example of capacity development. Farmers' organizations describe capacity development rationales. This is seen, for example, in how organizations link to enabling environment processes taking place in various fields through different sorts of engagement.

It is possible to capture this long-term view of capacity development, however, because the conceptual approach allows adding detail, integrating and extending the object itself. In effect, this reading is more concerned with a long-term view of the change agent, rather than with the more common emphasis on attribution, contribution, educational competence or impact expected in policy settings.

Effects are different depending on capacity development streams. In the systemic stream, some patterns discussed here show resemblances. As observable in the systemic approach there are "five core capabilities": the capability to commit and engage; the capability to carry out technical service delivery and logistical tasks; the capability to relate and attract support; the capability to adapt and self-renew; and finally, the capability to balance diversity and coherence (Brinkerhoff \& Morgan, 2010). The systemic approach, however, does not address aggregated forms of capacity, nor levels (how the actor adds to public sphere) or scaling (how the actor shifts boundary situations). Its scope results are limited to an isolated view of the actor and actually overlook the system.

The "institutional" stream is far less structured. The work of Alaerts and Kaspersma (2009), perhaps the more comprehensive, shows a rather linear picture. Aggregated levels appear in their analysis regarding a connection amongst individual-organization-enabling-environment civil society. The picture focuses on actors' and levels' functions, with little attention given to specific features of fields or those of agency.

A first contribution of the knowledge-repertoires perspective consists of integrating systemic patterns, while targeting its relation to aggregated societal levels as a complementary means of agency.

There is yet another aspect, a more substantive one. Capacity development is concerned with capacity development of other actors. As a 
policy development tool it aims at affect rationales of change agency itself-that is, on development actors as change agents-yet it does not acknowledge the full extent of their presence as actors. Capacity development is functional to developmental aims, sight focusing only in the counterparts of aid, the sight always on the other end of the string. The frame itself blocks awareness of possible impacts beyond this reach.

The knowledge-repertoires perspective allows a more comprehensive picture. Here it is possible to better see the full extent of change efforts, with a more detailed picture on how different actors might collude around new practices. Moreover, it makes possible illustrating how embedded institutions and rationales of these actors affect other parties and the extent (and deeper challenges) to achieve change itself.

The National Cocoa Network multi-sited case illustrates various interesting aspects. First, the very fact that project-based rural development constitutes a major field of practice, its protocols having a relevant effect on organizational performance. Second, projects are not exempt of embedding ill practice. Therefore, organizations have to deal with capable, incapable or ill expressions of public investment. The case highlights again governance of rural areas as a troublesome dimension, comprehensibly a pending subject of rural development initiatives, overlapping both sectorial and territorial dimensions. Close to this aspect, knowledge-related players (universities, for example), contents and flows, that are able to leverage long-term success of initiatives, often appear out of the picture.

\section{Contribution to the literature}

This research draws on a multi-disciplinary base, therefore it is possible to detect various areas of contribution. I will refer here to scholar work on producer organizations, institutional work and innovation intermediation, and a more ample line of work about change.

In the literature on producers' organizations, there are two main contributions. On one side, this research adds empirical substance to what have been so far indirect or theoretical approaches to the "political side" of farmers' organizations. This work especially dialogues with three lines of inquiry in this field. First, the work of Gouet et al. (2009) discusses the 
significance of producers' organizations for capacity development. Second, the work of Bijman (2016) tentatively approaches a typology of organizations. Last, the economics approach of DNP (2015) approaches the role of cooperatives in the governance of rural areas. It is worth noting that this research extends this line of work by filling empirical gaps and brings an original theoretical perspective to the field, focused specifically on farmers' organizations' agency at the meso level.

Another line of inquiry, closer to the realm of agency, relates to farmers' organizations' roles as innovation intermediaries. This line follows works of Kilelu et al. (2011) and Yang et al. (2014) and explores innovation journeys. Despite not sharing specifically the same analytical scale, this research adds to the understanding of other dimensions at stake in innovation processes and might open complementary routes of inquiry.

In the case of institutional work and innovation intermediation, the main contribution consists of bridging these scholar streams by noting the complementary aspects they touch upon. This means, in practical terms, shedding light on the cognitive aspects of institutional work on one side, especially on the line of work of Lawrence et al. (2013) and Zietsma and Lawrence (2010), while shedding light on the institutional aspects of innovation intermediation, especially the works of Howells (2006), Meyer and Kearnes (2013) and Van Lente (2003), on the other.

These connecting vessels, often noted but not developed in each stream, find here a fully fledged example. It is worth noting that the knowledgerepertoires perspective's more detailed view on institutions, innovation, practice and boundaries supposes a theoretical breakthrough. It draws on sharper definitions and examples of boundary and practice work and a closer view of its impact on institutions.

This last aspect brings about a more general contribution, dealing the corpus of literature on change, as is the case of the study of transitions and social change. Theoretical approaches include strategic niche management (Kemp, Schot, \& Hoogma, 1998), the multilevel perspective (Geels, 2002), innovation platforms (Kilelu, Klerkx, \& Leeuwis, 2013) and the social innovation framework (cf. Cajaiba-Santana, 2014), for example. This research expands this base out of a mature social change-oriented policy tool. 
Before finishing I would like to address policy. Although it is not directly under the scope of this research, its presence runs implicit throughout the text. I will make a twofold comment, referring to empirical and theoretical aspects worth considering from the policy realm.

Naturally, the empirical comment brings about farmers' organizations and their context, building on the fact that farmers' organizations deal with many forms of policy-making. Rural governance of areas with illfunctioning institutions is a challenge combining multi-sectorial and territorial manoeuvres. It requires change-oriented policy-making.

The multi-sited National Cocoa Network case brings about a couple of elements. On one hand, it refers the potential of fine cocoa as a strategic niche for smallholders. This subsector describes structural bottlenecks. It requires investment in research for characterization (that is, assessing existing varieties) and post-harvest niche-oriented specific protocols.

It is worth highlighting that beyond specific research results, research and extension capacity of the sector needs to be consolidated. It is worth bringing about a couple of salient aspects following this purpose: first, allocating resources to further develop a research function; and second, promoting collaboration amongst linkages from the chain.

Moreover, quality requirements of this niche could easily profit from the existing strong peer network. There is potential to deliver peer-based extension and audit services, useful to easily scale up public investment, which, in other words, appeals to local talent valorization capitalizing on existing potential as a relevant means of subsectorial policy.

On the other hand, there is a more complex but substantive aspect referring to institutions for governance of rural areas. Far less clear, it builds on the fact that few actors reckon the multifaceted role of farmers' organizations and their heft in institutional development. Farmers' organizations could easily perform as operators, partners, counterparts or witnesses to discuss other aspects affecting territories (illegal mining, for example) or design protocols to allocate social and extension services. To this extent, it is for rural authorities to draw on thicker descriptions, 
acknowledge their true potential and prompt change-oriented investments.

This brings about a set of recommendations based on the theoretical findings of this research: Change strategies applied by farmers' organizations can be used as change-oriented policy rationales. These five strategies, perform innerwise, collaborate to extend a practice field, bypass bottlenecks and re-scale, break a knowledge cycle to strengthen local practice and take part in the building of the public sphere, appear as plausible principles to design policy tools to deepen the existence and significance of non-ill institutions in rural areas.

This is my word. 


\section{References}


Abbott, A. (1988). The system of professions: An essay on the division of expert labor. University of Chicago Press.

Abdulai, A., Owusu, V., \& Bakang, J.-E. A. (2011). Adoption of safer irrigation technologies and cropping patterns: Evidence from Southern Ghana. Ecological economics, 70(7), 1415-1423. doi: http://dx.doi.org/10.1016/j.ecolecon.2011.03.004

Abend, G. (2008). The Meaning of 'Theory'*. Sociological Theory, 26(2), 173-199. doi: 10.1111/j.1467-9558.2008.00324.x

Alaerts, G., \& Kaspersma, J. (2009). Progress and challenges in knowledge and capacity development. In G. Alaerts, M. Blokland, M. Hare, \& J. Kaspersma (Eds.), Capacity Development for Improved Water Management. Delft: UNESCO-IHE.

Balanzó, A., \& Herrera Kit, P. (2016, en prensa). Cuando la descentralización no es suficiente: conceptos para la territorialización de políticas. En M. Moreno Pérez, \& L. Martínez Cerna (Coords.), Desafíos para el desarrollo: Políticas públicas y sostenibilidad (págs. 13-44). Santiago: Universidad Central de Chile-RIL editores.

Barham, J., \& Chitemi, C. (2009). Collective action initiatives to improve marketing performance: Lessons from farmer groups in Tanzania. Food Policy, 34(1), 53-59. doi: http://dx.doi.org/10.1016/j.foodpol.2008.10.002

Barnes, B. (2001). Practice as collective action. The practice turn in contemporary theory. In Schatzki, T. R., Knorr-Cetina, K., \& Von Savigny, E. (2001). The Practice Turn in Contemporary Theory. New York: Routledge, 17-28.

Bartel, C. A. (2001). Social Comparisons in Boundary-Spanning Work: Effects of Community Outreach on Members' Organizational Identity and Identification. Administrative Science Quarterly, 46(3), 379-413. doi: 10.2307/3094869

Battilana, J. (2009). How Actors Change Institutions: Towards a Theory of Institutional Entrepreneurship. The Academy of Management annals, 3(1), 65-107. 
Bebbington, A. (1996). Organizations and intensifications: Campesino federations, rural livelihoods and agricultural technology in the Andes and Amazonia. World Development, 24(7), 1161-1177. doi: http://dx.doi.org/10.1016/0305-750X(96)00028-9

Bebbington, A. (1999). Capitals and Capabilities: A Framework for Analyzing Peasant Viability, Rural Livelihoods and Poverty. World Development, 27(12), 2021-2044. doi: http://dx.doi.org/10.1016/S0305-750X(99)00104-7

Bechky, B. A. (2003). Sharing meaning across occupational communities: The transformation of understanding on a production floor. Organization Science, 14(3), 312-330.

Beinhocker, E. D. (2006). The Origin of Wealth: Evolution, Complexity, and the Radical Remaking of Economics. Harvard Business School Press.

Benford, R. D., \& Snow, D. A. (2000). Framing processes and social movements: An overview and assessment. Annual review of sociology, 26(1), 611-639.

Berdegué, J. A. (2001). Cooperating to compete. Associative Peasant Business Firms in Chile. Wageningen: University of Wageningen.

Berger, P., \& Luckmann, T. (1991). The Social Construction of Reality. London: Penguin Books.

Bernard, T., Collion, M.-H., de Janvry, A., Rondot, P., \& Sadoulet, E. (2008). Do Village Organizations Make a Difference in African Rural Development? A Study for Senegal and Burkina Faso. World Development, $\quad 36(11), \quad 2188-2204 . \quad$ doi: http://dx.doi.org/10.1016/j.worlddev.2007.10.010

Bernard, T., \& Spielman, D. J. (2009). Reaching the rural poor through rural producer organizations? A study of agricultural marketing cooperatives in Ethiopia. Food Policy, 34(1), 60-69. doi: http://dx.doi.org/10.1016/j.foodpol.2008.08.001

Bijman, J. (2016). The changing nature of farmer collective action: Introduction to the book. Bijman, J., Muradian R., Schuurman, J. 
(Ed.), Cooperatives, Economic Democratization and Rural

Development. London: Edward Elgar Publishing, Incorporated.

Bijman, J., Muradian, R., \& Schuurman, J. (2016). Cooperatives, Economic Democratization and Rural Development. London: Edward Elgar Publishing, Incorporated.

Bingen, J., Serrano, A., \& Howard, J. (2003). Linking farmers to markets: Different approaches to human capital development. Food Policy, 28(4), 405-419. doi: http://dx.doi.org/10.1016/j.foodpol.2003.08.007

Bogetoft, P., \& Olesen, H. B. (2004). Design of Production Contracts: Lessons from Theory and Agriculture. Copenhagen Business School Press.

Boisier, S. (2006). Imágenes en el espejo: Aportes a la discusión sobre crecimiento y desarrollo territorial Santiago de Chile: Puerto de Palos Editores.

Bratton, M. (1986). Farmer organizations and food production in Zimbabwe. World Development, 14(3), 367-384. doi: http://dx.doi.org/10.1016/0305-750X(86)90075-6

Brinkerhoff, D. W., \& Morgan, P. J. (2010). Capacity and capacity development: Coping with complexity. Public Administration and Development, 30(1), 2-10. doi: 10.1002/pad.559

Browne, S. (2002). Developing capacity through technical cooperation. New York: Earthscan.

Browne, S. (2003). Developing capacity through technical cooperation: Country experiences (Vol. 14). UNDP. London: Earthscan Publications Ltd..

Cajaiba-Santana, G. (2014). Social innovation: Moving the field forward. A conceptual framework. Technological Forecasting and Social Change, $\quad 82(0), \quad 42-51 . \quad$ doi: http://dx.doi.org/10.1016/j.techfore.2013.05.008

Callon, M. (1998). Laws of the Markets. Oxford: Wiley-Blackwell. 
Cante, N. D. (2012). Análisis de factores de capacidad institucional en municipios pequeños de los departamentos de Boyacá y Cundinamarca. Cuadernos de Administración, 28(47).

Carlile, P. (2002). A pragmatic view of knowledge and boundaries: Boundary objects in new product development. Organization Science, 13(4), 442-455.

Carlile, P., \& Rebentisch, E. (2003). Into the Black Box: The Knowledge Transformation Cycle. Management Science, 49(9), 1180-1195. doi: 10.1287/mnsc.49.9.1180.16564

Castellanos, O., Torres, L., Fonseca, S., Montanez, V., \& Sánchez, A. (2007). Agenda prospectiva de investigación y desarrollo tecnológico para la cadena productiva de cacao-chocolate en Colombia. Grupo de Investigación y Desarrollo en Gestión, Productividad y Competitividad-Biogestión, Universidad Nacional de Colombia.

CEPAC. (2003). Historia del Pueblo Afrocolombiano - Perspectiva Pastoral. Retrieved 17/08/2015 from http://axecali.tripod.com/cepac/hispafrocol/6.htm

Charmaz, K. (2014a). Constructing Grounded Theory. London: SAGE Publications Ltd.

Charmaz, K. (2014b). Grounded Theory in Global Perspective: Reviews by International Researchers. Qualitative Inquiry, 20(9), 1074-1084. doi: 10.1177/1077800414545235

Chia, R., \& Holt, R. (2006). Strategy as Practical Coping: A Heideggerian Perspective. Organization Studies, 27(5), 635-655. doi: 10.1177/0170840606064102

CINEP. (2014). Datos de información georeferenciada: Sintesis de la Violencia en Colombia 2002, 2007, 2010.

Cruz, I., Stahel, A., \& Max-Neef, M. (2009). Towards a systemic development approach: Building on the Human-Scale Development paradigm. Ecological economics, 68(7), 2021-2030.

Dabelstein, N. (2012). The Paris Declaration on the Aid Effectiveness: History and Significance. Canadian Journal of Program Evaluation, 27(3), 19-36. 
DAC-OECD. (2006). The challenge of capacity document. Working towards good practice.

DAC-OECD. (2011). Civil Society Organisations and Capacity Development. Perspectives Note. Paris.

De Souza Filho, H. M., Young, T., \& Burton, M. P. (1999). Factors Influencing the Adoption of Sustainable Agricultural Technologies: Evidence from the State of Espírito Santo, Brazil. Technological Forecasting and Social Change, 60(2), 97-112. doi: http://dx.doi.org/10.1016/S0040-1625(98)00040-7

Deng, H., Huang, J., Xu, Z., \& Rozelle, S. (2010). Policy support and emerging farmer professional cooperatives in rural China. China Economic Review, 21(4), 495-507. doi: http://dx.doi.org/10.1016/j.chieco.2010.04.009

Devaux, A., Horton, D., Velasco, C., Thiele, G., López, G., Bernet, T., Reinoso, I., \& Ordinola, M. (2009). Collective action for market chain innovation in the Andes. Food Policy, 34(1), 31-38. doi: http://dx.doi.org/10.1016/j.foodpol.2008.10.007

DiMaggio, P. J. (1988). Interest and agency in institutional theory. In L. G. Zucker (Ed.), Institutional patterns and organizations: Culture and environment (pp. 3-21). Cambridge, MA: Ballinger.

DNP. (2015). El campo colombiano: Un camino hacia el bienestar y la paz. Informe detallado de la misión para la transformación del campo. Bogota.

Doganova, L. (2013). Transfer and exploration: Two models of scienceindustry intermediation. Science and Public Policy, 40(4), 442-452. doi: $10.1093 / \mathrm{scipol} / \mathrm{sct} 033$

Downey, G. (1992). Human Agency in CAD/CAM Technology. Anthropology today, 8(5), 2-6.

DPS. (2012). Informe de Madurez Organizacional. (Convenio de Cooperacion No. 155 de 2012 ). Bogota: Organización Internacional para las Migraciones. 
ECDPM. (2008). Capacity Change and Performance, Insights and Implications for Development Cooperation. Policy Management Brief, European centre for development policy management (21).

Emprender-Paz. (2011). Banco de Buenas Practicas: Sector Privado y Construcción de Paz. Online: emprenderpaz.org

Fedecacao. (2013). FNC, Qué somos. Retrieved 17/08/2015 from http://www.fedecacao.com.co/site/index.php/1fnc-fondonacional-del-cacao/2fnc-que-es

Ferreira, S. (2012). Evolution and future of the knowledge commons: Emerging opportunities and challenges for less developed societies. Knowledge Management for Development Journal, 8(2-3), 141-168. doi: 10.1080/19474199.2012.717757

Fischer, E., \& Qaim, M. (2012). Linking Smallholders to Markets: Determinants and Impacts of Farmer Collective Action in Kenya. World Development, 40(6), 1255-1268. doi: http://dx.doi.org/10.1016/j.worlddev.2011.11.018

Fligstein, N. (2001). Social Skill and the Theory of Fields. Paper presented at the Power and Organization, Hamburg.

Fonseca Rodríguez, S. L., Arraut Camargo, L. C., Contreras Pedraza, C. A., Correa Cantillo, Z., Castellanos Domínguez, Ó. F., Universidad Nacional de Colombia , \& Universidad Tecnológica de Bolívar. (2011). Balance tecnológico de la cadena productiva y agroindustrial del cacao en el departamento de Bolívar: Colciencias; Cámara de Comercio de Cartagena de Indias; Gobernación de Bolívar.

Foucault, M. (1972). The Archaeology of Knowledge. New York: Pantheon Books.

Fujimura, J. H. (1987). Constructing 'Do-able' Problems in Cancer Research: Articulating Alignment. Social Studies of Science, 17(2), 257-293.

Fukuda-Parr, S., Lopes, C., \& Malik, K. (2002). Capacity for development. New solutions to old problems. New York: Earthscan.

Gangotena, J., \& Herrmann, P. (2007). Desarrollo de Capacidades el cambio nunca viene de afuera. Quito: Editorial Abya Yala. 
Gasper, D. (2003). Nussbaum's capabilities approach in perspective: Purposes, methods and sources for an ethics of human development. Working Papers. The Hague: Institute of Social Studies.

Geels, F. W. (2002). Technological transitions as evolutionary reconfiguration processes: A multi-level perspective and a casestudy. Research Policy, 31(8-9), 1257-1274. doi: http://dx.doi.org/10.1016/S0048-7333(02)00062-8

George, A. L., \& Bennett, A. (2005). Case Studies and Theory Development in the Social Sciences. Cambridge: MIT Press.

Gieryn, T. F. (1983). Boundary-work and the demarcation of science from non-science: Strains and interests in professional ideologies of scientists. American sociological review, 781-795.

Gieryn, T. F. (1999). Cultural boundaries of science: Credibility on the line. Chicago: University of Chicago Press.

Gilbert, E., Posner, J., \& Sumberg, J. (1990). Farming systems research within a small research system: A search for appropriate models. Agricultural Systems, 33(4), 327-346. doi: http://dx.doi.org/10.1016/0308-521X(90)90059-Y

Goldkuhl, G., \& Röstlinger, A. (2002). The practices of knowledgeinvestigating functions and sources. Paper presented at the Proc of the 3rd European Conference on Knowledge Management.

González, A. A., \& Nigh, R. (2005). Smallholder participation and certification of organic farm products in Mexico. Journal of Rural Studies, 21(4), 449-460. doi: http://dx.doi.org/10.1016/j.jrurstud.2005.08.004

Gouet, C., Leeuwis, C., \& Van Paassen, A. (2009). Theoretical perspectives on the role and significance of rural producer organisations in development: Implications for capacity development. Social and Economic Studies, 58(3/4), 75-109.

Gruère, G., Nagarajan, L., \& King, E. D. I. O. (2009). The role of collective action in the marketing of underutilized plant species: Lessons from a case study on minor millets in South India. Food Policy, 34(1), 3945. doi: http://dx.doi.org/10.1016/j.foodpol.2008.10.006 
Hagmann, J., \& Chuma, E. (2002). Enhancing the adaptive capacity of the resource users in natural resource management. Agricultural Systems, 73(1), 23-39. doi: http://dx.doi.org/10.1016/S0308$\underline{521 X(01) 00098-1}$

Hargadon, A., \& Sutton, R. I. (1997). Technology brokering and innovation in a product development firm. Administrative Science Quarterly, 716-749.

Heidegger, M. (1967). Being and Time. Oxford: Wiley-Blackwell.

Hellin, J., Lundy, M., \& Meijer, M. (2009). Farmer organization, collective action and market access in Meso-America. Food Policy, 34(1), 1622. doi: http://dx.doi.org/10.1016/j.foodpol.2008.10.003

Hoppe, R. (2010a). From 'knowledge use' towards 'boundary work'. Sketch of an emerging new agenda for inquiry into science-policy interaction. In R. J. i. t. Veld. (Ed.), Knowledge democracy. Consequences for Science, Politics and Media. (pp. 169-186). Heidelberg: Springer.

Hoppe, R. (2010b). Lost in translation? A boundary work perspective on making climate change governable.

Hornidge, A.-K. (2013). 'Knowledge', 'Knowledge Society' \& 'Knowledge for Development'. Studying Discourses of Knowledge in an International Context. In R. Keller \& I. Truschkat (Eds.), Methodologie und Praxis der Wissenssoziologischen Diskursanalyse (pp. 397-424): VS Verlag für Sozialwissenschaften.

Hornidge, A.-K., Oberkircher, L., \& Kudryavtseva, A. (2013). Boundary management and the discursive sphere - Negotiating 'realities' in Khorezm, Uzbekistan. Geoforum, 45(0), 266-274. doi: http://dx.doi.org/10.1016/j.geoforum.2012.11.014

Howells, J. (2006). Intermediation and the role of intermediaries in innovation. Research Policy, 35(5), 715-728.

Hupe, P. \& Hill, M. (2006). The three action levels of governance: reframing the policy process beyond the stages model. In B. G. Peters \& J. Pierre Handbook of public policy (pp. 13-30). London: SAGE Publications Ltd. doi: 10.4135/9781848608054.n2 
Hussein, K. (2001). Producer Organizations and Agricultural Technology in West Africa: Institutions that give farmers a voice. Development, 44(4), 61.

IFAD. (2011). Rural Poverty Report. Rome, Italy: International Fund for Agricultural Development.

Jessop, B. (2003). Governance and meta-governance: On reflexivity, requisite variety and requisite irony. In Bang, H. Ed. Governance as social and political communication, 101-116. Manchester: Manchester University Press

Jessop, B. (2006). From micro-powers to governmentality: Foucault's work on statehood, state formation, statecraft and state power. Political geography, 26(1), 34-40.

Jia, X., Huang, J., \& Xu, Z. (2012). Marketing of farmer professional cooperatives in the wave of transformed agrofood market in China. China Economic Review, 23(3), 665-674. doi: http://dx.doi.org/10.1016/j.chieco.2010.07.001

JICA Research Institute. (2008). Capacity assessment habndbook. Tokyo: Japan International Development Agency. JICA Research Institute (Ed.).

Kaganzi, E., Ferris, S., Barham, J., Abenakyo, A., Sanginga, P., \& Njuki, J. (2009). Sustaining linkages to high value markets through collective action in Uganda. Food Policy, 34(1), 23-30. doi: http://dx.doi.org/10.1016/j.foodpol.2008.10.004

Kaspersma, J. M. (2013). Competences in context. Knowledge and capacity development in public water management in Indonesia and the Netherlands. Delft: TU Delft, Delft University of Technology.

Keller, R. (2011). The Sociology of Knowledge Approach to Discourse (SKAD). Human Studies, 34(1), 43-65. doi: 10.1007/s10746-0119175-z

Kellogg, K. C., Orlikowski, W. J., \& Yates, J. (2006). Life in the trading zone: Structuring coordination across boundaries in postbureaucratic organizations. Organization Science, 17(1), 22-44. 
Kemp, R., Schot, J., \& Hoogma, R. (1998). Regime shifts to sustainability through processes of niche formation: The approach of strategic niche management. Technology Analysis \& Strategic Management, 10(2), 175-198.

Kilelu, C., Klerkx, L., \& Leeuwis, C. (2013). Unravelling the role of innovation platforms in supporting co-evolution of innovation: Contributions and tensions in a smallholder dairy development programme. Agricultural Systems, 118, 65-77.

Kilelu, C., Klerkx, L., Leeuwis, C., \& Hall, A. (2011). Beyond knowledge brokering: An exploratory study on innovation intermediaries in an evolving smallholder agricultural system in Kenya. Knowledge Management for Development Journal, 7(1), 84-108. doi: 10.1080/19474199.2011.593859

Klerkx, L., \& Leeuwis, C. (2009). Establishment and embedding of innovation brokers at different innovation system levels: Insights from the Dutch agricultural sector. Technological Forecasting and Social Change, 76(6), 849-860. doi: http://dx.doi.org/10.1016/j.techfore.2008.10.001

Klerkx, L., Pant, L. P., Leeuwis, C., Cummings, S., le Borgne, E., Kulis, I., Lamoureux, L., \& Senmartin, D. (2011). Beyond the conventional boundaries of knowledge management: Navigating the emergent pathways of learning and innovation for international development. Knowledge Management for Development Journal, 7(1), 1-7. doi: 10.1080/19474199.2011.593880

Klerkx, L., Schut, M., Leeuwis, C., \& Kilelu, C. (2012). Advances in knowledge brokering in the agricultural sector: Towards innovation system facilitation. IDS Bulletin, 43(5), 53-60.

Kruijssen, F., Keizer, M., \& Giuliani, A. (2009). Collective action for smallscale producers of agricultural biodiversity products. Food Policy, 34(1), $46-52$.

doi:

http://dx.doi.org/10.1016/j.foodpol.2008.10.008

Kuhlmann, S. (2002). Governance and Intelligence in Research and Innovation Systems. Universiteit Utrecht, Utrecht. 
Land, T., Hauck, V., \& Baser, H. (2009). Capacity change and performance. Capacity development: between planned interventions and emergent processes. Implications for development cooperation. Policy Management Brief, European centre for development policy management, (22), 8.

Latour, B. (1994). On technical mediation. Common knowledge, 3(2), 29 64.

Latour, B. (1999). Pandora's hope (Vol. 281): Cambridge, MA: Harvard University Press.

Lawrence, T. B., Leca, B., \& Zilber, T. B. (2013). Institutional work: Current research, new directions and overlooked issues. Organization Studies, 34(8), 1023-1033.

Lawrence, T. B., \& Suddaby, R. (2006). Institutions and Institutional Work. In Clegg, S., Hardy, C., Lawrence, T., Nord, W. The Sage handbook of organization studies, 2nd Edition (pp. 215-254). Sage Publications Ltd.

LenCD.org. (2013). LenCD Learning network on capacity development. Retrieved 30/09/2013 from http://www.lencd.org

Li, T. (1999). Compromising Power: Development, Culture, and Rule in Indonesia. Cultural anthropology, 14(3), 295-322.

MADR. (2013). Tutorial Proyecto Apoyo Alianzas Productivas. Retrieved $17 / 08 / 2015$ from http://alianzasproductivas.minagricultura.gov.co:81/tutorial/ Tutorial.aspx?idPadre $=66$

Maldonado, C. E. (2002). Filosofía de la sociedad civil: Siglo del hombre, Universidad Libre.

Marcus, G. E. (1995). Ethnography in/of the world system: The emergence of multi-sited ethnography. Annual review of anthropology, 95-117.

Maturana, H. R., \& Varela, F. J. (1990). El árbol del conocimiento: Las bases biológicas del conocimiento humano. Madrid: Debate.

Meinzen-Dick, R., DiGregorio, M., \& McCarthy, N. (2004). Methods for studying collective action in rural development. Agricultural 
Mentz, J. C. N. (1997) Personal and Institutional Factors in Capacity Building and Institutional Development. Vol. 14. Working Papers. Maastricht: European Centre for Development Policy Management.

Meyer, M., \& Kearnes, M. (2013). Introduction to special section: Intermediaries between science, policy and the market. Science and Public Policy, 40(4), 423-429. doi: 10.1093/scipol/sct051

Morgan, G. (2006). Images of Organization. Thousand oaks: SAGE Publications.

Morgan, P. (1997). The design and use of capacity development indicators. Political and Social Policies Division, Policy Branch, CIDA. Hull: Canadian International Development Agency (CIDA).

Morgan, P. (2005) The idea and practice of systems thinking and their relevance for capacity development Draft paper. The Hague.

Mosse, D. (2005). Cultivating Development: An Ethnography of Aid Policy and Practice. New York: Pluto Press.

Moustier, P., Tam, P. T. G., Anh, D. T., Binh, V. T., \& Loc, N. T. T. (2010). The role of farmer organizations in supplying supermarkets with quality food in Vietnam. Food Policy, 35(1), 69-78. doi: http://dx.doi.org/10.1016/j.foodpol.2009.08.003

Nadai, E., \& Maeder, C. (2009). Contours of the Field (s): Multi-sited Ethnography as a Theory-driven Research Strategy for Sociology. In Falzon, M. A., Multi-sited ethnography: Theory, praxis and locality in contemporary research, 233-250. Ashgate Publishing.

Narrod, C., Roy, D., Okello, J., Avendaño, B., Rich, K., \& Thorat, A. (2009). Public-private partnerships and collective action in high value fruit and vegetable supply chains. Food Policy, 34(1), 8-15. doi: http://dx.doi.org/10.1016/j.foodpol.2008.10.005

Ngwenya, H., \& Hagmann, J. (2011). Making innovation systems work in practice: Experiences in integrating innovation, social learning and knowledge in innovation platforms. Knowledge Management for 
Development Journal, $\quad 7(1), \quad 109-124 . \quad$ doi: 10.1080/19474199.2011.593867

North, D. C. (1990). Institutions, Institutional Change and Economic Performance. Cambridge: Cambridge University Press.

OECD. (2006). The challenge of capacity development. Working towards good practice.

Oliver, C. (1991). Strategic Responses to Institutional Processes. The Academy of Management Review, 16(1), 145-179. doi: $10.2307 / 258610$

Ortiz, O., Orrego, R., Pradel, W., Gildemacher, P., Castillo, R., Otiniano, R., Gabriel, J., Vallejo, J., Torres, O., Woldegiorgis, G., Damene, B., Kakuhenzire, R., Kasahija, I., \& Kahiu, I. (2013). Insights into potato innovation systems in Bolivia, Ethiopia, Peru and Uganda. Agricultural Systems, 114(0), 73-83. doi: http://dx.doi.org/10.1016/j.agsy.2012.08.007

Ospina, S. (2002). Construyendo capacidad institucional en América Latina: el papel de la evaluación como herramienta modernizadora. Paper presented at the Ponencia presentada en el VII Congreso Internacional del CLAD. Lisboa, Portugal.

Ostrom, E. (1996). Crossing the great divide: Coproduction, synergy, and development. World Development, 24(6), 1073-1087. doi: http://dx.doi.org/10.1016/0305-750X(96)00023-X

Ostrom, E. (2005). Understanding Institutional Diversity. New Jersey: Princeton University Press.

Ostrom, E. (2007). Institutional rational choice: An assessment of the institutional analysis and development framework. In Theories of the Policy Process, 2nd ed., P.A. Sabatier (ed.). Cambridge, MA: Westview Press.

Otoo, S., Agapitova, N., \& Behrens, J. (2009). The capacity development results framework. A strategic and results-oriented approach to learning for capacity development. The World Bank Institute.

Pacheco, D. F., York, J. G., Dean, T. J., \& Sarasvathy, S. D. (2010). The Coevolution of Institutional Entrepreneurship: A Tale of Two 
Theories. Journal of Management, 36(4), 974-1010. doi: $10.1177 / 0149206309360280$

PROCASUR. (2011). Catalogo Experiencias. Retrieved 03/07/2013 from http://www.procasur.org/catalogoexperiencias/

Rip, A., \& Kemp, R. (1998). Technological change. In: S. Rayner \& E.L. Malone (Eds.), Human choice and climate change. Vol. II, Resources and technology. Columbus: Battelle Press. pp. 327-399.

Röling, N., \& Engel, P. (1991). The development of the concept of agricultural knowledge and information systems (AKIS): Implications for extension. In Rivera, W., Gustafson, D. Agricultural extension: worldwide institutional evolution and forces for change. Elsevier Science Publishers BV, 1991. Pp 125-139.

Rondot, P., \& Collion, M.-H. (2001). Agricultural Producer Organizations: Their Contribution to Rural Capacity Building and Poverty Reduction. Washington: World Bank.

SARD. (2007). Sustainable Agriculture and Rural Development and Farmers' Organizations. Policy Brief 12. FAO, ILO, IFAD, IFAP, AGRICORD, ROPPA.

Schatzki, T. R., Knorr-Cetina, K., \& Von Savigny, E. (2001). The Practice Turn in Contemporary Theory. New York: Routledge.

Schejtman, A., \& Ranaboldo, C. (2009). El valor del patrimonio cultural. Territorios rurales, experiencias y proyecciones latinoamericanas. Lima: Instituto de Estudios Peruanos.

Schlierf, K., \& Meyer, M. (2013). Situating knowledge intermediation: Insights from science shops and knowledge brokers. Science and Public Policy, 40(4), 430-441. doi: 10.1093/scipol/sct034

Schoen, A., Könnölä, T., Warnke, P., Barré, R., \& Kuhlmann, S. (2011). Tailoring Foresight to field specificities. Futures, 43(3), 232-242. doi: http://dx.doi.org/10.1016/j.futures.2010.11.002

Schut, M., Van Paassen, A., Leeuwis, C., \& Klerkx, L. (2013). Towards dynamic research configurations: A framework for reflection on the contribution of research to policy and innovation processes. Science and Public Policy. (Pp 207-218) doi: 10.1093/scipol/sct048 
Schwartz-Shea, P., Yanov, D. (2012). Interpretive research design: Concepts and processes: New York: Routledge.

Semana. (2015, September 19). ¿Quién está matando a los líderes en Colombia? Revista Semana.

Shiferaw, B., Obare, G., Muricho, G. (2006) Rural Institutions and Producer Organizations in Imperfect Markets. Experiences from Producer Marketing Groups in Semi-Arid Eastern Kenya. Vol. 60. CAPRi Working Paper. CGIAR.

Smits, R., \& Kuhlmann, S. (2004). The rise of systemic instruments in innovation policy. International journal of foresight and innovation policy, 1(1-2), 4-32.

Star, S. L., \& Griesemer, J. R. (1989). Institutional Ecology, 'Translations' and Boundary Objects: Amateurs and Professionals in Berkeley's Museum of Vertebrate Zoology, 1907-39. Social Studies of Science, 19(3), 387-420. doi: 10.1177/030631289019003001

Swierstra, T., \& Rip, A. (2007). Nano-ethics as NEST-ethics: Patterns of Moral Argumentation About New and Emerging Science and Technology. NanoEthics, 1(1), 3-20. doi: 10.1007/s11569-007-0005-8

Taylor, P., \& Clarke, P. (2007). Capacity for a Change. London: Institute of Development Studies.

Thomas-Slayter, B. P. (1994). Structural change, power politics, and community organizations in Africa: Challenging the patterns, puzzles and paradoxes. World Development, 22(10), 1479-1490. doi: http://dx.doi.org/10.1016/0305-750X(94)90032-9

Thorp, R., Stewart, F., \& Heyer, A. (2005). When and how far is group formation a route out of chronic poverty? World Development, 33(6), 907-920.

doi:

http://dx.doi.org/10.1016/j.worlddev.2004.09.016

Tironi, M., Salazar, M., \& Valenzuela, D. (2013). Resisting and accepting: Farmers' hybrid epistemologies in the GMO controversy in Chile. Technology in Society, 35(2), 93-104. doi: http://dx.doi.org/10.1016/j.techsoc.2013.01.004 
Tole, L. (2010). Reforms from the Ground Up: A Review of CommunityBased Forest Management in Tropical Developing Countries. Environmental Management, 45(6), 1312-1331. doi: 10.1007/s00267-010-9489-z

Trærup, S. L. M. (2012). Informal networks and resilience to climate change impacts: A collective approach to index insurance. Global Environmental Change, 22(1), 255-267. doi: http://dx.doi.org/10.1016/j.gloenvcha.2011.09.017

Turnhout, E., Stuiver, M., Klostermann, J., Harms, B., \& Leeuwis, C. (2013). New roles of science in society: Different repertoires of knowledge brokering. Science and Public Policy, 40(3), 354-365. doi: $10.1093 / \mathrm{scipol} / \mathrm{scs} 114$

Ubels, J., Acquaye-Baddoo, N.-A., \& Fowler, A. (2010). Capacity development in practice. London: Earthscan.

UNDP. (2008). Capacity Development Practice Note. New York: United Nations Development Programme.

UNDP. (2010a). 'Capacity is Development' Global Event - A Report.

UNDP. (2010b). 'Capacity is Development' Global Event Video Summary (17 minute version - Part 1).

Uphoff, N. (1988). Participatory evaluation of farmer organizations' capacity for development tasks. Agricultural Administration and Extension, 30(1), 43-64. doi: http://dx.doi.org/10.1016/02697475(88)90047-5

Uphoff, N. (1993). Grassroots organizations and NGOs in rural development: Opportunities with diminishing states and expanding markets. World Development, 21(4), 607-622. doi: http://dx.doi.org/10.1016/0305-750X(93)90113-N

Van Egmond, S., \& Zeiss, R. (2010). Modeling for Policy. Science Studies, $23(1), 58-78$.

Van Lente, H. (2003). Roles of Systemic Intermediaries in Transition Processes. International journal of innovation management, 07(03), 247-279. 
Varela, F. (2000). El Fenómeno de la Vida Santiago de Chile: Dolmen Editores.

Von Bertalanffy, L. (1969). General system theory: Foundations, development, applications. New York: George Braziller Inc.

Voß, J.-P. (2007). Innovation processes in governance: The development of 'emissions trading' as a new policy instrument. Science and Public Policy, 34(5), 329-343. doi: 10.3152/030234207x228584

Wanyama, F. O., Develtere, P., \& Pollet, I. (2009). Reinventing the Wheel? African Cooperatives in a Liberalized Economic Environment. Annals of Public and Cooperative Economics, 80(3), 361-392. doi: 10.1111/j.1467-8292.2009.00390.x

Weber, M. (1949). The Methodology of the Social Sciences. Glencoe, Illinois: The Free Press.

Whittington, R. (2006). Completing the Practice Turn in Strategy Research. Organization Studies, 27(5), 613-634. doi: 10.1177/0170840606064101

Wienberg, D. H. (1987). Rural pockets of poverty. Rural Sociology, 52(3), 398.

Wood, G., \& Gough, I. (2006). A Comparative Welfare Regime Approach to Global Social Policy. World Development, 34(10), 1696-1712. doi: http://dx.doi.org/10.1016/j.worlddev.2006.02.001

Woolcock, M. (2010). The rise and routinization of social capital, 19882008. Annual review of political science, 13, 469-487.

World Bank. (2007). Enhancing Agricultural Innovation: How to Go Beyond the Strengthening of Research Systems. World Bank.

World Bank. (2011). Capacity Development Resource Center. Retrieved November 21, 2014, from http://go.worldbank.org/U7WIN8DE00

World Bank. (2012). Guide to evaluating capacity development results. A collection of guidance to notes to help development practitioners and evaluators assess capacity development efforts. 
Yadoo, A., \& Cruickshank, H. (2010). The value of cooperatives in rural electrification. Energy Policy, 38(6), 2941-2947. doi: http://dx.doi.org/10.1016/j.enpol.2010.01.031

Yang, H. (2013). Farmer Cooperatives as Intermediaries for Agricultural and Rural Development in China (Doctoral dissertation, Wageningen University, Wageningen).

Yang, H., Klerkx, L., \& Leeuwis, C. (2014). Functions and limitations of farmer cooperatives as innovation intermediaries: Findings from China. Agricultural Systems (pp115-125). doi: http://dx.doi.org/10.1016/j.agsy.2014.02.005

Yanow, D., \& Schwartz-Shea, P. (2015). Interpretation and method: Empirical research methods and the interpretive turn. New York: Routledge.

Zald, M. N., \& McCarthy, J. D. (1987). Social movements in an organizational society: Collected essays. New Jersey: Transaction publishers.

Zietsma, C., \& Lawrence, T. B. (2010). Institutional work in the transformation of an organizational field: The interplay of boundary work and practice work. Administrative Science Quarterly, 55(2), 189-221. 
Appendices 
Annex 1. Organizations of the National Cocoa Network

\begin{tabular}{|c|c|c|}
\hline NODE & ORGANIZATION & MUNICIPALITY \\
\hline \multirow{7}{*}{ NOR-OCCIDENTAL } & $\begin{array}{l}\text { Asociación de productores agroforestales de } \\
\text { acandi aprocafa }\end{array}$ & Acandi \\
\hline & $\begin{array}{l}\text { Asociación de productores agroforestales } \\
\text { japi tisle nait nega sapinega }\end{array}$ & Unguia \\
\hline & $\begin{array}{l}\text { Asociación de productores agropecuarios y } \\
\text { cacaoteros de caceres aproaca }\end{array}$ & Caceres \\
\hline & $\begin{array}{l}\text { Cooperativa de trabajo asociado } \\
\text { productores agropecuarios proasiv }\end{array}$ & Turbo \\
\hline & $\begin{array}{l}\text { Asociación municipal de cacaocultores de } \\
\text { anori asomucan }\end{array}$ & Anori \\
\hline & $\begin{array}{l}\text { Asociación de cooperativas y organizaciones } \\
\text { de tierralta y valencia activa g } 10\end{array}$ & Tierralta \\
\hline & Integrasinu & Tierralta \\
\hline \multirow{5}{*}{ SUR } & Asocacao sembrapaz - alto patia & Pasto \\
\hline & Consejo comunitario bajo mira y frontera & Tumaco \\
\hline & Consejo comunitario union del rio chagui & Tumaco \\
\hline & $\begin{array}{l}\text { Palmeros del pacifico sur sociedad agraria } \\
\text { de transformación palmasur }\end{array}$ & Tumaco \\
\hline & $\begin{array}{l}\text { Asociación de productores agropecuarios } \\
\text { asopa loro uno }\end{array}$ & $\begin{array}{l}\text { Valle del } \\
\text { guamuez }\end{array}$ \\
\hline \multirow{10}{*}{ CENTRO } & $\begin{array}{l}\text { Asociación de productores de cacao del } \\
\text { municpio de rivera asoprocar }\end{array}$ & Rivera \\
\hline & $\begin{array}{l}\text { Asociación de productores de cacao del } \\
\text { municipio de algeciras aprocal }\end{array}$ & Algeciras \\
\hline & $\begin{array}{l}\text { Asociación de productores de cacao del } \\
\text { municipio de pauna aprocampa }\end{array}$ & Pauna \\
\hline & $\begin{array}{l}\text { Asociación campesina de cacaoteros del } \\
\text { municipio de san pablo de borbur }\end{array}$ & $\begin{array}{l}\text { San pablo } \\
\text { borbur }\end{array}$ \\
\hline & $\begin{array}{l}\text { Cipaotanche. Cooperativa integral de } \\
\text { productores agropecuaris de otanche }\end{array}$ & Otanche \\
\hline & $\begin{array}{l}\text { Asociación de productores de cacao del sur } \\
\text { del tolima aprocasurt }\end{array}$ & Chaparral \\
\hline & $\begin{array}{l}\text { Cacaomet cooperativa agroindustrial de } \\
\text { cacaoteros del meta }\end{array}$ & Granada \\
\hline & $\begin{array}{l}\text { Proaspen asociación nacional agropecuaria } \\
\text { de productores de pensilvania. }\end{array}$ & Pensilvania \\
\hline & Asociación victoriana de cacaoteros & La victoria \\
\hline & Cooperativa multiactiva de producción y & Arauquita \\
\hline
\end{tabular}




\begin{tabular}{|c|c|c|}
\hline & $\begin{array}{l}\text { comercialización agropecuaria de arauquita } \\
\text { comprocar ltda }\end{array}$ & \\
\hline \multirow{7}{*}{ CARIBE } & $\begin{array}{l}\text { Asociación de productores agropecuarios de } \\
\text { maria la baja }\end{array}$ & Maria la baja \\
\hline & $\begin{array}{l}\text { Corporacion para el desarrollo integral de } \\
\text { los montes de maria }\end{array}$ & San jacinto \\
\hline & $\begin{array}{l}\text { Asociación de productores de cacao de los } \\
\text { montes de maria asprocamm }\end{array}$ & Ovejas \\
\hline & $\begin{array}{l}\text { Asociación de apicultores de coloso } \\
\text { asoapicol }\end{array}$ & Sincelejo \\
\hline & Asojuventud & Chalan \\
\hline & $\begin{array}{l}\text { Asociación de organizaciones agroturisticas } \\
\text { y sostenibles de bosques de la sierra nevada } \\
\text { de santa marta }\end{array}$ & Santa marta \\
\hline & $\begin{array}{l}\text { Asociación de productores organicos del } \\
\text { municipio de dibulla apomd }\end{array}$ & Dibulla \\
\hline \multirow{5}{*}{$\begin{array}{l}\text { MAGDALENA } \\
\text { MEDIO }\end{array}$} & $\begin{array}{l}\text { Asociación de productores de cacao del sur } \\
\text { de bolivar y magdalena medio aprocasur }\end{array}$ & $\begin{array}{l}\text { Santa rosa del } \\
\text { sur }\end{array}$ \\
\hline & Asocalima & $\begin{array}{l}\text { Santa rosa del } \\
\text { sur }\end{array}$ \\
\hline & $\begin{array}{l}\text { Asociación de productores agropecuarios e } \\
\text { industriales de colombia asoprolan }\end{array}$ & Cimitarra \\
\hline & $\begin{array}{l}\text { Corporacion tierra para la paz del } \\
\text { magdalena medio cortipaz }\end{array}$ & El carmen \\
\hline & $\begin{array}{l}\text { Asociación de productores de cacao frutales } \\
\text { y maderables de san vicente del chucuri } \\
\text { aprocafrum }\end{array}$ & San vicente \\
\hline \multirow{6}{*}{ CATATUMBO } & $\begin{array}{l}\text { Asociación gremial de productores } \\
\text { cacaoteros del municipio de tibu asocati }\end{array}$ & Tibu \\
\hline & $\begin{array}{l}\text { Asociación de productoresagropecuarios } \\
\text { semillas del futuro aprasef }\end{array}$ & Convencion \\
\hline & $\begin{array}{l}\text { Asociación de cacaoteros de sardinata } \\
\text { asocasar }\end{array}$ & Sardinata \\
\hline & $\begin{array}{l}\text { Asociación de productores del carmen } \\
\text { asoprocar }\end{array}$ & El carmen NS \\
\hline & $\begin{array}{l}\text { Asociación de productores cacaoteros de } \\
\text { paccelli }\end{array}$ & Tibu \\
\hline & $\begin{array}{l}\text { Cooperativa multiactiva veredal san pablo } \\
\text { ltda coomvesap ltda }\end{array}$ & Teorama \\
\hline
\end{tabular}


Annex 2. Data sources and coding

\begin{tabular}{|c|c|c|c|c|}
\hline Reference code & Content & Dataset Code & Type & Length \\
\hline \multirow{5}{*}{ Fg Mc, 14/01/14 } & \multirow{5}{*}{$\begin{array}{l}\text { Focus Group } \\
\text { Magdalena Medio, } \\
\text { Caribe. }\end{array}$} & VOC_140113-0036 & Audio & $00: 59: 59$ \\
\hline & & VOC_140113-0037 & Audio & $00: 44: 30$ \\
\hline & & VOC_140114-0040 & Audio & 00:11:00 \\
\hline & & VOC_140114-0042 & Audio & $00: 17: 50$ \\
\hline & & VOC_140114-0043 & Audio & $00: 29: 24$ \\
\hline Obs Mc, $14 / 01 / 14$ & $\begin{array}{l}\text { Observation } \\
\text { Magdalena Medio, } \\
\text { Caribe }\end{array}$ & Field Notes & Text & \\
\hline $\begin{array}{l}\text { Interview Ldr 001, } \\
13 / 01 / 14\end{array}$ & Leader Interview & VOC_140113-0044 & Audio & 00:16:37 \\
\hline $\begin{array}{l}\text { Interview Tm 001, } \\
\text { 16/01/14 }\end{array}$ & $\begin{array}{l}\text { Project officer } \\
\text { Interview }\end{array}$ & VOC_140115-0045 & Audio & 00:20:43 \\
\hline $\begin{array}{l}\text { Interview Tm 002, } \\
\text { 16/01/14 }\end{array}$ & $\begin{array}{l}\text { Project officer } \\
\text { Interview }\end{array}$ & VOC_140115-0046 & Audio & 00:03:22 \\
\hline \multirow{3}{*}{ Fg No, 16/01/14 } & \multirow{3}{*}{$\begin{array}{l}\text { Focus Group } \\
\text { Noroccidente }\end{array}$} & VOC_140116-0047 & Audio & 00:08:51 \\
\hline & & VOC_140116-0048 & Audio & 01:11:27 \\
\hline & & VOC_140117-0049 & Audio & 00:47:11 \\
\hline Obs No, 16/01/14 & $\begin{array}{l}\text { Observation } \\
\text { Noroccidente }\end{array}$ & Field Notes & Text & \\
\hline $\begin{array}{l}\text { Interview Ofc 003, } \\
16 / 01 / 14\end{array}$ & $\begin{array}{l}\text { Project officer } \\
\text { Interview }\end{array}$ & VOC_140118-0050 & Audio & 00:16:00 \\
\hline \multirow{2}{*}{ Fg Ct, 20/01/14 } & \multirow{2}{*}{$\begin{array}{l}\text { Focus Group, } \\
\text { Catatumbo }\end{array}$} & VOC_140120-0051 & Audio & $01: 10: 36$ \\
\hline & & VOC_140121-0052 & Audio & $01: 50: 25$ \\
\hline $\begin{array}{l}\text { Interview Tm 004, } \\
\text { 20/01/14 }\end{array}$ & $\begin{array}{l}\text { Project officer } \\
\text { Interview }\end{array}$ & VOC_140121-0053 & Audio & $00: 45: 22$ \\
\hline \multirow{3}{*}{ Fg Cn, 23/01/14 } & \multirow{3}{*}{$\begin{array}{l}\text { Focus Group, } \\
\text { Centro }\end{array}$} & VOC_140123-0054 & Audio & 01:33:31 \\
\hline & & VOC_140124-0055 & Audio & 00:03:42 \\
\hline & & VOC_140124-0056 & Audio & 00:33:33 \\
\hline Obs Cn, 23/01/14 & $\begin{array}{l}\text { Observation } \\
\text { Centro }\end{array}$ & Field Notes & Text & \\
\hline $\begin{array}{l}\text { Interview Ofc 001, } \\
05 / 02 / 14\end{array}$ & $\begin{array}{l}\text { National program } \\
\text { Officer } \\
\text { Interview }\end{array}$ & VOC_140204-0059 & Audio & 00:29:44 \\
\hline $\begin{array}{l}\text { Interview Ofc 002, } \\
05 / 02 / 14\end{array}$ & $\begin{array}{l}\text { National program } \\
\text { Officer } \\
\text { Interview }\end{array}$ & VOC_140218-0060 & Audio & 00:52:39 \\
\hline \multirow{5}{*}{ Amb, 14/02/14 } & Assembly - guests & VOC_140220-0061 & Audio & 01:00:51 \\
\hline & Assembly - guests & VOC_140220-0062 & Audio & 02:00:29 \\
\hline & Assembly - guests & VOC_140220-0063 & Audio & 00:09:30 \\
\hline & Centro & VOC_140220-0064 & Audio & 00:05:50 \\
\hline & Discussion & VOC_140220-0065 & Audio & $00: 18: 41$ \\
\hline
\end{tabular}




\begin{tabular}{|c|c|c|c|c|}
\hline Reference code & Content & Dataset Code & Type & Length \\
\hline & Discussion & VOC_140221-0066 & Audio & 00:25:48 \\
\hline & Assembly - guests & VOC_140221-0067 & Audio & $00: 40: 12$ \\
\hline \multirow{2}{*}{$\mathrm{Fg} \mathrm{Sr}, 27 / 01 / 14$} & \multirow{2}{*}{$\begin{array}{l}\text { Focus Group } \\
\text { Sur }\end{array}$} & VOC_140127_0057 & Audio & $02: 19: 42$ \\
\hline & & VOC_140127_0058 & Audio & 00:01:32 \\
\hline Obs Sur, 27/01/14 & $\begin{array}{l}\text { Observation } \\
\text { Sur }\end{array}$ & Field Notes & Text & \\
\hline Obs Pn, 19/03/15 & $\begin{array}{l}\text { Observation } \\
\text { Pauna }\end{array}$ & Field Notes & Text & \\
\hline $\begin{array}{l}\text { Interview Ldr 002, } \\
10 / 06 / 14\end{array}$ & Visit Centro & VOC_141006_0071 & Audio & $01: 15: 18$ \\
\hline \multirow{2}{*}{$\begin{array}{l}\text { Interview Ldr 003, } \\
16 / 06 / 14\end{array}$} & \multirow{2}{*}{$\begin{array}{l}\text { Community council } \\
\text { Leader }\end{array}$} & VOC_141006_0072 & Audio & 01:17:17 \\
\hline & & VOC_141006_0073 & Audio & $00: 05: 19$ \\
\hline $\begin{array}{l}\text { Interview Ldr 004, } \\
\text { 16/06/14 }\end{array}$ & $\begin{array}{l}\text { Community council } \\
\text { Leader }\end{array}$ & VOC_141016_0074 & Audio & 01:31:15 \\
\hline \multirow{2}{*}{$\begin{array}{l}\text { Interview Ofc 004, } \\
17 / 10 / 14\end{array}$} & \multirow{2}{*}{$\begin{array}{l}\text { NGO Officer } \\
\text { Interview }\end{array}$} & VOC_141017_0075 & Audio & $00: 13: 15$ \\
\hline & & VOC_141018_0076 & Audio & $00: 59: 35$ \\
\hline \multirow{2}{*}{$\begin{array}{l}\text { Interview Cmr 001, } \\
16 / 06 / 14\end{array}$} & \multirow{2}{*}{$\begin{array}{l}\text { Firm } \\
\text { Interview }\end{array}$} & VOC_141017_0077 & Audio & 00:59:14 \\
\hline & & VOC_130625_0033 & Audio & $01: 26: 12$ \\
\hline \multirow{8}{*}{ Asc, 07/07/14 } & Assembly 2 - guests & Clip 3 & Video & 00:33:30 \\
\hline & Assembly 2 - guests & Clip 6 & Video & $00: 20: 22$ \\
\hline & Assembly 2 - guests & Clip 7 & Video & 00:09:59 \\
\hline & Assembly 2 & Clip 8 & Video & 01:05:11 \\
\hline & Assembly 2 & Clip 9 & Video & $01: 22: 23$ \\
\hline & Assembly 2 & Clip 10 & Video & $01: 09: 56$ \\
\hline & Assembly 2 & Clip 11 & Video & 01:17:09 \\
\hline & Assembly 2 & Clip 12 & Video & $01: 30: 10$ \\
\hline $\begin{array}{l}\text { Obs Exprt 001, } \\
16 / 07 / 14\end{array}$ & $\begin{array}{l}\text { Legal advisor } \\
\text { Interview }\end{array}$ & Movie on 16-07-2014 & Video & $00: 41: 24$ \\
\hline Obs Am, 14/11/14 & Visit Amsterdam & Field Notes & Text & \\
\hline $\begin{array}{l}\text { Interview LdrSM 001, } \\
03 / 07 / 15\end{array}$ & $\begin{array}{l}\text { Social Movement } \\
\text { Leader }\end{array}$ & VOC_150307-0081 & Audio & 01:39:06 \\
\hline
\end{tabular}




\section{Dutch Summary}




\section{Samenvatting}

Dit boek beschrijft hoe boerenorganisaties omgaan met drijfzand om hen heen. Waar zwakke of afwezige spelregels, oorlog, plundering, illegale handel en corruptie alledaagse kost zijn, vormen boerenorganisaties dikwijls een middel tot orde en stabiliteit.

Dit beeld wekt de suggestie dat er meerdere spellen zijn die boerenorganisaties tegelijkertijd moeten spelen. Bovendien ontstaat het beeld dat omgaan met dergelijke complexiteiten wellicht niet alleen een kwestie is van het spelen van spellen, maar ook een kwestie is van het verschuiven van de spelregels die gelden voor dat spel.

Dit boek werpt een diepere blik op dit fenomeen, waar het niet zoals gebruikelijk primair focust op het speelveld, maar op de spelers zelf. Het geeft inzicht in hoe boerenorganisaties hun kans grijpen als 'change agents'. In plaats van een focus op de rollen van boerenorganisaties, of hun omstandigheden op een bepaald moment, richt dit boek zich primair op de wijze waarop de boerenorganisaties hun strategie bepalen tijdens het spel.

De achterliggende gedachte van deze benadering vindt zijn oorsprong bij de aanname dat een beter begrip van boerenorganisaties tevens betere sturingsinstrumenten voor rurale gebieden oplevert, vooral de gebieden die in de literatuur gekenmerkt worden als 'poverty pockets' (Wienberg, 1987).

Dit is het geval van Colombia, waar over vrede wordt onderhandeld na meer dan vijftig jaar oorlog. Een oorlog gehouden in de buitenwijken van het land, gebied waarvan de toekomst nu eindelijk een kans kan krijgen. $\mathrm{Na}$ de vredesbesprekingen heeft de Colombiaanse regering een adviescommissie ingesteld, om een toekomst visie te vormen op de rurale gebieden (DNP, 2015). Niet onverwacht wijzen de meeste suggesties naar rurale instituties die zouden moeten worden gevormd. De vraag ontstaat daarbij hoe deze nieuwe instituties kunnen aansluiten op, en bouwen op, het bestaande lokale potentieel, om zo hun impact te vergroten. 
Dit biedt mij een excuus om te starten met een uitweiding waarom de titel "Unfolding capacity", oftewel ontvouwende capaciteit, als zodanig is gekozen. Het alledaagse woord "capaciteit" refereert aan het vermogen of de kracht om iets te bereiken, zoals de definitie in de Oxford Dictionary luidt. Op het eerste gezicht gaat dit boek over de capaciteit van boerenorganisaties, dus hoe boerenorganisaties hun vermogen en kracht inzetten om zo om te gaan met complexiteit, en hun perspectieven naar voren weten te brengen in conflictgebieden of -omstandigheden.

Een casus volgt bijvoorbeeld een geval van een organisatie voor kleine boeren, die cacao produceren in zeven Colombiaanse regio's. Opgezet als multi-sited case study, gaat het door de vertellingen van deze organisaties, en beschrijft hoe het was om met onzekerheden om te gaan, en verandering te brengen. De bereidwilligheid van de boerenorganisaties om hun geschiedenis voor dit onderzoek te delen mogen we gerust zien als blijk van hun trots.

Maar er is meer met de term "capaciteit"; de term is overladen met een ontwikkelingshouding. De term is populair in Latijns Amerika, en wordt wijdverspreid gebruikt als een gemeenschappelijke referentie aan publieke aangelegenheden, vaak om te verwijzen naar een gebrek aan 'iets', gebrek aan actoren, middelen of vermogen, dat het succes ondermijnt van het betreffende maatschappelijke project (e.g. Cante, 2012; Gangotena \& Herrmann, 2007; Ospina, 2002).

De term capaciteit is ook populair binnen organisaties die zich richten tot globale ontwikkeling, zoals bijvoorbeeld het OECD en UNDP, waar het wordt gerelateerd aan de verschillende mogelijke wegen van globale veranderingen. Het is hier door de tijd gevoed met achtervoegsels, zoals 'capacity building' of 'capacity strengthening'. Binnen deze ontwikkelingspraktijk is het gegroeid als een aan beleid gerelateerd concept, die weinig aandacht krijgt buiten de academische stromen die direct zijn gerelateerd aan deze thematiek van globale ontwikkeling.

Gefascineerd door deze contouren van 'capaciteit' vraag ik mij af welke verklarende eigenschappen het concept heeft. Aan de buitenzijde van het concept is er weinig zichtbaar, maar ik zag iets in de tussenruimten; er zijn een aantal stromen binnen de wetenschap, die voeding gaven aan de inhoud van het concept. Meestal wordt dit echter niet expliciet gemaakt in beleidsdocumenten, die het concept presenteren als een hapklaar product. 
Het leek me een interessante academische onderneming om een constructieve benadering te gebruiken die voortbouwt op deze bestaande stromen. Beleidsinstrumenten worden immers bestempeld als governance technologieën (Voß, 2007) die tevens inpasbaar zijn in het pallet van sociale technologieën (Beinhocker, 2006), waarbij technologieën worden beschouwd als ontwerpen voor het organiseren van menselijke activiteiten. Ik werd geraakt door de vraag: wat kunnen we leren over sociale veranderingen, door epistemische fundamenten bij elkaar te brengen, te completeren, en deze bloot te leggen.

Deze twee zoektochten: een goede weergave van boerenorganisaties' strategieën enerzijds, en anderzijds een focus op capaciteit als een conceptueel instrument, vormen de basis van mijn onderzoek. Het vormt de kern van een verkenning waarvan de eerste stappen hier zijn weergegeven.

Deze tweeledige speurtocht gaat als vanzelf door het boek, als een dans. De onderzoek benadering is zodanig van opzet dat de empirische en theoretische bevindingen zich ontvouwen in parallel, elkaar versterkend. Beide domeinen laten hun eigen choreografie zien, terwijl ze tegelijkertijd resultaten bij de ander aandrijven. Dit boek beschrijft boerenorganisaties' zoektochten waarbij ze omgaan met een speelveld van actoren, en verandering teweer brengen. En om deze beschrijving mogelijk te maken ontwikkelt het boek concepten die de gestes duiden van actoren, dus hoe ze bewegen, en de manieren waarop kennis daarop drijft.

De resultaten laten een uitgebreid repertoire zien. Uitgezet als een creatieve methodologische onderneming, bouwt het boek op de waarde van de praktijk als een gids voor academische concepten. Het laat een andere kijk zien op meso-level agency, dus op organisatieniveau. Daarbij is er een focus op kennis repertoires, dus kennis gerelateerde stromen, en, eenmaal op die weg, wijst op een solide begrip van 'change-oriented agency', dat is gebouwd op de schouders van boerenorganisaties: de vele spellen waarin praktijk, instituties en grenzen met elkaar vervlechten.

Het boek is verdeeld in vier hoofd onderdelen. Het eerste onderdeel beschrijft de kaders van het onderzoek. Ik bediscussieer literatuur over boerenorganisaties, introduceer de onderzoeksvragen en motiveer het onderzoek. Het tweede onderdeel omvat het theoretische deel: ik beschrijf 
capaciteit ontwikkeling als een interpretatieve referentie, en presenteer theoretische perspectieven uit het bestaande kennisrepertoire. Het sluit af met een gedetailleerde verantwoording van kennisstandpunten als analytische units. Het derde onderdeel presenteert de empirische data. Ik beschrijf de onderzoeksmethodiek en beschrijf de multi-sited cases. Daarna beschrijf ik de veldwerkresultaten. Het vierder onderdeel beschrijft het onderzoeksresultaat. De analyse volgt een typologische motivering, waarbij de strategieën van boerenorganisaties worden bediscussieerd. Details worden gegeven over de speelvelden waar de boerenorganisaties in participeren, en de impact van hun vis-à-vis handelswijze, instituties en begrenzingen. De analyse eindigt met een filtering van strategieën die specifiek linken aan het begrip 'change agency'.

Stapt $\mathrm{u}$ alstublieft in, geniet van de dans. 



\section{"If you live in hell you have to talk to the Devil"}

\section{said a community representative.}

Organizations see their role as making things happen in the territory, opening windows of opportunity in an uncertain, conflictive and threatening environment.

(G. SR, 27/01/14)

Some leaders say the organizations are the state at the local level. In their view, organizations bridge relations between individual farmers and other actors beyond the local sphere, especially public actors.

(I. L. 004, 16/06/14)

\section{"They call us poor"}

We are not poor; we don't need mountains of money to be well. Our aim is managing what we have, get trained in every aspect to be free and own the knowledge

(I. L. 003, 16/06/14)

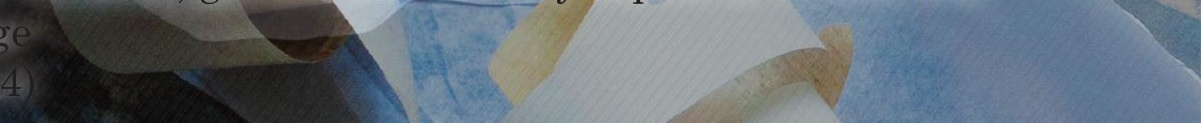

What are the strategies of farmers organizations as change agents?

This book develops a fresh and comprehensive lens to capture the many means by which these organizations strive to achieve peace in volatile places. It is a fascinating journey to the origins of practice, boundaries and institutions.

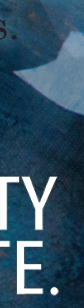

